Pontifícia Universidade Católica

\author{
Pedro Ferreira da Costa Blois de Assis
}

\title{
CONTROLE DE ATITUDE DE UM VEÍCULO ROBÓTICO ELÉTRICO EM FASE BALÍSTICA
}

\section{Tese de Doutorado}

Tese apresentada como requisito parcial para obtenção do título de Doutor pelo Programa de Pós-Graduação em Engenharia Mecânica da PUCRio.

Orientador: Prof. Marco Antonio Meggiolaro 


$$
\text { Pontifícia Universidade Católica }
$$

Pedro Ferreira da Costa Blois de Assis

\section{CONTROLE DE ATITUDE DE UM VEÍCULO ROBÓTICO ELÉTRICO EM FASE BALÍSTICA}

Tese apresentada como requisito parcial para obtenção do título de Doutor pelo Programa de Pós-Graduação em Engenharia Mecânica da PUC-Rio. Aprovada pela Comissão Examinadora abaixo assinada.

Prof. Marco Antonio Meggiolaro Orientador Departamento de Engenharia Mecânica - PUC-Rio

Prof. Hans Ingo Weber Departamento de Engenharia Mecânica - PUC-Rio

Prof. Mauro Speranza Neto Departamento de Engenharia Mecânica - PUC-Rio

Prof. Ricardo Teixeira da Costa Neto Seção de Engenharia Mecânica - IME

Prof. Fernando Ribeiro da Silva Departamento de Engenharia Mecânica - CEFET/RJ

Prof. Luciano Luporini Menegaldo Departamento de Engenharia Mecânica - COPPE/UFRJ

Prof. José Eugênio Leal Coordenador(a) Setorial do Centro Técnico Científico - PUC-Rio 
Todos os direitos reservados. É proibida a reprodução total ou parcial do trabalho sem autorização da universidade, do autor e do orientador.

Pedro Ferreira da Costa Blois de Assis Graduou-se em Engenharia de Controle e Automação (Pontifícia Universidade Católica do Rio de Janeiro) em 2005 e terminou o mestrado em Engenharia Mecânica na área de mecânica aplicada em 2007 também na PUC-Rio. Participa desde 2006 de projetos na área de robótica no Laboratório de Engenharia de Controle e Automação da PUC-Rio. Suas áreas de interesse abrangem robótica, controle e modelagem de sistemas, automação de processos, bioengenharia e dinâmica veicular.

Ficha Catalográfica

\begin{tabular}{l} 
Assis, Pedro Ferreira da Costa Blois de \\
Controle de atitude de um veículo \\
robótico elétrico em fase balística / Pedro Ferreira \\
da Costa Blois de Assis ; orientador: Marco \\
Antonio Meggiolaro. -2013. \\
152 f. : il. (color.); $30 \mathrm{~cm}$ \\
Tese (doutorado)-Pontifícia \\
Universidade Católica do Rio de Janeiro, \\
Departamento de Engenharia Mecânica, 2013. \\
Inclui bibliografia \\
1. Engenharia Mecânica - Teses. 2. \\
Veículo robótico. 3. Fase balística. 4. Estimativa \\
de toque externo. 5. Controle de atitude. I. \\
Meggiolaro, Marco Antonio. II. Pontifícia \\
Universidade Católica do Rio de Janeiro. \\
Departamento de Engenharia Mecânica. III. Título. \\
\hline
\end{tabular}

CDD: 621 


\section{Agradecimentos}

$>$ Ao CNPq pelo apoio financeiro;

$>$ À PUC-Rio pelo seu excelente corpo acadêmico que me deu as bases para este estudo;

Ao orientador Marco Antônio Meggiolaro pela oportunidade e confiança;

> Ao professor Moisés Henrique Szwarcman pelo apoio incondicional em momentos cruciais da pesquisa. Sem a ajuda dele esse trabalho não teria sido concluído;

$>$ À minha esposa Renata Lamarca pela paciência e atenção durante esses anos;

$>$ À minha família que me ensinou valores sem os quais não conseguiria lograr meus anseios;

> Aos grandes amigos Júlio Guedes, Ricardo Morrot, Guilherme Mourão, Alexandre Ormiga e Marcos Soares e à equipe Riobotz que me ajudaram durante toda a pesquisa;

Aos amigos de escalada que me ajudaram a aliviar o stress durante a pesquisa. 


\section{Resumo}

Assis, Pedro Ferreira da Costa Blois; Meggiolaro, Marco Antonio. Controle de atitude de um veículo robótico elétrico em fase balística. Rio de Janeiro, 2013. 152p. Tese de Doutorado - Departamento de Engenharia Mecânica, Pontifícia Universidade Católica do Rio de Janeiro.

Controle de estabilidade é uma técnica aplicada para aumentar a segurança em veículos automotivos. Ele compreende não apenas controle de guinada como controle de rolagem, principalmente em veículos altos como caminhões. Uma tendência na indústria automobilística já consagrada em sistemas robóticos de exploração são os veículos elétricos que possuem motores elétricos independentes em cada roda. Sua característica de não emitir qualquer poluente os torna ambientalmente atraentes e, devido à forma de atuação, tendem a ser mecanicamente menos complexos. Os controles de estabilidade atuais visam prevenir que o veículo chegue a uma situação de instabilidade. No entanto, veículos em alta velocidade que encontrem obstáculos nos terrenos podem perder o contato com o solo. Nessa situação, os controles de estabilidade atuais nada podem fazer para garantir um retorno seguro para o terreno. Este trabalho apresenta um algoritmo de detecção de descolamento da roda para identificação do início da fase balística e consequente determinação da ação necessária para aumentar as chances de um retorno seguro ao chão. São usados apenas sensores de corrente e velocidade dos motores para a detecção. O controle por roda de reação é aplicado ao veículo para estabilização durante a fase balística. O algoritmo também é capaz de estimar o torque externo aplicado sobre a roda usando os mesmo sensores utilizados para o controle de torque dos motores, tornando a técnica uma ferramenta sem custos adicionais ao sistema. Os algoritmos de controle e detecção apresentados foram testados experimentalmente e em um simulador desenvolvido para a pesquisa usando o modelo de um veículo robótico de sessenta quilogramas com quatro rodas independentes atuadas por meio de motores elétricos de corrente contínua. Os resultados obtidos mostram o potencial da técnica para futuras aplicações.

\section{Palavras-chave}

Controle de atitude; veículo robótico; fase balística 


\section{Abstract}

Assis, Pedro Ferreira da Costa Blois; Meggiolaro, Marco Antonio (Advisor). Attitude control of an electric robotic vehicle during ballistic motion. Rio de Janeiro, 2013. 152p. Tese de Doutorado - Departamento de Engenharia Mecânica, Pontifícia Universidade Católica do Rio de Janeiro.

Stability control is a known algorithm used to increase safety in passenger vehicles. It comprises not only yaw control but rollover as well, mainly in vehicles with high centers of gravity. Another already established trend in the automobile industry are electric vehicles with independently driven wheels. Its zero-emitting qualities have made them environmentally attractive and, due to their drivetrain design, they tend to be mechanically less complex. Stability controls used nowadays work to prevent the vehicle from reaching unstable situations. Nonetheless, high speed vehicles hitting obstacles may lose contact with the ground. In these situations, none of the existing stability controls can guarantee safe landing during ballistic motion. This work presents an algorithm for flying wheel detection to help identify ballistic motion tendencies and therefore determine the appropriate action to increase the odds of a safe landing. Current sensors and encoders are used by the algorithm. A reaction wheel based control is proposed to stabilize and adjust the pitch angle during ballistic motion and set up the vehicle to a better position to return to land. The flying wheel detection algorithm can also estimate external torques acting on the wheel using the same sensors already installed in the motor for current control, making it a costless technique. The detection algorithm and pitch control algorithm presented were tested experimentally and in a simulator developed for the research. The results show the potential of the algorithms presented for future implementations.

\section{Keywords}

Torque control; attitude control; robotic vehicles; ballistic motion 


\section{Sumário}

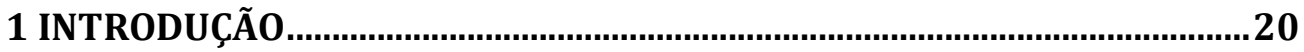

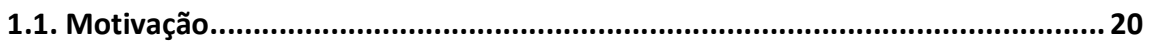

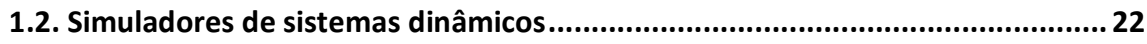

1.3. Avaliação sobre a instabilidade de um veículo.................................................. 26

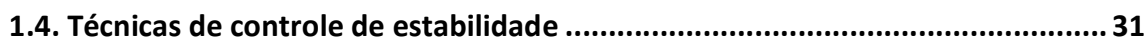

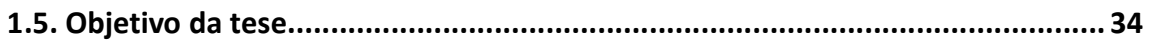

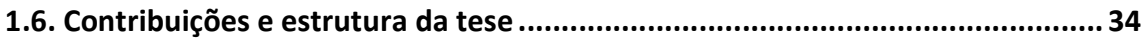

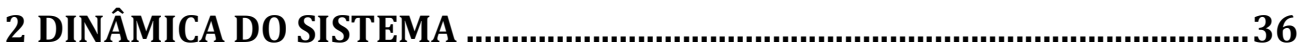

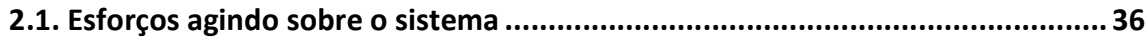

2.2. Quantidade de movimento linear e angular do veículo ..................................39

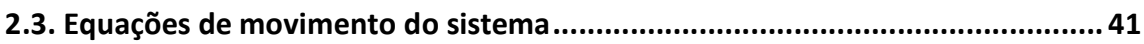

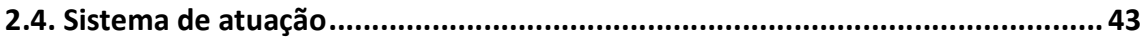

2.5. Representação em forma de espaço de estados ............................................... 45

3 DETECÇÃO DO DESCOLAMENTO DAS RODAS E DA FASE BALÍSTICA ... 50

3.1. Estimativa do torque externo e detecção do descolamento da roda .................51

3.2. Detecção da fase balística ................................................................................ 52

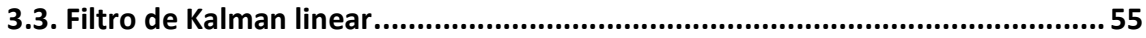

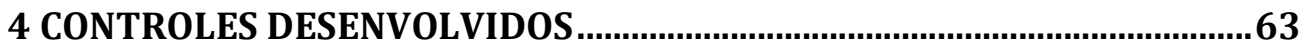

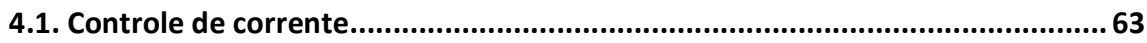

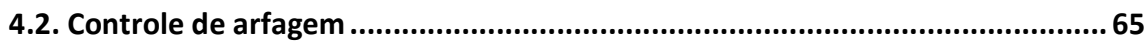

5 SIMULADOR DESENVOLVIDO ..................................................................... 71

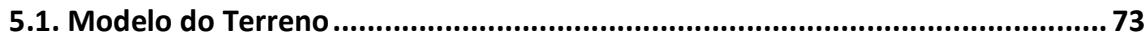

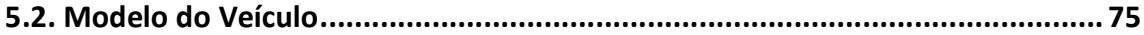

5.3. Determinação do ponto de contato entre pneus e terreno............................. 76

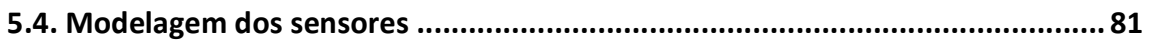

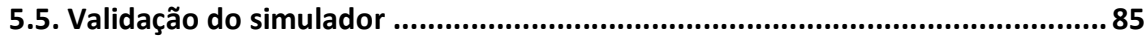


6 SIMULAÇÕES E RESULTADOS EXPERIMENTAIS.................................... 95

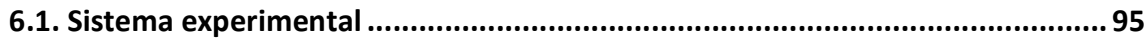

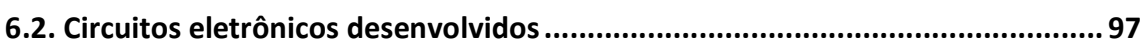

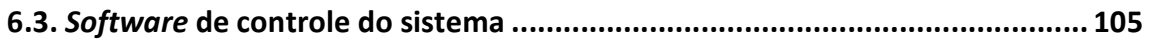

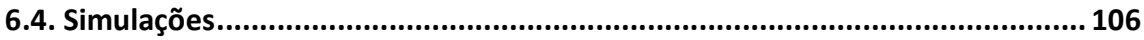

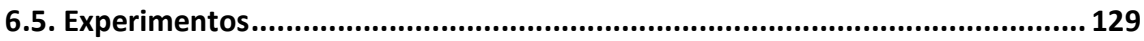

7 CONCLUSÃO E TRABALHOS FUTUROS .................................................... 139

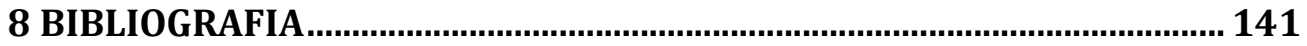

1 SISTEMAS DE REFERÊNCIAS E AS ROTAÇÕES ENTRE ELES ................. 147

2 VELOCIDADES E ACELERAÇÕES IMPORTANTES DO SISTEMA .............. 149 


\section{Lista de figuras}

Figura 1: Cena retirada de um exemplo de simulação utilizando Newton Games Dynamics (http://newtondynamics.com) acessado dia 10/09/09.

Figura 2: Ilustração do ângulo-força de estabilidade: a) estável, b) instável (15).

Figura 3: Formato típico da variação do coeficiente de atrito em função da deriva longitudinal (17).

Figura 4: Diagrama de corpo livre de uma das rodas do veículo.

Figura 5: Diagrama de corpo livre de um quarto do veículo.

Figura 13: Progressão do ângulo de arfagem durante a simulação do controle na fase balística.

Figura 14: Cena do simulador na versão desenvolvida em C++.

Figura 15: Desenho ilustrando as variáveis para a interpolação do terreno.

Figura 16: Esquema mostrando o deslocamento imposto à suspensão.

Figura 17: Esquema mostrando as dimensões do chassi.

Figura 18: Esquema do ponto de contato da roda.

Figura 19: Esquema do algoritmo de determinação do ponto de contato entre a roda e o terreno.

Figura 20: Comparação entre a curva de velocidade de rotação obtida experimentalmente com a gerada pelo simulador para uma tensão de alimentação de $18 \mathrm{~V}$.

Figura 21: Comparação entre a curva de corrente drenada obtida experimentalmente com a obtida pelo simulador para uma tensão de alimentação de $18 \mathrm{~V}$.

Figura 22: Comparação entre a curva de velocidade de rotação obtida experimentalmente com a obtida pelo simulador para uma tensão de alimentação de $10 \mathrm{~V}$.

Figura 23: Comparação entre a curva de corrente drenada obtida experimentalmente com a obtida pelo simulador para uma tensão de alimentação de $10 \mathrm{~V}$.

Figura 25: Simulação de arrancada mostrando o comportamento das forças normais traseira e dianteira do veículo. 
Figura 26: Simulação de descolamento das rodas dianteiras mediante altos torques aplicados às rodas traseiras.

Figura 27: Perfil de tensão diferencial aplicado no veículo durante a manobra Fishhook.

Figura 28: Indicador de estabilidade mostrado na equação (1.1) calculado durante manobra Fishhook para diferentes velocidades.

Figura 29: Comparação entre quatro indicadores de estabilidade durante a manobra Fishhook publicada em (15).

Figura 30: Veículo robótico elétrico desenvolvido no laboratório de robótica da PUC-Rio para inspeção de tubulações.

Figura 32: Sistema de eixo de coordenadas (38).

Figura 33: Componentes principais do sistema e suas formas de interação.

Figura 37: Fluxograma do firmware da eletrônica $\mathrm{ARM}_{\mathrm{E}}$.

Figura 38: Interface principal do software de comando desenvolvido em LabVIEW.

Figura 39: Interface secundária do sistema desenvolvido utilizada para leitura dos arquivos de $\log$.

Figura 40: Excitações no motor na simulação para estimativa do torque externo.

Figura 41: Corrente nos motores durante a primeira simulação em que as rodas não encostam no chão, mas são excitadas com a mesma tensão e o mesmo torque externo.

Figura 42: Velocidade angular das rodas durante a primeira simulação em que as rodas não encostam no chão, mas são excitadas com a mesma tensão e o mesmo torque externo.

Figura 43: Estimativa do torque externo sobre as rodas durante a primeira simulação em que as rodas não encostam no chão, mas são excitadas com a mesma tensão e o mesmo torque externo.

Figura 44: Comparação entre os sinais de comando elétrico sobre o motor, o torque externo aplicado e a estimativa do mesmo.

Figura 45: Detalhe da forma de onda simulada para o encoder.

Figura 46: Corrente nos motores durante a segunda simulação em que as rodas encostam no chão e são excitadas com a mesma tensão.

Figura 47: Velocidade angular das rodas durante a segunda simulação em 
que as rodas encostam no chão e são excitadas com a mesma tensão.

Figura 48: Simulação com a estimativa do torque externo em terreno plano e horizontal.

Figura 49: Comparação entre os sinais de comando elétrico sobre o motor, a estimativa do torque externo e a aceleração do centro de massa do veículo.

Figura 50: Comparação entre a estimativa de torque externo para o sistema com perdas por atrito viscoso e sem perdas.

Figura 51: Perfil do terreno usado nas primeiras simulações.

Figura 52: Progressão do ângulo e da velocidade de arfagem durante a simulação com os algoritmos propostos.

Figura 54: Perfil de tensão aplicada no motor traseiro direito durante a simulação com os algoritmos propostos.

Figura 55: Progressão do ângulo e da velocidade de arfagem durante a simulação com os controladores PIs.

Figura 56: Somatório das forças normais e indicador de estágio do controle de arfagem durante a simulação com os controladores PIs.

Figura 57: Perfil de tensão aplicada no motor traseiro direito durante a simulação com os controladores PIs.

Figura 58: Progressão do ângulo e da velocidade de arfagem durante a simulação com os controladores PIs desligados na fase balística.

Figura 59: Progressão do ângulo e da velocidade de arfagem durante a simulação com os algoritmos propostos.

Figura 60: Somatório das forças normais e indicador de estágio do controle de arfagem durante a simulação com os algoritmos propostos.

Figura 61: Perfil de tensão aplicada no motor traseiro direito durante a simulação com os algoritmos propostos.

Figura 62: Progressão do ângulo e da velocidade de arfagem durante a simulação com os controladores PIs.

Figura 63: Somatório das forças normais e indicador de estágio do controle de arfagem durante a simulação com os controladores PIs.

Figura 64: Perfil de tensão aplicada no motor traseiro direito durante a simulação com os controladores PIs.

Figura 65: Correntes induzidas nos motores durante o experimento.

Figura 66: Velocidades angulares das rodas durante o experimento. 
Figura 67: Estimativa do torque externo sobre a roda traseira direita e o perfil de tensão aplicada sobre a mesma.

Figura 68: Acelerações nos três eixos durante o ensaio de fase balística.

Figura 69: Velocidade angular das rodas durante o ensaio de fase balística.

Figura 70: Estimativa dos torques externos sobre as rodas durante o ensaio de fase balística.

Figura 71: Indicadores de descolamento e da fase de controle durante ensaio de fase balística.

Figura 72: Ângulo de velocidade de arfagem durante ensaio de fase balística.

Figura 73: Perfil do comando de corrente desejada durante ensaio de fase balística.

Figura 74: Correntes nos motores durante ensaio de fase balística. 


\section{Lista de símbolos}

Codificação das variáveis ao longo do texto:

- $\quad \mathrm{x}$ - (normal) número escalar;

- $x$ - (itálico) sistema referencial;

- $\quad \boldsymbol{x}$ - (negrito e itálico) vetor $\mathfrak{R}^{3 \times 1}$;

- $\underline{\mathrm{x}}$ - (barra inferior) matriz $\mathfrak{R}^{3 \times 3}$.

$F$ - Sistema referencial inercial (global);

$\boldsymbol{O}$ - Origem do sistema referencial $F$;

${ }^{\boldsymbol{F}} \boldsymbol{a}_{\mathbf{1}},{ }^{\boldsymbol{F}} \boldsymbol{b}_{\mathbf{1}}$ e ${ }^{\boldsymbol{F}} \boldsymbol{c}_{\mathbf{1}}-$ Base de vetores que formam o referencial $F$;

$S$ - Sistema referencial solidário ao chassi do veículo;

$\boldsymbol{A}$ - Origem do sistema referencial $S$;

${ }^{s} \boldsymbol{n},{ }^{S} \boldsymbol{t}$ e ${ }^{S} \boldsymbol{b}$ - Base de vetores que formam o referencial $S$;

$\theta_{1}, \theta_{2}$ e $\theta_{3}$ - Rotações elementares que levam do referencial $F$ ao referencial $S$;

${ }^{S} \underline{T}^{F}$ - Matriz de transformação do referencial $F$ para o referencial $S$;

$T_{11}, T_{12}, T_{13}, T_{21}, T_{22}, T_{23}, T_{31}, T_{32}$ e $T_{33}$ - Componentes de ${ }^{S} \underline{T}^{F}$;

${ }_{F}^{S} \boldsymbol{\omega}_{S}$ - Velocidade de rotação do chassi no referencial $S$;

$\omega_{x}, \omega_{y}$ e $\omega_{z}-$ Componentes de ${ }_{F}^{S} \boldsymbol{\omega}_{S} ;$

${ }_{F}^{S} \dot{\boldsymbol{\omega}}_{S}$ - Aceleração angular do chassi no referencial $S$;

$\dot{\omega}_{x}, \dot{\omega}_{y}$ e $\dot{\omega}_{z}-$ Componentes de ${ }_{F}^{S} \dot{\omega}_{S}$;

${ }^{F} \boldsymbol{r}_{A}$ - Posição do centro de massa do veículo no referencial $F$;

${ }^{S} \boldsymbol{v}_{A}$ - Velocidade linear do centro de massa do veículo no referencial $S$;

$v_{x}, v_{y}$ e $v_{z}$ - Componentes de ${ }^{S} \boldsymbol{v}_{A}$;

${ }^{S} \boldsymbol{a}_{A}$ - Aceleração linear do centro de massa do veículo no referencial $S$;

$\ddot{x}, \ddot{y}$ e $\ddot{z}$ - Componentes de ${ }^{S} \boldsymbol{a}_{A}$;

${ }^{F} \boldsymbol{r}_{i}$ - Posição do centro de massa da roda $i$ no referencial $F$;

$R x_{i}, R y_{i}$ e $R z_{i}$ - Componentes de ${ }^{F} \boldsymbol{r}_{i}$; 
$r_{x}, r_{y}$ e $r_{z}$ - Distâncias nas direções, respectivamente, $\boldsymbol{n}, \boldsymbol{t}$ e $\boldsymbol{b}$ do referencial $\mathrm{S}$ das rodas de maneira que ${ }^{s} \boldsymbol{r}_{0}=\left[\begin{array}{c}-r_{x} \\ -r_{y} \\ -r_{z}\end{array}\right], \quad{ }^{s} \boldsymbol{r}_{1}=\left[\begin{array}{c}r_{x} \\ -r_{y} \\ -r_{z}\end{array}\right], \quad{ }^{s} \boldsymbol{r}_{2}=\left[\begin{array}{c}r_{x} \\ r_{y} \\ -r_{z}\end{array}\right]$ e $\quad{ }^{s} \boldsymbol{r}_{3}=$ $\left[\begin{array}{c}-r_{x} \\ r_{y} \\ -r_{z}\end{array}\right]$

${ }^{F} \boldsymbol{v}_{i}$ - Velocidade linear do centro de massa da roda $i$ no referencial $F$;

${ }^{S} \boldsymbol{\omega}_{i}$ - Velocidade angular da roda $i$ no referencial $S$;

$\dot{\varphi}_{i}$ - Velocidade de spin da roda $i$

$\ddot{\varphi}_{i}$ - Aceleração de spin da roda $i$;

${ }^{S} \dot{\boldsymbol{\omega}}_{i}$ - Aceleração angular da roda $i$ no referencial $S$;

${ }^{S} \boldsymbol{r}_{B}$ - Posição do sensor inercial no referencial $S$;

${ }^{F} \boldsymbol{v}_{B}$ - Velocidade linear do sensor inercial no referencial $F$;

${ }^{F} \boldsymbol{a}_{B}$ - Aceleração linear do sensor inercial no referencial $F$;

$R x_{B}, R y_{B}$ e $R z_{B}$ - Componentes de ${ }^{F} \boldsymbol{r}_{B}$;

${ }^{S} \boldsymbol{F}_{\text {int }_{i}}$ - Força interna entre o chassi e a roda $i$ no referencial S;

$F_{n i}, F_{t i}$ e $F_{b i}-$ Componentes de ${ }^{S} \boldsymbol{F}_{\text {int }}$;

${ }^{S} \boldsymbol{F}_{n i}$ - Força interna entre o chassi e a roda $i$ na direção ${ }^{S} \boldsymbol{n}$ no referencial S;

${ }^{S} \boldsymbol{F}_{t i}$ - Força interna entre o chassi e a roda $i$ na direção ${ }^{S} \boldsymbol{t}$ no referencial $\mathrm{S}$;

${ }^{S} \boldsymbol{F}_{b i}$ - Força interna entre o chassi e a roda $i$ na direção ${ }^{S} \boldsymbol{b}$ no referencial S;

$\xi_{i}$ - Deformação da suspensão;

$\xi_{\text {sat }}$ - Valor de saturação para a deformação da suspensão;

$\dot{\xi}_{i}$ - Velocidade de deformação da suspensão;

$C$ - Sistema referencial solidário ao terreno no ponto de contato com a roda $i$;

${ }^{C} \boldsymbol{x},{ }^{C} \boldsymbol{y}$ e ${ }^{C} \boldsymbol{z}$ - Base de vetores que formam o referencial $C$;

${ }^{S} \underline{T}_{i}^{C}$ - Matriz de transformação do referencial $C$ para o referencial $S$;

${ }^{S} \boldsymbol{F}_{\text {ext }_{i}}$ - Força externa sobre a roda $i$ no referencial $S$;

$F_{x i}, F_{y i}$ e $F_{z i}-$ Componentes de ${ }^{S} \boldsymbol{F}_{\text {ext }}$;

${ }^{C} \boldsymbol{F}_{x i}$ - Força externa sobre a roda $i$ na direção ${ }^{C} \boldsymbol{x}$ no referencial $C$;

${ }^{C} \boldsymbol{F}_{y i}$ - Força externa sobre a roda $i$ na direção ${ }^{C} \boldsymbol{y}$ no referencial $C$;

${ }^{C} \boldsymbol{F}_{z i}$ - Força externa sobre a roda $i$ na direção ${ }^{C} \boldsymbol{Z}$ no referencial $C$;

${ }^{s} \boldsymbol{M}_{\text {int }_{i}}$ - Momento interno entre o chassi e a roda $i$ no referencial $S$; 
$M_{n i}, M_{t i}$ e $M_{b i}$ - Componentes de ${ }^{S} \boldsymbol{M}_{\text {int }_{i}} ;$

${ }^{S} \boldsymbol{M}_{n i}$ - Momento interno entre o chassi e a roda $i$ na direção ${ }^{S} \boldsymbol{n}$ no referencial S;

${ }^{s} \boldsymbol{M}_{t i}$ - Momento interno entre o chassi e a roda $i$ na direção ${ }^{s} \boldsymbol{t}$ no referencial S;

${ }^{S} \boldsymbol{M}_{b i}$ - Momento interno entre o chassi e a roda $i$ na direção ${ }^{S} \boldsymbol{b}$ no referencial S;

$\gamma_{i}$ - Ângulo, no plano ${ }^{S} \boldsymbol{n} \times{ }^{s} \boldsymbol{b}$, entre a normal do terreno e $-{ }^{s} \boldsymbol{b}$ calculado no ponto de contato entre a roda $i$ e o terreno;

$c_{\gamma i}$ e $s_{\gamma i}$ - Respectivamente cosseno e seno de $\gamma_{i}$;

$\alpha_{i}$ - Ângulo, no plano ${ }^{S} \boldsymbol{t} \times{ }^{S} \boldsymbol{b}$, entre a normal do terreno e $-{ }^{S} \boldsymbol{b}$ calculado no ponto de contato entre a roda $i$ e o terreno;

$c_{\alpha i}$ e $s_{\alpha i}$ - Respectivamente cosseno e seno de $\alpha_{i}$;

${ }^{s} \boldsymbol{F}_{i}$ - Somatório de forças sobre a roda i no referencial $S$;

${ }^{s} \boldsymbol{r}_{p c i}$ - Posição do ponto de contato entre a roda $i$ e o terreno em relação ao centro de massa da roda no referencial $S$;

${ }^{S} \boldsymbol{M}_{i}$ - Somatório de momentos sobre a roda $i$ no referencial $S$;

${ }^{S} \boldsymbol{H}_{\boldsymbol{i}}$ - Quantidade de movimento angular da roda $i$ no referencial $S$;

${ }^{S} I_{r}$ - Tensor de inércia da roda no referencial $S$;

$I_{r}^{1}, I_{r}^{2}$ e $I_{r}^{1}$ - Momentos de inércia da roda nas suas direções principais no referencial $S$;

${ }^{S} \boldsymbol{F}$ - Somatório de forças sobre o chassi no referencial $S$;

${ }^{F}$ Grav - Força peso do veículo no referencial $F$;

${ }^{S} \boldsymbol{M}_{\boldsymbol{A}}$ - Somatório de momentos em relação ao centro de massa do chassi no referencial $S$;

${ }^{S} \boldsymbol{G}$ - Quantidade de movimento linear do chassi no referencial $S$;

${ }^{S} \boldsymbol{H}_{\boldsymbol{A}}$ - Quantidade de movimento angular do chassi no referencial $S$;

$S_{I_{A}}$ - Tensor de inércia do chassi no referencial $S$;

$I_{c}^{1}, I_{c}^{2}$ e $I_{c}^{3}-$ Momentos de inércia do chassi nas suas direções principais no referencial $S$;

$\tau_{i}$ - Torque do motor sobre a roda $i$

$m$ - Massa do veículo;

$g$ - Aceleração da gravidade;

$j_{i}$ - Corrente drenada pelo motor da roda $i$;

$V_{i}$ - Tensão elétrica aplicada no motor da roda $i$; 
$\tau_{\text {ext }_{i}}$ - Torque externo agindo sobre o motor da roda $i$;

$R$ - Resistência elétrica do motor;

$L$ - Indutância elétrica do motor;

$K_{t}$ - Constante de torque do motor;

$G_{b}$ - Relação da caixa de redução do motor;

$\underline{A}$ - Matriz de estado do modelo do motor;

$\underline{B}$ - Matriz de entrada do modelo do motor;

$\underline{C}$ - Matriz de saída do modelo do motor ou matriz de observação no filtro de Kalman;

$\underline{D}$ - Matriz de transmissão direta do modelo do motor;

$\boldsymbol{X}$ - Vetor de estado do modelo do motor;

$\dot{\boldsymbol{X}}$ - Derivada temporal do vetor de estado do modelo do motor;

$\boldsymbol{U}$ - Vetor de entradas do modelo do motor ou vetor de entradas no filtro de Kalman;

$\boldsymbol{Y}$ - Vetor de saída do modelo do motor ou medida dos sensores no filtro de Kalman;

$\boldsymbol{X}_{\boldsymbol{T}}$ - Vetor de estado do sistema linearizado;

$a_{k}$ - Constantes do modelo de estado do sistema;

$c_{1}$ e $c_{2}$ - Constantes auxiliares do modelo de estado do sistema;

$\boldsymbol{X}_{k}$ - Vetor de estado atual do modelo do motor discretizado ou estimativa do estado da interação anterior no filtro de Kalman;

$\boldsymbol{X}_{k+1}-$ Vetor do estado seguinte do modelo do motor discretizado quando apenas uma tensão elétrica é aplicada;

$\boldsymbol{U}_{v}-$ Vetor com a excitação elétrica do modelo do motor discretizado;

$\boldsymbol{U}_{\tau}$ - Vetor com o torque externo do modelo do motor discretizado;

$\boldsymbol{Y}$ - Vetor de saídas do modelo do motor discretizado;

$\underline{\Phi}$ - Matriz de estado do modelo do motor discretizado;

$\underline{\Gamma}$ - Matriz de entrada do modelo do motor discretizado;

$\underline{H}$ - Matriz de saída do modelo do motor discretizado;

J- Matriz de transmissão do modelo do motor discretizado;

$\boldsymbol{X}_{k+1}^{\prime}$ - Vetor do estado seguinte do modelo do motor discretizado quando uma tensão elétrica e um torque externo são aplicados;

$\tau_{\text {lim }}$ - Valor limite para determinar se a roda descolou do terreno; 
$\boldsymbol{X}_{\text {corr }}$ - Correção da estimativa do estado no filtro de Kalman;

$\underline{P}_{c o r r}$ - Correção da estimativa da matriz de covariância no filtro de Kalman;

$\underline{P}_{k}$ - Matriz de covariância do erro, estimada na iteração anterior no filtro de Kalman;

$\underline{P}_{k+1}$ - Nova estimativa da matriz de covariância do erro no filtro de Kalman;

$\underline{K}$ - Ganho ótimo no filtro de Kalman;

$\underline{V}$ - Matriz de covariância do ruído das medidas no filtro de Kalman;

$\underline{W}$ - Matriz de covariância do ruído do sistema no filtro de Kalman;

$w_{j}$ e $w_{\omega}$ - Ruídos aleatórios do sistema na estimativa de estado do motor por filtro de Kalman;

$W_{j}$ e $W_{\omega}$ - Desvios padrão dos ruídos aleatórios do sistema na estimativa de estado do motor por filtro de Kalman;

$v_{j}$ e $v_{\omega}$ - Ruídos aleatórios das medidas na estimativa de estado do motor por filtro de Kalman;

$V_{j}$ e $V_{\omega}$ - Desvios padrão dos ruídos aleatórios das medidas na estimativa de estado do motor por filtro de Kalman;

${ }^{s} \boldsymbol{A}_{t}-$ Aceleração do veículo devido aos torques dos motores;

${ }^{S} \widehat{\boldsymbol{G}}_{A}-$ Estimativa do vetor aceleração da gravidade no referencial $S$;

$\boldsymbol{e}_{G}-$ Vetor direção da aceleração da gravidade;

$\boldsymbol{M}_{m}$ - Leitura do magnetômetro;

$\boldsymbol{M}^{\prime}$ - Leitura do magnetômetro sem a componente na direção da aceleração da gravidade;

$\boldsymbol{e}_{M}$ - Vetor direção da leitura do magnetômetro sem a componente na direção da aceleração da gravidade;

$\boldsymbol{e}_{Y}-$ Vetor perpendicular a $\boldsymbol{e}_{G}$ e a $\boldsymbol{e}_{M}$ de norma unitária;

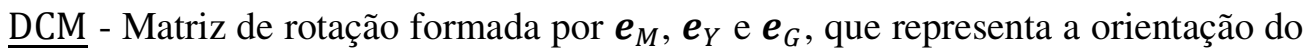
chassi no referencial $F$;

$\underline{\mathrm{DCM}}_{o}^{T}$ - Matriz de rotação transposta, formada por $\boldsymbol{e}_{M}, \boldsymbol{e}_{Y}$ e $\boldsymbol{e}_{G}$, que representa a orientação do chassi no instante inicial do experimento no referencial $F$;

$\boldsymbol{N}$ - Vetor orientação do chassi;

$\theta_{1}, \theta_{2}$ e $\theta_{3}$ - Componentes de $\boldsymbol{N}$

$H(s)$ - Função de transferência de malha fechada do sistema de controle de arfagem; 
$K_{p}$ - Ganho proporcional do controle de arfagem;

$T_{d}$ - Ganho derivativo do controle de arfagem;

$\omega_{y 0}$ - Velocidade angular do chassi no momento da detecção da fase balística;

$\phi_{y 0}$ - Ângulo de arfagem do chassi no momento da detecção da fase balística;

$\underline{\mathrm{M}}$ - Matriz representando o terreno no simulador;

$x_{\min }, x_{\max }, y_{\min }$ e $y_{\max }$ - Coordenadas extremas do terreno no simulador;

$n_{x}$ e $n_{y}-$ Respectivamente o número de linhas e de colunas de $\underline{\mathrm{M}}$;

$M_{i x, i y}$ - Elemento da matriz $\underline{\mathrm{M}}$ cuja coordenada é $\left(i_{x}, i_{y}\right)$;

$a u x_{x}$ e $a u x_{y}$ - são as coordenadas do ponto desejado convertidas para o sistema de coordenadas da matriz $\underline{\mathrm{M}}$

$Z_{f}$ - Resultado da interpolação dos elementos do terreno na posição desejada;

$\boldsymbol{X}_{\boldsymbol{c}}$ - Posição final do centro de massa da roda no simulador considerando a suspensão;

$\boldsymbol{X}_{n t \boldsymbol{b}}$ - Posição do centro de massa da roda no simulador sem considerar a suspensão;

$\boldsymbol{X}_{\boldsymbol{c} \boldsymbol{p}}$ - Posição do ponto de contado entre a roda e o terreno no simulador;

$X_{c p}, Y_{c p}$ e $Z_{c p}$ - Coordenadas de $\boldsymbol{X}_{\boldsymbol{c} \boldsymbol{p}}$;

$\boldsymbol{h}_{\text {sat }}$ - Deslocamento máximo da suspensão no simulador;

$h_{\text {top }}$ - Distância entre o centro de massa do chassi e sua extremidade superior;

$h_{\text {bottom }}$ - Distância entre o centro de massa do chassi e a sua extremidade inferior;

$L_{1}$ - Distância entre o centro de massa do chassi e a sua extremidade traseira;

$L_{2}$ - Distância entre o centro de massa do chassi e a sua extremidade dianteira;

$W_{1}$ - Distância entre o centro de massa do chassi e a sua extremidade direita;

$W_{2}$ - Distância entre o centro de massa do chassi e a sua extremidade esquerda;

$\kappa$ - Deriva longitudinal usada na "Fórmula Mágica";

$\alpha$ - Deriva lateral usada na "Fórmula Mágica";

$F_{x}$ e $F_{y}$ - Respectivamente as magnitudes das forças longitudinal e lateral calculada pela "Fórmula Mágica";

$\Lambda$ - Variável de entrada da "Fórmula Mágica";

$S_{v}, S_{h}$ - Offsets vertical e horizontal usadas na "Fórmula Mágica";

$G_{y \kappa}$ e $G_{x \alpha}$ - Respectivamente os fatores de ajuste da força lateral e longitudinal usados pela "Fórmula Mágica"; 


\section{1 Introdução}

\section{1. Motivação}

Num país em que ainda existem montadoras que consideram a segurança nos veículos de passeio um item de luxo ${ }^{1}$, um sistema de controle de estabilidade mais simples e barato se faz necessário. Paralelamente, seguindo a tendência mundial de diminuição da poluição, carros híbridos e puramente elétricos vêm sendo desenvolvidos. Estima-se que o número de carros elétricos já nas ruas no mundo cresceu de 50.000 em 2011 para mais de 180.000 em 2012. A maioria deles se concentra nos países desenvolvidos como EUA, Japão e países europeus. China e Índia também aparecem entre os países com grande número de carros elétricos nas ruas (1).

Dos carros com motores elétricos, os que possuem motores individuais para cada roda (como o Mercedez SLS AMG Electric Drive) apresentam uma menor complexidade mecânica na construção, principalmente no sistema de transmissão. Essa simplicidade aumenta a confiabilidade e longevidade dos equipamentos e diminui as perdas no sistema, aumentando a eficiência do veículo. Aliada a essa simplicidade na mecânica do veículo está a facilidade de implementação de sistemas de controle, pois os torques são distribuídos de maneira independente e direta às rodas, sem o uso de diferenciais (2). Sistemas na área de segurança como controle de estabilidade e de frenagem e sistemas na área de automação como controle de velocidade e trajetória que possibilita o deslocamento do usuário sem a sua intervenção, são alguns exemplos. Este último, além de proporcionar conforto ao usuário, também auxilia na segurança, uma vez que elimina a variável humana do trânsito responsável por grande parte dos acidentes.

Um dos grandes obstáculos nas vendas de carros elétricos é o custo das baterias, normalmente de lítio-íon. Novas tecnologias nessa área estão surgindo

\footnotetext{
${ }^{1}$ Sites consultados: www.ford.com.br; www.chevrolet.com.br; www.fiat.com.br e www.vw.com.br em 28/02/2013
} 
e esse custo vem diminuindo significativamente. Mais recentemente, a empresa Phinergy (www.phinergy.com) oferece baterias de metal-ar (alumínio-ar e zincoar) com densidade de energia 100 vezes maior que as baterias convencionais de lítio-íon.

Uma área em que veículos puramente elétricos com rodas independentemente atuadas são utilizados é a robótica. Os veículos robóticos podem ser utilizados em terrenos acidentados como florestas ou minas, realizando tarefas como localização e resgate de objetos e/ou pessoas, inspeção de lugares nocivos ao ser humano, exploração de planetas ou crateras vulcânicas etc.. Essas aplicações requerem que os robôs atravessem terrenos acidentados demais para veículos de locomoção convencionais, para inspeção e transporte de carga. Os terrenos arenosos e íngremes, onde o solo cede, são exemplos em que o robô tem a sua mobilidade comprometida.

Muitos algoritmos de controle preditivo foram desenvolvidos para impedir que manobras abruptas de motoristas ou variações no coeficiente de atrito desestabilizassem o veículo (3), (4), (5), (6) e (7). Ao notar que a combinação entre perfil do terreno, velocidades (linear e angular) do veículo e comando do motorista podem desestabilizar o sistema, os sistemas de controle de estabilidade produzem sinais de correção para a velocidade linear e/ou direção do veículo para prevenir possíveis acidentes. Esses sistemas de controle, tanto em carros de passeio quanto em veículos robóticos, foram desenvolvidos para situações envolvendo altas velocidades em terrenos planos ou baixas velocidades em terrenos acidentados. Em (8), um algoritmo de reação para evitar obstáculos é apresentado para veículos robóticos trafegando em altas velocidades sobre terrenos acidentados.

Devido às altas velocidades, obstáculos encontrados pelo veículo podem instabilizá-lo provocando o descolamento de uma ou mais rodas do terreno antes que o algoritmo de controle preditivo ou reativo seja capaz de atuar. Essa pesquisa visa estudar a dinâmica de um veículo de quatro rodas atuadas independentemente por quatro motores elétricos de corrente contínua trafegando em alta velocidade sobre terrenos acidentados. São exploradas situações em que o veículo perde contato de uma ou mais rodas com o terreno. É mostrado que é possível reverter situações que normalmente estariam fadadas ao desastre, aumentando a probabilidade de uma aterrissagem mais segura. 


\section{2.}

\section{Simuladores de sistemas dinâmicos}

Simuladores são utilizados para testar sistemas dinâmicos usando modelos suficientemente precisos, pode-se ensaiar algoritmos e estruturas e verificar a eficiência do projeto. Nos simuladores é possível testar exaustivamente os modelos desenvolvidos em quaisquer condições de operação, como outros planetas (experimentando forças gravitacionais diferentes), vulcões (onde há altas temperaturas), prédios desmoronados (onde a iluminação é baixa e a mobilidade é restrita devido às barreiras formadas pela estrutura do prédio colapsado), no fundo do mar (em altas pressões), dentre outros. Outra vantagem dos simuladores inclui a possibilidade de testar o sistema até a sua falha, sem acarretar em prejuízos financeiros. As falhas, assim como quaisquer fragilidades do sistema modelado, podem ser analisadas enquanto acontecem, permitindo um rápido diagnóstico das limitações do projeto.

No entanto, simular comportamentos dinâmicos não-lineares em sistemas onde há interação entre dois ou mais corpos rígidos, não é uma tarefa simples. Duas técnicas para a simulação de sistemas dinâmicos consistem na dinâmica de partículas, comumente utilizada em jogos computacionais, e a modelagem física do sistema a ser analisado.

As equações da dinâmica de corpos rígidos podem ser obtidas por meio das equações encontradas no estudo da dinâmica de partículas, substituindo as massas de cada partícula por uma massa infinitesimal $d m$ e os somatórios para todas as partículas por integrais no corpo. Como em computadores é necessário trabalhar com sistemas discretos, a utilização das equações da dinâmica para sistemas discretizados em partículas é mais apropriada (9). Em sistemas mais complexos há necessidade de se utilizar uma grande quantidade de partículas para simular os ambientes (cenários e carros/personagens) e efeitos não-lineares. Essa necessidade faz com que seja imperativo que os computadores sejam equipados com placas de vídeo contendo centenas de processadores trabalhando em paralelo para resolver o sistema de equações em tempo real.

Para simular sistemas com manipuladores robóticos usando dinâmica de partículas, seria necessária alta resolução para representar adequadamente efeitos 
dinâmicos como giroscópicos, forças de Coriolis e centrípetas, essenciais no estudo da dinâmica de robôs móveis e manipuladores. Considerando o sistema de equações lineares obtidas pela técnica, um computador com processadores comuns levaria mais tempo resolvendo-o do que se fossem utilizadas as equações analíticas da dinâmica de manipuladores já conhecidas (10).

A seguir, são mostrados exemplos de simuladores dinâmicos.

\subsection{1.}

Jogos computacionais

Os jogos computacionais, em que veículos motorizados e seres humanos são simulados, utilizam bibliotecas de funções em que equações da dinâmica do sistema de corpos rígidos são resolvidas em tempo real. A seguir são listadas algumas dessas bibliotecas:

ODE (http://www.ode.org);

$>$ Bullet (http://www.bulletphysics.com);

> Newton Game Dynamics (http://newtondynamics.com);

$>$ PhysX (http://www.nvidia.com/object/physx_new.html);

$>$ Havok (http://www.havok.com);

$>$ Euphoria (http://www.naturalmotion.com/euphoria.htm);

Apenas as duas primeiras possuem o código aberto (as linhas de código da biblioteca são acessíveis gratuitamente por qualquer pessoa). O Euphoria, em particular, foi desenvolvido especificamente para simular seres humanos. Esses e outros pacotes são amplamente usados em jogos comerciais desenvolvidos para videogames de última geração como Playstation 3, XBox 360 e Nintendo Wii. Eles simulam colisões entre dois ou mais corpos rígidos, comportamento de fluidos e tecidos e as possíveis interações entre os mesmos (11). A flexibilidade dessas bibliotecas permite que os objetos tenham geometrias diversas conectadas ou não por juntas de vários tipos. Para abranger essa variedade de situações, é utilizada a dinâmica de partículas onde todos os objetos são representados por um conjunto de partículas (11). As partículas são modeladas por esferas de diâmetro finito. Essa forma de representação é bastante utilizada em computação gráfica, 
modelos físicos e animações de fenômenos naturais, e de comportamento de grupos, além de ser utilizada também em sistemas dinâmicos complexos (12).

Em geral, as bibliotecas possuem dois principais componentes: dinâmica de corpos rígidos e detecção de colisões. A componente da dinâmica de corpos rígidos é responsável por determinar as forças que estão agindo sobre todos os objetos móveis do sistema e calcular os seus novos estados. A componente das colisões por sua vez calcula todos os pontos de contato e retorna (para o cálculo das forças) a profundidade da penetração, a coordenada espacial e a normal às superfícies de contato. Os objetos são conectados entre si por juntas representadas por restrições que podem ser pouco ou muito violadas dependendo de parâmetros (CFM “Constrain Force Mixing” e ERP “Error Reduction Parameter") a serem ajustados. Esses parâmetros podem ser combinados de forma que os objetos apresentem comportamentos similares a sistemas do tipo massa-mola-amortecedor (13).

Um dos problemas desses simuladores é o fato de as restrições nas conexões das juntas poderem ser violadas em situações normais de operação criando situações irreais e proporcionando comportamentos dinamicamente anormais durante a simulação. Um exemplo disso é mostrado na Figura 1, onde o carro, depois de um impacto ao começar a subir uma rampa, tem suas rodas traseiras chegando ao nível do teto do veículo.

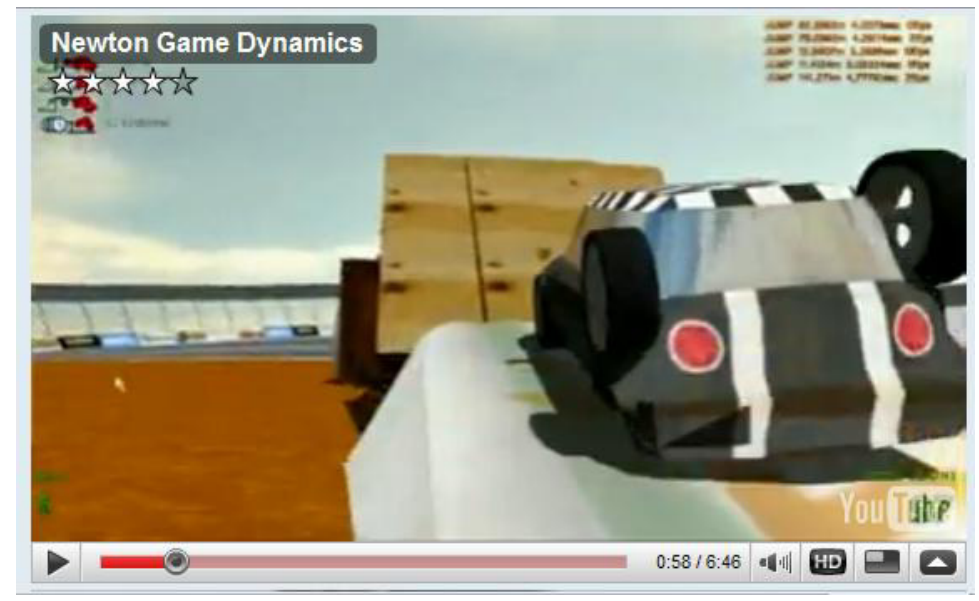

Figura 1: Cena retirada de um exemplo de simulação utilizando Newton Games Dynamics (http://newtondynamics.com) acessado dia 10/09/09. 


\subsection{2.}

Simuladores existentes no mercado

Existem alguns simuladores de sistemas veiculares desenvolvidos e disponibilizados no mercado com maior fidelidade na simulação. Abaixo, são citados alguns deles.

$>$ Gazebo (http://playerstage.sourceforge.net/index.php?src=gazebo);

$>$ CLARAty (http://claraty.jpl.nasa.gov/man/overview/index.php);

$>$ Rover Graphical Simulator (http://www.techbriefs.com/content/view/1782/34/);

$>$ Universal Mechanism (http://www.umlab.ru/);

Todos os softwares citados acima simulam veículos robóticos em ambientes 3D, sendo que apenas o Gazebo tem sua versão completa gratuita e com código aberto. O Universal Mechanism tem versões acadêmicas custando entre US\$100,00 e US\$1100,00 e o CLARAty disponibiliza alguns módulos gratuitamente para o público em geral. Os outros são restritos (preços, condições e sites consultados em 10/09/09).

O Gazebo apresenta a possibilidade de trabalhar com diversos robôs interagindo entre si e com o ambiente. Ele simula em tempo real tanto as respostas dos sensores quanto as interações físicas, permitindo que o usuário interaja com o sistema durante a simulação. Ele utiliza o pacote de ODE (citado no item 1.2.1) para o cálculo da dinâmica do sistema.

O CLARAty é um framework ${ }^{2}$ que oferece softwares de robótica reutilizáveis permitindo a simulação de veículos em terrenos acidentados. Ele foi desenvolvido para suportar plataformas heterogêneas de robôs móveis e integrar habilidades avançadas de robótica de diversos institutos de ensino e pesquisa. Consequentemente, ele é portável, modular, flexível e expansível. Parte do seu código é aberto e fica disponível em um repositório acessível remotamente pela internet.

${ }^{2}$ Framework, na área de programação, é uma abstração em que códigos comuns provendo funcionalidades genéricas podem ser seletivamente sobre-escritos ou especializados por códigos de usuários com uma funcionalidade específica. 
O usuário pode baixar o código, compilá-lo, executá-lo, implementar novas funcionalidades e descarregá-las no repositório de modo que todos os pesquisadores envolvidos no projeto tenham acesso. No entanto, nem todos os módulos do projeto são acessíveis publicamente. Os módulos de controle e outros mais importantes são restritos e só podem ser acessados a quem for autorizado pela NASA mediante pagamento. O módulo para simulação em tempo real é um dos que não são disponíveis publicamente.

O Rover Graphical Simulator é a nova geração do Clarity que produz imagens da movimentação de um veículo robótico exploratório (rover) trafegando em terreno acidentado. Os rovers simulados se movem autonomamente utilizando estratégias de navegação criadas por lógica fuzzy para tomadas de decisões na escolha de caminhos entre o estado inicial e o final não permitindo, portanto, a interação com o usuário em tempo real.

O Universal Mechanism é um software com simulação em terrenos acidentados e utiliza equações da dinâmica de veículos considerando modelos complexos dos pneus, suspensões etc. No entanto, sua licença é cara, a introdução de leis de controle avançadas no programa é difícil e suas simulações são feitas offline, não permitindo a interação com o usuário durante a execução.

Os softwares citados acima não oferecem ao mesmo tempo a possibilidade de se ter um simulador de veículos robóticos com a resolução das equações da dinâmica em tempo real (impossibilitando que o usuário comande o veículo pelo ambiente durante a simulação) e a um preço acessível.

Eles também possuem baixo desempenho em máquinas sem placas de vídeos dedicadas.

\section{3.}

\section{Avaliação sobre a instabilidade de um veículo}

Métricas de instabilidade de veículos são apresentadas na literatura (14), (15) e (7), tendo o último feito um bom resumo das principais metodologias utilizadas nas métricas. No plano das rodas do veículo, a velocidade de guinada é o principal determinante de instabilidade dos veículos de passeio. Se a taxa de variação do ângulo de guinada for diferente da desejada pelo motorista, considerase que o veículo está instável e medidas corretivas devem ser tomadas para garantir a segurança dos passageiros. Os termos usados para essa instabilidade são 
sobresterçamento, quando a velocidade de guinada é maior que a desejada, e subesterçamento, caso contrário. Essas instabilidades são frequentemente atingidas devido a altas velocidades durante as curvas e/ou diferentes coeficientes de atrito experimentados por cada roda (6).

Os outros dois ângulos de rotação do veículo (rolagem e arfagem) não apresentam problemas de instabilidades para veículos de passeios em terrenos planos e horizontais devido à relação das distâncias entre rodas e a altura do centro de massa do chassi. A combinação de baixo centro de massa do chassi com largas distâncias entre rodas aumentam os limites das acelerações laterais e/ou longitudinais necessárias para a capotagem. No entanto, a força de tração disponível nos pneus não é suficiente para sustentar essas acelerações, levando o veículo a instabilidades no ângulo de guinada (6). Em veículos mais altos como utilitários, ônibus e caminhões, essa relação não é satisfeita e a instabilidade no ângulo de rolagem passa a ser uma preocupação.

Em (15) e (7) diversos algoritmos para avaliação da instabilidade do veículo são detalhados. A transferência de carga entre rodas do veículo é uma métrica comum para distribuição de forças de contato e é definida pela diferença entre as forças normais dos lados direito e esquerdo do veículo, como mostra a equação (1.1). A proximidade do indicador aos extremos 1.0 e -1.0 mostra a tendência à instabilidade do veículo, e a igualdade aos mesmos, indicará que pelo menos uma roda já descolou do terreno.

$$
R=\frac{F_{R}-F_{L}}{F_{R}+F_{L}}
$$

A implementação em sistemas experimentais não é simples, pois requer a medição das forças normais em cada roda, e para isso precisa de sensores de força, normalmente caros. No entanto, em terrenos planos a estimativa da transferência de carga pode ser feita com informação da aceleração lateral e/ou ângulo de rolagem.

Outra métrica usada é a comparação entre a aceleração lateral $a_{y}$ do veículo com uma aceleração crítica $a_{c r i t}$ a partir da qual o veículo capotaria. Para essa abordagem, o modelo do sistema para o cálculo da aceleração crítica determina a 
acurácia do limiar, podendo ser necessário considerar a inclinação do terreno, dinâmica das suspensões etc..

O trabalho (14) apresenta uma medida para a estabilidade de um veículo em terrenos acidentados chamada ângulo-força de estabilidade. A Figura 2 mostra um caso estável e outro instável segundo a métrica de estabilidade ângulo de força proposta por (15).

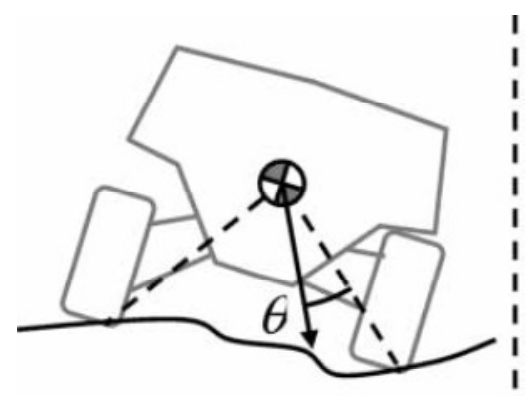

(a)

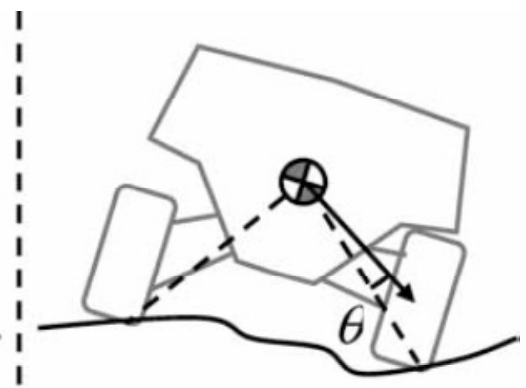

(b)

Figura 2: Ilustração do ângulo-força de estabilidade: a) estável, b) instável (15).

O indicador é calculado considerando-se a disposição dos pontos de contato entre as rodas e o terreno em relação ao centro de massa do veículo, as acelerações lineares e angulares as quais o veículo está sujeito e as forças externas agindo sobre o mesmo. Com isso, um mesmo veículo em um mesmo terreno pode estar ou não estável, dependendo da sua velocidade, aceleração e forças externas.

O eixo de capotagem pode ser definido como uma linha imaginária entre dois pontos de contatos consecutivos do veículo com o terreno. Um veículo de passeio comum, por exemplo, possui dois eixos de capotagem longitudinais (frontal, entre as rodas dianteiras, e traseiro, entre as rodas traseiras) e dois eixos de capotagem laterais (direito, entre as rodas dianteira direita e traseira direita, e esquerdo, entre as rodas dianteira esquerda e traseira esquerda).

Um ângulo é calculado para cada eixo de capotagem e a estabilidade é dada pelo menor deles, como mostra a equação (1.2). A instabilidade é atingida quando $\beta$ é negativo. 


$$
\beta=\min \left(\theta_{i}\left\|d_{i}\right\|\left\|f_{i}^{*}\right\|\right) \quad p / i=1, \ldots, n
$$

onde:

- $\theta_{i}$ é o ângulo entre a força resultante e a normal ao eixo de capotagem que passa pelo centro de massa do veículo;

- $d_{i}$ é a menor distância entre a força resultante e o eixo de capotagem;

- $f_{i}^{*}$ é a força resultante agindo sobre o centro de massa;

- $i$ representa cada eixo de capotagem.

Em (15) um indicador baseado apenas nas medições de sensores inerciais (desconsiderando-se forças externas como aerodinâmica, magnética etc.) é apresentado. Para o seu cálculo, eixos de capotagem também são criados entre dois pontos de contato pneu-terreno. Tipicamente, em um veículo de quatro rodas, esses eixos seriam o lateral direito, frontal, lateral esquerdo e traseiro. Os momentos resultantes das forças e momentos inerciais e das forças externas são tomados em relação a um ponto $b_{0}$ arbitrário em cima de cada um desses eixos como mostra a equação (1.3).

$$
\begin{gathered}
S M_{j}=\left\{\sum_{i=1}^{l+1}\left[{ }^{B} \underline{T}^{i}\left({ }^{i} \boldsymbol{\omega}_{c i} \times{ }^{i} \underline{I}_{c i}{ }^{i} \boldsymbol{\omega}_{c i}+{ }^{i} \underline{I}_{c i}{ }^{i} \dot{\boldsymbol{\omega}}_{c i}\right)+{ }_{b}^{B} \boldsymbol{c}_{c i} \times m_{i}{ }_{b}^{B} \boldsymbol{a}_{c i}\right]\right. \\
\left.-\sum_{i=1}^{k}\left({ }_{b}^{B} \boldsymbol{q}_{c i} \times{ }_{b}^{B} \boldsymbol{B}_{c i}\right)\right\}{ }_{b}^{B} \boldsymbol{r}_{c i}
\end{gathered}
$$

onde:

- $l$ é o número de rodas do veículo (somatório até $l+1$ considerando-se o chassi);

- $k$ é o número de forças externas sobre o mesmo;

- ${ }^{i}{ }_{c i},{ }^{i} \boldsymbol{\omega}_{c i}$ e ${ }^{i} \dot{\boldsymbol{\omega}}_{c i}$ são, respectivamente, a matriz de inércia, velocidade de angular (leitura do girômetro) e aceleração angular (derivada temporal da leitura do girômetro) do corpo $i$ (rodas e chassi) no sistema referencial local;

- $m_{i}$ é a massa do corpo $i$; 
- ${ }^{B} T^{i}$ é a matriz de transformação do referencial local do corpo $i$ para o referencial solidário ao chassi;

- ${ }_{b}^{B} c_{c i}$ é o vetor posição entre o centro do corpo $i$ e $b_{0}$;

- ${ }_{b}^{B} \boldsymbol{a}_{c i}$ é a leitura do acelerômetro no referencial solidário;

$-{ }_{b}^{B} \boldsymbol{q}_{c i}$ é o vetor posição entre a força externa e $b_{0}$;

- ${ }_{b}^{B} \boldsymbol{B}_{c i}$ é a força externa;

- ${ }_{b}^{B} \boldsymbol{r}_{c i}$ é o eixo de instabilidade no referencial solidário.

Assume-se que o veículo possui $l$ rodas e um chassi.

Considerando que a probabilidade de se capotar um veículo lateralmente é maior do que frontalmente, uma estimativa adimensional da estabilidade do veículo pode ser calculada utilizando a menor métrica normalizada dentre as laterais, como mostra a equação (1.4). A normalização das métricas é feita considerando o maior valor $S M_{\max }$ da métrica quando o veículo se encontra em repouso em um terreno plano e horizontal.

$$
R_{S M}=\min \left(\frac{S M_{L}}{S M_{\max }}, \frac{S M_{R}}{S M_{\max }}\right)
$$

Um valor negativo fornecido pela métrica não garante que um capotamento acontecerá e sim que o veículo está sujeito a um momento desestabilizante. Em contrapartida, um valor positivo assegura que o veículo se encontra com as rodas em contato com o terreno ou que está desacelerando de um eventual início de capotamento (16). Em (16), uma análise sobre a influência do posicionamento do acelerômetro distante do centro de massa do veículo é apresentada, juntamente com uma alternativa para minimizar esses erros caso a distância ao centro de massa seja estimada. Excluindo-se as forças externas, a grande vantagem dessa métrica é poder calcular seu valor usando apenas sensores inerciais como giroscópio e acelerômetro. 


\section{4.}

Técnicas de controle de estabilidade

Em veículos de passeio, o primeiro controle de estabilidade foi o ABS (AntiLock Braking System), introduzido pela Bosch num veículo da Mercedes-Benz em 1978. Utilizado até hoje, esse sistema libera os freios intermitentemente durante uma freada brusca do usuário para evitar que as rodas travem, maximizando a frenagem enquanto mantem a dirigibilidade do veículo durante a manobra (3).

O próximo passo foi desenvolver um sistema de controle que monitorasse a intenção do motorista e a comparasse com o atual comportamento do veículo. Caso os dois sejam criticamente diferentes, sinais de controle são enviados para os atuadores do veículo, procurando corrigir os erros. Esse sistema é chamado de YSC (Yaw Stability Control) e possui diversos nomes dependendo do fabricante (3).

O sistema de controle de guinada (YSC) usando ABS é o mais comum e utiliza o princípio da frenagem diferencial para o controle de estabilidade, onde o sistema envia comandos de frenagem diferentes para cada roda do veículo para causar um momento sobre o sistema corrigindo assim o erro na velocidade de guinada do chassi. Ele recebe o nome de EBD (Electronic Brake Distribution) e uma das suas desvantagens é a obrigatória frenagem em todos os atos de correção, afetando diretamente a dinâmica longitudinal do veículo.

Outros dois princípios utilizados para o controle são o steer-by-wire e distribuição ativa de torques. O steer-by-wire sobrescreve o comando de esterçamento do motorista para corrigir o erro, enquanto a distribuição ativa de torques utiliza diferenciais eletronicamente atuados que delegam diferentes torques a cada uma das rodas para obter a velocidade angular desejada do chassi (6).

Para veículos altos como ônibus e caminhões, a capotagem passa a ser outra possível situação de instabilidade. O RSC (Roll Stability Control) foi desenvolvido para prevenir capotagens utilizando os mesmos sistemas de atuação do YSC e corrigindo eventuais tendências desestabilizadoras (6).

Trabalhos mais recentes, como (3), (4) e (17), apresentam controles de estabilidade para carros de passeio onde são assumidas simplificações como terrenos planos e pouca transferência de carga entre eixos durante as manobras. Nessas condições o peso do chassi é considerado igualmente distribuído entre as 
rodas (normais iguais) e ângulos de contato entre pneu e solo são constantes e nulos.

O controle de guinada e/ou rolagem só pode ser conseguido se a tração do veículo também estiver controlada. A maioria dos trabalhos desenvolve controles de tração de maneira a maximizá-la pela observação da deriva longitudinal. A deriva longitudinal pode ser entendida como o escorregamento longitudinal entre a roda e o terreno que ocorre, normalmente, quando o veículo está acelerando ou freando (ver seção 5.3.1). O formato típico da variação do coeficiente de atrito em função da deriva longitudinal pode ser visto na Figura 3. Nela percebe-se que o coeficiente de atrito é máximo para baixos valores de deriva. O controle de tração procura trabalhar com derivas nessa região. No entanto, (5) apresenta um controle de tração que lida com as não-linearidades da combinação de altas derivas longitudinal e lateral em veículos trafegando em alta velocidade.

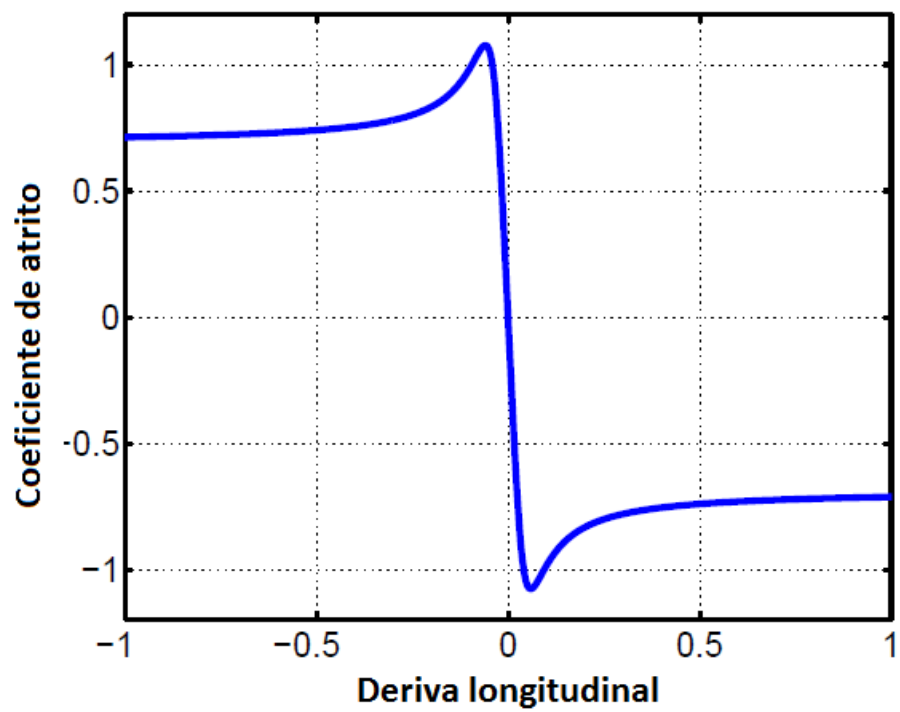

Figura 3: Formato típico da variação do coeficiente de atrito em função da deriva longitudinal (17).

Em (2) um controlador da família PID com ganho proporcional variando em função da velocidade de rotação da roda é apresentado como controle de tração com bons resultados experimentais. $\mathrm{O}$ modelo assumido permite ainda fazer uma boa estimativa das condições da rodovia em termos de atrito.

Os trabalhos (18), (19) e (20) apresentam um controle de estabilidade de veículos robóticos em terrenos acidentados apenas no plano de capotagem (ângulo de arfagem). O controle desenvolvido procura manter a velocidade desejada 
usando torques calculados a partir do modelo desenvolvido. Como existe mais de uma combinação de torques que atende a manutenção da velocidade desejada, algoritmos de otimização de critérios, como minimização de potência e maximização da razão de tração (razão entre a força de tração e a normal sobre a roda) foram implementados com bons resultados.

Modelos da dinâmica de veículos são encontrados extensivamente na literatura (3), (4), (21), (22), (6) e(7). O principal modelo usado é o chamado modelo de bicicleta. Nele o veículo é considerado tendo uma roda dianteira esterçável e uma traseira sempre paralela ao chassi. As dinâmicas longitudinal, lateral e de guinada são abordadas considerando os efeitos da rolagem, arfagem e dinâmica vertical, desprezíveis na análise de instabilidades. Os trabalhos que propõem sistemas de controle também para a rolagem aproximam o veículo por um pêndulo invertido. Transferências de cargas entre eixos capazes de alterar significativamente as forças normais sobre as rodas são consideradas em análises com acelerações constantes, longitudinais ou laterais. Os casos abordados são em análises de arrancadas a acelerações constantes ou curvas de raio fixo com velocidades linear e angular constantes (aceleração centrípeta constante). Nessas situações, as normais possuem uma componente chamada de termo estático considerado um quarto do peso do veículo ao qual é somado (ou subtraído dependendo da roda analisada) um termo dinâmico proporcional à aceleração a qual o veículo está submetido.

Veículos que trafegam outros tipos de terrenos exigem diferentes abordagens para o controle de estabilidade. Robôs desenvolvidos para explorar outros planetas, ou mesmo áreas remotas da Terra, devem lidar com problemas intrínsecos a terrenos acidentados, como pedras soltas, buracos, terreno arenoso, pântanos etc.. Nessas situações, as velocidades costumam ser menores e o problema de instabilidade na rolagem (seja ela lateral ou longitudinal) passa a ter maior destaque em relação à guinada (23). Outra preocupação é evitar atolamentos. Devido a essas exigências, veículos robóticos para terrenos acidentados costumam ter rodas individualmente atuadas por motores elétricos e suspensões ativamente articuladas. Seu sensoriamento é mais complexo, podendo incluir câmeras, sensores de pressão nas rodas, sensores de força nos braços das suspensões, dentre outros (23). 


\section{5 .}

\section{Objetivo da tese}

Essa pesquisa tem o objetivo de desenvolver um algoritmo de detecção da fase balística para veículos robóticos elétricos com rodas, utilizando sensores de baixo custo de aquisição (encoders e amperímetros, comumente presentes em sistema com controle de torque de motores elétricos de corrente contínua) e controle de atitude durante a mesma, com o intuito de aumentar as chances de um retorno seguro ao terreno.

\section{6.}

\section{Contribuições e estrutura da tese}

Controle de estabilidade de veículos automotivos requer bom sensoriamento e modelos dinâmicos confiáveis. Essa tese apresenta contribuições na área de estimativa de parâmetros e condições de estabilidade de um veículo robótico trafegando por terrenos acidentados em grandes velocidades. Os algoritmos são desenvolvidos procurando-se utilizar do mínimo de sensores necessários de maneira a reduzir o custo de desenvolvimento de sistemas de controle de estabilidade em veículos automotivos. Um breve resumo das contribuições é mostrado a seguir.

No capítulo 2 é desenvolvido o modelo dinâmico de um veículo robótico com rodas sem esterçamento (sempre paralelas ao chassi) e sem suspensões. Os modelos largamente utilizados em controle de tração e estabilidade de veículos em altas velocidades simplificam as interações com o terreno assumindo normais constantes e sempre perpendiculares ao plano do chassi. Essas simplificações deixam de ser boas aproximações em terrenos acidentados. $\mathrm{O}$ modelo desenvolvido leva em consideração a distribuição dinâmica do peso do veículo e das forças de D'Alembert sobre cada roda durante manobras em grandes velocidades. Os ângulos de contato entre o terreno e o pneu são considerados não nulos, generalizando o modelo para terrenos acidentados.

No capítulo 3 é apresentada uma proposta de algoritmo para estimativa do torque externo agindo sobre as rodas. A partir dessa estimativa, um algoritmo de detecção de descolamento da roda em relação ao terreno e a determinação da fase balística são desenvolvidos. As métricas de instabilidade de veículos em movimento baseadas em sensores inerciais informam apenas tendências à 
desestabilização. O efetivo descolamento de uma ou mais rodas do terreno só é assegurado utilizando-se sensores instalados diretamente nas rodas ou em suspensões, e costumam ser de alto custo. Baseado no modelo linear do motor de corrente contínua, o capítulo mostra um algoritmo bastante simples para a estimativa do torque externo sendo aplicado sobre o eixo do motor. A influência do nível de ruído na leitura da velocidade de rotação do motor na estimativa é comentada. No capítulo são detalhados os algoritmos de estimativa de variáveis necessárias para o estudo da estabilidade do veículo.

No capítulo 4 o algoritmo de controle de estabilidade durante a fase balística é detalhado. Em muitos casos, a partir do momento em que o veículo perde contato com o solo, nada pode ser feito até o contato ser reestabelecido. Essa pesquisa propõe um algoritmo de controle de arfagem para aumentar as chances do retorno ao solo ser bem sucedido.

No capítulo 5, o simulador desenvolvido durante a primeira metade da pesquisa em conjunto com o mestrado do aluno Ricardo Morrot (24) é apresentado. Como não foi possível encontrar um simulador que atendesse às necessidades do projeto, tanto técnicas quanto financeiras, decidiu-se desenvolver um. O capítulo apresenta brevemente os requisitos do software relevantes para as simulações feitas. Maiores detalhes sobre a arquitetura do software são encontrados em (24).

No capítulo 6 são mostradas as simulações e experimentos feitos com os algoritmos desenvolvidos, e, no último capítulo, conclusões são apresentadas juntamente com sugestões para trabalhos futuros. 


\section{Dinâmica do sistema}

\section{1 .}

\section{Esforços agindo sobre o sistema}

Para determinar a dinâmica do sistema, é necessário determinar os esforços agindo sobre o chassi e as rodas. Os esforços externos compreendem as forças da interação pneu-solo e a força gravitacional. Foram desprezados os efeitos aerodinâmicos. Dos esforços internos, os únicos que contribuem para alteração da energia do sistema são os torques aplicados pelos motores às rodas (foi desprezado o atrito nos eixos das rodas). A Figura 4 mostra o diagrama de corpo livre da roda.
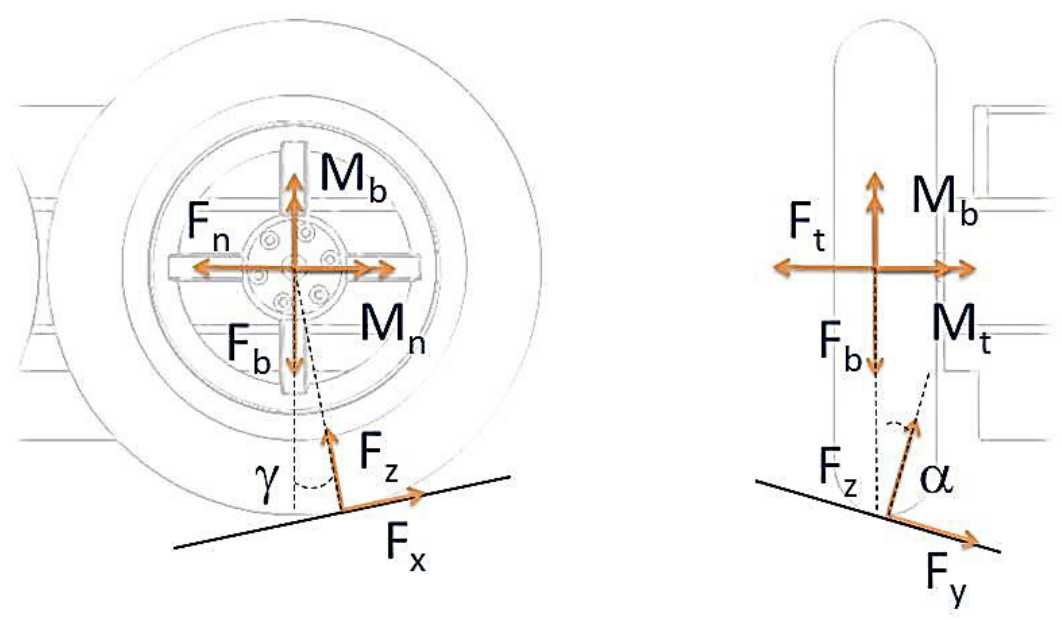

Figura 4: Diagrama de corpo livre de uma das rodas do veículo.

As definições dos referenciais usados, juntamente com as posições, velocidade e acelerações importantes para a modelagem do sistema, se encontram nos anexos. 
No diagrama de corpo livre consideraram-se as forças internas de reação que o chassi aplica nas rodas ${ }^{S} \boldsymbol{F}_{n},{ }^{S} \boldsymbol{F}_{t}$ e ${ }^{S} \boldsymbol{F}_{b}$ paralelas aos vetores unitários ${ }^{S} \boldsymbol{n}$, ${ }^{S} \boldsymbol{t}$ e ${ }^{S} \boldsymbol{b}$, respectivamente e os momentos internos de reação ${ }^{S} \boldsymbol{M}_{n},{ }^{S} \boldsymbol{M}_{t}$ e ${ }^{S} \boldsymbol{M}_{b}$ todos também paralelos a ${ }^{S} \boldsymbol{n},{ }^{S} \boldsymbol{t}$ e ${ }^{S} \boldsymbol{b}$, respectivamente. Da interação com o solo, considerou-se o conjunto de forças também ortogonais entre si ${ }^{C} \boldsymbol{F}_{x},{ }^{C} \boldsymbol{F}_{y} \mathrm{e}$ ${ }^{C} \boldsymbol{F}_{z}$ rotacionadas de $\gamma$ em torno de ${ }^{\mathrm{s}} \boldsymbol{t}$ e $\alpha$ em torno de ${ }^{C} \boldsymbol{n} .{ }^{C} \boldsymbol{F}_{x}$ é a força de tração paralela ao solo e pertencente ao plano formado pelos cursores ${ }^{S} \boldsymbol{n}$ e ${ }^{S} \boldsymbol{b}$, ${ }^{C} \boldsymbol{F}_{y}$ é a força de tração lateral e ${ }^{C} \boldsymbol{F}_{z}$ é a força normal. Determina-se o somatório de forças internas ${ }^{S} \boldsymbol{F}_{\text {int }_{i}}$, forças externas ${ }^{S} \boldsymbol{F}_{\text {ext }_{i}}$ e momentos internos ${ }^{S} \boldsymbol{M}_{\text {int }_{i}}$ para cada roda $i$ como:

$$
\begin{aligned}
& { }^{s} \boldsymbol{F}_{\text {int }_{i}}={ }^{s} \boldsymbol{F}_{n i}+{ }^{s} \boldsymbol{F}_{t i}+{ }^{s} \boldsymbol{F}_{b i} \\
& { }^{S} \boldsymbol{F}_{\text {ext }_{i}}={ }^{S} \underline{T}_{i}^{C}\left({ }^{C} \boldsymbol{F}_{x i}+{ }^{C} \boldsymbol{F}_{y i}+{ }^{C} \boldsymbol{F}_{z i}\right) \\
& { }^{s} \boldsymbol{M}_{\text {int }_{i}}={ }^{s} \boldsymbol{M}_{n i}+{ }^{s} \boldsymbol{M}_{t i}+{ }^{s} \boldsymbol{M}_{b i} \\
& s_{T_{i}^{C}}=\underbrace{\left[\begin{array}{ccc}
c_{\gamma i} & 0 & s_{\gamma i} \\
0 & 1 & 0 \\
-s_{\gamma i} & 0 & c_{\gamma i}
\end{array}\right]}_{\underline{T}_{\gamma i}} \underbrace{\left[\begin{array}{ccc}
1 & 0 & 0 \\
0 & c_{\alpha i} & -s_{\alpha i} \\
0 & s_{\alpha i} & c_{\alpha i}
\end{array}\right]}_{\underline{T}_{\alpha i}}=\left[\begin{array}{ccc}
c_{\gamma i} & s_{\gamma i} s_{\alpha i} & s_{\gamma i} c_{\alpha i} \\
0 & c_{\alpha i} & -s_{\alpha i} \\
-s_{\gamma i} & c_{\gamma i} s_{\alpha i} & c_{\gamma i} c_{\alpha i}
\end{array}\right]
\end{aligned}
$$

Despreza-se o momento de alinhamento entre o terreno e o pneu responsável por forçar o realinhamento das rodas de um carro em movimento durante uma curva, conhecido por momento (ou torque) de autoalinhamento (22).

Os somatórios de forças e momentos no referencial local $S$ são, portanto:

$$
\begin{gathered}
{ }^{S} \boldsymbol{F}_{i}={ }^{S} \boldsymbol{F}_{\text {ext }_{i}}-{ }^{S} \boldsymbol{F}_{\text {int }_{i}} \\
{ }^{S} \boldsymbol{M}_{i}={ }^{S} \boldsymbol{r}_{p c i} \times{ }^{S} \boldsymbol{F}_{\text {ext }_{i}}+{ }^{S} \boldsymbol{M}_{\text {int }_{i}}
\end{gathered}
$$


onde ${ }^{S} \boldsymbol{r}_{p c i}=-r\left(\underline{T}_{\gamma i}{ }^{\mathrm{S}} \boldsymbol{b}\right)$ é a posição do ponto de contato do pneu com o chão em relação ao centro geométrico da roda, cujo raio efetivo é $r$ (considerando a deformação do pneu devido à força normal).

Para o cálculo das inércias do veículo, a massa das rodas é incorporada à massa do chassi por não se considerar suspensões entre as rodas e o mesmo. No entanto, a inércia de rotação das rodas é utilizada na dinâmica de rotação do sistema. Como as rodas não transladam em relação ao chassi ( ${ }^{S} \boldsymbol{a}_{i}=$ $\left[\begin{array}{lll}0 & 0 & 0\end{array}\right]^{T}$ ), tem-se que o somatório de forças para cada roda será nulo:

$$
{ }^{s} \boldsymbol{F}_{i}=\left[\begin{array}{l}
0 \\
0 \\
0
\end{array}\right] \therefore{ }^{s} \boldsymbol{F}_{\text {ext }_{i}}={ }^{s} \boldsymbol{F}_{\text {int }_{i}}
$$

A roda é presa diretamente ao eixo da caixa de redução. Esse acoplamento restringe a movimentação das rodas, só permitindo que as mesmas girem em torno de ${ }^{\mathrm{S}} \boldsymbol{t}$. Com isso, a quantidade de movimento angular no referencial $S$ de cada roda será:

$$
{ }^{s} \boldsymbol{H}_{\boldsymbol{i}}={ }^{s} \underline{I}_{r}\left({ }_{F}^{S} \boldsymbol{\omega}_{S}+{ }^{s} \dot{\boldsymbol{\varphi}}_{i}\right)={ }^{s} \underline{I}_{r}\left({ }_{F}^{S} \boldsymbol{\omega}_{S}+\left[\begin{array}{c}
0 \\
\dot{\varphi}_{i} \\
0
\end{array}\right]\right)
$$

onde ${ }^{S} I_{r}=\left[\begin{array}{ccc}I_{r}^{1} & 0 & 0 \\ 0 & I_{r}^{2} & 0 \\ 0 & 0 & I_{r}^{1}\end{array}\right]$ é o tensor de inércia da roda ${ }_{F}^{S} \omega_{S}$ a velocidade angular absoluta do chassi, ambos descritos no referencial $S$.

Sua variação no tempo é dada pela soma de momentos em relação ao centro geométrico da roda $\frac{d\left({ }^{S} \boldsymbol{H}_{\boldsymbol{i}}\right)}{d t}={ }^{S} \boldsymbol{M}_{i}$, levando à equação (2.9):

$$
\begin{aligned}
& { }^{S} \boldsymbol{M}_{i}={ }^{S} I_{r}\left({ }_{F}^{S} \dot{\boldsymbol{\omega}}_{S}+{ }^{S} \ddot{\boldsymbol{\varphi}}_{i}\right)+{ }_{F}^{S} \boldsymbol{\omega}_{S} \times{ }^{S} I_{r}\left({ }_{F}^{S} \boldsymbol{\omega}_{S}+{ }^{S} \dot{\boldsymbol{\varphi}}_{i}\right)= \\
& { }^{S} \boldsymbol{r}_{p c i} \times{ }^{S} \boldsymbol{F}_{\text {ext }_{i}}+{ }^{S} \boldsymbol{M}_{\text {int }_{i}}
\end{aligned}
$$


A fim de facilitar a compreensão, a Figura 5 mostra um quarto do diagrama de corpo livre do chassi para destacar a interação de uma das rodas com o mesmo. É mostrada também a força gravitacional agindo no centro de massa do veículo.
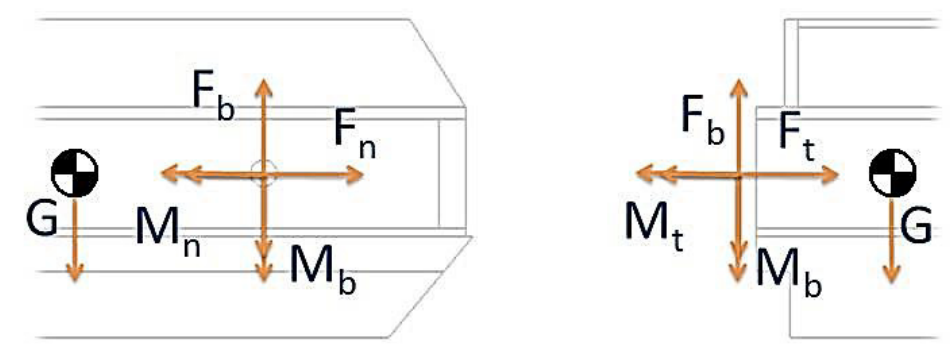

Figura 5: Diagrama de corpo livre de um quarto do veículo.

Sobre o chassi estão atuando as forças e momentos de reação de cada roda e a força gravitacional. Portanto, o somatório de forças e momentos sobre o chassi em relação ao seu centro de massa A descritos no referencial local é:

$$
\begin{gathered}
{ }^{S} \boldsymbol{F}=\sum_{i=0}^{3}{ }^{s} \boldsymbol{F}_{\text {int }_{i}}-{ }^{s} \underline{T}^{F}{ }^{F} \boldsymbol{G r a v} \\
{ }^{s} \boldsymbol{M}_{\boldsymbol{A}}=\sum_{i=0}^{3}\left({ }^{s} \boldsymbol{r}_{i} \times{ }^{s} \boldsymbol{F}_{\text {int }_{i}}-{ }^{s} \boldsymbol{M}_{\text {int }_{i}}\right)
\end{gathered}
$$

onde ${ }^{S} \boldsymbol{r}_{i}$ é a posição do eixo de cada roda em relação ao centro de massa do veículo.

\section{2.}

Quantidade de movimento linear e angular do veículo

A quantidade de movimento linear do veículo é simples, pois as massas das rodas são incorporadas à do chassi por não possuírem movimento de translação relativo ao mesmo. Dessa forma, tem-se: 


$$
{ }^{s} \boldsymbol{G}=m^{S} \boldsymbol{v}_{A}
$$

De acordo com a segunda lei de Newton, a variação da quantidade de movimento linear do veículo é igual ao somatório de forças aplicadas, como mostra a equação (2.13):

$$
\frac{d\left({ }^{s} \boldsymbol{G}\right)}{d t}={ }^{s} \boldsymbol{F}=m{ }^{s} \boldsymbol{a}_{A}+m\left({ }_{F}^{S} \boldsymbol{\omega}_{S} \times{ }^{s} \boldsymbol{v}_{A}\right)
$$

A quantidade de movimento angular no referencial local $S$, em relação ao centro de massa do veículo pode ser descrita como:

$$
{ }^{s} \boldsymbol{H}_{\boldsymbol{A}}={ }^{s} \underline{I}_{A F}^{S} \boldsymbol{\omega}_{S}
$$

onde ${ }^{S} I_{A}=\left[\begin{array}{ccc}I_{c}^{1} & 0 & 0 \\ 0 & I_{c}^{2} & 0 \\ 0 & 0 & I_{c}^{3}\end{array}\right]$ é o tensor de inércia do chassi.

Segundo a lei de Newton-Euler, a variação da quantidade de movimento angular do veículo é igual ao somatório de momentos aplicados, como mostra a equação (2.15):

$$
\frac{d\left({ }^{S} \boldsymbol{H}_{\boldsymbol{A}}\right)}{d t}={ }^{S} \boldsymbol{M}_{\boldsymbol{A}}={ }^{S}{ }_{I_{A}}{ }_{F} \dot{\boldsymbol{\omega}}_{S}+{ }_{F}^{S} \boldsymbol{\omega}_{S} \times{ }^{S_{I_{A}}}{ }_{F}^{S} \boldsymbol{\omega}_{S}
$$




\section{3.}

\section{Equações de movimento do sistema}

Expandindo as equações (2.7) e (2.9), chega-se ao seguinte conjunto de equações para cada roda i:

$$
\begin{gathered}
F_{n i}=F_{x i} c_{\gamma i}+F_{y i} s_{\gamma i} s_{\alpha i}+F_{z i} s_{\gamma i} c_{\alpha i} \\
F_{t i}=F_{y i} c_{\alpha i}-F_{z i} s_{\alpha i} \\
F_{b i}=-F_{x i} s_{\gamma i}+F_{y i} c_{\gamma i} s_{\alpha i}+F_{z i} c_{\gamma i} c_{\alpha i} \\
M_{n i}=-r F_{y i} c_{\gamma i} c_{\alpha i}+r F_{z i} c_{\gamma i} S_{\alpha i}-I_{r}^{2}\left(\dot{\varphi}_{i}+\omega_{y}\right) \omega_{z} \\
+I_{r}^{1}\left(\dot{\omega}_{x}+\omega_{y} \omega_{z}\right) \\
M_{t i}=I_{r}^{2}\left(\ddot{\varphi}_{i}+\dot{\omega}_{y}\right)=\tau_{i}-r F_{x i} \\
M_{b i}=r F_{y i} S_{\gamma i} c_{\alpha i}-r F_{z i} s_{\gamma i} s_{\alpha i}+I_{r}^{2}\left(\dot{\varphi}_{i}+\omega_{y}\right) \omega_{x}+I_{r}^{1}\left(\dot{\omega}_{z}-\omega_{x} \omega_{y}\right)
\end{gathered}
$$

onde $\tau_{i}$ é o torque aplicado pelo motor à roda $\mathrm{i}$.

Substituindo as equações (2.10) e (2.11) nas equações (2.13) e (2.15) temse:

$$
\begin{gathered}
\left(\sum F_{n i}\right)-m T_{13} g-m\left(\omega_{y} v_{z}-\omega_{z} v_{y}\right)=m \ddot{x} \\
\left(\sum F_{t i}\right)-m T_{23} g-m\left(\omega_{z} v_{x}-\omega_{x} v_{z}\right)=m \ddot{y} \\
\left(\sum F_{b i}\right)-m T_{33} g-m\left(\omega_{x} v_{y}-\omega_{y} v_{x}\right)=m \ddot{z} \\
r_{y}\left(-F_{b 0}-F_{b 1}+F_{b 2}+F_{b 3}\right)+\sum\left(r_{z} F_{t i}-M_{n i}\right) \\
=I_{c}^{1} \dot{\omega}_{x}+\omega_{y} \omega_{z}\left(I_{c}^{3}-I_{c}^{2}\right) \\
r_{x}\left(F_{b 0}-F_{b 1}-F_{b 2}+F_{b 3}\right)+\sum\left(-r_{z} F_{n i}-\left(\tau_{i}-r F_{x i}\right)\right) \\
=I_{c}^{2} \dot{\omega}_{y}+\omega_{x} \omega_{z}\left(I_{c}^{1}-I_{c}^{3}\right)
\end{gathered}
$$




$$
\begin{gathered}
r_{y}\left(F_{n 0}+F_{n 1}-\right. \\
\left.F_{n 2}-F_{n 3}\right)+r_{x}\left(-F_{t 0}+F_{t 1}+F_{t 2}-F_{t 3}\right)-\sum M_{b i} \\
=I_{c}^{3} \dot{\omega}_{z}+\omega_{y} \omega_{x}\left(I_{c}^{2}-I_{c}^{1}\right)
\end{gathered}
$$

onde:

- $T_{i j}$ é o elemento da linha i e da coluna j da matriz de transformação ${ }^{S} \underline{T}^{F}$;

- $\omega_{x}, \omega_{y}$ e $\omega_{z}$ são os elementos da velocidade angular ${ }_{F}^{S} \boldsymbol{\omega}_{S}$;

- $\dot{\omega}_{x}, \dot{\omega}_{y}$ e $\dot{\omega}_{z}$ são os elementos da aceleração angular ${ }_{F}^{S} \dot{\omega}_{S}$;

- $r_{x}, r_{y}$ e $r_{z}$ são os elementos do vetor posição ${ }^{S} \boldsymbol{r}_{i}$ de cada roda em relação ao centro de massa.

Como o veículo é considerado simétrico, o módulo das componentes de ${ }^{S} \boldsymbol{r}_{i}$ é o mesmo para todas as rodas e apenas o sinal das mesmas varia.

Apenas no simulador foi considerado um acoplamento mola-amortecedor entre o chassi e o solo como um recurso para evitar lidar com problemas de rigidez muito alta no contato com o terreno. Para tal, a força interna $F_{b i}$ foi considerada como sendo exercida por uma suspensão e, portanto, substituída pela expressão:

$$
F_{b i}=c \dot{\xi}_{i}+k \xi_{i}
$$

onde:

- $c$ é a constante de amortecimento;

- $k$ é a rigidez;

- $\xi_{i}$ é a deformação da suspensão;

- $\dot{\xi}_{i}$ é a sua taxa de deformação no tempo.

Apesar da existência de uma suspensão entre o chassi e a roda, a última permaneceu sendo considerada sem massa durante as simulações, não influenciando na dinâmica translacional do chassi.

Foi considerado um limite de saturação para a deformação da suspensão de modo a evitar situações em que a roda tivesse um deslocamento excessivo. Para 
deformações além do limite, a força aplicada entre o chassi e a roda assume a seguinte expressão:

$$
F_{b i}=c \dot{\xi}_{i}+k\left[\xi_{i}+10\left(\xi_{i}-\xi_{s a t}\right)^{2}\right]
$$

\section{4 .}

\section{Sistema de atuação}

Motores elétricos de corrente contínua possuem modelos bem conhecidos e explorados na literatura (25) e (26). A estimativa dos parâmetros do motor pode ser feita aquisitando dados de ensaios de resposta ao degrau em bancadas de teste e ajustando parâmetros do modelo por meio de um método de mínimos quadrados (27) e (28).

O veículo robótico do sistema é modelado com quatro motores elétricos de corrente contínua atuando individualmente em cada roda. Os parâmetros do modelo do motor implementado são do motor Ampflow modelo A28-150 de 3HP e velocidade de rotação final de $6.000 \mathrm{rpm}$. Outras características do motor são encontradas em (29). São consideradas caixas de redução com fator de redução de 7,14:1, simulando a caixa de redução modelo TWM3M da empresa Team Whyachi.

O modelo para a dinâmica do motor acoplado à caixa de redução com a roda no eixo de saída (eixo de rotação mais lenta), utilizado para os algoritmos de filtragem e controle do motor é descrito nas equações (2.30) a (2.33)(30):

$$
\begin{gathered}
L \frac{d j}{d t}=V-F e m-R j \\
I \frac{d \omega_{r}}{d t}=T_{m}-b \omega_{r}-\tau_{e x t} \\
T_{m}=K_{t} G_{b} j \\
\text { Fem }=K_{t} \omega_{e}
\end{gathered}
$$


onde:

- L é a constante de indutância equivalente dos enrolamentos do rotor;

- $R$ é a constante de resistência elétrica equivalente do sistema e engloba os enrolamentos do motor, a bateria e a eletrônica de controle;

- $j$ é a corrente elétrica drenada pelo sistema;

- $V$ é a tensão elétrica aplicada no motor;

- I é o momento de inércia equivalente da roda com as engrenagens da caixa de redução;

- $b$ é o coeficiente de atrito viscoso equivalente do sistema;

- $\tau_{\text {ext }}$ é a soma dos torques externos agindo sobre o eixo do motor;

- $\omega_{e}$ é a velocidade de rotação do eixo do rotor antes da caixa de redução;

- $\omega_{r}$ é a velocidade de rotação da roda depois da caixa de redução;

- $G_{b}$ é a relação da caixa de redução;

- $K_{t}$ é a constante de torque do motor.

Nesse modelo de motor em particular, a constante de torque é igual à constante da tensão contra eletromotriz, usualmente representada pela sigla $K_{v}$.

As variáveis intermediárias Fem e $T_{m}$ são, respectivamente, a tensão contra eletromotriz e o torque no eixo do rotor depois da caixa de redução.

Devido à caixa de redução, a rotação da roda será $\omega_{r}=\omega_{e} / G_{b}$. Substituindo na equação (2.31) tem-se:

$$
\begin{gathered}
\frac{I}{G_{b}} \frac{d \omega_{e}}{d t}=K_{t} j G_{b}-\frac{b \omega_{e}}{G_{b}}-\tau_{\text {ext }} \\
I \frac{d \omega_{e}}{d t}=K_{t} j G_{b}^{2}-b \omega_{e}-G_{b} \tau_{\text {ext }}
\end{gathered}
$$

O modelo no espaço de estados do sistema (31) é mostrado pela equação (2.36):

$$
\left\{\begin{array}{l}
\dot{\boldsymbol{X}}=\underline{A} \boldsymbol{X}+\underline{B} \boldsymbol{U} \\
\boldsymbol{Y}=\underline{C} \boldsymbol{X}+\underline{D} \boldsymbol{U}
\end{array}\right.
$$

onde: 
- $\boldsymbol{X}=\left[\begin{array}{c}j \\ \omega_{e}\end{array}\right]$ é o vetor de estado do sistema formado pela corrente $j$ e a velocidade de rotação $\omega_{e}$;

$-\underline{A}=\left[\begin{array}{cc}-R / L & -K_{t} / L \\ K_{t} G_{b}^{2} / I & -b / I\end{array}\right]$ é a matriz de estado;

- $\underline{B}=\left[\begin{array}{cc}1 / L & 0 \\ 0 & -G_{b} / I\end{array}\right]$ é a matriz de entrada;

- $\underline{C}=\left[\begin{array}{ll}1 & 0 \\ 0 & 1\end{array}\right]$ é a matriz de saída;

- $\underline{D}=\left[\begin{array}{ll}0 & 0 \\ 0 & 0\end{array}\right]$ é a matriz de transmissão direta;

- Y é a leitura dos sensores (amperímetro e encoder);

- $\boldsymbol{U}=\left[\begin{array}{c}V \\ \tau_{\text {ext }}\end{array}\right]$ é a excitação do sistema.

As matrizes de saída e de transmissão direta são escolhidas de forma a representarem a leitura dos sensores simulados para controle dos motores (amperímetros e encoders).

\section{5.}

\section{Representação em forma de espaço de estados}

As equações apresentadas na seção 2.3 foram linearizadas e acopladas com as equações do sistema de atuação para apresentação em forma de espaço de estados do sistema completo. As variáveis de estados escolhidas foram as velocidades (angulares e lineares) do chassi, as velocidades de spin das rodas e as correntes dos motores. $\mathrm{O}$ vetor de estado $\boldsymbol{X}_{\boldsymbol{T}}$ do sistema é apresentado na equação (2.37).

$$
\boldsymbol{X}_{\boldsymbol{T}}=\left[\begin{array}{llll}
{ }^{S} \boldsymbol{v}_{A} & { }_{F}^{S} \boldsymbol{\omega}_{S} & \dot{\boldsymbol{\varphi}} & \boldsymbol{j}
\end{array}\right]^{T}
$$

onde $\dot{\boldsymbol{\varphi}}=\left[\begin{array}{llll}\dot{\varphi}_{0} & \dot{\varphi}_{1} & \dot{\varphi}_{2} & \dot{\varphi}_{3}\end{array}\right]$ são os spins das rodas e $\boldsymbol{j}=\left[\begin{array}{llll}j_{0} & j_{1} & j_{2} & j_{3}\end{array}\right]$ são as correntes dos motores. 
Para o acoplamento do sistema de atuação com a dinâmica veicular, são feitas adaptações nas equações (2.30) e (2.35) mostrada nas equações (2.38) e (2.39).

$$
\begin{gathered}
L \frac{d j_{i}}{d t}=V_{i}-K_{t}\left(\dot{\varphi}_{i}-\dot{\varphi}_{i p}\right)-R\left(j_{i}-j_{i p}\right)-K_{t} \dot{\varphi}_{i p}-R j_{i p} \\
I \frac{d \dot{\varphi}_{i}}{d t}=K_{t} G_{b}^{2}\left(j_{i}-j_{i p}\right)-b\left(\dot{\varphi}_{i}-\dot{\varphi}_{i p}\right)-G_{b} \tau_{\text {ext }}+K_{t} G_{b}^{2} j_{i p}-b \dot{\varphi}_{i p}
\end{gathered}
$$

As equações foram linearizadas usando série de Taylor de grau 1 em torno do estado atual como mostra a equação (2.40).

$$
\dot{\boldsymbol{X}}_{\boldsymbol{T}}=\underbrace{\left.\nabla \boldsymbol{F}\right|_{\boldsymbol{X}_{p}}}_{\underline{A_{p}}} \Delta \boldsymbol{X}+\boldsymbol{F}\left(\boldsymbol{X}_{\boldsymbol{p}}\right)
$$

onde $A_{p}$ é a matriz de estado linearizada, $\boldsymbol{X}_{\boldsymbol{p}}$ é o estado em torno do qual o sistema está sendo linearizado (mostrado na equação (2.57)), $\left.\nabla \boldsymbol{F}\right|_{X_{p}}$ é o gradiente das equações calculado no estado $\boldsymbol{X}_{\boldsymbol{p}}, \boldsymbol{F}\left(\boldsymbol{X}_{\boldsymbol{p}}\right)$ são as equações calculadas no estado $\boldsymbol{X}_{\boldsymbol{p}}$ e $\Delta \boldsymbol{X}=\boldsymbol{X}_{T}-\boldsymbol{X}_{\boldsymbol{p}}$.

As equações (2.41) à (2.48) mostram as equações do sistema linearizadas.

$$
\begin{gathered}
\frac{d v_{x}}{d t}=v_{y p}\left(\omega_{z}-\omega_{z p}\right)+\omega_{z p}\left(v_{y}-v_{y p}\right)-v_{z p}\left(\omega_{y}-\omega_{y p}\right) \\
-\omega_{y p}\left(v_{z}-v_{z p}\right)+F_{v_{x p}} \\
\frac{d v_{y}}{d t}=v_{z p}\left(\omega_{x}-\omega_{x p}\right)+\omega_{x p}\left(v_{z}-v_{z p}\right)-v_{x p}\left(\omega_{z}-\omega_{z p}\right) \\
-\omega_{z p}\left(v_{x}-v_{x p}\right)+F_{v_{y p}} \\
\frac{d v_{z}}{d t}=v_{x p}\left(\omega_{y}-\omega_{y p}\right)+\omega_{y p}\left(v_{x}-v_{x p}\right)-v_{y p}\left(\omega_{x}-\omega_{x p}\right) \\
-\omega_{x p}\left(v_{y}-v_{y p}\right)+F_{v_{z p}}
\end{gathered}
$$




$$
\begin{aligned}
& \frac{d \omega_{x}}{d t}=a_{1}\left[\omega_{y p}\left(\omega_{z}-\omega_{z p}\right)+\omega_{z p}\left(\omega_{y}-\omega_{y p}\right)\right] \\
& +a_{2}\left[\sum \dot{\varphi}_{i p}\left(\omega_{z}-\omega_{z p}\right)+\omega_{z p} \sum\left(\dot{\varphi}_{i}-\dot{\varphi}_{i p}\right)\right] \\
& +F_{\omega_{x p}} \\
& \frac{d \omega_{y}}{d t}=a_{3}\left[\omega_{x p}\left(\omega_{z}-\omega_{z p}\right)+\omega_{z p}\left(\omega_{x}-\omega_{x p}\right)\right]+F_{\omega_{y p}} \\
& \frac{d \omega_{z}}{d t}=a_{4}\left[\omega_{y p}\left(\omega_{x}-\omega_{x p}\right)+\omega_{x p}\left(\omega_{y}-\omega_{y p}\right)\right] \\
& +a_{5}\left[\sum \dot{\varphi}_{i p}\left(\omega_{x}-\omega_{x p}\right)+\omega_{x p} \sum\left(\dot{\varphi}_{i}-\dot{\varphi}_{i p}\right)\right] \\
& +F_{\omega_{z p}} \\
& \frac{d \dot{\varphi}_{i}}{d t}=a_{6}\left(j_{i}-j_{i p}\right)+a_{7}\left(\dot{\varphi}_{i}-\dot{\varphi}_{i p}\right)+F_{\dot{\varphi}_{i} p} \\
& \frac{d j_{i}}{d t}=a_{8}\left(\dot{\varphi}_{i}-\dot{\varphi}_{i p}\right)+a_{9}\left(j_{i}-j_{i p}\right)+F_{j_{i} p}
\end{aligned}
$$

onde:

$$
\begin{gathered}
F_{v_{x p}}=\omega_{z p} v_{y p}-\omega_{y p} v_{z p}+\frac{\sum F_{n i}}{m}-g T_{13} \\
F_{v_{y p}}=\omega_{x p} v_{z p}-\omega_{z p} v_{x p}+\frac{\sum F_{t i}}{m}-g T_{23} \\
F_{v_{z p}}=\omega_{y p} v_{x p}-\omega_{x p} v_{y p}+\frac{\sum F_{b i}}{m}-g T_{33} \\
F_{\omega_{x p}}=a_{1} \omega_{x p} \omega_{z p}+a_{2} \omega_{z p} \sum \dot{\varphi}_{i p}+\frac{r_{y}\left(-F_{b 0}-F_{b 1}+F_{b 2}+F_{b 3}\right)}{I_{c}^{1}+4 I_{r}^{1}} \\
+\frac{r_{z} \sum F_{t i}-r \sum\left(F_{z i} c_{\gamma i} s_{\alpha i}-F_{y i} c_{\gamma i} c_{\alpha i}\right)}{I_{c}^{1}+4 I_{r}^{1}} \\
+\frac{r_{x}\left(F_{b 0}-F_{b 1}-F_{b 2}+F_{b 3}\right)}{I_{c}^{2}} \\
\left.F_{\omega_{y p}}=a_{3} \omega_{x p} \omega_{z p}+r_{z} F_{n i}-\tau_{i}+r F_{x i}\right) \\
F_{\omega_{z p}}^{2} \\
=a_{1} \omega_{x p} \omega_{z p}+a_{2} \omega_{z p} \sum \dot{\varphi}_{i p}+\frac{r_{y}\left(F_{n 0}+F_{n 1}-F_{n 2}-F_{n 3}\right)}{I_{c}^{3}+4 I_{r}^{1}} \\
+\frac{r_{x}\left(-F_{t 0}+F_{t 1}+F_{t 2}-F_{t 3}\right)+r \sum\left(F_{z i} s_{\gamma i} s_{\alpha i}-F_{y i} s_{\gamma i} c_{\alpha i}\right)}{I_{c}^{3}+4 I_{r}^{1}}
\end{gathered}
$$




$$
\begin{gathered}
F_{\dot{\varphi}_{i} p}=a_{6} j_{i p}+a_{7} \dot{\varphi}_{i p}-\frac{G_{b} \tau_{\text {ext }}}{I_{r}^{2}} \\
F_{j_{i} p}=a_{8} \dot{\varphi}_{i p}+a_{9} j_{i p}+\frac{V_{i}}{L}
\end{gathered}
$$

onde:

$$
\begin{aligned}
& -a_{1}=\frac{I_{c}^{2}-I_{c}^{3}-4 I_{r}^{1}+4 I_{r}^{2}}{I_{c}^{1}+4 I_{r}^{1}} ; \\
& -a_{2}=\frac{I_{r}^{2}}{I_{c}^{1}+4 I_{r}^{1}} \\
& -a_{3}=\frac{I_{c}^{3}-I_{c}^{1}}{I_{c}^{2}} ; \\
& -a_{4}=\frac{I_{c}^{1}-I_{c}^{2}+4 I_{r}^{1}-4 I_{r}^{2}}{I_{c}^{3}+4 I_{r}^{1}} ; \\
& -a_{5}=-\frac{I_{r}^{2}}{I_{c}^{3}+4 I_{r}^{1}} \\
& -a_{6}=\frac{G_{b}^{2} K_{t}}{I_{r}^{2}} \\
& -a_{7}=-\frac{b}{I_{r}^{2}} \\
& -a_{8}=-\frac{K_{t}}{L} ; \\
& -a_{9}=-\frac{R}{L} ; \\
& -c_{1}=a_{1} \omega_{y p}+a_{2} \sum \dot{\varphi}_{i p} ; \\
& -c_{2}=a_{4} \omega_{y p}+a_{5} \sum \dot{\varphi}_{i p} ;
\end{aligned}
$$

A matriz de estado é apresentada na equação (2.58). 

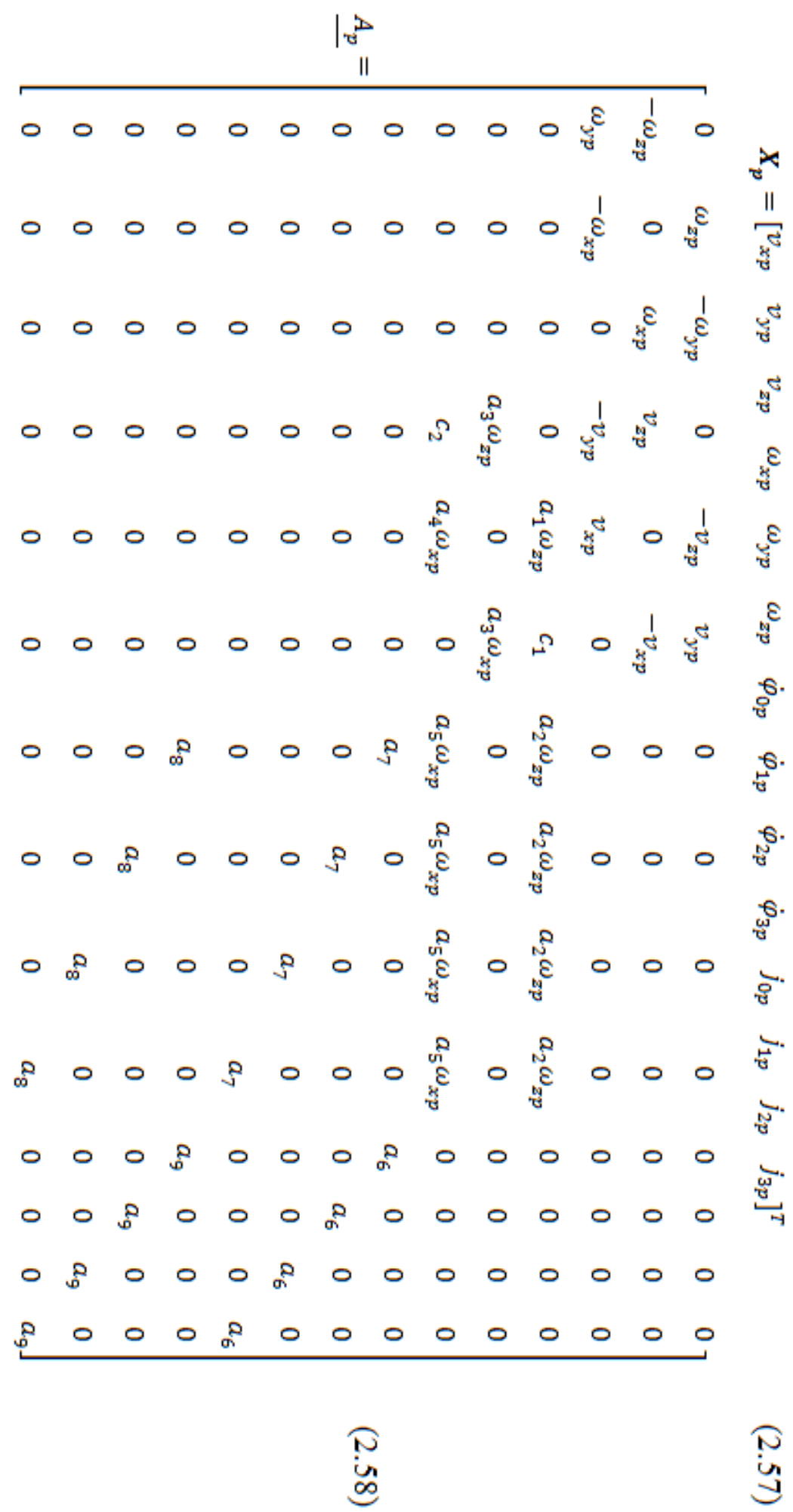

No capítulo 3 as técnicas de detecção de descolamento das rodas são apresentadas. 


\section{3 Detecção do descolamento das rodas e da fase balística}

As métricas para avaliação da estabilidade do veículo auxiliam na tomada de decisão de controladores, mas não determinam se alguma roda descolou do terreno (iniciando uma potencial situação de capotagem) e nem qual roda descolou. As métricas baseadas em transferência de cargas, como a mostrada pela equação (1.1), fornecem informações mais acuradas. No entanto, necessitam de sensores para medir o comprimento atual das suspensões ou células de carga instaladas nas mesmas (15). A Figura 6 mostra uma sequência de fotos de um caso em que um veículo robótico perde o contato com o terreno ao passar em alta velocidade por um buraco.

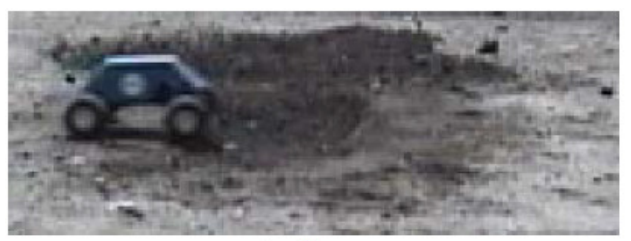

$\mathrm{t}=0 \mathrm{~s}$

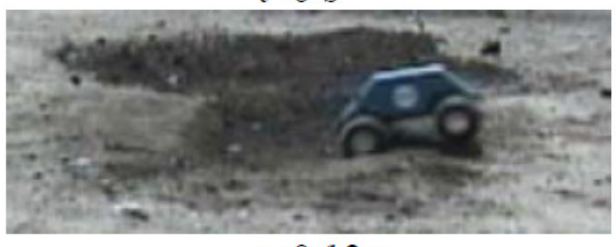

$\mathrm{t}=0.13 \mathrm{~s}$

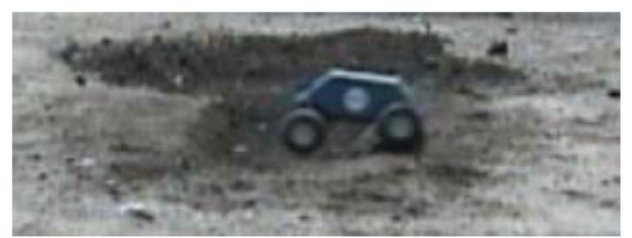

$\mathrm{t}=0.10 \mathrm{~s}$

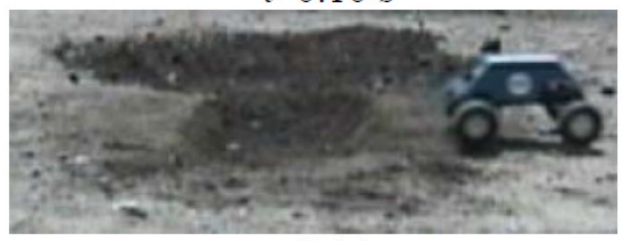

$\mathrm{t}=0.16 \mathrm{~s}$

Figura 6: Sequência de fotos de um veículo robótico em alta velocidade perdendo o contato com o terreno ao passar por um buraco (8).

Para evitar recorrer ao uso de sensores exclusivos para detecção do descolamento da roda, a dinâmica do motor elétrico em cada roda do veículo pode ser usada para fornecer uma estimativa do torque sobre a roda. Uma das vantagens dessa estimativa, em relação às métricas de estabilidade, é a simplicidade do modelo de um motor de corrente contínua comparado à dinâmica de um veículo. Para implementação da métrica proposta em (15), é necessário ter um 
acelerômetro triaxial e um girômetro, também triaxial, para o cálculo do indicador. Além disso, é necessário saber as inércias de translação e rotação do sistema. Uma grande fonte de erro pode surgir se uma má estimativa da posição do acelerômetro relativa ao centro de massa for feita. Como raramente o acelerômetro é instalado no centro de massa do veículo (localização ideal), rotações do chassi causam erros na estimativa da aceleração do centro de massa devido a efeitos de acelerações, como detalhado em (15).

\section{1.}

\section{Estimativa do torque externo e detecção do descolamento da roda}

Mesmo em terrenos planos, há situações em que uma ou mais rodas podem se descolar do solo devido a manobras bruscas. Uma vez detectado o descolamento de uma ou mais rodas, é necessário tomar atitudes que restabeleçam o contato com o terreno para reverter prováveis situações de instabilidade.

$\mathrm{O}$ algoritmo de estimativa do torque externo se baseia no conhecimento da dinâmica de rotação da roda quando atuada apenas pelo motor, sem a influência de torques externos aplicados. Uma vez conhecido o estado atual do motor (corrente e velocidade de rotação), sabe-se qual será o próximo estado em função da tensão aplicada. Qualquer desvio pode ser considerado perturbação devido a um torque externo e, portanto, o contato com o solo é acusado.

Discretizando o modelo apresentado pelo sistema de equações (2.36) por meio do equivalente ZOH (Zero Order Hold) (32), para o período de controle T (em segundos), chega-se ao seguinte sistema de equações:

$$
\left\{\begin{array}{c}
\boldsymbol{X}_{k+1}=\underline{\Phi} \boldsymbol{X}_{k}+\underline{\Gamma}_{v} \\
\boldsymbol{Y}=\underline{H}_{k}+\underline{\boldsymbol{U}}_{v}
\end{array}\right.
$$

onde:

- $\underline{\Phi}=e^{A T}, \underline{\Gamma}=\underline{\mathrm{B}} \int_{0}^{T} e^{A s} d s, \underline{H}=\underline{C}, \underline{J}=\underline{D} ;$

- $\boldsymbol{X}_{k}$ é o estado atual;

- $\boldsymbol{Y}$ são as leituras dos sensores;

- $\boldsymbol{U}_{v}=\left[\begin{array}{ll}V & 0\end{array}\right]^{T}$ é a excitação do sistema compreendido pela tensão aplicada no motor. 
Para a detecção do descolamento, uma simples comparação entre a leitura atual dos sensores e o novo estado estimado pelo modelo a partir da leitura dos sensores na iteração anterior seria suficiente. No entanto, a diferença entre o estado real e o estado estimado contém informações do torque externo aplicado sobre o motor. Se sobre o mesmo estado $\boldsymbol{X}_{k}$ for aplicado além da tensão $V$, um torque $\tau_{\text {ext }}$, o novo estado será $\boldsymbol{X}_{k+1}^{\prime}$, diferente de $\boldsymbol{X}_{k+1}$. Essa diferença se dará exclusivamente pelo termo $\underline{\Gamma} \boldsymbol{U}_{\tau}$, onde $\boldsymbol{U}_{\tau}=\left[\begin{array}{ll}0 & \tau_{\text {ext }}\end{array}\right]^{T}$, de forma que $\boldsymbol{X}_{k+1}^{\prime}=$ $\underline{\Phi} \boldsymbol{X}_{k}+\underline{\Gamma}_{v}+\underline{\Gamma} \boldsymbol{U}_{\tau}$. Mas $\boldsymbol{X}_{k+1}=\underline{\Phi} \boldsymbol{X}_{k}+\underline{\Gamma} \boldsymbol{U}_{v}$, com isso tem-se:

$$
\boldsymbol{X}_{k+1}^{\prime}-\boldsymbol{X}_{k+1}=\underline{\Gamma} \boldsymbol{U}_{\tau}
$$

Como $[$ depende de parâmetros mecânicos e elétricos do motor, seu determinante é diferente de zero, logo, sua inversa existe. Com isso, tem-se:

$$
\boldsymbol{U}_{\tau}=\underline{\Gamma}^{-1}\left(\boldsymbol{X}_{k+1}^{\prime}-\boldsymbol{X}_{k+1}\right)
$$

Para determinar o descolamento da roda, compara-se $\tau=\left[\begin{array}{ll}0 & \operatorname{sign}(V)\end{array}\right] \boldsymbol{U}_{\tau}$, com um valor limite $\tau_{\text {lim }}$ (escolhido de acordo com o nível de ruído do sistema). Se esse valor estiver acima de $\tau_{\text {lim }}$, então existe um toque externo agindo sobre o motor (portanto a roda está em contato com o terreno), no sentido de resistir à tensão de comando no mesmo. Se o valor estiver abaixo de $-\tau_{\text {lim }}$, então existe um toque externo agindo sobre o motor (portanto a roda está em contato com o terreno), no sentido de ajudar o comando de tensão enviado. Caso contrário, $-\tau_{\text {lim }}<\tau<\tau_{\text {lim }}$, a roda encontra-se descolada do terreno.

\section{2.}

Detecção da fase balística

Considerando que o veículo utilizado na pesquisa é do tipo skid steer (com deslocamento semelhante a veículos com lagarta), durante o funcionamento normal do sistema, o controlador principal envia comandos de torques para os motores para controle de velocidade, direção, estabilidade ou qualquer outra necessidade do sistema. $\mathrm{O}$ controle de arfagem assume o controle dos torques do 
veículo sempre que a fase balística é detectada. A Figura 7 mostra uma imagem, feita durante os experimentos realizados na pesquisa, mostrando um veículo robótico em fase balística depois de percorrer uma mesa de 3,1m de comprimento e $1 \mathrm{~m}$ de altura em alta velocidade.

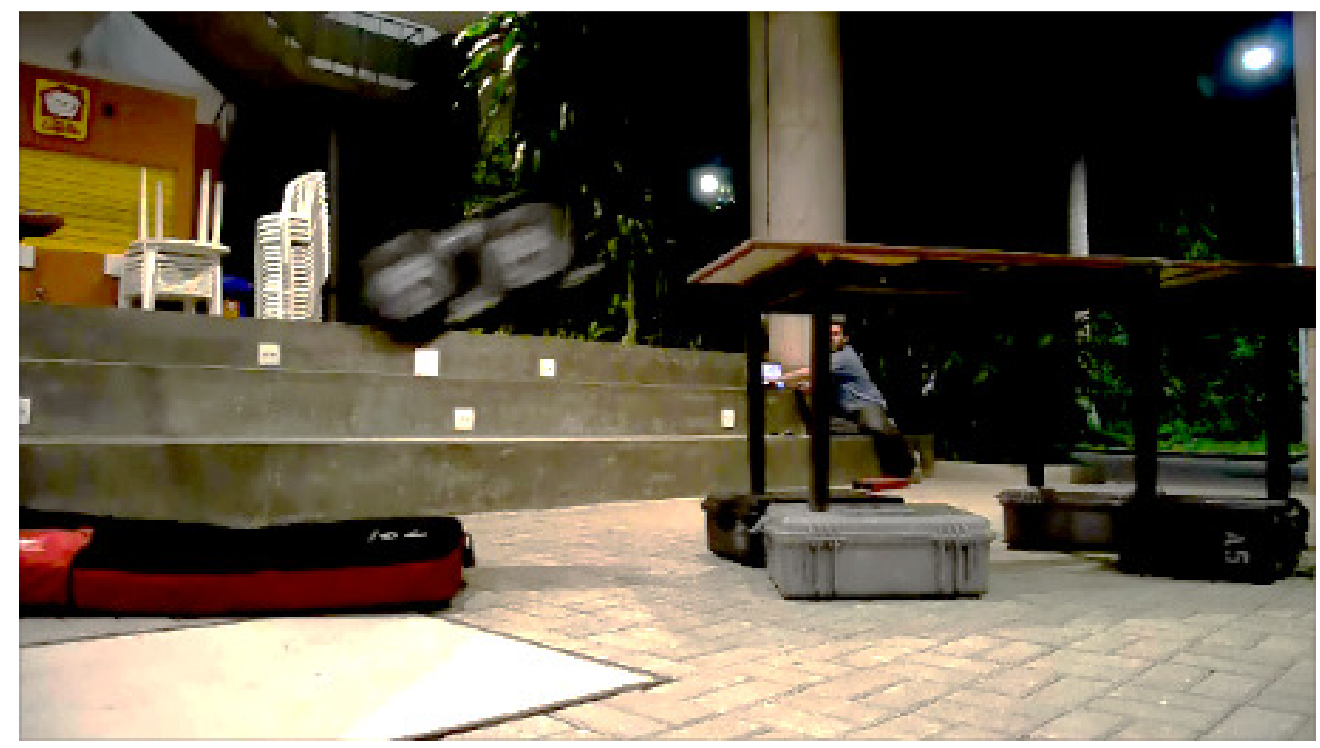

Figura 7: Veículo robótico em fase balística após percorrer uma mesa em alta velocidade.

Para auxiliar o algoritmo de detecção, um indicador de descolamento foi introduzido para mostrar quais pares de rodas foram acusadas livres por meio de simples comparação entre a estimativa do torque externo e os limiares estipulados. Esse indicador é representado por um número inteiro de três bits, onde o menos significativo representa o descolamento de todas as rodas, o segundo bit representa o descolamento das rodas traseiras e o bit mais significativo representa o descolamento das rodas dianteiras. Caso o indicador adquira seu valor máximo (sete), todas as rodas são consideradas fora do chão.

O algoritmo proposto de detecção da fase balística foi implementado contendo quatro estágios. Esses estágios são selecionados pela combinação entre o indicador de descolamento das rodas e o tempo de descolamento das rodas, como é descrito a seguir. A Figura 8 mostra uma sequência de cenas tiradas do simulador mostrando a evolução do indicador de descolamento das rodas e dos 
estágios de detecção da fase balística durante a simulação de salto a partir de uma rampa.

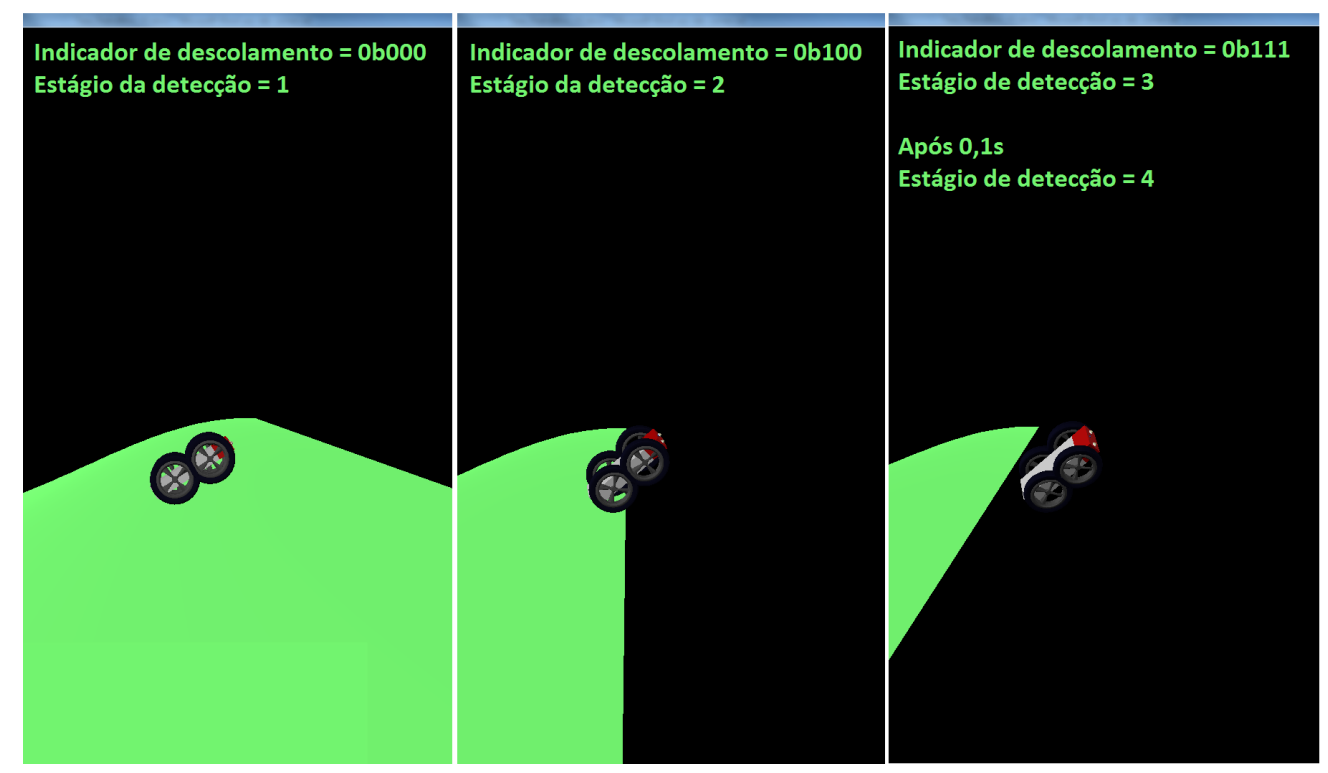

Figura 8: Sequência de cenas mostrando a evolução dos indicadores propostos.

O primeiro deles é o de condição de normalidade, onde todas as rodas estão em contato com o terreno. Nesse estágio nenhuma ação que não a do controle principal é tomada.

O segundo estágio corresponde à detecção de descolamento das rodas dianteiras. Esse estágio pode ocorrer em situações como subidas íngremes, onde o veículo esteja aumentando sua velocidade no sentido de subir a rampa, ou mesmo ao acelerar um veículo cujo centro de massa seja muito alto em relação à distância entre os eixos dianteiro e traseiro. Como dificilmente essa situação pode ocorrer, devido a impactos com obstáculos em alta velocidade ou ao se encontrar buracos (onde normalmente todas as rodas descolam do terreno), nenhuma ação foi prevista nessa pesquisa para esse estágio.

O terceiro estágio corresponde a um nível de alerta antes que a fase balística seja acusada. Ele serve como zona morta, em que as estimativas de torque externo podem estar informando condições de torques nulos que serão breves, conforme será comentado na seção 6.4.1. Ele também é usada como filtro para eventuais oscilações da estimativa de torque perto dos limites de detecção de descolamento. Durante esse estágio, os torques enviados às rodas são nulos e o sistema espera as 
próximas estimativas durante $0,1 \mathrm{~s}$ para decidir se a fase balística foi iniciada ou não.

No quarto e último estágio a fase balística foi detectada e o controle de arfagem passa a decidir os torques necessários nas rodas para ajuste do ângulo de arfagem do veículo. O sistema só sai do quarto estágio depois de $0,1 \mathrm{~s}$ de estimativas de torque externo que evidenciem o retorno ao terreno.

\section{3.}

Filtro de Kalman linear

O filtro de Kalman atualiza as estimativas ora por meio de medidas fornecidas pelos $m$ sensores, ora por integração no tempo do modelo de $n$ variáveis de estado (33). Isso permite a utilização de sensores com diferentes taxas de atualização, como a fusão de acelerômetros e girômetros com GPS. Nesse caso, o algoritmo passa a maior parte do tempo integrando os sinais de aceleração e de velocidade angular e, quando disponível, corrige o modelo com as informações do GPS. Dessa forma o sistema é capaz de remover quaisquer tendências inseridas pela integração dos sensores com bias móvel (33). Os filtros de Kalman também podem ser usados em situações onde os sensores são muito ruidosos, seja por problemas do equipamento, ou por influência do ambiente. Um exemplo são as acelerações centrípetas medidas pelo acelerômetro, que são consideradas ruídos quando o mesmo é usado em aeromodelismo, para fornecer informações de orientação.

Os filtros implementados no simulador são lineares e suas equações são detalhadas de (3.4) a (3.6).

$$
\begin{gathered}
\boldsymbol{X}_{\text {corr }}=\boldsymbol{X}_{k}+\underline{K}\left(\boldsymbol{Y}-\underline{C} \boldsymbol{X}_{k}\right) \\
\underline{K}=\underline{P}_{k} \underline{C}^{T}\left(\underline{C P}_{k} \underline{C}^{T}+\underline{V}\right)^{-1} \\
\underline{P}_{c o r r}=\left(\underline{I}_{n \times n}-\underline{K C}\right) \underline{P}_{k}
\end{gathered}
$$

onde:

$$
\text { - } \boldsymbol{X}_{\text {corr }}[n \times 1] \text { correção da estimativa do estado do sistema; }
$$


- $\boldsymbol{X}_{k}[n \times 1]$ estimativa da iteração anterior do estado do sistema;

- $\underline{P}_{c o r r}[n \times n]$ correção da estimativa da matriz de covariância do erro;

- $\underline{P}_{k}[n \times n]$ matriz de covariância do erro estimada na iteração anterior;

- $\underline{K}[n \times m]$ ganho ótimo de Kalman;

- $\boldsymbol{Y}[m \times 1]$ nova medida dos sensores;

- $\underline{C}[m \times n]$ matriz de observação do sistema;

- $\underline{V}[m \times m]$ matriz de covariância do ruído nas medidas.

Quando as medidas não estão disponíveis, a matriz de observação é nula, implicando que não haverá correção do vetor de estado estimado.

As equações do filtro de Kalman, usadas para a parte de atualização do estado por integração, são detalhadas em (3.7) e (3.8).

$$
\begin{gathered}
\boldsymbol{X}_{k+1}=\underline{\Phi} \boldsymbol{X}_{c o r r}+\underline{\Gamma} \\
\underline{P}_{k+1}=\underline{\Phi P_{c o r r}} \underline{\Phi}^{T}+\underline{W}
\end{gathered}
$$

onde:

- $\boldsymbol{X}_{k+1}[n \times 1]$ nova estimativa do estado do sistema;

- $\underline{P}_{k+1}[n \times n]$ nova estimativa da matriz de covariância do erro;

- $\underline{\Phi}[n \times n]$ matriz de estado do sistema discretizada;

- $\underline{\Gamma}[n \times p]$ matriz de entrada do sistema discretizada;

- $\boldsymbol{Y}[m \times 1]$ nova medida dos sensores;

- $\boldsymbol{U}[p \times 1]$ entrada do sistema;

- $\underline{W}[n \times n]$ matriz de covariância do ruído do sistema.

\subsection{1.}

\section{Estimativa do estado do motor}

O filtro de Kalman, utilizado para melhorar a leitura de corrente e velocidade de rotação dos motores, se baseia no modelo de motor de corrente 
contínua, descrito na seção 2.4, que pode ser reescrita segundo as equações (3.9) e (3.10).

$$
\begin{gathered}
\frac{d j}{d t}=\frac{U_{c}-\omega_{e} K_{t}}{L}-\frac{R}{L} j+w_{j} \\
\frac{d \omega_{e}}{d t}=\frac{K_{t} j G_{b}^{2}-G_{b} \tau_{\text {ext }}}{I}-\frac{b}{I} \omega_{e}+w_{\omega}
\end{gathered}
$$

onde $w_{j}$ e $w_{\omega}$ são ruídos aleatórios (de média nula e desvio padrão $W_{j}$ e $W_{\omega}$ respectivamente) do sistema, representando variações dos parâmetros do modelo e incertezas do mesmo.

Assume-se que as leituras de corrente medida pelo amperímetro $\left(j_{m}\right)$ e de velocidade angular medida pelo encoder $\left(\omega_{m}\right)$ possuem uma parte proveniente de um ruído aleatório, $v_{j}$ e $v_{\omega}$, também de médias nulas e desvios padrões $V_{j}$ e $V_{\omega}$ e o valor real das variáveis $j$ e $\omega$, como mostram as equações (3.11) e (3.12).

$$
\begin{gathered}
j_{m}=j+v_{j} \\
\omega_{m}=\omega+v_{\omega}
\end{gathered}
$$

Se for utilizado um vetor de estado formado pela corrente real e a velocidade angular real do motor $\boldsymbol{X}=\left[\begin{array}{ll}j & \omega\end{array}\right]^{T}$, chega-se ao sistema de equações diferenciais mostrado em (3.13) semelhante ao da seção 2.4, com a adição dos termos aleatórios:

$$
\begin{gathered}
\frac{d}{d t}\left(\left[\begin{array}{c}
j \\
\omega
\end{array}\right]\right)=\left[\begin{array}{cc}
-R / L & -K_{t} / L \\
K_{t} G_{b}^{2} / I & -b / I
\end{array}\right]\left[\begin{array}{c}
j \\
\omega
\end{array}\right]+\left[\begin{array}{cc}
1 / L & 0 \\
0 & -G_{b} / I
\end{array}\right]\left[\begin{array}{c}
U_{c} \\
\tau_{\text {ext }}
\end{array}\right]+\left[\begin{array}{c}
w_{j} \\
w_{\omega}
\end{array}\right] \\
{\left[\begin{array}{c}
j_{m} \\
\omega_{m}
\end{array}\right]=\left[\begin{array}{ll}
1 & 0 \\
0 & 1
\end{array}\right]\left[\begin{array}{c}
j \\
\omega
\end{array}\right]+\left[\begin{array}{c}
v_{j} \\
v_{\omega}
\end{array}\right]}
\end{gathered}
$$


As matrizes do modelo de estado são discretizadas usando um equivalente $\mathrm{ZOH}$ para um período de controle $\mathrm{T}$ (em segundos) e utilizadas nas equações do filtro de Kalman mostrado na seção 3.3.

\subsection{2.}

\section{Estimativa da orientação do veículo}

Para estimar a orientação do veículo nos três eixos, podem ser utilizadas as informações de um acelerômetro, magnetômetro e girômetro. O primeiro, que fornece sempre uma medida da aceleração da gravidade, é capaz de prover informações do ângulo de rolagem (em torno do eixo ${ }^{F} \boldsymbol{X}$ ) e arfagem (em torno do eixo ${ }^{F} \boldsymbol{Y}$ ), enquanto que o segundo, que fornece a direção do norte magnético da Terra, pode informar o ângulo de guinada (em torno do eixo ${ }^{F} \boldsymbol{Z}$ ). Essas informações absolutas são usadas para corrigir as estimativas feitas a partir do girômetro na fase de integração no tempo do filtro.

As informações absolutas (acelerômetro e magnetômetro) por si só não podem ser usadas, por serem ruidosas devido às vibrações do veículo e às interferências eletromagnéticas. Apesar de essas perturbações poderem ser parcialmente previstas, sua atenuação é mais significativa com o auxílio do girômetro.

\subsubsection{Pré-processamento do acelerômetro}

Se o local onde está instalado o acelerômetro estiver com o vetor velocidade linear constante (nula ou não), o mesmo fornece uma medida da aceleração da gravidade no local. Para a determinação da orientação, essa é a informação necessária proveniente do sensor e considera-se que quaisquer variações são ruídos. Esses ruídos podem ser produzidos em manobras como curvas longas em que a aceleração centrípeta é constante o suficiente para ser confundida com um ângulo de rolagem.

Como pode ser visto pela equação (13) do anexo, o termo ${ }^{S} \boldsymbol{a}_{\text {acel }}$ ainda contém efeitos indesejados para a estimativa da aceleração da gravidade devido a localização do sensor não ser exatamente no centro de massa do veículo.

O sinal do acelerômetro possui ainda uma perturbação vinda da aceleração tangencial do veículo devido ao torque dos motores. Essa influência pode ser 
estimada, usando-se a estimativa de torque externo detalhada na seção 3.1, como mostra a equação (3.14).

$$
{ }^{s} \boldsymbol{A}_{t}=\sum \frac{\tau_{\text {ext }}}{m r}
$$

Com isso, a estimativa de ${ }^{S} \widehat{\boldsymbol{G}}_{A}$ será:

$$
{ }^{S} \widehat{\boldsymbol{G}}_{A}={ }^{S} \boldsymbol{a}_{\text {acel }}-\left[{ }_{F}^{S} \dot{\boldsymbol{\omega}}_{S} \times{ }_{A}^{S} \boldsymbol{r}_{B}+{ }_{F}^{S} \boldsymbol{\omega}_{S} \times\left({ }_{F}^{S} \boldsymbol{\omega}_{S} \times{ }_{A}^{S} \boldsymbol{r}_{B}\right)\right]-\sum \frac{\tau_{\text {ext }}}{m r}
$$

onde:

- ${ }_{A}^{S} \boldsymbol{r}_{B}$ é o vetor posição que leva do centro de massa, localizado em $\boldsymbol{A}$, ao sensor, localizado em $\boldsymbol{B}$, descrito no referencial local $S$;

- $m$ é a massa do veículo;

- $r$ é o raio da roda.

\subsubsection{2.}

\section{Cálculo da orientação}

Os sensores magnetômetro e acelerômetro por si só não fornecem a orientação absoluta do veículo nas três dimensões. Assumindo que o veículo não anda de "cabeça para baixo" e que os ângulos de rolagem e de arfagem são sempre muito menores que $\pi / 2$, pode-se considerar que o acelerômetro fornece informações de rolagem e arfagem, enquanto que o magnetômetro é responsável pela guinada.

Para extrair a informação de orientação nas três dimensões a partir desses sensores, pode-se ortogonalizá-los e usá-los para compor uma matriz de rotação. A ortogonalização se dá primeiramente normalizando-se a aceleração, obtendo-se assim o cursor $\boldsymbol{e}_{G}$. Em seguida, retira-se da informação do campo magnético $\left(\boldsymbol{M}_{m}\right)$ a componente na direção de $\boldsymbol{e}_{G}$, como mostra a equação (3.16): 


$$
\boldsymbol{M}^{\prime}=\boldsymbol{M}_{m}-\boldsymbol{e}_{G}\left(\boldsymbol{e}_{G}^{T} \boldsymbol{M}_{m}\right) \rightarrow \boldsymbol{e}_{M}=\frac{\boldsymbol{M}^{\prime}}{\left|\boldsymbol{M}^{\prime}\right|}
$$

Utilizando os cursores perpendiculares entre si $\boldsymbol{e}_{G}$ e $\boldsymbol{e}_{M}$, determina-se o terceiro cursor $\boldsymbol{e}_{Y}=\boldsymbol{e}_{G} \times \boldsymbol{e}_{M}$ de forma a constituir uma base ortonomal. A partir desses cursores, pode-se determinar a matriz de rotação $\underline{\mathrm{DCM}}=\left[\begin{array}{lll}\boldsymbol{e}_{M} & \boldsymbol{e}_{Y} & \boldsymbol{e}_{G}\end{array}\right]$, que representa a orientação do sistema em relação ao referencial fixo $F$.

Extrair os ângulos cardânicos dessa matriz forneceria uma orientação absoluta. No entanto, é mais interessante ter uma informação relativa à orientação inicial do veículo no experimento. Para isso, pode-se pré-multiplicar a primeira matriz de rotação (calculada no início do teste) transposta $\left(\underline{\operatorname{DCM}}_{o}^{T}\right)$ pela nova matriz calculada DCM.

Suponha que o cursor ${ }^{S} \boldsymbol{n}$ transformado para o referencial fixo pela primeira matriz de rotação $\left(\underline{\mathrm{DCM}}_{0}\right)$, calculada no instante inicial da simulação, seja:

$$
{ }^{F} \boldsymbol{x}_{0}={\underline{\mathrm{DCM}_{0}}}_{0}{ }^{S} \boldsymbol{n}
$$

e num instante seguinte, uma nova matriz de rotação é calculada (DCM). O mesmo cursor transformado para o referencial fixo com a nova matriz de rotação será:

$$
{ }^{F} \boldsymbol{x}=\underline{\mathrm{DCM}}^{S} \boldsymbol{n}
$$

Sabendo-se que $\underline{\mathrm{DCM}}_{o}^{T} * \underline{\mathrm{DCM}}_{0}=\underline{I}_{3 \times 3}$ tem-se que:

$$
{ }^{S} \boldsymbol{n}=\underline{\mathrm{DCM}}_{o}^{T F} \boldsymbol{x}_{0}
$$

A matriz de rotação entre os instantes inicial e atual que leva o vetor ${ }^{F} \boldsymbol{x}_{0}$ para ${ }^{F} \boldsymbol{x}$ $\left({ }^{F} \boldsymbol{x}=\underline{T}^{F} \boldsymbol{x}_{0}\right)$ será: 


$$
{ }^{F} \boldsymbol{x}=\underline{\mathrm{DCM}}\left(\underline{\mathrm{DCM}}_{O}^{T}{ }^{F} \boldsymbol{x}_{0}\right)
$$

Uma vez calculada $\underline{T}=\underline{\mathrm{DCM}} * \underline{\mathrm{DCM}}_{o}^{T}$, tem-se, examinando a equação (4) do anexo, os ângulos cardânicos de acordo com as equações (3.21), (3.22) e (3.23). Assume-se que as linhas e colunas de uma matriz iniciam com índice 0 e, para sistemas tridimensionais, vão até o índice 2.

$$
\begin{gathered}
\theta_{1}=\operatorname{atan} 2(-\underline{T}(1,2), \underline{T}(2,2)) \\
\theta_{2}=\operatorname{asin}(\underline{T}(0,2)) \\
\theta_{3}=\operatorname{atan} 2(-\underline{T}(0,1), \underline{T}(0,0))
\end{gathered}
$$

Por fim, o vetor orientação será $\boldsymbol{N}=\left[\begin{array}{lll}\theta_{1} & \theta_{2} & \theta_{3}\end{array}\right]^{T}$.

\subsubsection{3.}

\section{Estimativa utilizando filtro de Kalman}

Com os sinais do magnetômetro e acelerômetro pré-processados, a estimativa da orientação do veículo pode ser feita com menos erros. Para isso, foi considerado que as leituras da velocidade angular do veículo pelo girômetro e a informação de orientação extraída a partir do acelerômetro e do magnetômetro são decompostas de acordo com as equações (3.24) e (3.25):

$$
\begin{gathered}
\boldsymbol{\omega}_{m}=\dot{\boldsymbol{N}}+\boldsymbol{\omega}_{\text {bias }}+\boldsymbol{w}_{i} \\
\boldsymbol{N}_{m}=\boldsymbol{N}+\boldsymbol{v}_{i}
\end{gathered}
$$

onde: 
- $\boldsymbol{w}_{i}$ e $\boldsymbol{v}_{i}$ são ruídos aleatórios (de média nula e desvio padrão $W_{i}$ e $V_{i}$ respectivamente) do sistema representando variações dos parâmetros do modelo e incertezas dos sensores;

- $\boldsymbol{\omega}_{m}$ é a velocidade angular do veículo medida pelo girômetro e convertida para o referencial fixo $F$;

- $\dot{\boldsymbol{N}}$ é a velocidade angular real;

- $\boldsymbol{\omega}_{\text {bias }}$ é o bias variável da orientação;

- $\boldsymbol{N}_{m}$ é a orientação medida;

- $\boldsymbol{N}$ é a orientação real.

O sistema de equações em (3.24) e (3.25) é representado matricialmente por:

$$
\begin{gathered}
{\left[\begin{array}{c}
\dot{\boldsymbol{N}} \\
\dot{\boldsymbol{\omega}}_{\text {bias }}
\end{array}\right]=\left[\begin{array}{cc}
\underline{0}_{3 \times 3} & -\left(\underline{I}_{3 \times 3}\right) \\
\underline{0}_{3 \times 3} & \underline{0}_{3 \times 3}
\end{array}\right] \underbrace{\left[\begin{array}{c}
\boldsymbol{N} \\
\boldsymbol{\omega}_{\text {bias }}
\end{array}\right]}_{\boldsymbol{X}_{k}}+\left[\begin{array}{c}
\underline{I}_{3 \times 3} \\
\underline{0}_{3 \times 3}
\end{array}\right] \boldsymbol{\omega}_{m}+\boldsymbol{w}_{i}} \\
\boldsymbol{N}_{m}=\left[\begin{array}{ll}
\underline{I}_{3 \times 3} & \underline{0}_{3 \times 3}
\end{array}\right]\left[\begin{array}{c}
\boldsymbol{N} \\
\boldsymbol{\omega}_{\text {bias }}
\end{array}\right]+\boldsymbol{v}_{i}
\end{gathered}
$$

O filtro de Kalman para as equações descritas em (3.26) e (3.27) (utilizando o mesmo método de discretização do item 3.3.1) é:

$$
\begin{gathered}
\boldsymbol{X}_{k+1}=\underline{\Phi} \boldsymbol{X}_{k}+\underline{\Gamma} \boldsymbol{\omega}_{m} \\
\boldsymbol{Y}=\underline{C} \boldsymbol{X}_{k+1}
\end{gathered}
$$

onde:

$$
\begin{gathered}
\underline{\Phi}=\left[\begin{array}{cc}
\underline{I}_{3 \times 3} & -d t\left(\underline{I}_{3 \times 3}\right) \\
\underline{0}_{3 \times 3} & \underline{I}_{3 \times 3}
\end{array}\right] \\
\underline{\Gamma}=\left[\begin{array}{c}
d t\left(\underline{I}_{3 \times 3}\right) \\
\underline{0}_{3 \times 3}
\end{array}\right] \\
\underline{C}=\left[\begin{array}{ll}
\underline{I}_{3 \times 3} & \underline{0}_{3 \times 3}
\end{array}\right]
\end{gathered}
$$

Uma vez detectada a condição de descolamento das rodas, é necessário controlar o sistema para garantir sua estabilidade. O capítulo 4 apresenta os sistemas de controle desenvolvidos. 


\section{Controles desenvolvidos}

\section{1.}

\section{Controle de corrente}

Controles de estabilidade de veículos costumam usar algoritmos que determinam as forças de tração necessárias para corrigir o comportamento do veículo e ainda variar a velocidade e direção do mesmo até os valores desejados (6). No sistema em questão (veículo robótico terrestre elétrico sem suspensão), essa força é produzida por meio do torque transmitido pelos motores a cada uma das rodas. Portanto, o controle do torque em cada motor é necessário. Para um motor de corrente contínua, levando-se em consideração o modelo matemático adotado, o controle de torque implica em controlar a corrente por ser diretamente proporcional ao torque através da constante de torque $K_{t}$.

Na Figura 9 é apresentado o diagrama de blocos que representa o modelo matemático, utilizado na pesquisa, do motor de corrente contínua com caixa de redução.

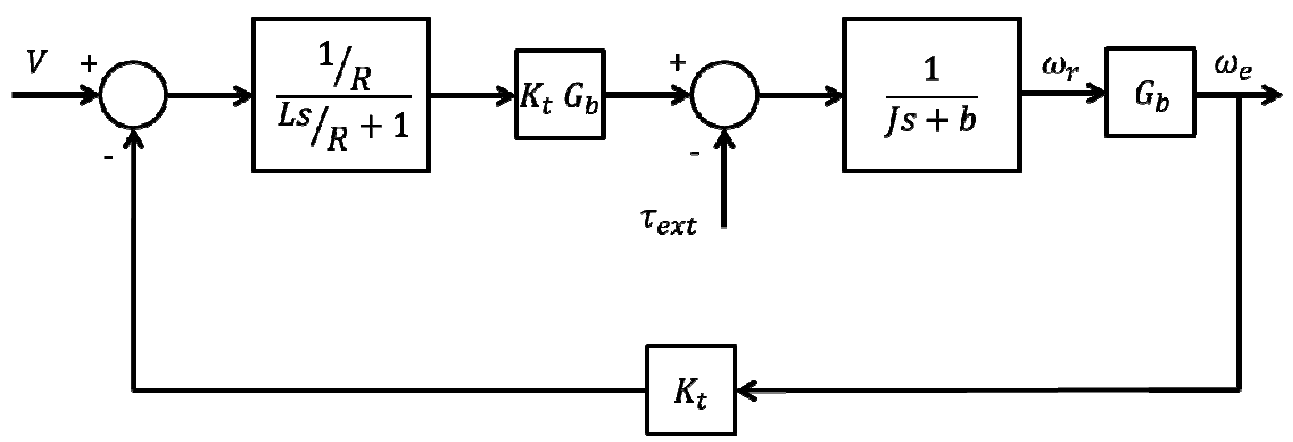

Figura 9: Diagrama de blocos representando o modelo matemático, utilizado na pesquisa, do motor de corrente contínua com caixa de redução.

A estratégia de controle adotada é a realimentação positiva de estado, visando eliminar a influência da velocidade de rotação do eixo no controle de corrente, como é mostrado no diagrama de blocos da Figura 10. Para tal, 
determinou-se a matriz de ganhos $\underline{K}=\left[\begin{array}{cc}0 & K_{t} \\ 0 & 0\end{array}\right]$. É adicionado um valor de atuação proporcional à corrente desejada $i_{d}$, como mostra a equação (4.1).

$$
U=\underline{K} \boldsymbol{X}+R\left[\begin{array}{c}
i_{d} \\
0
\end{array}\right]
$$

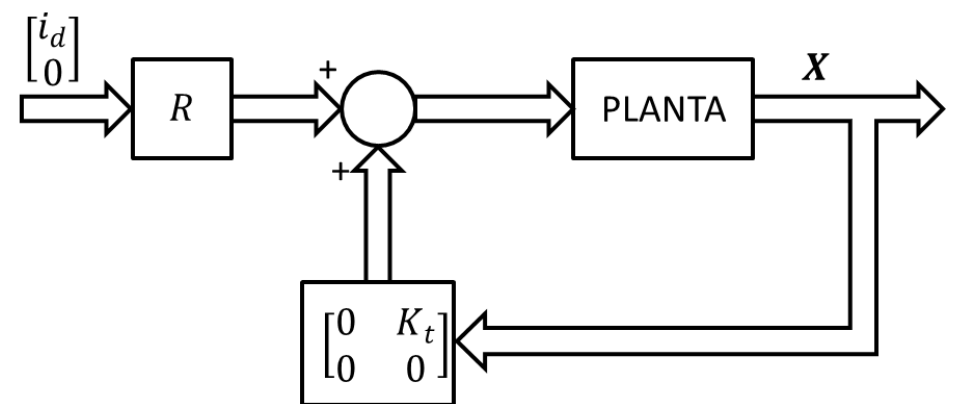

Figura 10: Diagrama de blocos representando a malha de controle de corrente utilizada.

Com essa lei de controle, a dinâmica da parte elétrica do motor é simplificada, como mostram as equações (4.2) e (4.3).

$$
\begin{gathered}
L \frac{d i}{d t}=R i_{d}+K_{t} \omega_{e}-R i-K_{t} \omega_{e} \\
L \frac{d i}{d t}=R\left(i_{d}-i\right)
\end{gathered}
$$

Nessa situação ideal, a dinâmica de rotação do motor deixa de influenciar o sistema.

Caso haja erros nos valores estimados de $K_{t}$ e $R$, esse cancelamento não ocorre. Um erro no valor de $\hat{R}$, assumindo $K_{t}$ correto, leva a um erro no valor final da corrente de $i=i_{d} \hat{R} / R$, pois $\hat{R} i_{d}-R i=0$. Já para a constante de torque $\widehat{K_{t}}$, um erro em sua estimativa não cancela a influência da parte mecânica no controle de corrente, e uma nova constante de torque $\left(K_{t}-\widehat{K_{t}}\right)$ passa a representar essa influência. Caso a estimativa seja maior que o valor real, a nova constante de torque é negativa e sua influência desestabiliza o sistema. Caso contrário, o valor 
da corrente atual decai lentamente (proporcional a $\left.\left(K_{t}-\widehat{K_{t}}\right) \omega_{e}\right)$ em relação ao valor desejado.

No sistema real, os valores estimados podem ser utilizados como ganhos a serem ajustados. Primeiramente ajusta-se a constante de torque até que o valor atual de corrente pare de divergir do desejado. Em seguida, depois de estabilizada a corrente, o valor da resistência pode ser ajustado até que a corrente atual seja igual à desejada.

Com o uso dos motores essas estimativas podem mudar, principalmente a resistência interna, e novos ajustes podem ser necessários.

\section{2. \\ Controle de arfagem}

Em (8) são propostos controles de estabilidade baseados em comportamentos reativos em que respostas pré-definidas em uma base de dados são selecionadas de acordo com o obstáculo. Essas ações são calculadas, a priori, baseadas na dinâmica do sistema. As respostas são acionadas assim que a leitura de um ou mais sensores acusa um comportamento de perigo.

A perda de contato com o solo para veículos robóticos com rodas acontece devido a impactos sobre obstáculos ou a depressões no terreno muito acentuadas, como buracos. Uma vez que uma ou mais rodas perdem contato com o terreno, não é mais possível controlar a trajetória do veículo apenas com o torque sobre as rodas. Em alguns casos particulares pode-se apenas aumentar a probabilidade de um retorno seguro ao terreno e esperar que o relevo do mesmo ajude na estabilização. A pesquisa não explora qual ângulo de arfagem é ideal para que essa probabilidade seja máxima e assume, portanto, que a posição horizontal (ângulo de arfagem nulo) é uma boa suposição.

Essa pesquisa propõe que essa correção no ângulo de arfagem do veículo durante a fase balística seja feita aplicando-se um torque nas rodas do veículo. $\mathrm{O}$ controle de arfagem proposto tem inspiração no sistema de controle de atitude de satélites usando rodas de reação. Uma massa girante é instalada dentro do sistema por meio de um motor fixo no mesmo. A massa é então acelerada e o torque de reação sobre o motor fixo ao chassi do veículo o faz girar no sentido contrário, como mostra a Figura 11 (34) e (35). 


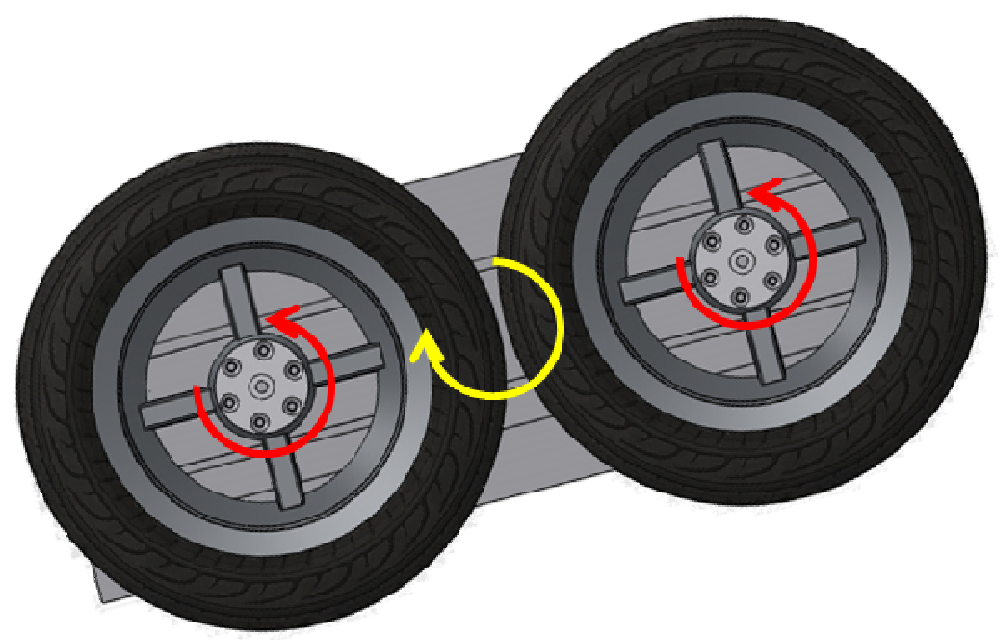

Figura 11: Representação gráfica do princípio do controle por rodas de reação.

A desestabilização do veículo por descolamento das rodas pode ser dividida em três níveis de acordo com a controlabilidade do mesmo: instabilidade lateral, quando duas rodas do mesmo lado perdem contato com o terreno; longitudinal, quando as duas rodas dianteiras ou traseiras descolam do solo; e total, durante a fase balística.

Considerando o modelo de veículo utilizado na pesquisa, no caso de duas rodas do mesmo lado descolarem, nada pode ser feito. Pela equação (2.25), repetida em (4.4), a única influência direta da força de tração das rodas remanescentes no chão na rotação do veículo em torno do eixo longitudinal, é através das forças $F_{b i}$. No entanto, pela equação (2.18), essa influência é proporcional ao seno do ângulo entre a roda e o terreno, que nessa pesquisa é assumido muito pequeno, quando pelo menos um par de rodas dianteira- traseira está em contato com o solo.

$$
\begin{gathered}
r_{y}\left(-F_{b 0}-F_{b 1}+F_{b 2}+F_{b 3}\right)+\sum\left(r_{z} F_{t i}-M_{n i}\right) \\
=I_{c}^{1} \dot{\omega}_{x}+\omega_{y} \omega_{z}\left(I_{c}^{3}-I_{c}^{2}\right)
\end{gathered}
$$

Caso as duas rodas dianteiras ou traseiras descolem, o controle de reação a ser tomado é frear as rodas traseiras para o primeiro caso e acelerar as rodas dianteiras para o segundo caso. Em caso de impactos com obstáculos, o fator 
desestabilizador é a alta velocidade do veículo e o tempo entre detecção do descolamento das rodas e o capotamento é muito curto. Para uma reação rápida suficiente, a ação corretiva é aplicar torque máximo nas rodas ainda em contato com o solo até o reestabelecimento do contato. Para o caso de descolamento das rodas dianteiras devido a depressões abruptas no terreno, a reação é anular os torques nas rodas e esperar a fase balística para o controle de atitude total. A opção por esperar a fase balística se deve a melhor leitura do ângulo de arfagem quando não há influência do terreno na dinâmica do veículo. O discernimento entre o descolamento por impacto e o descolamento por depressão abrupta do terreno é feito pelos níveis de aceleração no momento da detecção da instabilidade.

$\mathrm{Na}$ fase balística, o controle tem que orientar uma inércia livre para girar. A situação pode ser modelada como uma função de transferência com dois pólos na origem. Para o controle da orientação do chassi, usa-se uma realimentação de estado similar a um controlador da família PID com um ganho proporcional e outro derivativo. A função de transferência da malha descrita é de segunda ordem, como mostra a equação (4.5).

$$
F T M F \Rightarrow H(s)=\frac{K_{p}\left(T_{d} s+1\right)}{I_{c} s^{2}+K_{p}\left(T_{d} s+1\right)}
$$

onde $K_{p}$ e $T_{d}$ são, respectivamente análogos aos ganhos proporcional e derivativo do controlador e $I_{c}$ é a inércia do chassi. Segundo (36), o menor tempo de assentamento para um sistema de segunda ordem acontece quando o fator de amortecimento $\xi$ é 0,76 para uma tolerância de $2 \%$ do valor final. Como objetivo para ajuste de ganhos, determinou-se que o controle seja capaz de reorientar o chassi em menos de 0,3 s nos experimentos planejados. Esse valor leva em consideração uma altura mínima de $1 \mathrm{~m}$ do veículo em queda livre para a correção. Outra limitação do sistema é a saturação do torque na roda de $40 \mathrm{Nm}$ no sistema experimental desenvolvido.

Assumindo que o sinal de controle máximo enviado ao motor ocorre no instante em que é detectada a fase balística e que os valores desejados para a orientação e velocidade angular final são nulos, tem-se: 


$$
U=K_{p}\left(T_{d} \omega_{y 0}+\phi_{y 0}\right)
$$

onde:

- $\phi_{y 0}$ é o ângulo de arfagem do chassi no momento da detecção da fase balística;

- $\omega_{y 0}$ é a velocidade angular do chassi no momento da detecção da fase balística;

- $U$ é o sinal de controle enviado para o controle de torque.

A escolha de um fator de amortecimento de 0,76 leva a uma dependência entre o ganho proporcional e o ganho derivativo segundo a equação (4.7) (36):

$$
K_{p}=\frac{0,76^{2} 4 I_{c}}{T_{d}^{2}}
$$

Substituindo a equação (4.7) em (4.6) e considerando o limite de saturação do sinal de torque, tem-se:

$$
U=\frac{2,31 I_{c}}{T_{d}{ }^{2}}\left(\phi_{y 0}+T_{d} \omega_{y 0}\right) \leq 160 \mathrm{Nm}
$$

O tempo de convergência de um sistema de segunda ordem para uma tolerância de $2 \%$ equivale a quatro vezes a constante de tempo $\sigma$ do sistema. Ao determinar-se que esse tempo deva ser no máximo de $0,3 \mathrm{~s}$ e sabendo que $\sigma=-1 / \mathfrak{R}\{p\}$, conclui-se que $\mathfrak{R}\{p\} \leq-13, \overline{3}$, onde $\mathfrak{R}\{$.$\} representa a parte real$ de um número qualquer. Substituindo (4.7) em (4.5) e calculando os pólos da função de transferência, chega-se a condição que $T_{d} \geq 0,17 \mathrm{~s}$. Uma vez determinado o valor de $T_{d}$, tem-se, usando (4.7), $K_{p}=76,3 I_{c}$. Usando os valores de $K_{p}$ e $T_{d}$ em (4.8), chega-se a uma dependência dos possíveis valores de 
condições iniciais para a fase balística que garantem o chassi sem velocidade de rotação e na horizontal antes de retornar ao solo se a altura inicial for de pelo menos $1 \mathrm{~m}$. Essa dependência, para um $T_{d}$ limite de $0,17 \mathrm{~s}$ e uma inércia de 2,03 $\mathrm{kgm}^{2}$ é mostrada na inequação (4.9).

$$
\begin{aligned}
& \phi_{y 0}+T_{d} \omega_{y 0} \leq 160 \frac{T_{d}{ }^{2}}{2,31 I_{c}} \\
& \phi_{y 0} \leq 160 \frac{T_{d}{ }^{2}}{2,31 I_{c}}-T_{d} \omega_{y 0}
\end{aligned}
$$

A equação (4.10) assegura, por exemplo, que para velocidades angulares iniciais de $+/-0,4 \mathrm{rad} / \mathrm{s}$ o controle proposto converge sem saturar os motores em até $0,3 \mathrm{~s}$ se, e somente se, o ângulo de saída do terreno do chassi não ultrapassar $0,92 \mathrm{rad}$ e 1,05 rad respectivamente. A Figura 12 mostra uma simulação em que os motores chegam próximos da saturação de $160 \mathrm{Nm}$.

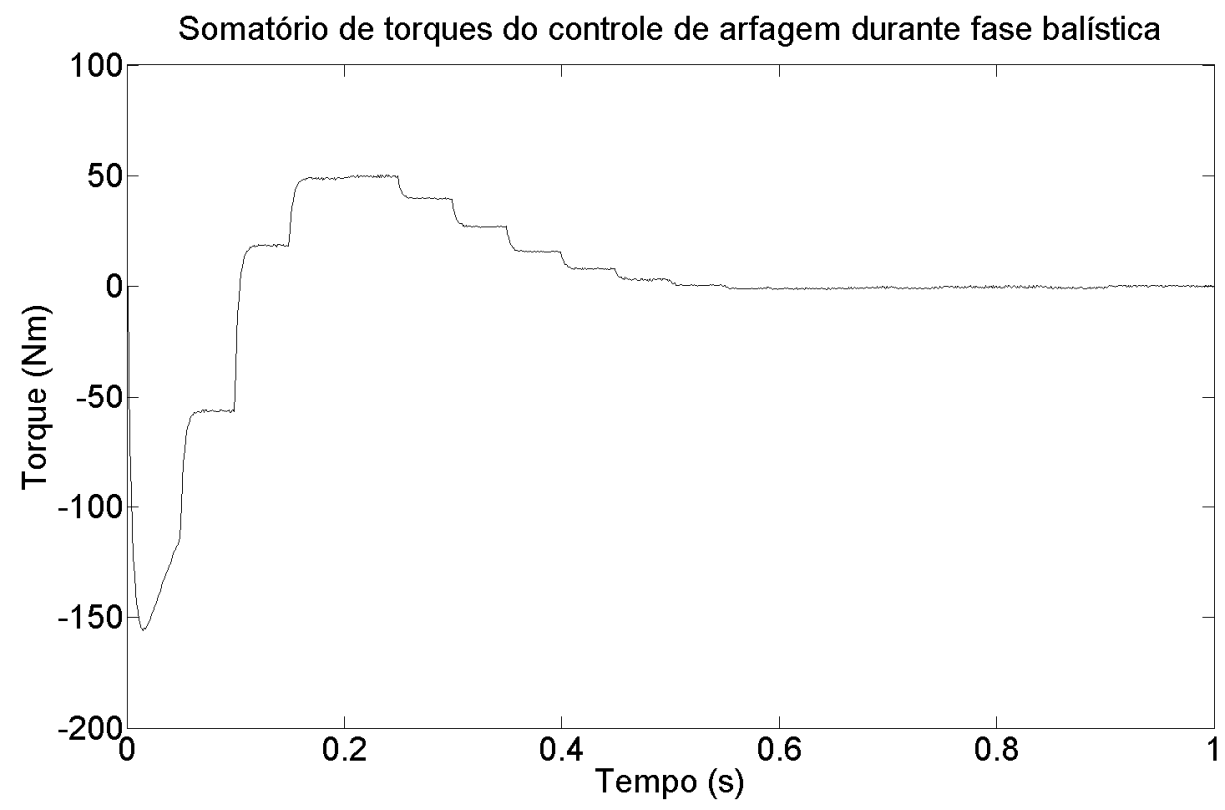

Figura 12: Curva de torque gerada pelo controle de arfagem durante uma simulação de fase balística. 
Nessa simulação, o veículo foi inicializado já em fase balística com uma velocidade angular inicial de $-0,4 \mathrm{rad} / \mathrm{s}$ e um ângulo de arfagem inicial de 1,05 rad. Os degraus observados na curva de torque mostram o período de controle de $20 \mathrm{~Hz}$ utilizado pelo controlador.

A Figura 13 mostra o comportamento do ângulo de arfagem e da velocidade angular durante a simulação.

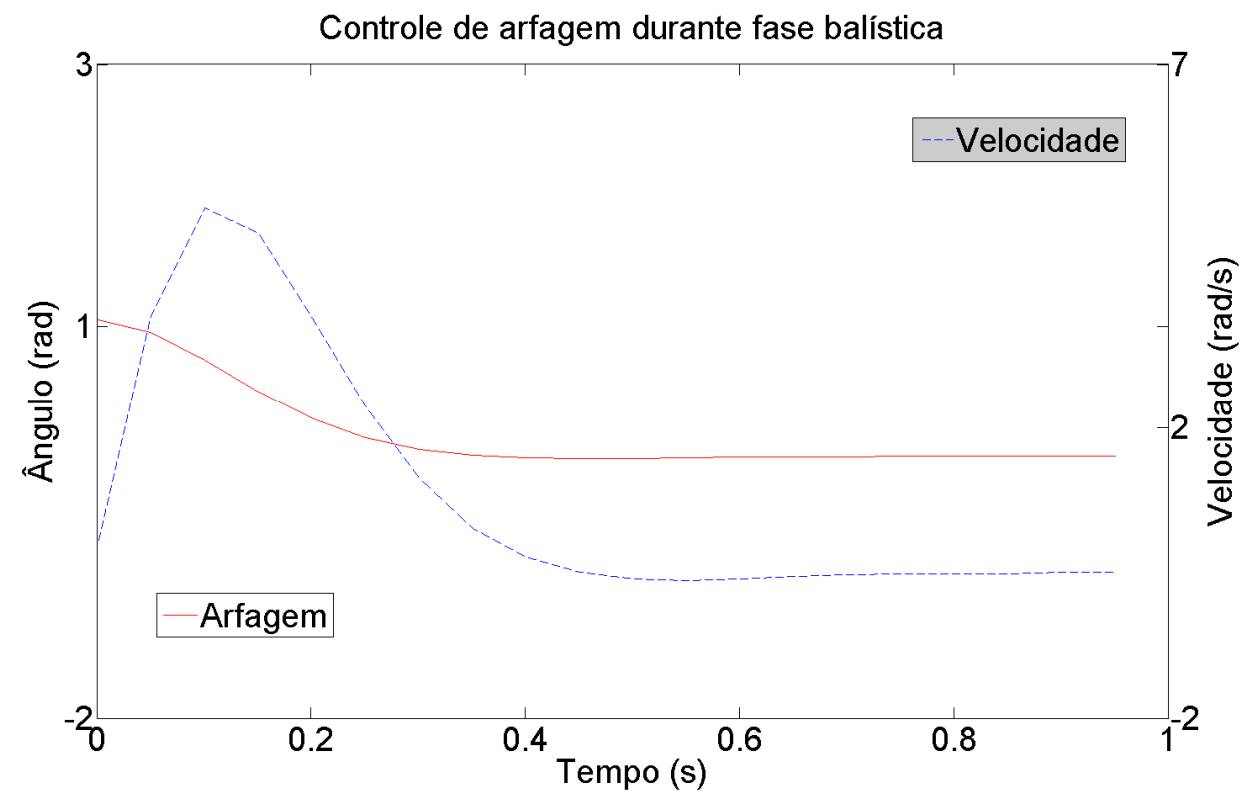

Figura 13: Progressão do ângulo de arfagem durante a simulação do controle na fase balística.

No capítulo 5, o simulador desenvolvido para validar as técnicas propostas é apresentado. 


\section{5 \\ Simulador desenvolvido}

O software de simulação de veículos robóticos em terrenos acidentados foi desenvolvido em conjunto com o aluno de mestrado Ricardo Morrot. A linguagem de programação utilizada foi $\mathrm{C}++$ e a interface de programação de aplicativos (API) é o OpenGL. Maiores detalhes sobre a arquitetura do software são encontrados em (24). A Figura 14 mostra uma cena do simulador.

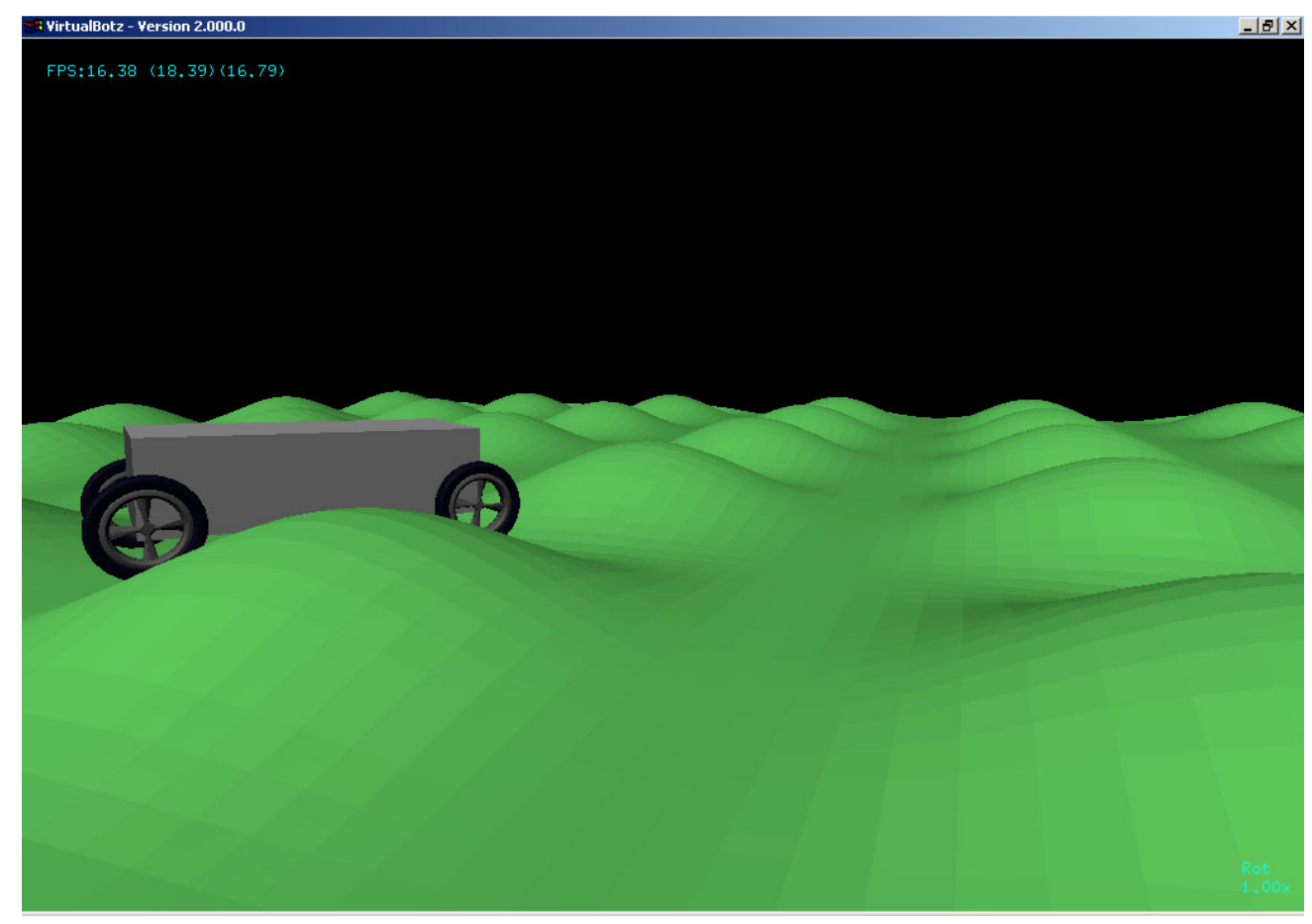

Figura 14: Cena do simulador na versão desenvolvida em C++.

Os requisitos da versão final do software são os seguintes:

Uma janela contendo a animação 3D em tempo real do sistema robô + terreno; 
A possibilidade de importar um terreno qualquer representado por um modelo 2,5D através de uma matriz bi-dimesional, bem como a escolha de terrenos pré-definidos;

$>$ Simulação de veículo robótico com duas ou mais rodas posicionadas em qualquer lugar do chassi;

Implementação de algoritmos de controles, desenvolvidos pelo usuário;

Implementação de sensores e atuadores, simulando efeitos de ruídos e discretização nas medições (amperímetros, encoders, acelerômetros, girômetros, magnetômetro e GPS já se encontram implementados);

> Simulação da fusão de sensores por filtro de Kalman;

$>$ Interação com o veículo robótico no ambiente virtual através do teclado, mouse ou joystick em tempo real;

$>$ Gravação de quaisquer dados produzidos durante a simulação em diferentes arquivos textos;

$>$ Geração de vídeos durante a simulação;

$>$ Possibilidade de visualização da cena através de diferentes câmeras (ângulos de vistas).

A simulação mostra o comportamento dinâmico do veículo no ambiente em tempo real (aos comandos do usuário) levando-se em consideração as equações descritas na seção 2. Com o simulador, o usuário é capaz de testar se o conjunto robô + controle + sensores desenvolvido é capaz de executar as tarefas desejadas para um determinado ambiente em terreno arbitrário com um desempenho satisfatório, viabilizando ou não o projeto. O simulador não contempla impactos acarretando em instabilidades quando a velocidade do veículo é grande em relação ao tempo de iteração e um obstáculo é encontrado. Grandes saltos também não são possíveis devido às grandes velocidades verticais do veículo ao voltar ao terreno.

Foram implementados sensores juntamente com suas características como ruídos, resolução etc., motores de corrente contínua e diferentes taxas de loopings de controle, simulando um sistema real em que o controle de corrente é feito em processadores dedicados, já que necessitam de altas taxas de controle, enquanto que o resto do sistema pode ser executado mais lentamente por se tratar de 
dinâmicas mais lentas. As taxas implementadas foram de $1 \mathrm{kHz}$ para o controle de corrente e $20 \mathrm{~Hz}$ para o loop principal.

Uma versão do simulador foi feita em Matlab. Nesta versão, não há a possibilidade de importar nem terrenos ou veículos, não há sensores nem filtro de Kalman e não é executado em tempo real, inviabilizando a interação com o usuário. Ele foi desenvolvido apenas para testar as primeiras equações desenvolvidas para a dinâmica de veículos e, como foi implementado em Matlab, não pode ser executado em tempo real, pois o tempo de cálculo de cada iteração é maior que o maior passo possível de integração. Ela contempla a possibilidade do veículo ter quantas rodas o usuário quiser em qualquer lugar do chassi, no entanto elas são fixas e paralelas ao mesmo, sem a possibilidade de esterçamento.

\section{1. \\ Modelo do Terreno}

O terreno é especificado como uma matriz $\underline{\mathrm{M}}$ de duas dimensões, onde cada elemento de $\underline{\mathrm{M}}$ corresponde à altura $\mathrm{z}$ do terreno em um sistema de coordenadas xy em um plano horizontal. A partir dos extremos das coordenadas $\left(\mathrm{x}_{\min }, \mathrm{x}_{\max }\right) \mathrm{e}$ $\left(\mathrm{y}_{\min }, \mathrm{y}_{\max }\right)$ do terreno no software, um elemento cuja linha e coluna em $\underline{\mathrm{M}}$ seja $(\mathrm{i}, \mathrm{j})$ terá as seguintes coordenadas espaciais no software:

$$
\begin{aligned}
& x=x_{\min }+i \frac{x_{\max }-x_{\min }}{n_{x}-1} \\
& y=y_{\min }+j \frac{y_{\max }-y_{\min }}{n_{y}-1}
\end{aligned}
$$

onde $n_{x}$ e $n_{y}$ são respectivamente o número de linhas e colunas de M.

Foi implementado um algoritmo de interpolação linear para determinar a altura do terreno entre elementos da matriz $\underline{\mathrm{M}}$. Esse algoritmo procura o elemento da matriz imediatamente anterior (tanto em x quanto em y) ao ponto desejado e o pondera utilizando os outros três elementos vizinhos da seguinte maneira: 


$$
\begin{gathered}
z_{1}=M_{i x+1, i y}\left(\operatorname{aux}_{x}-i_{x}\right)+M_{i x, i y}\left[1-\left(\operatorname{aux}_{x}-i_{x}\right)\right] \\
z_{2}=M_{i x+1, i y+1}\left(\operatorname{aux}_{x}-i_{x}\right)+M_{i x, i y+1}\left[1-\left(\operatorname{aux}_{x}-i_{x}\right)\right] \\
z_{f}=z_{2}\left(\operatorname{aux}_{y}-i_{y}\right)+z_{1}\left[1-\left(\operatorname{aux}_{y}-i_{y}\right)\right]
\end{gathered}
$$

onde:

- $\left(i_{x}, i_{y}\right)$ são as coordenadas do elemento de $\underline{\mathrm{M}}$ imediatamente anterior ao elemento desejado;

- $\operatorname{aux}_{x}$ e $\operatorname{aux}_{y}$ são as coordenadas do ponto desejado convertidas para o sistema de coordenadas da matriz $\underline{\mathrm{M}}$;

- $M_{i, j}$ é o elemento $(i, j)$ de $\underline{\mathrm{M}}$;

- $\mathrm{Z}_{\mathrm{f}}$ é o resultado da interpolação dos elementos do terreno na posição desejada.

A Figura 15 ilustra as variáveis descritas.

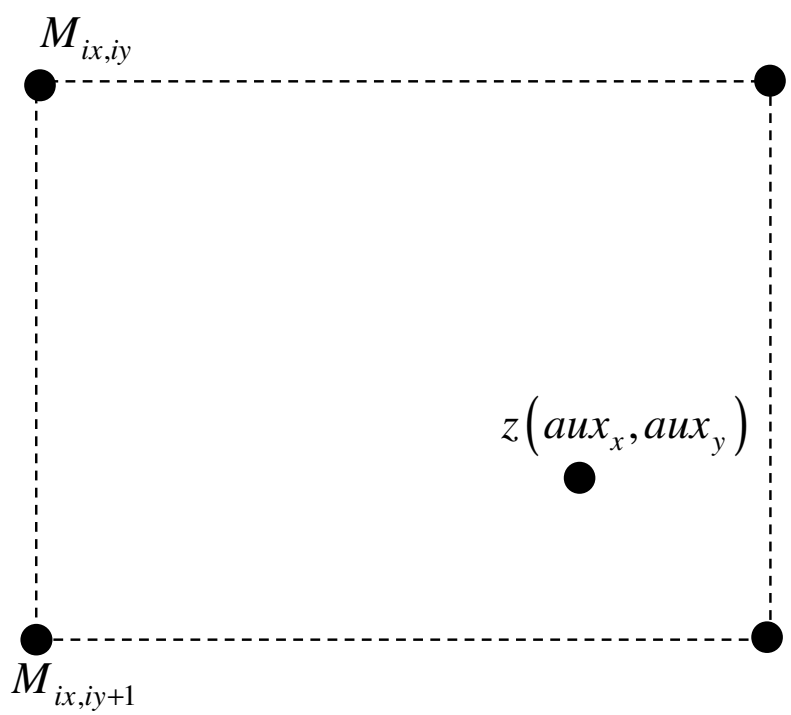

$M_{i x+1, i y}$

$M_{i x+1, i y+1}$

Figura 15: Desenho ilustrando as variáveis para a interpolação do terreno. 


\section{2. \\ Modelo do Veículo}

A orientação do veículo robótico é representada por três vetores unitários $\boldsymbol{n}, \boldsymbol{t}$ e $\boldsymbol{b}$ que correspondem, respectivamente, às direções $\boldsymbol{x}, \boldsymbol{y}$ e $\boldsymbol{z}$ do sistema local preso ao chassi (longitudinal x, lateral y, e vertical z ao chassi). A posição do seu centro de massa é o vetor $\boldsymbol{X}_{\boldsymbol{c}}$, representado no sistema inercial global. Cada roda do veículo possui o seu centro de massa representado por três possíveis vetores. São eles: $\boldsymbol{X}$ (posição teórica sem nenhuma deformação da suspensão segundo o referencial global), $\boldsymbol{X}_{n t b}$ (posição teórica sem nenhuma deformação da suspensão segundo o referencial ntb local) e $\boldsymbol{X}_{\boldsymbol{c}}$ (posição real considerando os efeitos das suspensões segundo o referencial global). O ponto de contato entre a roda e o terreno é representado pelo vetor $\boldsymbol{X}_{\boldsymbol{c}}$ (representado no sistema de coordenadas global). Apesar de se considerar uma suspensão entre o chassi e as rodas, as mesmas foram consideradas sem inércia translacional, apenas a inércia rotacional foi considerada na dinâmica do sistema. A suspensão foi inserida no sistema de maneira a modelar a interação entre o veículo e o terreno sem ter que lidar com rigidezes muito altas intrínsecas aos sólidos.

Na Figura 16, é mostrado o deslocamento h imposto pelo terreno sobre a suspensão. É admitido que se esse deslocamento estiver dentro da faixa de valores entre 0 e $\mathrm{h}_{\text {sat }}$, as equações para a força exercida pela suspensão são lineares. Caso o deslocamento seja maior que o limite $\mathrm{h}_{\text {sat }}$, uma relação não-linear é utilizada.

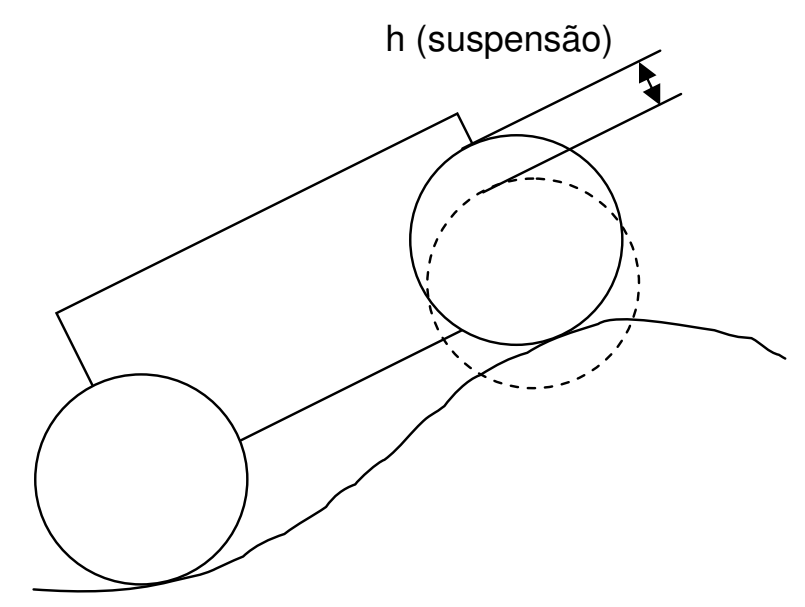

Figura 16: Esquema mostrando o deslocamento imposto à suspensão. 
A Figura 17 mostra as variáveis que descrevem as dimensões do chassi do veículo. A altura do chassi é determinada pela soma de $h_{\text {top }}$ e $h_{\text {bottom, onde o }}$ primeiro é a distância entre o teto e o centro de massa do veículo e o segundo é a distância complementar. A largura é dada pela soma de $\mathrm{W}_{1} \operatorname{com} \mathrm{W}_{2}$ e o comprimento pela soma de $\mathrm{L}_{1}$ e $\mathrm{L}_{2}$. As quatro distâncias são medidas em relação ao centro de massa e como este não está necessariamente no centro geométrico do chassi, $\mathrm{W}_{1}$ e $\mathrm{W}_{2}$ não precisam ser iguais, assim como $\mathrm{L}_{1}$ e $\mathrm{L}_{2}$.

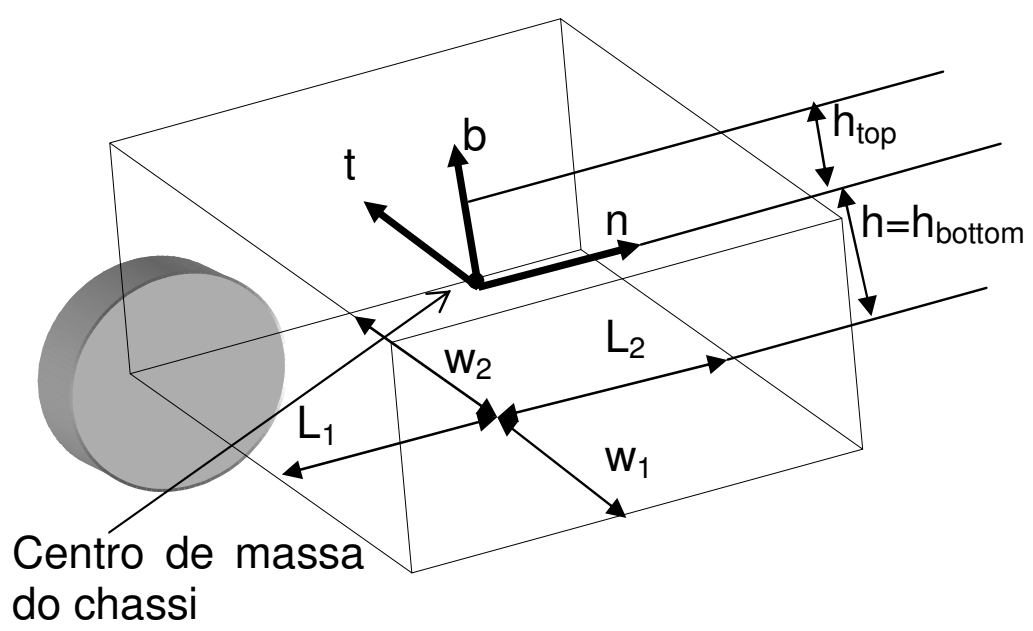

Figura 17: Esquema mostrando as dimensões do chassi.

\section{3. Determinação do ponto de contato entre pneus e terreno}

A Figura 18 e a Figura 19 ilustram o algoritmo de determinação do ponto de contato entre a roda e o terreno. Para um dado instante, se o terreno não existisse, a posição do centro da roda seria $\boldsymbol{X}$. Uma vez determinado o deslocamento h da suspensão, a posição real do centro da roda $\boldsymbol{X}_{\boldsymbol{c}}$ e o ponto de contato $\boldsymbol{X}_{\boldsymbol{c} p}$ serão:

$$
\begin{gathered}
\boldsymbol{X}_{c}=\boldsymbol{X}+h \boldsymbol{b} \\
\boldsymbol{X}_{c p}=\boldsymbol{X}_{c}+\left(r s_{\gamma}\right) \boldsymbol{n}-\left(r c_{\gamma}\right) \boldsymbol{n} \pm \frac{w}{2} \boldsymbol{t}
\end{gathered}
$$

onde: 
- w é a largura da roda (conseqüentemente $\pm w / 2$ t indicará que o contato se deu pela parte de dentro ou parte de fora da roda);

- r é o raio da roda;

- $\gamma$ é o ângulo entre a linha de trabalho da suspensão e a normal.

O ângulo $\gamma$ está diretamente ligado ao ponto da circunferência da roda que está efetivamente em contato com o solo (admitindo que o pneu não deforme). A determinação desse ponto de contato não é trivial, tendo em vista que o terreno pode ser irregular.

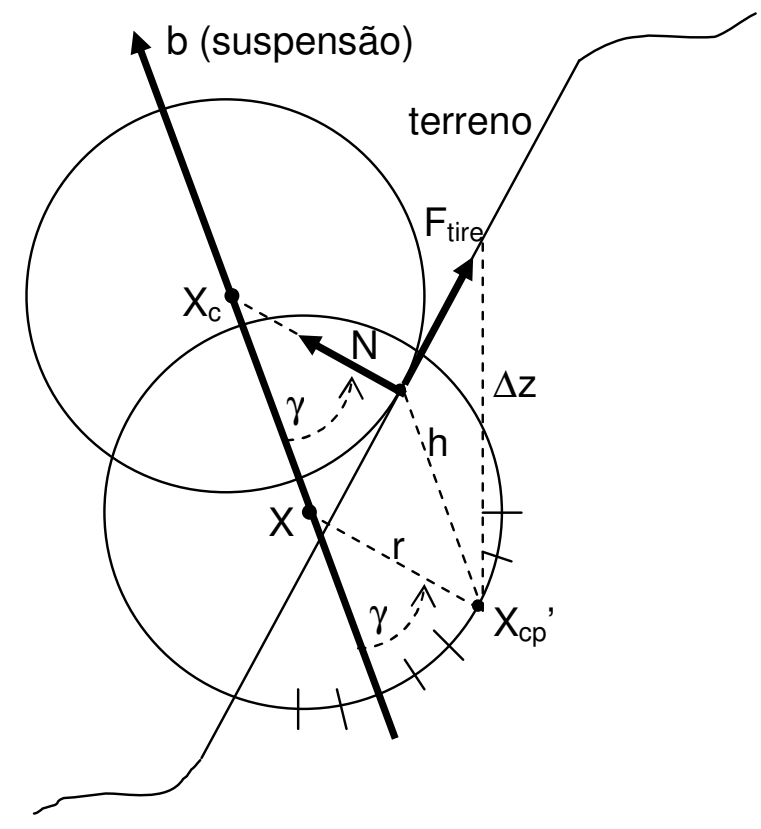

Figura 18: Esquema do ponto de contato da roda.

Para determinar $\gamma \mathrm{e}$, consequentemente, o ponto de contato com o terreno $\left(\boldsymbol{X}_{\boldsymbol{c}}\right)$, discretiza-se a parte inferior da circunferência da roda em $\mathrm{n}_{\text {step }}$ pontos. Para cada ponto, correspondendo a um ângulo $\gamma$, estima-se o deslocamento $h$ da suspensão. Dentre os deslocamentos calculados, escolhe-se o maior deles e com isso a direção da força normal $(\boldsymbol{N})$, da força de tração $\left(\boldsymbol{F}_{t}\right)$ e o centro real da roda estão definidos.

Para a estimativa do deslocamento h, utiliza-se um método iterativo em que se procura um valor de h que satisfaça: 


$$
\Delta z=Z_{c p}-f\left(X_{c p}, Y_{c p}\right)=0
$$

onde:

- $\mathrm{X}_{\mathrm{cp}}, \mathrm{Y}_{\mathrm{cp}}$ e $\mathrm{Z}_{\mathrm{cp}}$ são as coordenadas do vetor $\boldsymbol{X}_{\boldsymbol{c}}$ (ponto teórico de contato entre a roda e o terreno para um determinado $\gamma$ );

- $f$ é uma função interpoladora que retorna a altura do terreno para um determinado par de coordenadas XY.

A obtenção de $\boldsymbol{X}_{\boldsymbol{c} \boldsymbol{p}}$ é feita de acordo com a Equação (5.9) de forma análoga à Equação (5.6):

$$
\boldsymbol{X}_{c p}=\boldsymbol{X}_{c p}{ }^{\prime}+h \boldsymbol{b}
$$

onde o h a ser utilizado é um valor ajustado iterativamente.

$\mathrm{O}$ valor de h é procurado de maneira semelhante ao método da bissecção. O novo valor, $\mathrm{h}_{\text {med}}$, é obtido por meio da ponderação dos valores de $\Delta \mathrm{z}$ encontrados. A estimativa de $\mathrm{h}_{\text {med }}$ é feita de acordo com

$$
h_{\text {med }}=h_{\min }+\frac{\left(h_{\max }-h_{\min }\right)\left(-\Delta z_{\min }\right)}{\Delta z_{\max }-\Delta z_{\min }}
$$

onde (na primeira iteração) $h_{\max }$ é o máximo deslocamento da suspensão e $h_{\min }$ é o deslocamento mínimo, $\Delta z_{\max }$ e $\Delta z_{\min }$ são obtidos utilizando-se respectivamente $\mathrm{h}_{\max }$ e $\mathrm{h}_{\min }$ nas Equações (5.9) e (5.8). Uma vez estimado $\mathrm{h}_{\text {med }}, \Delta \mathrm{z}_{\text {med }}$ é obtido usando as mesmas equações. Determinadas as distâncias $\Delta \mathrm{z}_{\max }, \Delta \mathrm{z}_{\mathrm{med}}$ e $\Delta \mathrm{z}_{\min }$ (Figura 19), verificam-se os sinais das mesmas. Caso $\Delta z_{\max }$ seja positivo e $\Delta z_{\text {med }}$ negativo, ou vice-versa, então o valor desejado encontra-se entre os valores de $\mathrm{h}_{\max } \mathrm{e} \mathrm{h}_{\text {med}}$. Logo, $\mathrm{h}_{\text {med }}$ passará a ser o $\mathrm{h}_{\text {min }}$ na próxima iteração. Para o caso em que $\Delta z_{\text {med }}$ é negativo e $\Delta z_{\text {min }}$ positivo, ou vice-versa, o novo $h_{\text {med }}$ encontrado passará a ser o $\mathrm{h}_{\max }$ na próxima iteração. Se ambos $\Delta \mathrm{z}_{\max }$ e $\Delta \mathrm{z}_{\min }$ forem positivos, então a roda não faz contato com o terreno e portanto $h=0$. Finalmente, se ambos forem negativos, então a suspensão está trabalhando na região não-linear e com isso $\mathrm{o} \mathrm{h}_{\text {med }}$ passa a ser $\mathrm{o} \mathrm{h}_{\text {sat }}$. $\mathrm{O}$ método iterativo termina quando a variação 
absoluta entre valores sucessivos de $h_{\text {med }}$ é menor que um valor percentual de $h_{\text {sat }}$ pré-determinado ou quando $h_{\text {med }}$ atinge um dos valores extremos 0 ou $h_{\text {sat }}$.

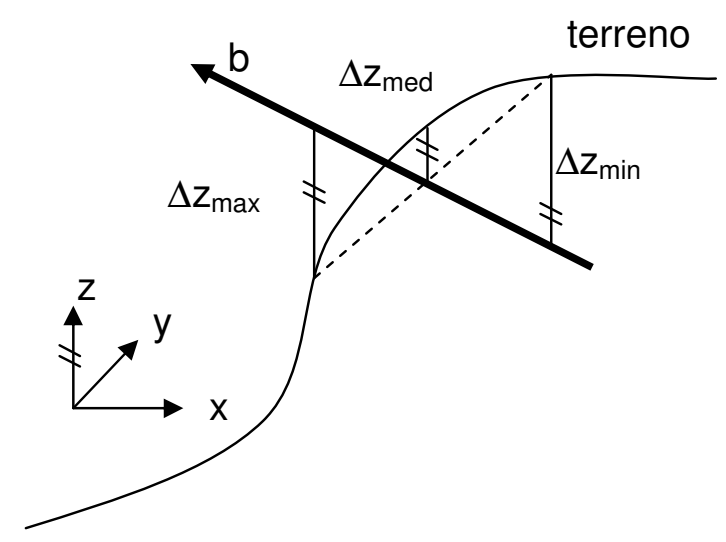

Figura 19: Esquema do algoritmo de determinação do ponto de contato entre a roda e o terreno.

\subsection{1. \\ Força de interação entre pneu e solo}

Foi implementado um modelo semi-empírico para lidar com a interação entre o pneu e o solo. O modelo utilizado é conhecido como "fórmula mágica" e é extensamente explorado em (37). Alterando-se as variáveis utilizadas, a mesma expressão fornece tanto as forças lateral e longitudinal quanto o momento de autoalinhamento. A expressão é função da força normal agindo sobre o pneu e das derivas longitudinal $\kappa$ e lateral $\alpha$. Uma versão mais genérica utiliza também o ângulo de cambagem, mas esse cenário não é contemplado no simulador. Como no veículo simulado as rodas são sempre paralelas ao chassi, o momento de autoalinhamento também foi desprezado.

As derivas podem ser consideradas como medidas do deslizamento entre o pneu e o terreno e seus cálculos são mostrados nas equações (5.11) e (5.12).

$$
\begin{gathered}
\kappa=\frac{r \omega-V_{x}}{V_{x}} \\
\alpha=\operatorname{atan}\left(-\frac{V_{y}}{V_{x}}\right)
\end{gathered}
$$


onde:

- $r$ é o raio do pneu;

- $\omega$ é a velocidade de rotação do pneu;

- $V_{x}$ é a velocidade longitudinal do pneu;

- $V_{y}$ é a velocidade lateral do pneu;

A "fórmula mágica" é calculada por meio das equações (5.13), (5.14) e (5.15).

$$
\begin{gathered}
f(a, b, c, \lambda)=b \cdot \operatorname{atan}\{a \lambda-c(a \lambda-\operatorname{atan}[a \lambda])\} \\
F(\lambda)=D \cdot \sin [f(B, C, E, \lambda)]+S_{v} \\
\lambda=\Lambda+S_{h}
\end{gathered}
$$

onde:

- F é a variável de saída (força longitudinal $F_{x}$ ou força lateral $F_{y}$ );

- $\Lambda$ é a variável de entrada ( $\kappa$ para a saída $F_{x}$ ou $\tan (\alpha)$ para $F_{y}$ );

- $B$ é o fator de rigidez;

- $C$ é o fator de forma;

- $D$ é o valor de pico;

- E é o fator de curvatura;

- $S_{v}$ é o offset vertical;

- $S_{h}$ é o offset horizontal;

A "fórmula mágica", como foi apresentada acima, fornece valores de força longitudinal ou lateral nos casos em que há deslizamento do pneu apenas em uma das direções. Para o caso em que há derivas longitudinal e lateral combinadas, as novas forças longitudinal $F_{x c}$ e lateral $F_{y c}$ serão as calculadas anteriormente, multiplicadas pelos fatores $G_{x \alpha}$ e $G_{y \kappa}$ respectivamente. Este ajuste garante que a força de atrito máxima do pneu não seja excedida. As equações dos fatores de ajuste são mostradas nas equações (5.16) e (5.17). 


$$
\begin{aligned}
G_{y \kappa} & =\frac{\cos \left[f\left(B_{y \kappa}, C_{y \kappa}, E_{y \kappa}, \kappa+S_{H y \kappa}\right)\right]}{\cos \left[f\left(B_{y \kappa}, C_{y \kappa}, E_{y \kappa}, S_{H y \kappa}\right)\right]} \\
G_{x \alpha} & =\frac{\cos \left[f\left(B_{x \alpha}, C_{x \alpha}, E_{x \alpha}, \alpha+S_{H x \alpha}\right)\right]}{\cos \left[f\left(B_{x \alpha}, C_{x \alpha}, E_{x \alpha}, S_{H x \alpha}\right)\right]}
\end{aligned}
$$

Os parâmetros $B, C, D, E, S_{v}, S_{h}, B_{y \kappa}, C_{y \kappa}, E_{y \kappa}, S_{H y \kappa}, B_{x \alpha}, C_{x \alpha}, E_{x \alpha}$ e $S_{H x \alpha}$ dependem de diversas constantes e da força normal agindo sobre o pneu. Maiores detalhes podem ser encontrados em (37).

\section{4 . \\ Modelagem dos sensores}

Foram implementados no simulador sensores comumente utilizados em controle de estabilidade de veículos. Para essa pesquisa escolheu-se trabalhar com acelerômetros, girômetros, magnetômetro, GPS, amperímetros e encoders. Foram introduzidos nas leituras efeitos como ruídos, resolução, sensitividade, saturação e local de instalação. Esses parâmetros foram retirados de datasheets de sensores reais especificados para o sensoriamento do veículo robótico usado como inspiração para a pesquisa. A seguir cada sensor e suas características são detalhados.

\subsection{1.}

Amperímetro

O sensor usado como referência para o modelo do amperímetro foi o ACS758KCB-150B-PFF-T da Allegro. É um sensor analógico que mede a corrente por efeito Hall e possui uma saturação de 150 A em ambas as direções. Sua sensitividade é proporcional à alimentação fornecida e para $3,3 \mathrm{~V}$ fornece $8,8 \mathrm{~m} \mathrm{~V}$ a cada $1 \mathrm{~A}$. O ruído informado pelo fabricante é de $4 \mathrm{mV}$ e foi adicionado a medida como um ruído Gaussiano de média nula e desvio padrão de $4 \mathrm{mV}$. Para incluir o ruído na informação de corrente, modelou-se também o circuito de condicionamento do sinal que é usado em eletrônicas embarcadas. Esse condicionamento é feito com amplificadores operacionais que adequam offsets e ranges do sinal à níveis compatíveis com a aquisição de dados. Para o simulador, 
foi considerada uma aquisição de dados com faixa de $0 \mathrm{~V}$ a 3,3 $\mathrm{V}$ e resolução de 10 bits. Foi incluído um deslocamento na medida de 1,65 V, típico para o sensor quando alimentado por 3,3 V. O condicionador de sinal foi considerado adicionar um valor de $-0,33 \mathrm{~V}$ e ter um ganho de 1,25 , de maneira a mapear a leitura do sensor que varia de $0,33 \mathrm{~V}$ a 2,97 $\mathrm{V}$ no range da aquisição que é de $0 \mathrm{~V}$ a $3,3 \mathrm{~V}$. Por final, a medida fornecida é multiplicada pela resolução da aquisição que é de 3,3/1024 V/LSB e arredondada para o inteiro mais próximo. A equação final para o sensor é mostrada em (5.19).

$$
\begin{gathered}
I=\operatorname{round}\left[\left(I_{\text {sim }} S_{I}+N_{I}+S O_{I}+C O_{I}\right) \frac{C S_{I}}{R_{I}}\right] \\
I_{\text {med }}=\operatorname{sat}\left[\frac{(I-512) 150}{512} ;-150 ; 150\right]
\end{gathered}
$$

onde:

- $I_{\text {sim }}$ é a corrente produzida pelo modelo do motor;

- $S_{I}$ é a sensitividade do sensor;

- $N_{I}$ é o ruído adicionado à medida;

- $S O_{I}$ é o offset do sensor;

- $C O_{I}$ é o offset do condicionador;

- $C S_{I}$ é o ganho do condicionador;

- $R_{I}$ é a resolução da aquisição de sinal.

\subsection{2.}

\section{Encoder}

O sensor usado como referência para o modelo do encoder foi o sistema encoder óptico rotatório incremental da US Digital e um $\mu$ Controlador, de maneira que o resultado já fosse uma medida da velocidade produzida por um código embarcado. O disco do encoder possui 900 divisões por volta. O sensor possui dois canais para fornecer um sinal em quadratura, possibilitando a determinação do sentido de rotação. Esses dois canais permitem também o aumento da resolução para 3600 pulsos por revolução. Sua sensitividade 
dependerá da taxa de aquisição do $\mu$ Controlador. Não há ruído a ser considerado devido à natureza da informação produzida pelo sensor. A equação final para o sensor é mostrada em (5.20).

$$
\varphi_{\text {med }}=\operatorname{round}\left[\left(\varphi_{\operatorname{sim}} \frac{3600 \Delta t}{2 \pi}\right)\right] \frac{2 \pi}{3600 \Delta t}
$$

onde:

- $\varphi_{\text {sim }}$ é a velocidade de rotação produzida pelo modelo do motor;

- $\Delta t$ é o período do loop de controle.

\subsection{3.}

Acelerômetro

O sensor usado como referência para o modelo do acelerômetro foi o ADXL345 da Analog Devices. É um sensor digital com fundo de escala variando de +/-3 g a +/-16 g. Escolheu-se trabalhar com o +/-4 g, fornecendo uma sensitividade de $128 \mathrm{LSB} / \mathrm{g}$. O ruído informado pelo fabricante é de 1,5 LSB. Foi incorporada à leitura do sensor efeitos de sua instalação fora do centro de massa do veículo, representados pela equação (5.21) e a aceleração da gravidade (16).

$$
{ }^{F} \boldsymbol{a}_{o f f}={ }^{F} \dot{\boldsymbol{\omega}}_{S} \times{ }_{C}^{F} \boldsymbol{R}_{A}+{ }^{F} \boldsymbol{\omega}_{S} \times\left({ }^{F} \boldsymbol{\omega}_{S} \times{ }_{C}^{F} \boldsymbol{R}_{A}\right)
$$

onde:

- ${ }^{F} \dot{\boldsymbol{\omega}}_{S}$ é a aceleração angular do sistema no referencial fixo;

- ${ }^{F} \boldsymbol{\omega}_{S}$ é a velocidade angular do sistema no referencial fixo;

- ${ }_{c}^{F} \boldsymbol{R}_{A}={ }^{F}{ }_{T}{ }_{C}^{S} \boldsymbol{R}_{A}$ é a posição do acelerômetro em relação ao centro de massa do veículo descrita no referencial fixo.

Por último, esses sensores fornecem os valores em $\mathrm{g}$ e com sentido invertido. A equação final para o sensor é mostrada em (5.23). 


$$
\boldsymbol{A}=\frac{\operatorname{round}\left\{\left[\frac{{ }^{{ }^{T}}{ }^{F}\left({ }^{F} \boldsymbol{A}_{\text {sim }}+{ }^{F} \boldsymbol{a}_{\text {off }}+{ }^{F} \boldsymbol{G}\right)}{9,81}\right] S_{A}+N_{A}\right\}}{S_{A}}
$$

$$
\boldsymbol{A}_{\text {med }}=\operatorname{sat}[-\boldsymbol{A} ;-4 ; 4]
$$

onde:

- ${ }^{F} \boldsymbol{A}_{\text {sim }}$ é a aceleração produzida pelo modelo do veículo no referencial fixo;

- $S_{A}$ é a sensitividade do sensor;

- $N_{A}$ é o ruído;

- ${ }^{F} \boldsymbol{G}$ é o vetor aceleração da gravidade.

\subsection{4.}

Girômetro

O sensor usado como referência para o modelo do girômetro foi o ITG3200 da InvenSense. É um sensor digital com fundo de escala fixo em +/-34,9 rad/s com uma sensitividade de $823,6 \mathrm{LSB} /(\mathrm{rad} / \mathrm{s})$. O ruído informado pelo fabricante é de $0,007 \mathrm{rad} / \mathrm{s}$. A equação final para o sensor é mostrada em (5.25).

$$
\begin{gathered}
\boldsymbol{\omega}=\frac{\operatorname{round}\left[\left({ }^{{ }^{F}}{ }^{F}{ }^{F} \boldsymbol{\omega}_{\text {sim }}+N_{\omega}\right) S_{\omega}\right]}{S_{\omega}} \\
\boldsymbol{\omega}_{\text {med }}=\operatorname{sat}[-\boldsymbol{\omega} ;-34,9 ; 34,9]
\end{gathered}
$$

onde:

- $\boldsymbol{\omega}_{\text {sim }}$ é a aceleração produzida pelo modelo do veículo;

- $\boldsymbol{\omega}_{A}$ é a sensitividade do sensor;

- $N_{\omega}$ é o ruído. 


\subsection{5.}

Magnetômetro

O sensor usado como referência para o modelo do magnetômetro foi o LSM303DLM da STMicroelectronics. Esse equipamento possui um fundo de escala programável de +/- 1,3 Gauss a 8,1 Gauss. Como o objetivo é medir o campo magnético da Terra (da ordem de 0,4 Gauss), o fundo de escala selecionado foi o menor deles. Sua sensitividade é de 1100 LSB/Gauss para os eixos X e Y e de 980 LSB/Gauss para o eixo Z. Esse sensor é digital com condicionamento de sinal interno e seus níveis de ruído não são informados pelo fabricante. Um valor de 2 mGauss típico para o sensor foi usado. A simulação do campo magnético foi feita rotacionando-se um vetor iniciado aleatoriamente, mas com pequena componente no eixo vertical no início da simulação, e com magnitude de 0,3 Gauss. Essa rotação é feita utilizando-se a matriz de orientação do veículo. A equação final para o sensor é mostrada em (5.27).

$$
\begin{gathered}
\boldsymbol{M}=\frac{\operatorname{round}\left[\left(\boldsymbol{M}_{\operatorname{sim}}+N_{M}\right) S_{M}\right]}{S_{M}} \\
\boldsymbol{M}_{\text {med }}=\operatorname{sat}[\boldsymbol{M} ;-1,3 ; 1,3]
\end{gathered}
$$

onde:

- $\boldsymbol{M}_{\text {sim }}$ é o campo magnético simulado;

- $S_{M}$ é a sensitividade do eixo do sensor;

- $N_{M}$ é o ruído adicionado à medida.

\section{5 .}

\section{Validação do simulador}

A validação do simulador foi feita com simulações de cenários em que os resultados analíticos são encontrados na literatura (22) e em comparações com experimentos realizados. Nessa seção, além das comparações com resultados analíticos, é mostrado um experimento feito com um motor preso à bancada 
apenas para validação do simulador. $\mathrm{Na}$ seção 6, são apresentados outros experimentos onde há comparações com os resultados simulados também para efeitos de validação.

\subsection{1.}

\section{Ensaio de partida do motor}

Um experimento com o motor usado como referência para o simulador desenvolvido foi feito. Nesse experimento o conjunto formado pelo motor e a caixa de redução é preso a uma bancada e no eixo de saída da caixa de redução é colocada a roda. Dois ensaios de partida do motor foram feitos com tensões de 18 $\mathrm{V}$ e $10 \mathrm{~V}$, aplicados durante $1 \mathrm{~s}$. Os dados de corrente e velocidade angular foram aquisitados a uma taxa de $300 \mathrm{~Hz}$. Os resultados são comparados com os modelos implementados no simulador. A Figura 20, a Figura 21, a Figura 22 e a Figura 23 mostram a comparação entre as formas de ondas aquisitadas no experimento com as geradas no simulador.

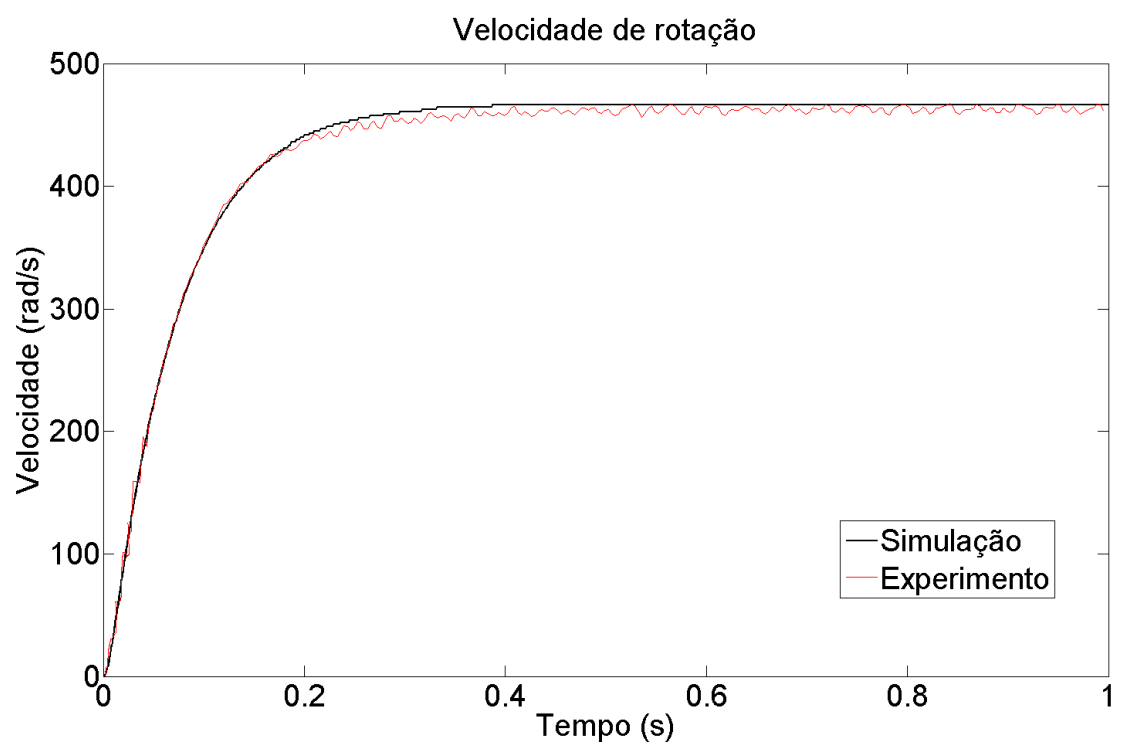

Figura 20: Comparação entre a curva de velocidade de rotação obtida experimentalmente com a gerada pelo simulador para uma tensão de alimentação de $18 \mathrm{~V}$. 


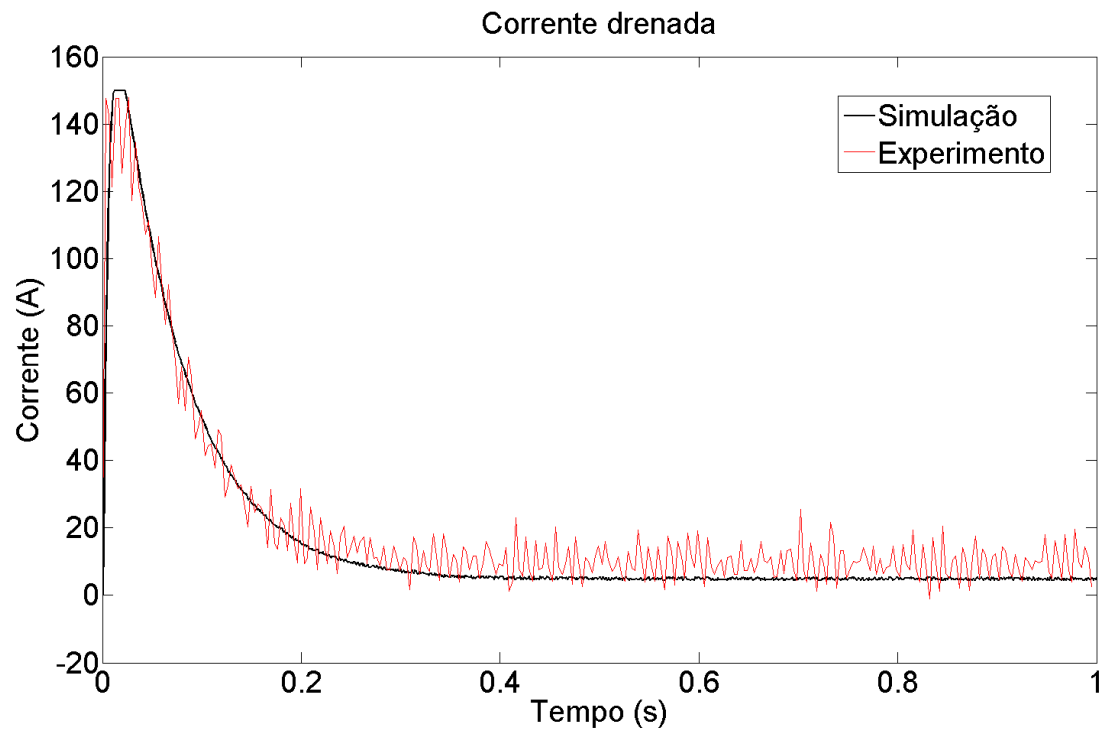

Figura 21: Comparação entre a curva de corrente drenada obtida experimentalmente com a obtida pelo simulador para uma tensão de alimentação de $18 \mathrm{~V}$.

A comparação das curvas com excitação a $10 \mathrm{~V}$ apresentou um desvio RMS em regime permanente de $6,5 \mathrm{rad} / \mathrm{s}$ entre as curvas de velocidade e de 5,6 A entre as curvas de corrente. Nos testes com $18 \mathrm{~V}$ os desvios foram menores chegando a $3,2 \mathrm{rad} / \mathrm{s}$ entre as curvas de velocidade e 5,0 A entre as curvas de corrente.

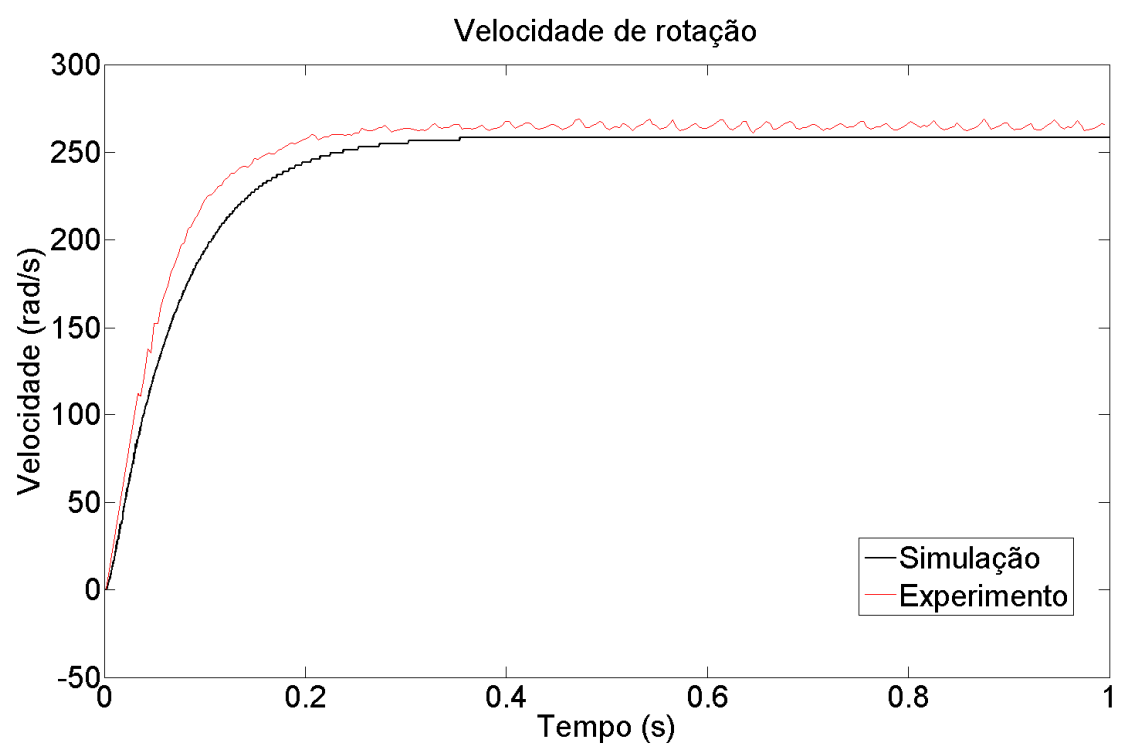

Figura 22: Comparação entre a curva de velocidade de rotação obtida experimentalmente com a obtida pelo simulador para uma tensão de alimentação de $10 \mathrm{~V}$. 


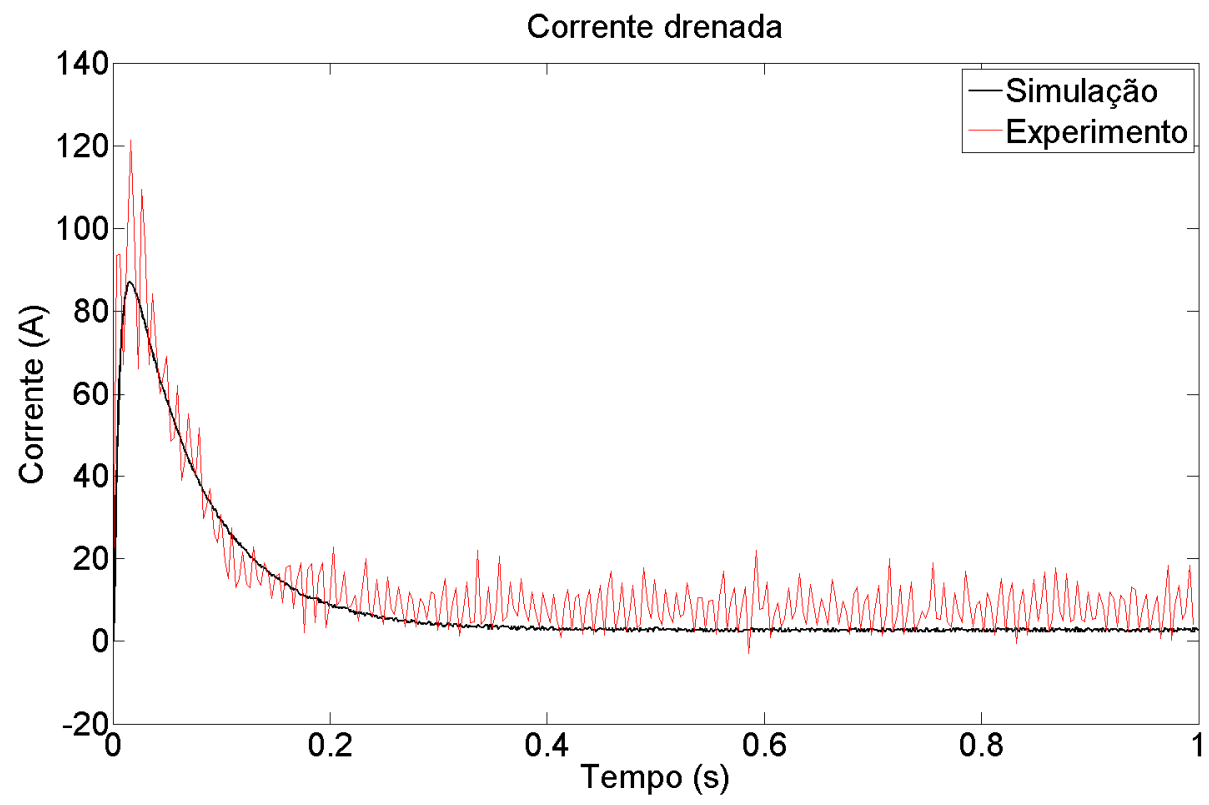

Figura 23: Comparação entre a curva de corrente drenada obtida experimentalmente com a obtida pelo simulador para uma tensão de alimentação de $10 \mathrm{~V}$.

O ruído encontrado nas curvas experimentais de corrente é atribuído em parte ao sensor, descrito na seção 5.4.1, e em parte à forma de atuação sobre o motor. Os motores são atuados utilizando um PWM de $8 \mathrm{kHz}$. O ruído sobre as curvas de velocidade angular é atribuído à vibração da bancada onde o motor foi preso.

O ajuste dos parâmetros utilizados na simulação foi feito por meio dos métodos dos mínimos quadrados. Os valores finais utilizados no simulador relativos ao motor são mostrados na Tabela 1 .

Tabela 1: Tabela de valores das constantes do sistema ajustadas.

\begin{tabular}{|c|c|}
\hline$L$ & $0,5 \mathrm{mH}$ \\
\hline$R_{\text {tot }}$ & $0,1 \Omega$ \\
\hline$J$ & $0,054 \mathrm{~kg} \cdot \mathrm{m}^{2}$ \\
\hline$K_{t}$ & $0,038 \mathrm{~N} \cdot \mathrm{m} / \mathrm{A}$ \\
\hline$b$ & $0,02 \mathrm{~N} . \mathrm{s} / \mathrm{m}$ \\
\hline
\end{tabular}




\subsection{2.}

\section{Teste de arrancada}

No teste de arrancada um torque constante é aplicado em cada motor e tanto a aceleração resultante quanto a distribuição das forças normais são monitoradas. A Figura 24 mostra os parâmetros utilizados no cálculo da distribuição das normais durante a arrancada do veículo em terreno plano e horizontal.

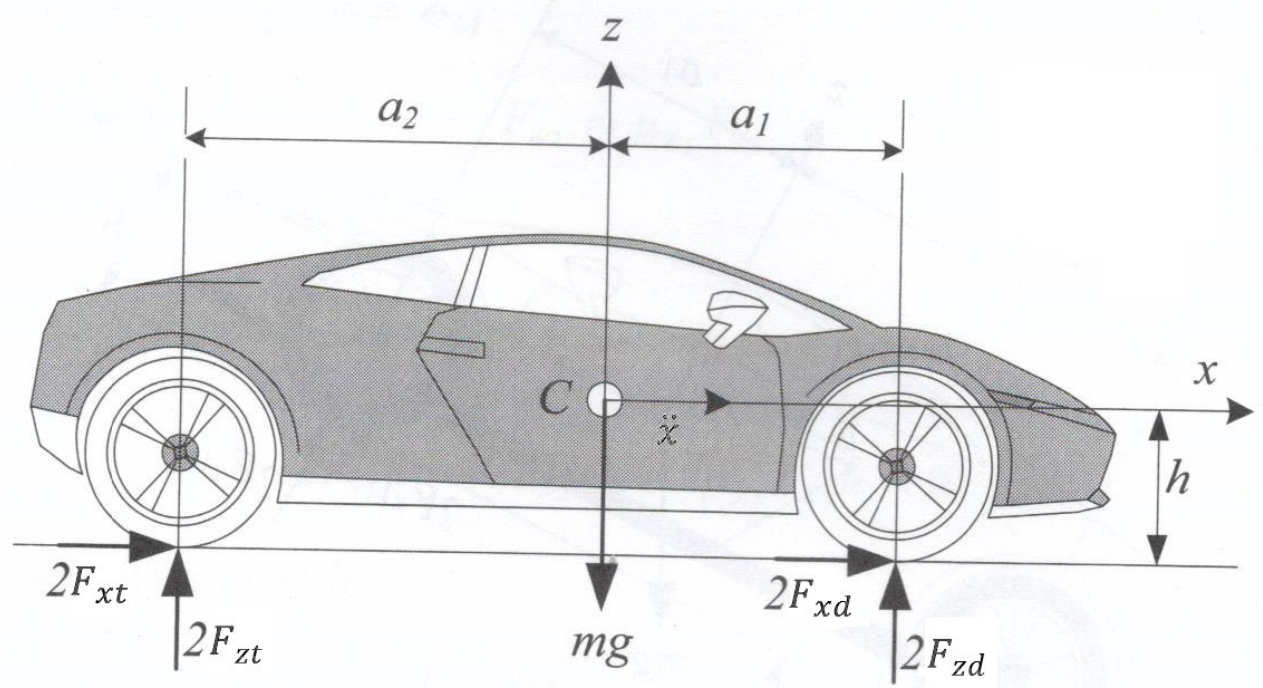

Figura 24: Veículo acelerando em um terreno plano (22).

Sabe-se que a distribuição das normais longitudinalmente, em cada roda, durante a aceleração do veículo (considerando que não há suspensão) em um terreno plano, horizontal e rígido é dada pelas equações (5.28) e (5.29):

$$
\begin{gathered}
F_{z d}=\frac{m g a_{2}}{2 l}-\frac{m h \ddot{x}}{2 l} \\
F_{z t}=\frac{m g a_{1}}{2 l}+\frac{m h \ddot{x}}{2 l}
\end{gathered}
$$

onde:

- $m$ é a massa do veículo;

- $g$ é a aceleração da gravidade;

- $\ddot{x}$ é a aceleração longitudinal do veículo; 
- $2 l$ é a distância entre-eixos;

- $h$ é a altura do centro de massa do veículo;

- $a_{l}$ é a distância entre o centro de massa do veículo e o eixo dianteiro;

- $a_{2}$ é a distância entre o centro de massa do veículo e o eixo traseiro;

- $F_{x d}$ e $F_{x t}$ são, respectivamente, as forças de tração dianteira e traseira que impulsionam o veículo.

A primeira parte de ambas as equações é formada por um termo que depende apenas da aceleração da gravidade e da geometria do veículo e por isso é chamado de parte estática enquanto o segundo varia com a aceleração do veículo e é denominado de parte dinâmica.

A simulação de arrancada foi feita aplicando-se um torque constante nos motores traseiros de $10 \mathrm{Nm}$ por $1 \mathrm{~s}$. Assim como em (15), um coeficiente de atrito artificial de 2,5 foi usado para minimizar o deslizamento entre as rodas e o terreno durante a arrancada. Nessas condições, segundo as equações (5.28) e (5.29), o módulo das forças normais esperadas para as rodas traseiras é de $177,9 \mathrm{~N}$ e de 106,6N para as dianteiras. Um desvio máximo de 0,4\% foi encontrado. A Figura 25 mostra o comportamento das forças normais durante a simulação e destaca o valor das mesmas em regime permanente.

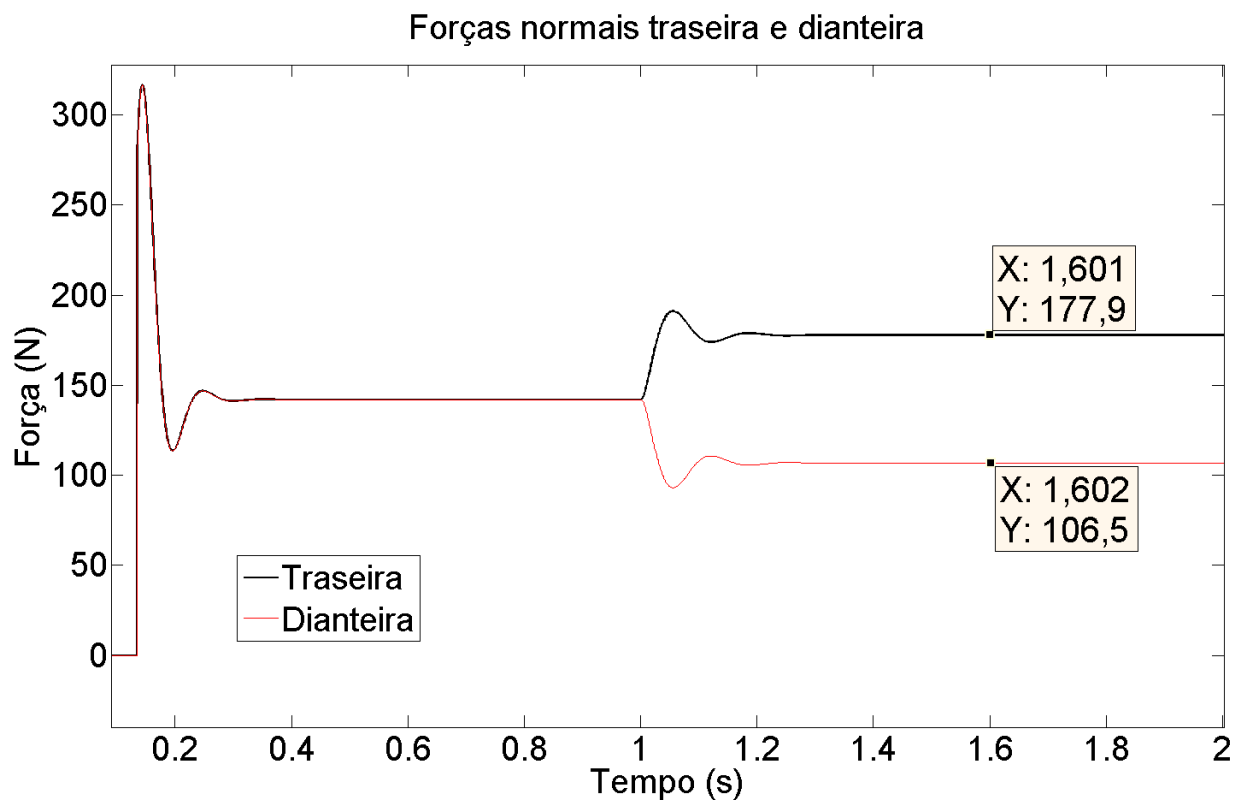

Figura 25: Simulação de arrancada mostrando o comportamento das forças normais traseira e dianteira do veículo. 
As simulações são iniciadas com o veículo sendo largado de uma altura qualquer, fora do terreno (sem nenhuma roda estar em contato com o mesmo). A variação das forças normais, ilustradas na Figura 25, durante o primeiro segundo são referentes ao assentamento do sistema mola-amortecedor (ver equação (2.28)) entre as rodas e o terreno no momento em que o veículo entra em contato com o mesmo. Após o primeiro segundo de simulação, depois que as normais se estabilizaram, a arrancada é iniciada com a aplicação dos torques de $10 \mathrm{Nm}$ nas rodas traseiras.

\subsection{3.}

\section{Limite para descolamento das rodas dianteiras}

Ainda de acordo com a equação (5.28), uma aceleração longitudinal de $\ddot{x}=\frac{g a_{2}}{h}=8,0 \mathrm{~m} / \mathrm{s}^{2}$ fará a força normal sobre as rodas dianteiras nula, evidenciando um descolamento das mesmas. Usando o mesmo coeficiente de atrito artificial de 2,5 e uma curva de torque exponencial crescente para minimizar deslizamentos da roda, simulou-se uma arrancada com um torque máximo de 40 $\mathrm{Nm}$ em cada uma das rodas traseiras. A curva de torque aplicado seguiu a curva $\tau=40\left(1-e^{\left[\frac{-4(t-1)}{3}\right]}\right)$ que converge em aproximadamente 3 s e possui uma espera de $1 \mathrm{~s}$.

A Figura 26 mostra o comportamento da força normal sobre as rodas traseiras e dianteiras juntamente com a aceleração do centro de massa do veículo. É destacado o momento em que as rodas dianteiras perdem contato com o terreno, identificado pela força normal nula. Este momento acontece um pouco antes da aceleração longitudinal ser $7,97 \mathrm{~m} / \mathrm{s}^{2}$, representando um desvio de $3,5 \%$ do valor previsto. Na figura percebe-se ainda que o tempo em que o veículo ficou sujeito a aceleração crítica não foi o suficiente para fazê-lo capotar. Aproximadamente 0,5 $\mathrm{s}$ depois de perder contato com o terreno as rodas dianteiras tocam novamente o chão. 


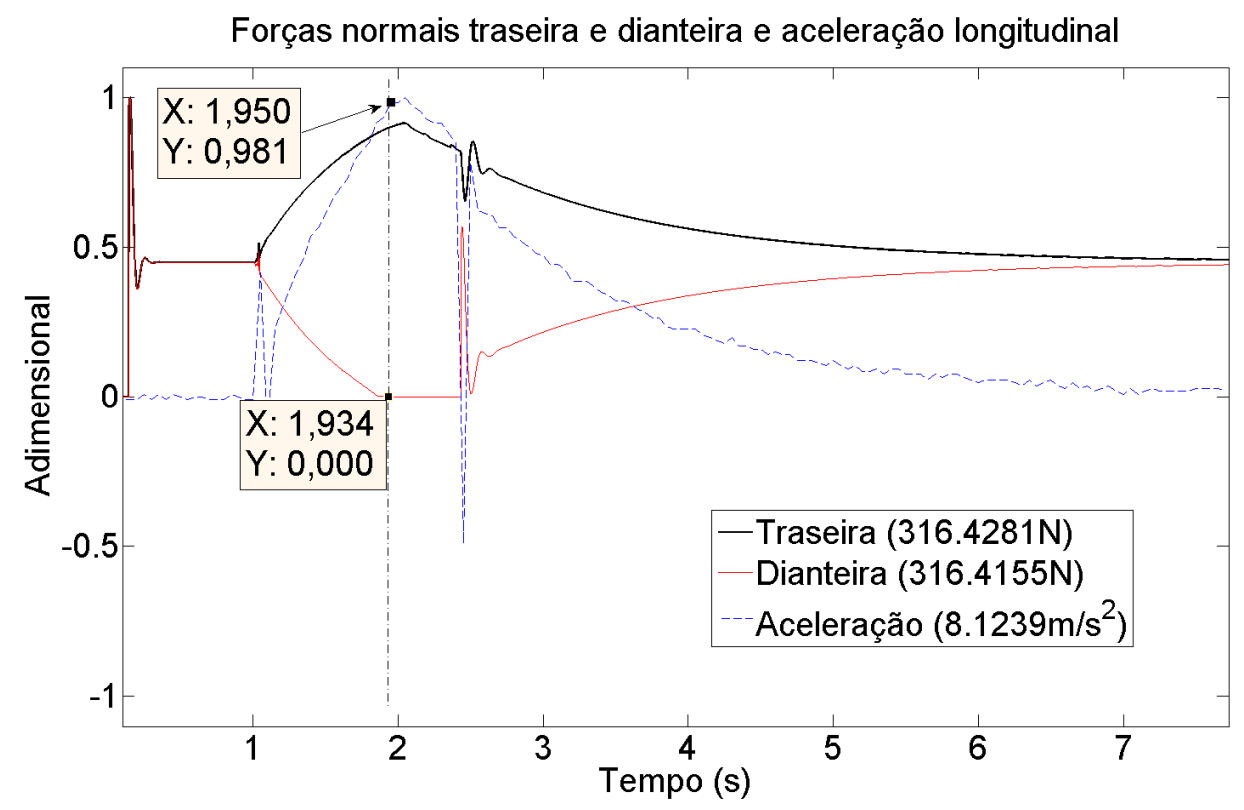

Figura 26: Simulação de descolamento das rodas dianteiras mediante altos torques aplicados às rodas traseiras.

$\mathrm{Na}$ figura acima, os valores das forças normais e da aceleração foram normalizados em relação ao maior valor obtido durante a simulação. Esses valores máximos encontram-se discriminados na legenda.

\subsection{4. \\ Manobra Fishhook}

Outra simulação para validação do simulador foi feita reproduzindo-se um caso considerado benchmark para estudos de estabilidade lateral (16). Uma comparação qualitativa será feita com os resultados publicados por (15). Na simulação foi implementada a manobra Fishhook usada por montadoras de carros de passeio para determinação do nível de segurança em relação a capotagem lateral do veículo.

O Fishhook é uma manobra excitatória da dinâmica de rolagem do veículo onde o motorista gira o volante para os dois lado rapidamente. Para um veículo com direção diferencial (skidsteer), a guinada do volante é replicada pelo perfil da diferença entre as tensões enviadas aos motores. A diferença entre as tensões nos motores da direita em relação aos da esquerda é mostrada na Figura 27. 


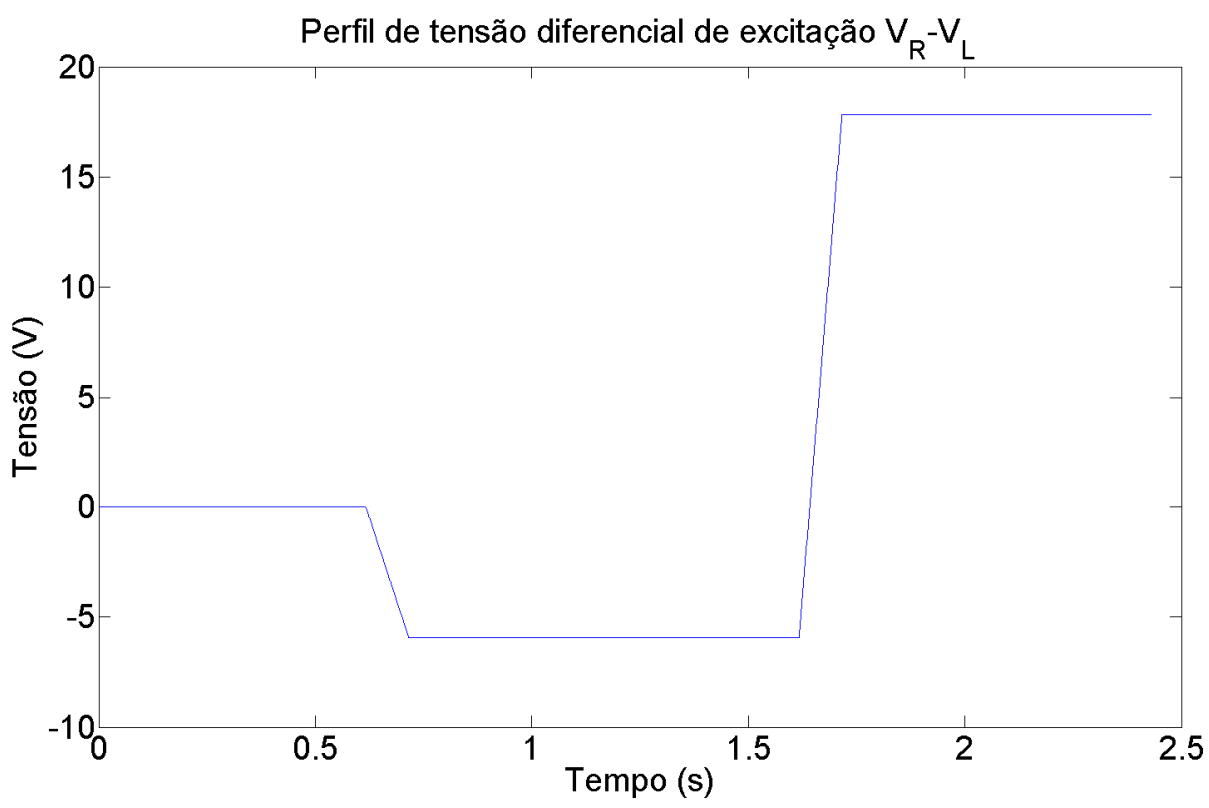

Figura 27: Perfil de tensão diferencial aplicado no veículo durante a manobra Fishhook.

Foram simuladas quatro tensões (velocidades) diferentes e o valor da métrica de estabilidade calculada usando transferência de carga entre os pneus é mostrado como resultado. As tensões simuladas foram de $5 \mathrm{~V}, 10 \mathrm{~V}, 15 \mathrm{~V}$ e $20 \mathrm{~V}$. Para a última tensão, houve o capotamento logo após os $2 \mathrm{~s}$. A simulação com 15 $\mathrm{V}$ ficou muito próxima do capotamento também. A Figura 28 mostra o indicador de estabilidade para os quatro casos simulados.

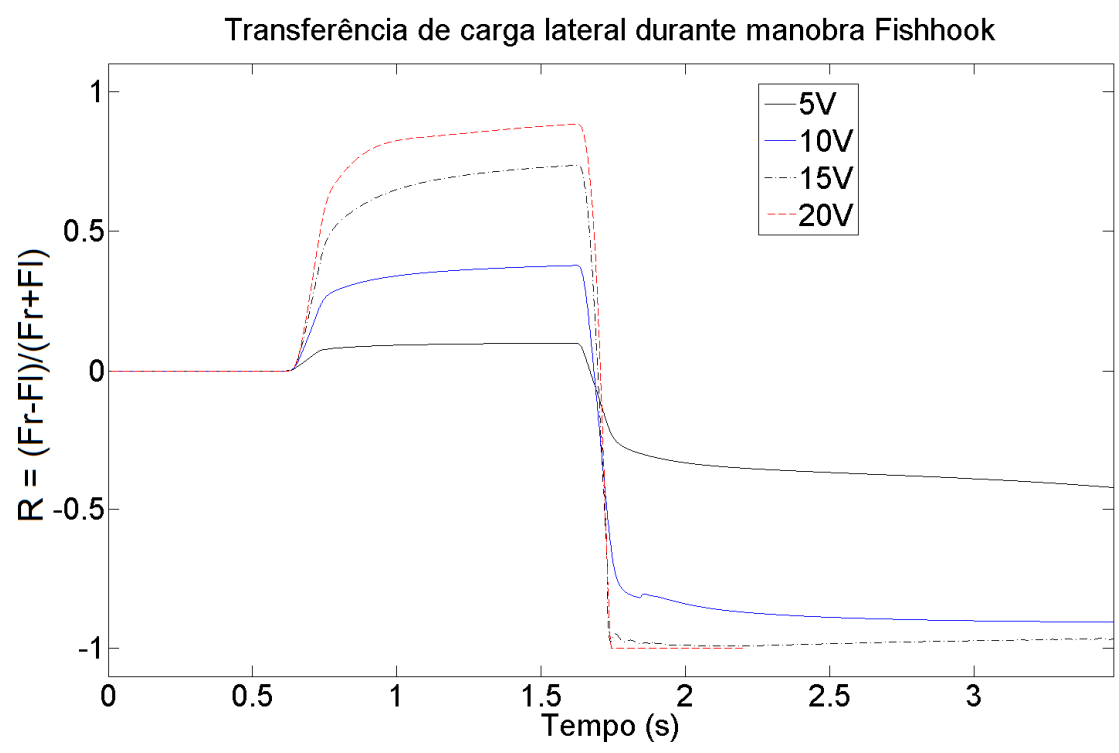

Figura 28: Indicador de estabilidade mostrado na equação (1.1) calculado durante manobra Fishhook para diferentes velocidades. 
Em (15) quatro indicadores de estabilidade são comparados usando simulação, como mostra a Figura 29.

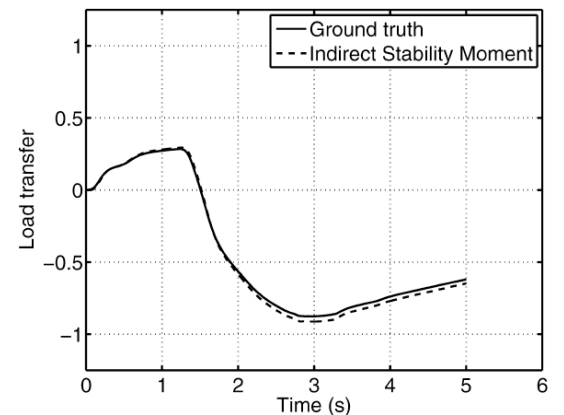

(a)

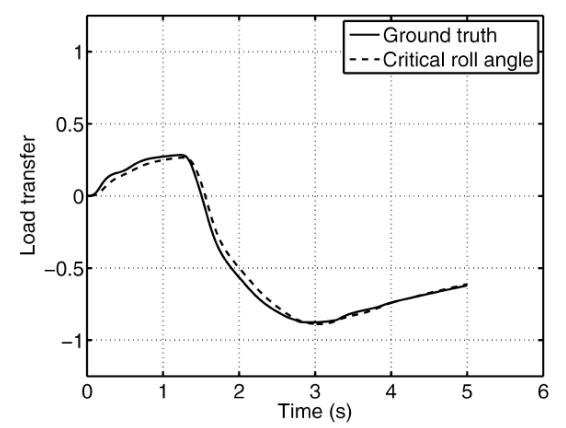

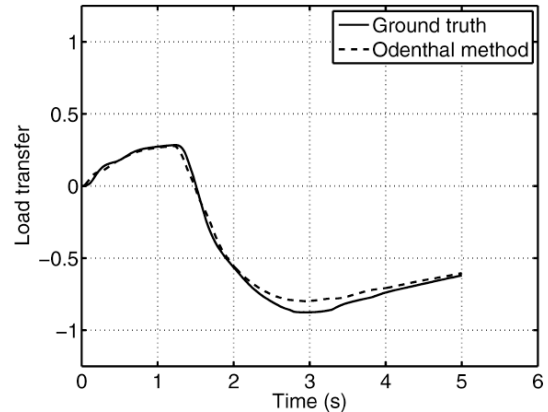

(b)

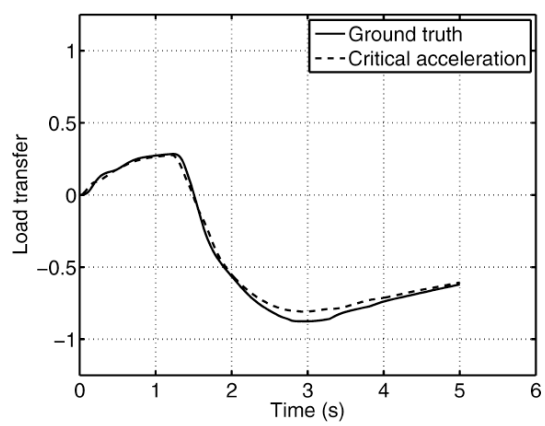

Figura 29: Comparação entre quatro indicadores de estabilidade durante a manobra Fishhook publicada em (15).

A Figura 29 mostra o comportamento de um veículo de passeio do tipo utilitário simulado utilizando o pacote de softwares ADAMS realizando a manobra Fishhook. O veículo simulado possui rodas dianteiras esterçáveis e pesa mais de $2000 \mathrm{~kg}$. O comportamento é similar ao mostrado na Figura 28. Considerando as curvas para $10 \mathrm{~V}$ e $15 \mathrm{~V}$, ambos os trabalhos apresentam uma menor tendência à instabilidade durante a primeira guinada quando comparada a segunda. A diferença entre as curvas no final da manobra se deve à possível perda de velocidade do utilitário na simulação feita no ADAMS. O autor fez a simulação sem acelerar ou frear o veículo durante a manobra enquanto que nas simulações mostradas pela Figura 28 a tensão elétrica é aplicada durante toda a manobra. 


\section{6}

\section{Simulações e resultados experimentais}

\section{1.}

Sistema experimental

A pesquisa visou estudar o comportamento dinâmico do veículo robótico elétrico de inspeção de tubulação desenvolvido no laboratório de robótica da PUC-Rio. Esse veículo possui rodas sem esterçamento e seu direcionamento é feito através de tração diferencial (similar à locomoção de um veículo sobre esteiras). Não há suspensões entre as rodas e o chassi.

Um modelo feito em SolidWorks é mostrado na Figura 30.

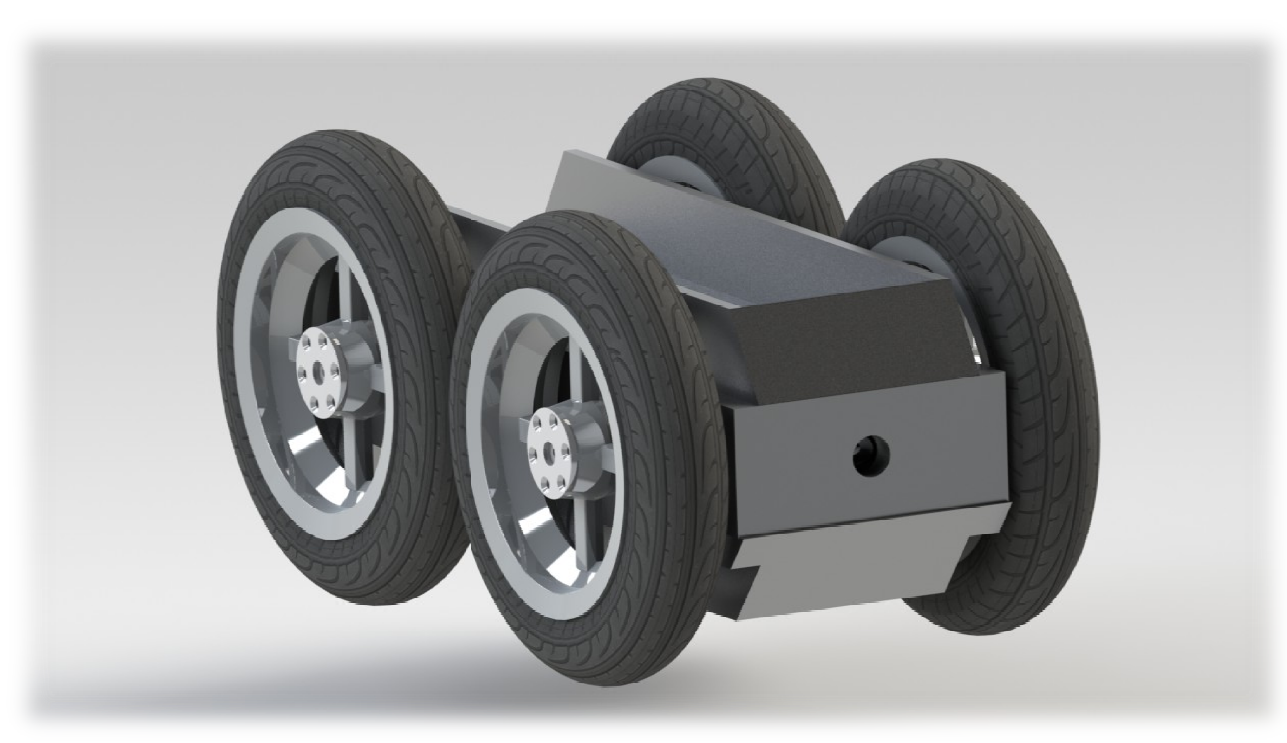

Figura 30: Veículo robótico elétrico desenvolvido no laboratório de robótica da PUC-Rio para inspeção de tubulações.

A atuação nas rodas é feita por motores elétricos MagMotor S28-150 com $2183 \mathrm{~W}$ de potência teórica, velocidade de rotação máxima de 638,8 rad/s (para $24 \mathrm{~V}$ de alimentação) e torque máximo de $6 \mathrm{Nm}$ de corrente contínua. Entre os motores e as rodas foram instaladas caixas de redução com razão de 7,14:1. O 
fornecimento de corrente ao sistema é proporcionado por quatro baterias de $\mathrm{NiCd}$ de $26 \mathrm{~V}$ por 3,6 Ah cada. As rodas são consideradas presas na mesma altura do centro de massa do veículo. Na Tabela 2 são mostradas outras propriedades do veículo utilizado nos experimentos. A Figura 31 mostra a numeração adotada para as rodas na modelagem.

Tabela 2: Propriedades do sistema experimental.

\begin{tabular}{|c|c|}
\hline Comprimento do chassi & $0,65 \mathrm{~m}$ \\
\hline Largura do chassi & $0,22 \mathrm{~m}$ \\
\hline Altura do chassi & $0,10 \mathrm{~m}$ \\
\hline Raio da roda & $0,17 \mathrm{~m}$ \\
\hline Distância entre-eixos & $0,35 \mathrm{~m}$ \\
\hline Massa total do veículo & $53 \mathrm{~kg}$ \\
\hline
\end{tabular}

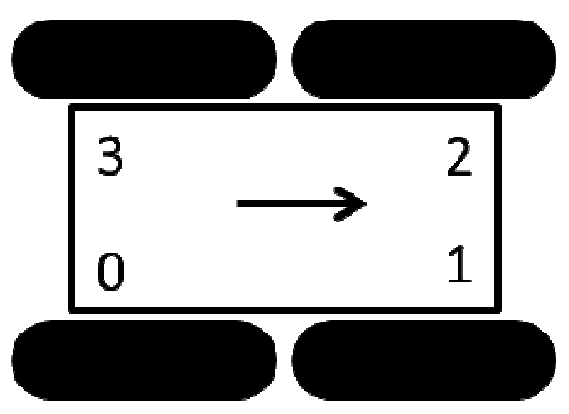

Figura 31: Numeração das rodas usada na modelagem.

O sistema de coordenadas utilizado na modelagem foi o referencial ISO (38), mostrado na Figura 32. As rotações rolagem, arfagem e guinada são respectivamente relativas aos eixos x, y e z. A direção longitudinal do veículo coincide com o eixo x com o sentido apontando para frente. A direção vertical do sistema coincide com o eixo z com o sentido para cima. Pela regra da mão direita, o sentido do eixo y será da direita para a esquerda do motorista. 


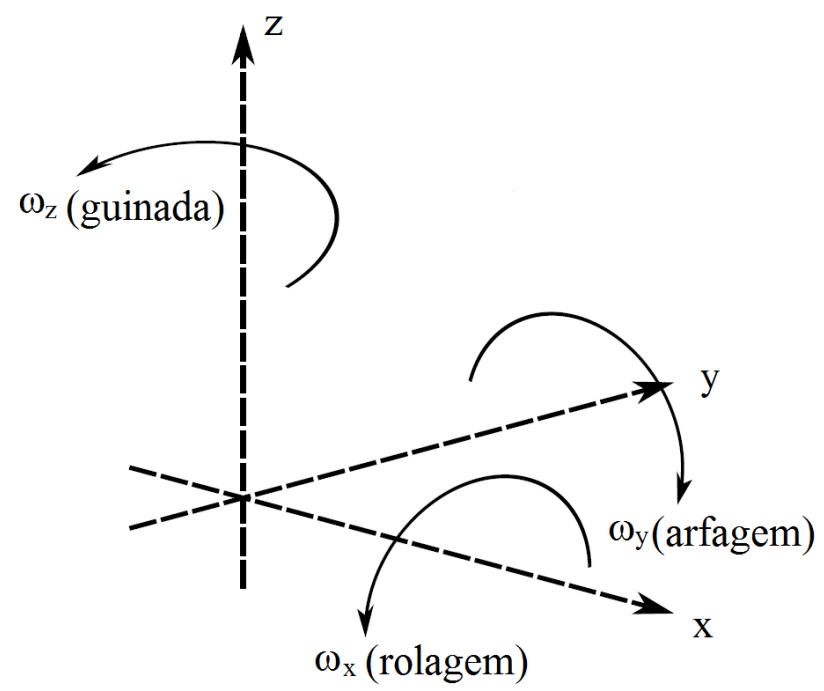

Figura 32: Sistema de eixo de coordenadas (38).

\section{2. \\ Circuitos eletrônicos desenvolvidos}

Foram desenvolvidos os circuitos eletrônicos embarcados no veículo robótico responsáveis pela lógica. Suas funcionalidades incluem aquisição de dados dos sensores, interface de comando para os atuadores, interface de comunicação entre o veículo e a estação de rádio controle (circuito eletrônico e laptop) e a implementação dos algoritmos de controle do sistema. A eletrônica desenvolvida ainda é capaz, dentre outras funcionalidades, de armazenar quaisquer dados obtidos durante os experimentos em um cartão de memória microSD de até 16 GB para futura análise.

A eletrônica de controle do sistema possui três placas de circuito impresso que operam embarcadas no veículo recebendo os comandos do laptop via rádio. Duas eletrônicas (dsPIC $\mathrm{D}_{\mathrm{D}}$ e dsPIC $\mathrm{C}_{\mathrm{T}}$ ) são idênticas, em termos de componentes, e possuem o microcontrolador dsPIC33FJ128MC202. A outra $\left(\mathrm{ARM}_{\mathrm{E}}\right)$ possui o microcontrolador LPC2148.

O sistema foi desenvolvido para que as eletrônicas dsPIC $\mathrm{D}_{\mathrm{D}}$ e dsPIC $\mathrm{P}_{\mathrm{T}}$ fossem responsáveis unicamente pelo controle de torque das rodas, por necessitarem de uma alta frequência de loop de controle. A eletrônica $\mathrm{dsPIC}_{\mathrm{D}}$ é responsável pelas duas rodas dianteiras e a dsPIC $\mathrm{T}_{\mathrm{T}}$ é responsável pelas rodas traseiras. Com essa 
exclusividade, elas podem executar o algoritmo desenvolvido para o controle de torque a frequências de até $1 \mathrm{kHz}$.

A eletrônica $\mathrm{ARM}_{\mathrm{E}}$ foi desenvolvida para executar os algoritmos desenvolvidos que requerem leituras dos sensores e cálculos além das tarefas complementares do sistema como comunicação com a base, armazenamento de dados e condicionamento de sinais.

A eletrônica de potência do sistema foi adquirida no mercado por se tratar de uma tecnologia já desenvolvida. Uma das eletrônicas de potência utilizadas pela equipe RioBotz (e escolhida para a pesquisa) é a OSMC (Open Source Motor Controller) fabricada pela Robot Power, que disponibiliza todo o projeto da eletrônica no próprio site (www.robotpower.com). Ela suporta tensões de até $50 \mathrm{~V}$ e correntes contínuas de até 160 A e picos de 400 A. Um dos seus benefícios, além da alta potência de trabalho, é o seu comando através de sinais do tipo PWM de até $16 \mathrm{kHz}$, permitindo assim altas frequência de loops de controle.

Para comunicação com o veículo robótico, foi utilizado o sistema 3DR Radio Telemetry System da 3D Robotics UAV Technology.

A Figura 33 mostra os componentes principais do sistema e as formas de interação entre si.

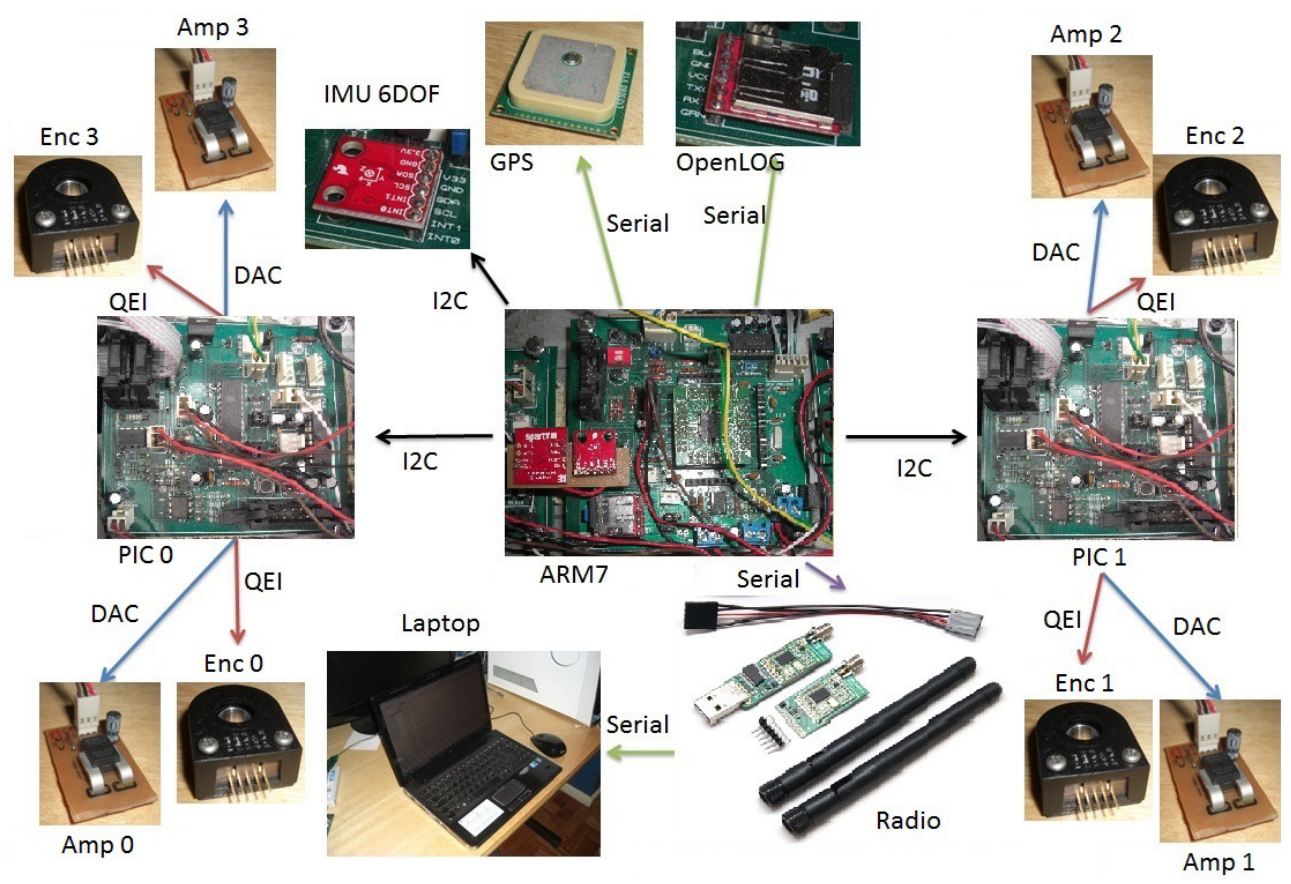

Figura 33: Componentes principais do sistema e suas formas de interação. 


\subsection{1. \\ Eletrônica ARM}

Essa é a principal eletrônica do sistema. Ela possui o $\mu$ Controlador LPC2138 que executa, dentre outras coisas, o algoritmo de controle de arfagem proposto na pesquisa. $\mathrm{O} \mu$ Controlador recebe dados de uma estação inercial que possui o acelerômetro ADXL345, o girômetro ITG3200 e o magnetômetro LSM303DLMTR, todos com medições nos três eixos. A ele ainda estão conectados um armazenador de dados (OpenLog), responsável por gravar as informações desejadas no cartão de memória microSD. Ainda existe um conector para um GPS de $5 \mathrm{~V}$ com comunicação serial TTL, não usado na pesquisa.

A comunicação com os sensores inerciais é feita por meio do protocolo $\mathrm{I}^{2} \mathrm{C}$, enquanto que com OpenLog a comunicação é via serial TTL.

A eletrônica $\mathrm{ARM}_{\mathrm{E}}$ possui os circuitos reguladores de tensão que convertem a tensão de alimentação da bateria $(8,5 \mathrm{~V})$ nas tensões $(3,3 \mathrm{~V}$ e $5 \mathrm{~V})$ que alimentam todos os sensores e $\mu$ Controladores embarcados no veículo.

A programação do $\mu$ Controlador é feita utilizando ISP (via RS232) sem a necessidade de retirar o mesmo do circuito.

A Figura 34 mostra a eletrônica $\mathrm{ARM}_{\mathrm{E}}$ com os equipamentos descritos acima acoplados.

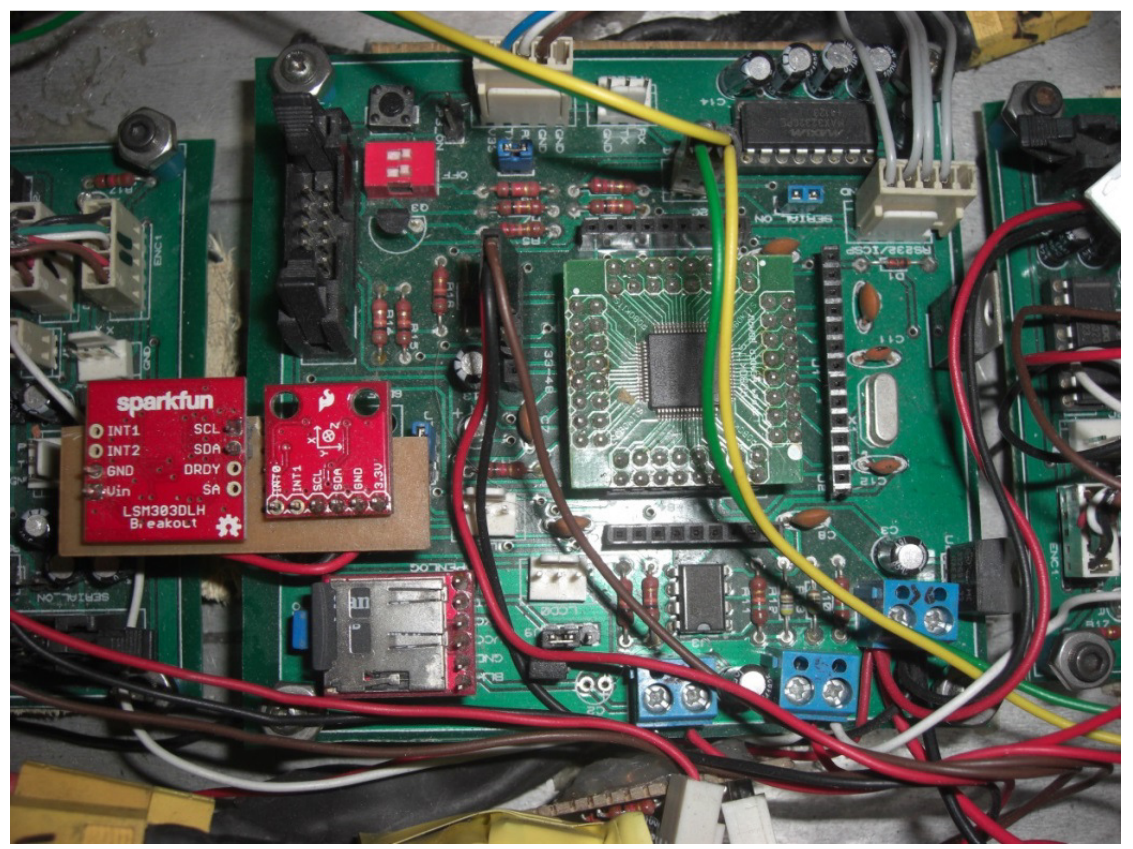

Figura 34: Eletrônica principal de controle $\left(\mathrm{ARM}_{\mathrm{E}}\right)$ do veículo robótico. 


\subsection{2.}

\section{Eletrônicas dsPIC $C_{D}$ e dsPIC}

Ambas as eletrônicas possuem exatamente os mesmos componentes e são comandados pelo $\mu$ Controlador dsPIC33FJ128MC202. Cada uma é responsável por dois motores.

A leitura da corrente drenada pelo motor é feita pelo sensor ACS758KCB150B-PFF-T. As eletrônicas recebem os sinais $(0,33 \mathrm{~V}$ a $2,97 \mathrm{~V})$ dos amperímetros e os convertem em níveis de tensões compatíveis com o microcontrolador $(0 \mathrm{~V}$ a 3,3 V) mediante uma eletrônica condicionadora de sinais. Esse sensor é capaz de medir correntes de até 150 A nas duas direções.

O encoder utilizado para o cálculo da velocidade de rotação das rodas é o E2-900-394-I-H-D-B, que possui quadratura. Os sinais produzidos são processados pelo $\mu$ Controlador que tem um hardware específico para determinar a direção de rotação do eixo e a contagem de todas as transições de ambos os canais A e B do encoder, aumentando assim a resolução do sensor em quatro vezes (de 900 PPR para 3600 PPR). A vantagem de usar esse $\mu$ Controlador é que essa contagem é feita por um periférico independente e não demanda processamento do mesmo, permitindo que o código implementado seja executado em paralelo à contagem dos pulsos dos dois encoders.

A eletrônica ainda é responsável por enviar comandos para o driver de potência (OSMC) que excita o motor. Para tal o $\mu$ Controlador também possui um periférico dedicado para gerar os dois sinais do tipo PWM paralelamente à execução do código de controle.

A programação do $\mu$ Controlador é feita utilizando ICSP (através de um gravador de dsPICs externo) sem a necessidade de retirar o mesmo do circuito. É necessário apenas disponibilizar um conector para a ligação do gravador à placa onde o $\mu$ Controlador se encontra.

A Figura 35 mostra a eletrônica de controle dos motores. 


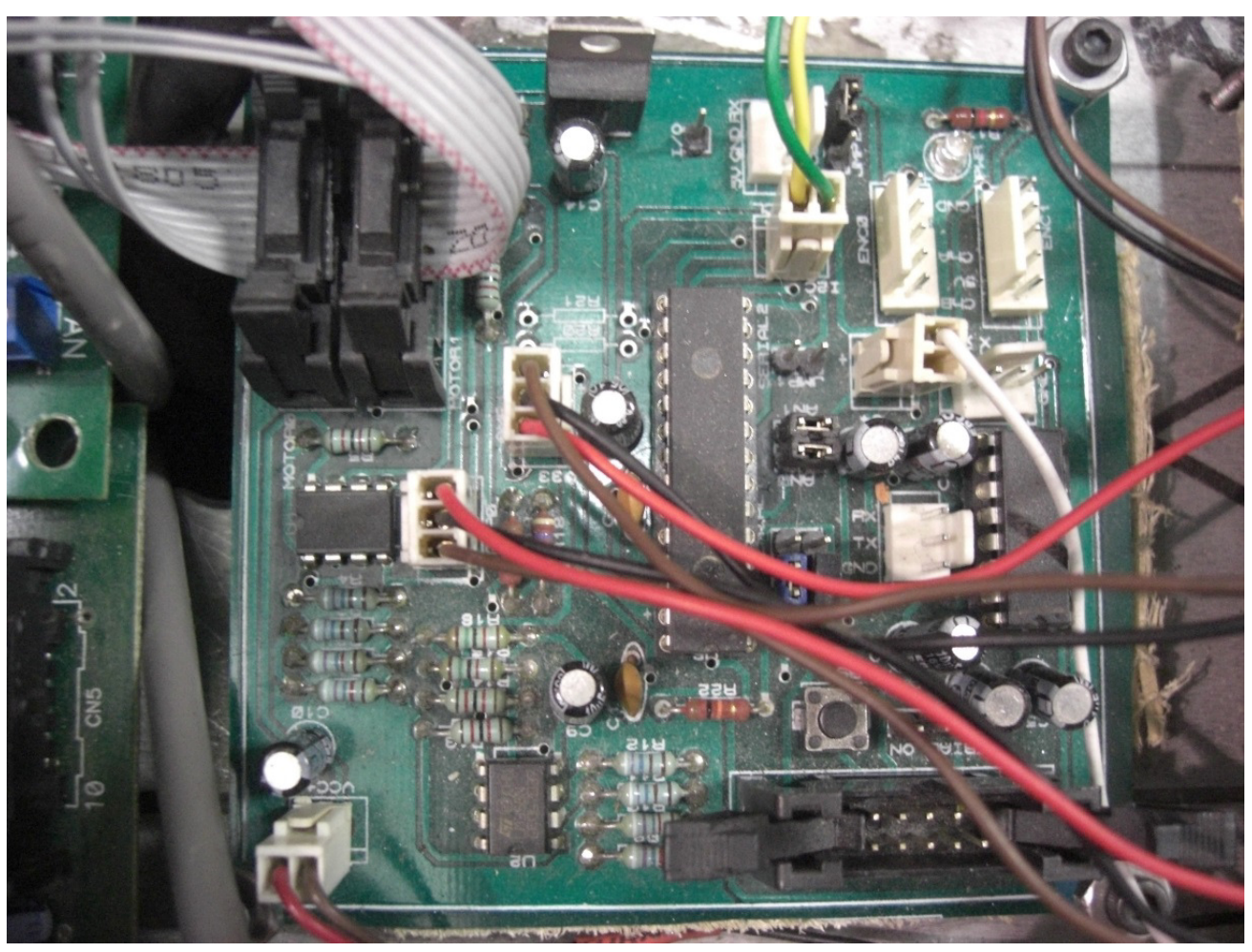

Figura 35: Eletrônica de controle dos motores do veículo robótico.

\subsection{3. \\ Firmware das eletrônicas}

Foi desenvolvido um firmware para cada uma das eletrônicas utilizadas nos experimentos. Esta seção descreve as funcionalidades básicas de cada.

As três eletrônicas embarcadas se comunicam através do protocolo serial $\mathrm{I}^{2} \mathrm{C}$. Em comum, os firmwares possuem três estados de funcionamento: inicialização, execução e falha. O estado de inicialização só termina depois que um comando de WakeUp é enviado às eletrônicas. Em seguida o modo de execução é iniciado e os algoritmos são executados normalmente. Durante o modo de execução, o modo de falha pode ser acionado a qualquer momento via comando de rádio ou devido ao mau funcionamento de algum componente do sistema.

A Figura 36 mostra o fluxograma do firmware das eletrônicas dsPIC $_{D}$ e dsPIC $_{\mathrm{T}}$. Antes do estado de execução, as eletrônicas realizam configurações internas do próprio $\mu$ Controlador e em seguida leem os sensores e processam apenas comandos de configuração, aquisição de dados e de WakeUp. Uma vez 
que o modo de execução do sistema se inicia (mediante o comando WakeUp), o loop principal verifica novos comandos, lê sensores, verifica erros no sistema e executa os algoritmos desenvolvidos. Este último depende de um flag ativado pela eletrônica principal $\mathrm{ARM}_{\mathrm{E}}$. As fontes de erros verificadas pelo firmware são a tensão das baterias de alimentação e ligação com os motores. Caso a tensão nas baterias de alimentação dos motores esteja abaixo de $21 \mathrm{~V}$, e/ou um sinal de comando faça o motor girar no sentido contrário, e produza uma corrente também no sentido contrário, o modo de falha é acionado e o código de erro correspondente é enviado à eletrônica principal.

O firmware da eletrônica principal é mais complexo, e suas funcionalidades básicas podem ser vistas na Figura 37. Durante sua inicialização, além das configurações do $\mu$ Controlador, uma leitura de teste é feita com todos os sensores e com as eletrônicas dsPIC $\mathrm{T}_{\mathrm{T}}$ e dsPIC $\mathrm{D}_{\mathrm{D}}$ e a configuração do OpenLOG é feita. Caso alguma leitura não seja bem sucedida, ou o OpenLOG produza algum erro de comunicação, um erro de inicialização é produzido, colocando o sistema automaticamente em modo de falha. Em seguida, o sistema aguarda o comando de WakeUp da base para iniciar a execução do código principal. Enquanto o WakeUp não é dado, a base pode apenas reconfigurar os parâmetros do sistema.

Depois de "acordado", o sistema começa a executar seu loop principal. Nele todos os sensores do sistema são lidos e os motores podem ser acionados de três maneiras distintas: pelo controle principal onde os torques são calculados pelo algoritmo de controle, por comandos de torque ou de tensão vindos diretamente da base. 


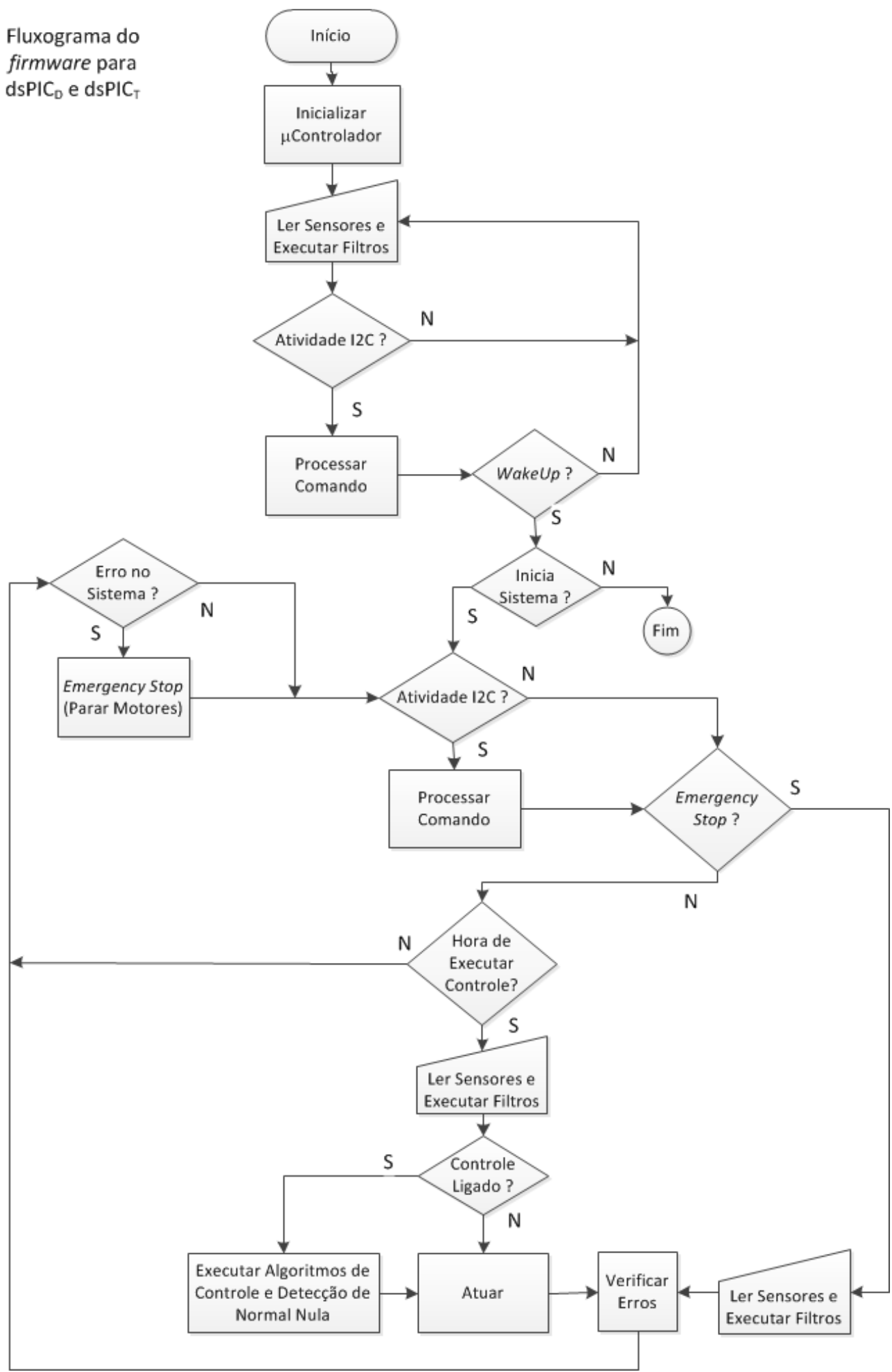

Figura 36: Fluxograma do firmware das eletrônicas dsPIC $\mathrm{D}_{\mathrm{D}}$ e dsPIC $\mathrm{C}_{\mathrm{T}}$. 


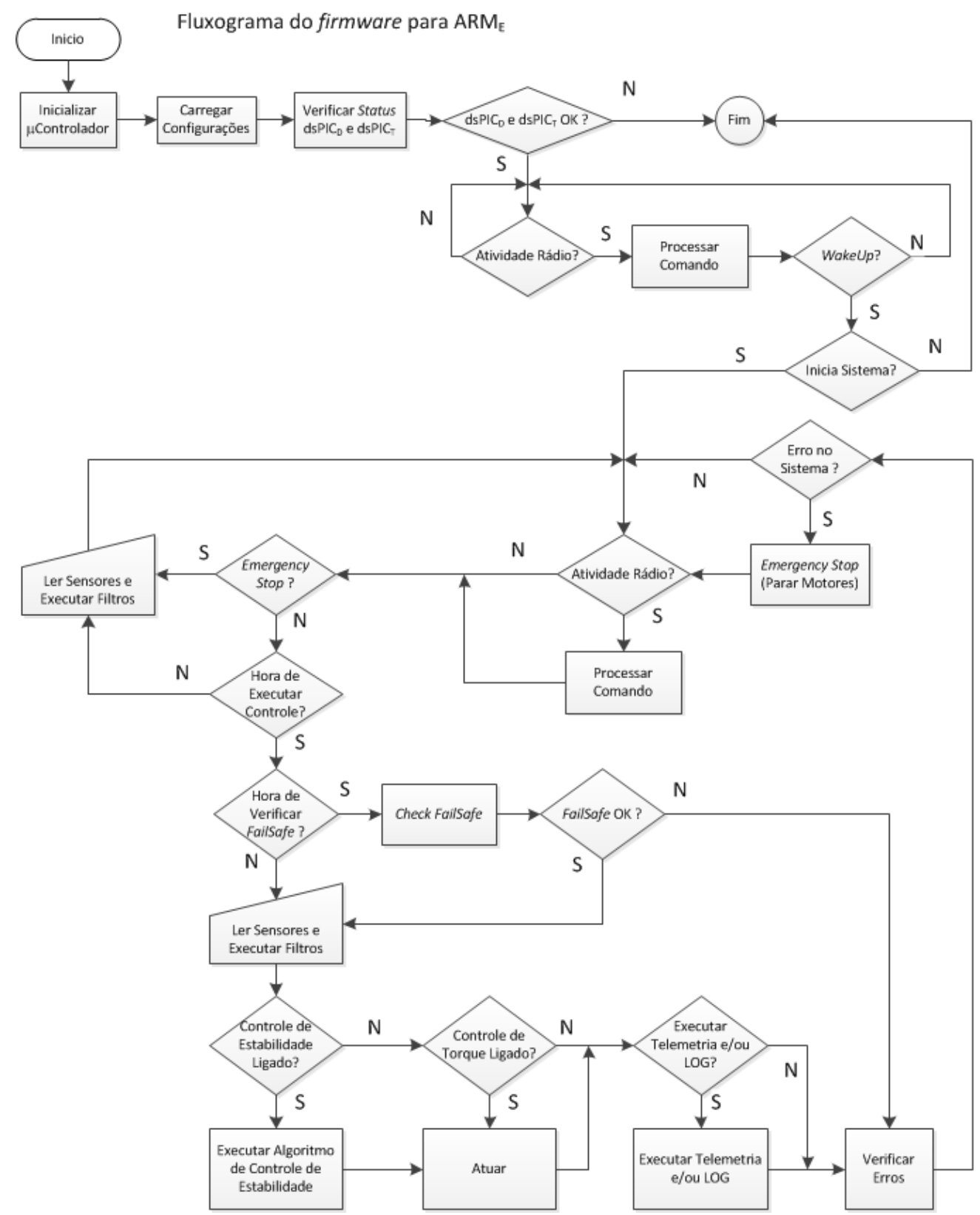

Figura 37: Fluxograma do firmware da eletrônica $\mathrm{ARM}_{\mathrm{E}}$.

O firmware pode enviar dados para telemetria a uma frequência de $5 \mathrm{~Hz}$ ou armazená-los no cartão de memória a uma frequência de $10 \mathrm{~Hz}$. Os dados a serem enviados ou armazenados são selecionados pela base. Essas frequências podem ser maiores, mas o custo da execução de cada uma é muito grande e pode atrapalhar os algoritmos implementados.

Se o sistema não receber qualquer comando da base por mais de um segundo, um byte de verificação é enviado para a base e uma resposta é aguardada 
(FailSafe). Caso a resposta não chegue, o sistema entra em modo de falha. $\mathrm{O}$ sistema também entra em modo de falha se a tensão na bateria que alimenta a eletrônica embarcada for menor que $7 \mathrm{~V}$.

\section{3.}

\section{Software de controle do sistema}

Foi desenvolvido um software em LabVIEW para interagir com o sistema. Dele é possível configurar as eletrônicas (ajustando a frequência dos loops de controle, ganhos de controladores etc.), enviar setpoints, tensões nos motores, ligar/desligar telemetria e/ou log de dados, ligar/desligar filtros e gravar dados de telemetria. Por ele é possível também visualizar os dados gravados no cartão microSD durante o $\log$ de dados.

O software possui ainda leds mostrando o status do sistema que compreende, além dos erros possíveis em cada uma das eletrônicas (como sensores com falha, baterias fracas e motores ligados com polaridades invertidas), indicação de algoritmos de controle ligados/desligados, telemetria e/ou log ligados/desligados.

Por segurança, ele possui também um grande botão para parar os motores (Emergency Stop), comando este também acessível pela tecla 'esc' do teclado. A Figura 38 e a Figura 39 mostram as interfaces desenvolvidas para o sistema.

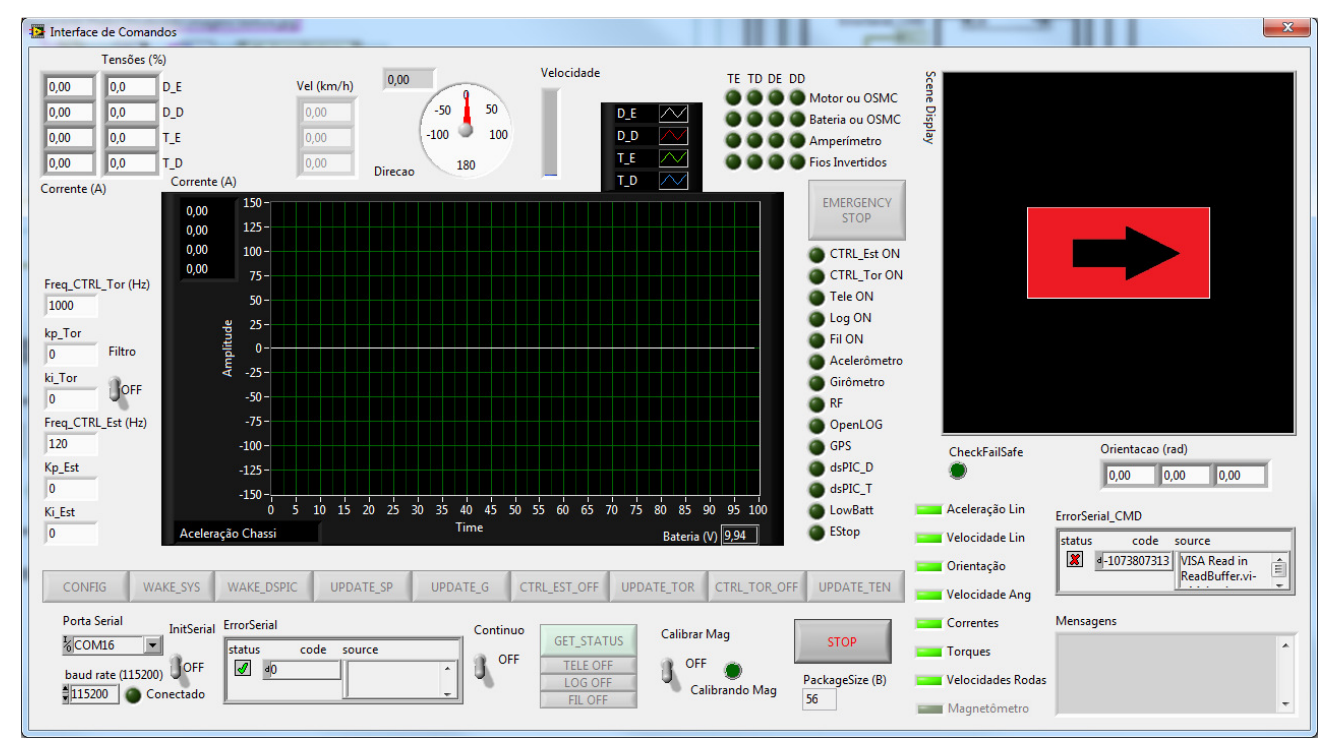

Figura 38: Interface principal do software de comando desenvolvido em LabVIEW. 


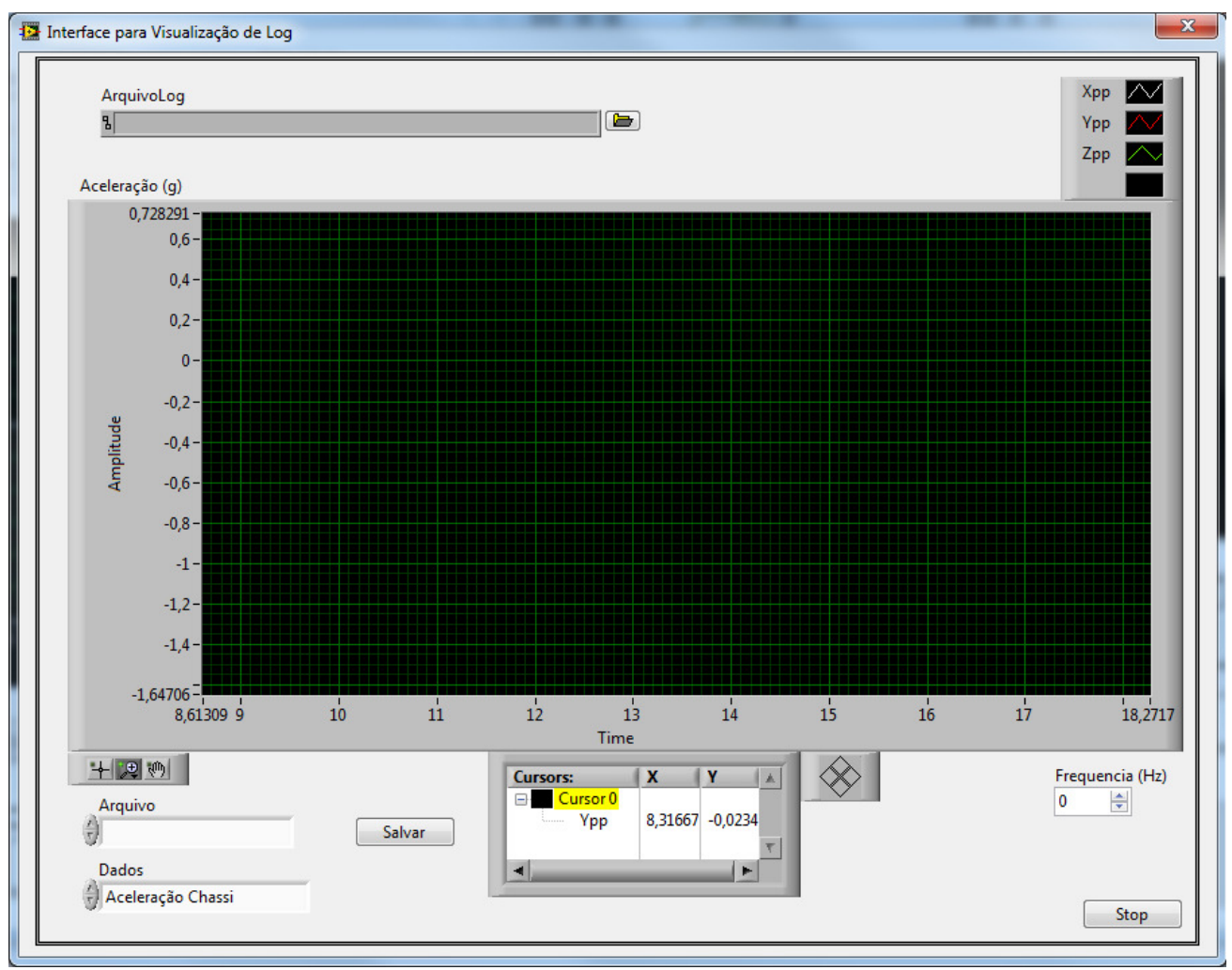

Figura 39: Interface secundária do sistema desenvolvido utilizada para leitura dos arquivos de $\log$.

\section{4 .}

\section{Simulações}

A seguir são mostradas as simulações utilizando os algoritmos desenvolvidos na pesquisa. O limiar usado na decisão sobre o descolamento das rodas foi de $+/-1 \mathrm{Nm}$.

\subsection{1.}

\section{Estimativa do torque externo}

Duas simulações foram feitas para demonstrar o funcionamento do algoritmo. Em ambas, um perfil de tensão de alimentação de $20 \mathrm{Vpp}$ com um offset de $5 \mathrm{~V}$ e uma frequência de $0,2 \mathrm{~Hz}$, foi aplicado às rodas. $\mathrm{Na}$ primeira, o veículo foi simulado em uma bancada sem encostar as rodas no chão, e o perfil de torque externo mostrado na Figura 40 foi aplicado à roda. Na segunda, o veículo foi simulado em um terreno plano e horizontal. 
Nas legendas dos gráficos, TD, DD e DE significam respectivamente traseiro direito, dianteiro direito e dianteiro esquerdo. Como a tensão de excitação e o torque externo são os mesmos para todas as rodas, seus comportamentos serão muito próximos. Só haverá uma diferença significativa no início da simulação do veículo no segundo teste quando em contato com o chão, onde a aceleração do mesmo altera a distribuição das normais sobre as rodas, variando o torque aplicado em cada uma delas.

Essa semelhança permite colocar no mesmo gráfico, respostas de três rodas diferentes para comparações entre informação sem ruído, com ruído e com ruído filtrado. Essas comparações são necessárias para comentar os resultados do algoritmo.

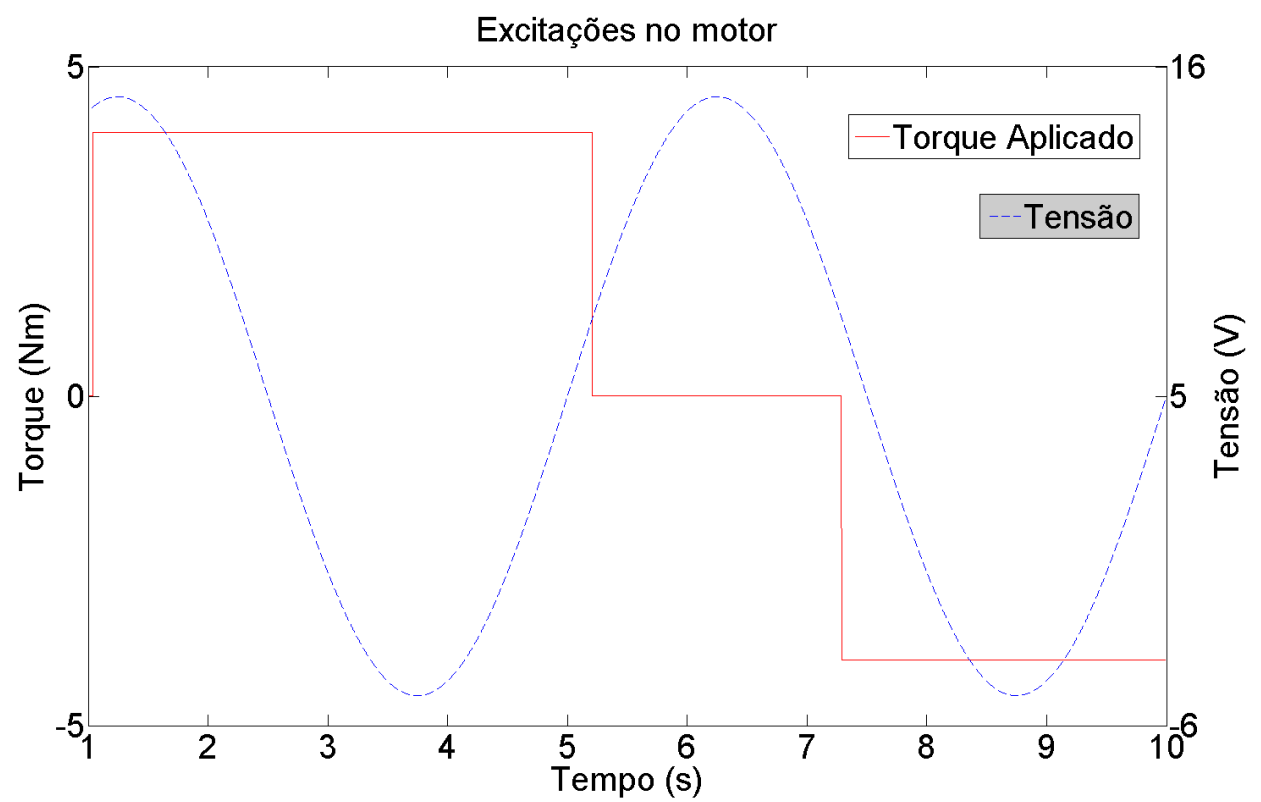

Figura 40: Excitações no motor na simulação para estimativa do torque externo.

Na primeira simulação, o torque externo aplicado aos motores possui três valores distintos $(4,0 ; 0,0 ;-4,0)$. A Figura 41 e a Figura 42 mostram o comportamento das rodas durante a simulação. 


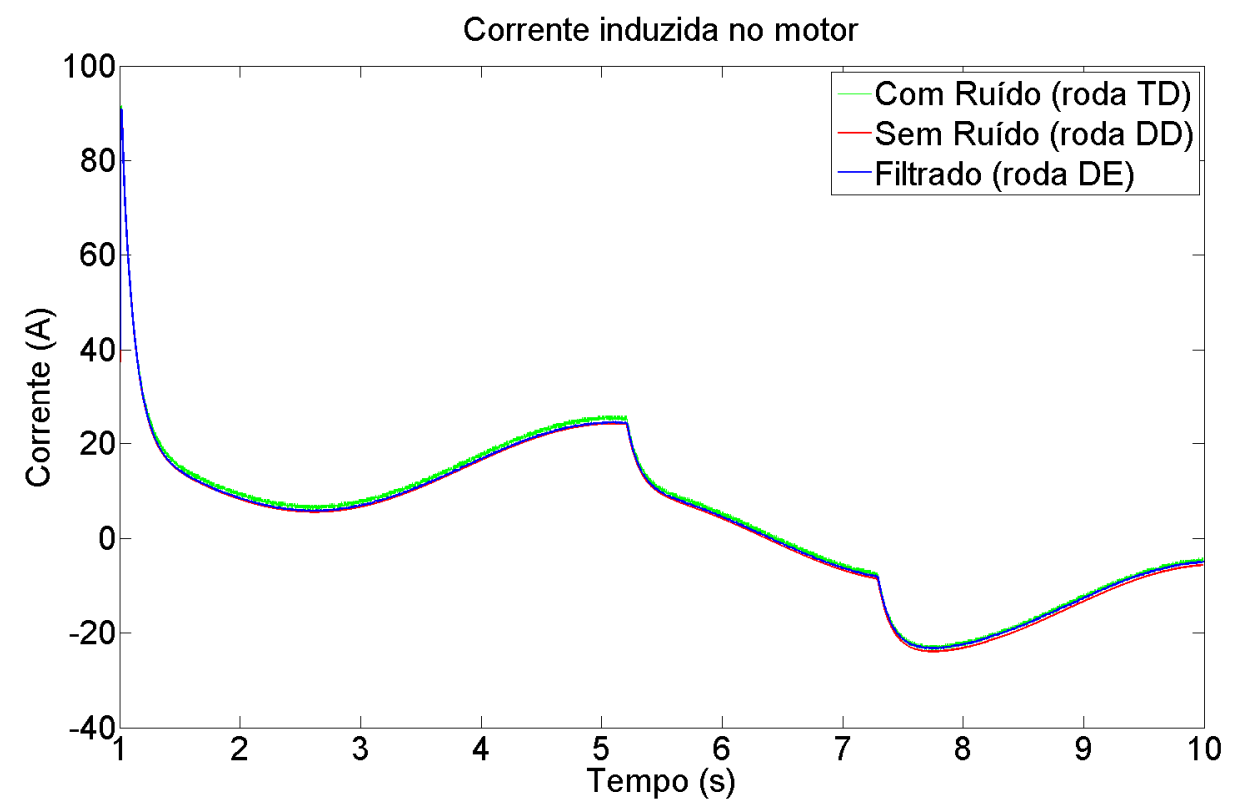

Figura 41: Corrente nos motores durante a primeira simulação em que as rodas não encostam no chão, mas são excitadas com a mesma tensão e o mesmo torque externo.

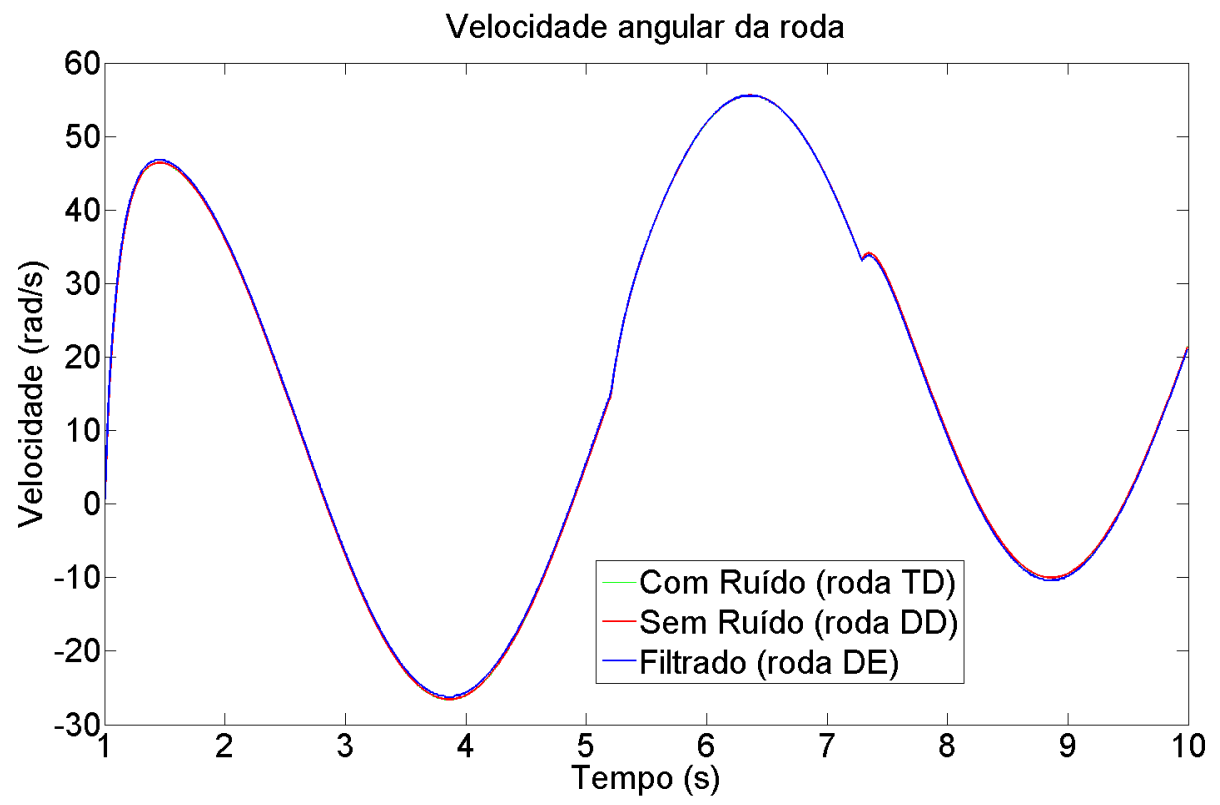

Figura 42: Velocidade angular das rodas durante a primeira simulação em que as rodas não encostam no chão, mas são excitadas com a mesma tensão e o mesmo torque externo. 
O resultado da estimativa do torque externo sobre a roda é mostrado na Figura 43. As diferenças entre a estimativa do torque e o torque aplicado se devem ao objetivo proposto pelo algoritmo e explicado em seguida.

A Figura 44 mostra uma comparação entre o comando elétrico, o torque externo e o torque estimado.

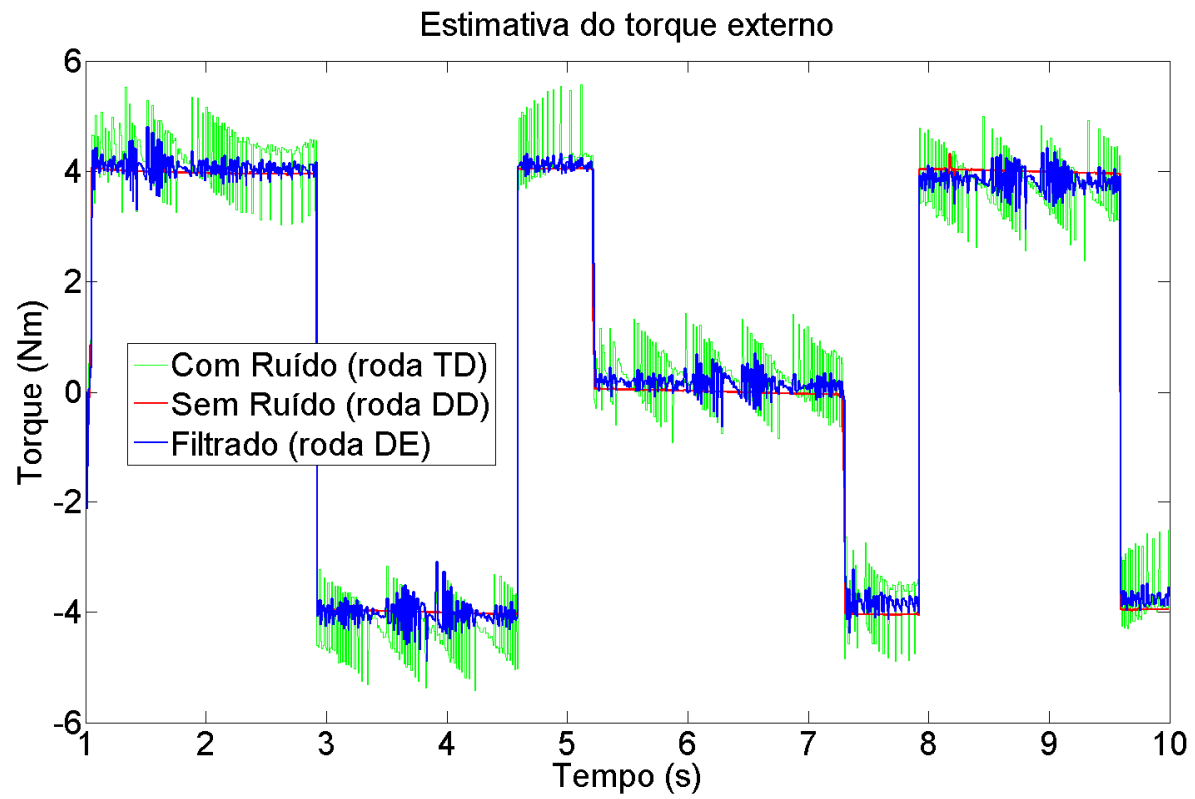

Figura 43: Estimativa do torque externo sobre as rodas durante a primeira simulação em que as rodas não encostam no chão, mas são excitadas com a mesma tensão e o mesmo torque externo.

$\mathrm{Na}$ Figura 44 foi utilizada a estimativa sobre a roda dianteira direita cujos sensores foram simulados sem a introdução de ruído. Examinando a Figura 44, tem-se que entre os instantes $\mathrm{A}$ e B tanto o torque externo quanto o comando são positivos, resultando em uma estimativa positiva do torque externo. $\mathrm{O}$ mesmo acontece no intervalo de $\mathrm{C}$ a $\mathrm{E}$. De $\mathrm{B}$ à $\mathrm{C}$ o torque externo permanece positivo mas a tensão de comando passa a ser negativa. Nesse caso o torque externo está agindo a favor do comando, fornecendo uma estimativa negativa do mesmo. Um caso similar mas com sinais trocados pode ser visto no intervalo entre E e F. Finalmente no último intervalo tanto a tensão de comando quanto o torque externo são negativos, produzindo uma estimativa positiva por motivo semelhante ao do intervalo $\mathrm{AB}$. 


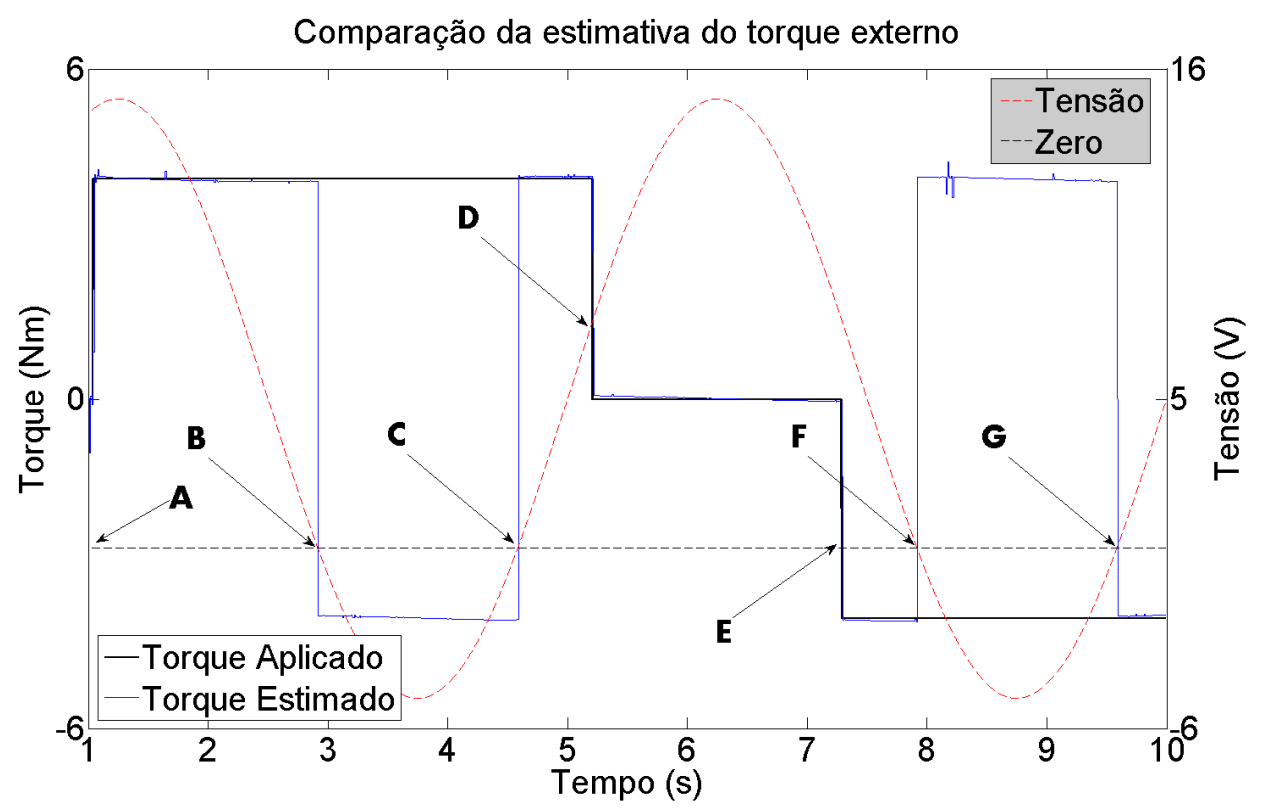

Figura 44: Comparação entre os sinais de comando elétrico sobre o motor, o torque externo aplicado e a estimativa do mesmo.

A Figura 45 mostra um detalhe que ilustra a causa do ruído na estimativa do torque externo, visto na Figura 43. A simulação dos sensores procurou fornecer os mesmos desafios encontrados em aplicações práticas. Uma delas é que a resolução da informação de velocidade de rotação produzida por um encoder depende da relação entre taxa de aquisição e a velocidade do eixo e da resolução do disco de óptico. Essa combinação acaba gerando degraus na medida fornecida como pode ser visto na curva "Com Ruído (roda TD)" da Figura 45. O ruído nesse caso não é aleatório como o encontrado tipicamente em sensores analógicos e sim um ruído de quantização normalmente visto em sensores cujos valores analógicos são lidos por meio de conversores analógicos-digitais (ADC).

A estimativa do torque externo depende do inverso da matriz $\underline{\Gamma}$ que relaciona o quanto o estado é influenciado pela excitação. Para a parte mecânica do motor simulado na pesquisa, a inversa de $\underline{\Gamma}$ possui uma amplificação de módulo igual a 7,5613 se discretizados a um período de $1 \mathrm{~ms}$. Como mostra a Figura 45, a variação da leitura do encoder é da ordem de $0,3 \mathrm{rad} / \mathrm{s}$, o que implica em uma variação na estimativa de aproximadamente $2,2 \mathrm{Nm}$ para o torque externo. Para minimizar esse efeito, foi introduzido um filtro de Kalman na 
simulação e seu resultado pode ser visto na curva do gráfico referente à roda dianteira esquerda.

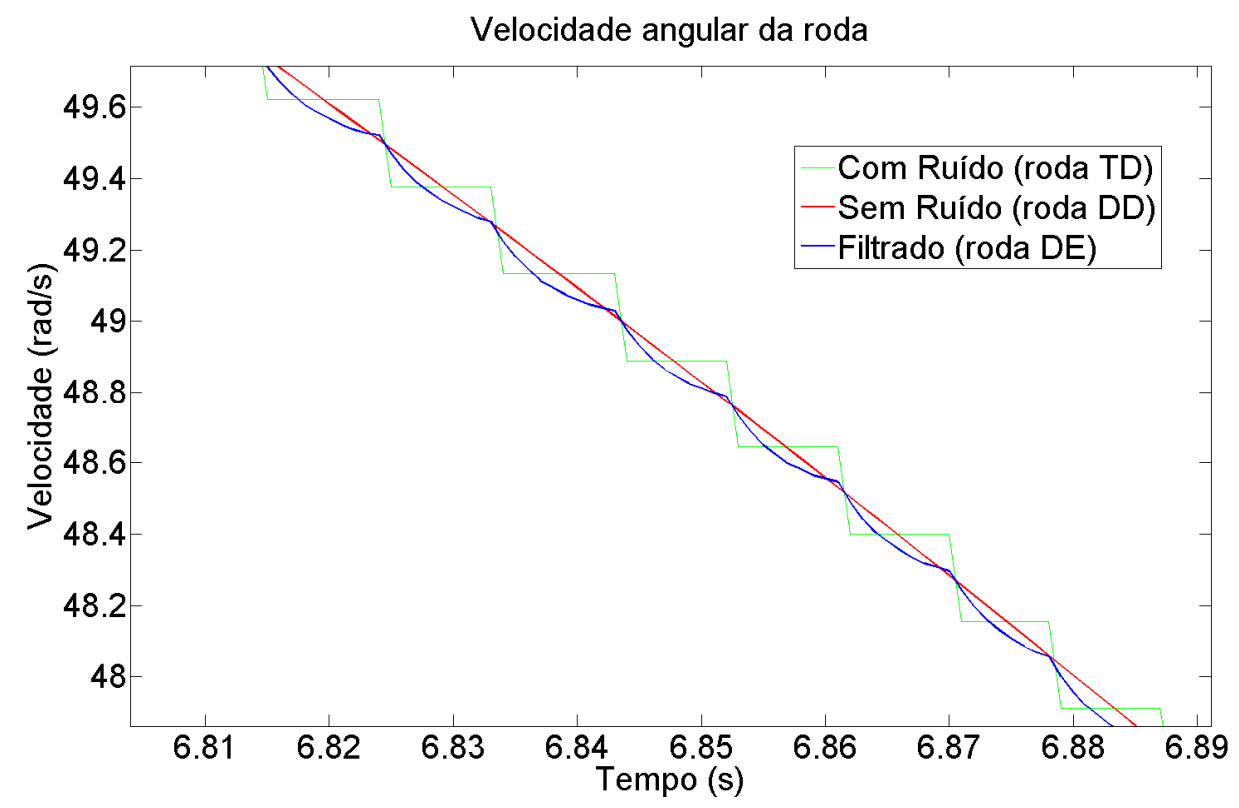

Figura 45: Detalhe da forma de onda simulada para o encoder.

Na segunda simulação, uma excitação elétrica de mesma amplitude, mas com metade da frequência foi aplicada sobre o veículo em contato com o terreno. A Figura 46 e a Figura 47 mostram o comportamento do estado ao longo da simulação. 


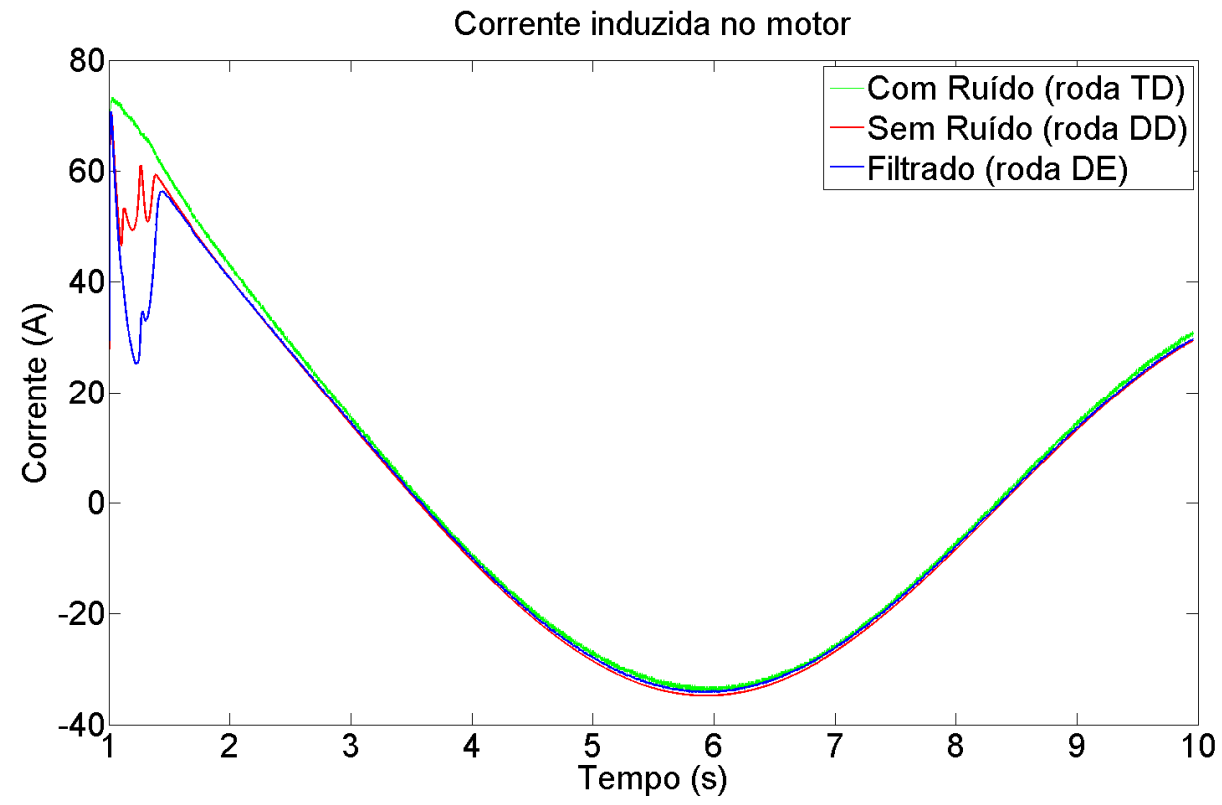

Figura 46: Corrente nos motores durante a segunda simulação em que as rodas encostam no chão e são excitadas com a mesma tensão.

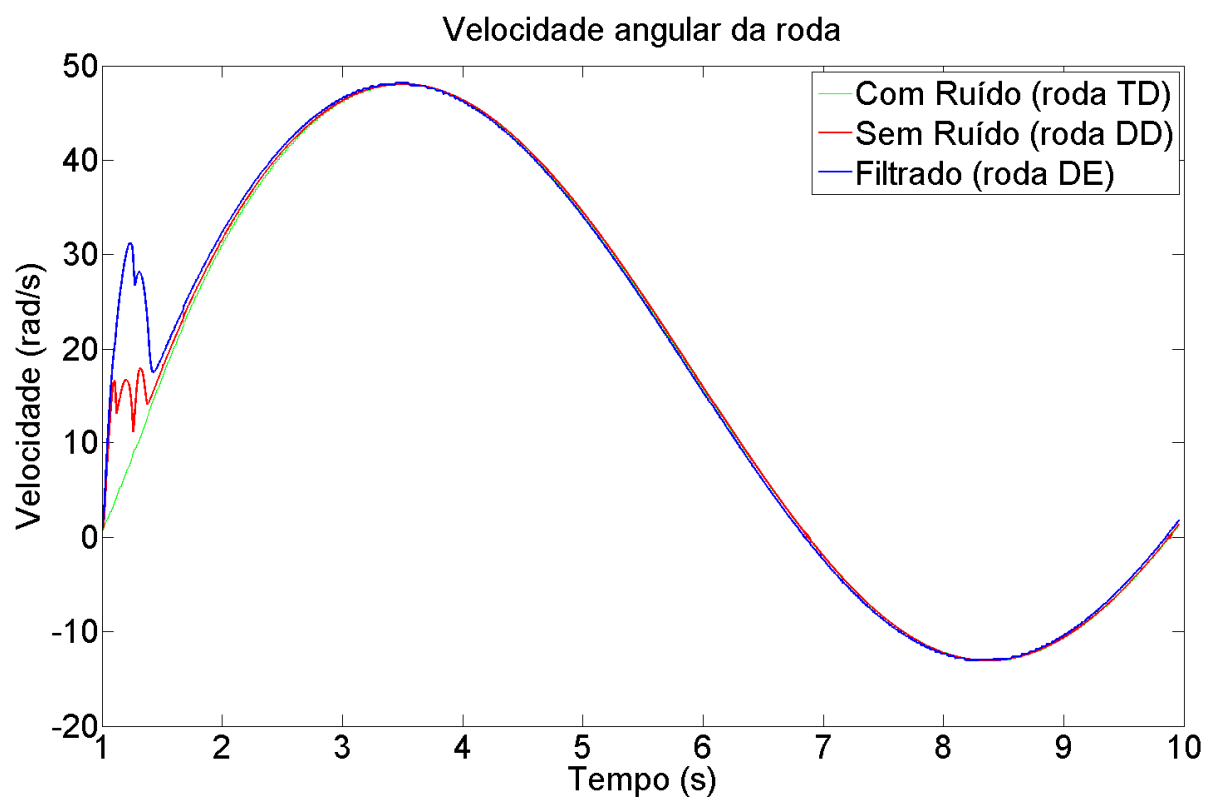

Figura 47: Velocidade angular das rodas durante a segunda simulação em que as rodas encostam no chão e são excitadas com a mesma tensão.

A suavidade da excitação ao longo da simulação permitiu que o veículo se movesse sem grandes acelerações, permitindo a comparação entre o comportamento de três rodas diferentes. Essa condição só não é verdade nos primeiros $2 \mathrm{~s}$ de simulação quando uma tensão de aproximadamente $20 \mathrm{~V}$ é 
aplicada subitamente. Essa atuação provoca uma aceleração no veículo que diminui a força normal sobre as rodas dianteiras. Essa variação, por sua vez, diminui a força de atrito nessas rodas aumentando as suas velocidades de rotação. Esse comportamento pode ser comprovado pela diferença entre as velocidades angulares das rodas dianteiras e a velocidade angular da roda traseira direita. Este comportamento também pode ser visto na Figura 46 com a diminuição da corrente drenada pelos motores da rodas dianteiras, tendo em vista que a força de atrito é menor, exigindo menos torque dos atuadores.

Passado os $2 \mathrm{~s}$ iniciais da simulação todas as rodas passam a ter aproximadamente a mesma velocidade, permitindo uma comparação entre seus comportamentos.

A Figura 48 apresenta a estimativa do torque externo sobre as rodas durante a segunda simulação.

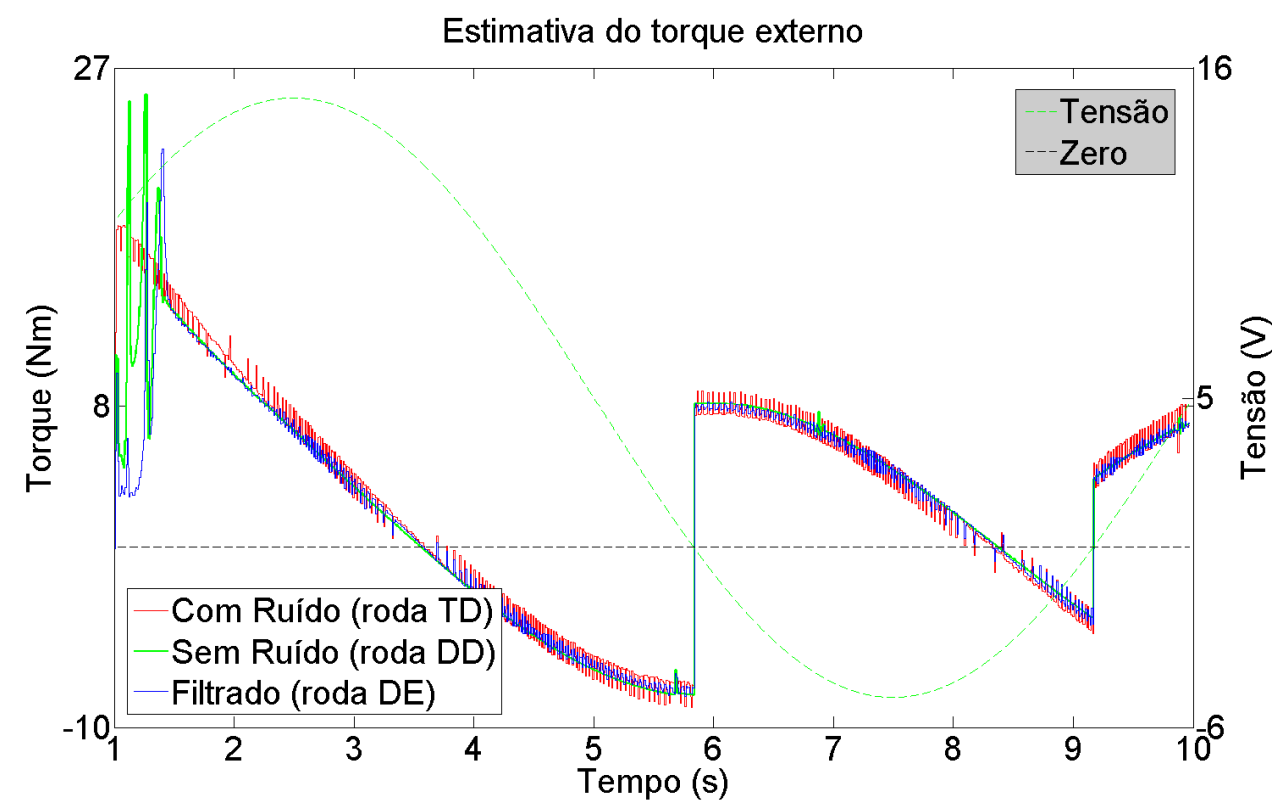

Figura 48: Simulação com a estimativa do torque externo em terreno plano e horizontal.

Para uma melhor análise do comportamento do algoritmo, foram inseridas na mesma figura a estimativa do torque externo, a aceleração do centro de massa do veículo e a tensão de comando, como pode ser visto na Figura 49. 


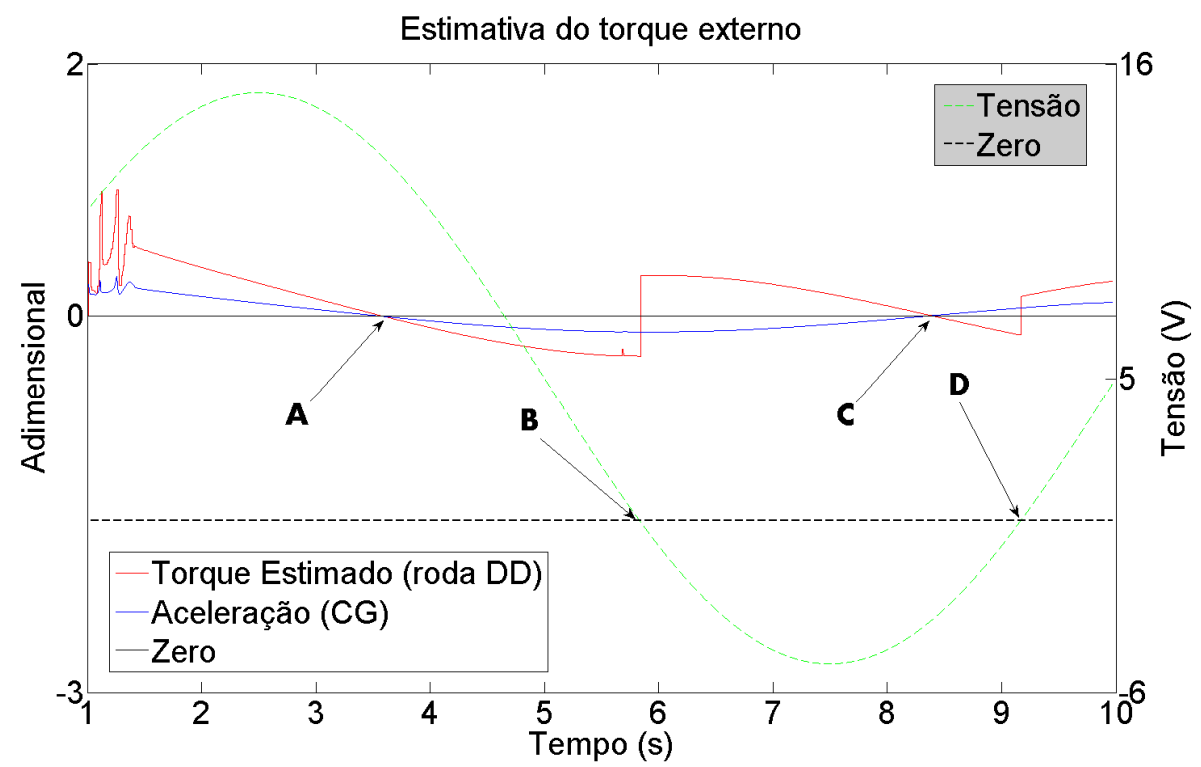

Figura 49: Comparação entre os sinais de comando elétrico sobre o motor, a estimativa do torque externo e a aceleração do centro de massa do veículo.

Foram destacados na figura acima quatro momentos durante a segunda simulação. Do início da simulação até o instante A o veículo está sendo acelerado. Nesta situação, a inércia do veículo se opõe ao sinal de comando, resistindo ao movimento. A partir desse instante, a velocidade das rodas é maior que a comandada pela tensão aplicada e o motor passa a funcionar no modo freio (corrente negativa que pode ser vista na Figura 46 entre $3 \mathrm{~s}$ e 4 s), causando uma aceleração negativa. No entanto, a tensão de comando continua positiva, e do ponto de vista do controle, a inércia passa a ajudar o comando, produzindo uma estimativa negativa do torque externo. Essa situação se mantém até o instante B, quando a tensão passa a ser negativa, causando um salto para valores positivos da estimativa. Nesse ponto, a quantidade de movimento linear do veículo continua para frente, mas o comando de tensão é negativo, indicando ao algoritmo que há um torque resistindo ao comando. Em C ocorre a mesma situação analisada em A, mas com sinais trocados, onde a velocidade da roda em módulo passa a ser maior que a referente à tensão aplicada. Nessa situação, o motor volta a funcionar em modo freio (ou gerador), produzindo uma corrente positiva. A partir de D o comando passa a ser positivo e contrário ao movimento (velocidade negativa que pode ser vista na Figura 47 próximo dos 9 s). 
A Figura 49 mostra uma fonte para a detecção de falsos-positivos pelo algoritmo. Nos instantes A e C, o algoritmo detectaria uma situação de descolamento da roda devido à estimativa nula do torque externo. No entanto sabe-se que a roda está em contato com terreno durante toda a simulação. Essas situações podem acontecer quando a aceleração longitudinal do veículo é nula ou quando a gravidade está a favor do movimento. Para o caso em que a aceleração longitudinal é nula, pode-se considerar que ou o veículo está em velocidade de cruzeiro sobre um terreno plano e horizontal ou está no meio de uma manobra (como reversão de velocidade). Na segunda hipótese, o instante de tempo tende a ser curto, acarretando em breves falsos-positivos. A primeira hipótese só será verdadeira em sistemas sem atrito algum.

Foram feitas duas simulações, uma para o caso com perdas no sistema e outra para o caso sem perdas. Em ambas as simulações o veículo foi excitado com $10 \mathrm{~V}$ nos quatro motores em um terreno plano e horizontal. As perdas foram simuladas como um atrito viscoso de $0,4 \mathrm{Ns} / \mathrm{m}$ que, na velocidade máxima do veículo, corresponde a um quinto da força máxima de impulsão do sistema de atuação. A Figura 50 mostra a estimativa do torque externo para os casos em que não há atrito ou qualquer tipo de perdas no sistema e para sistemas ideais, sem perdas.

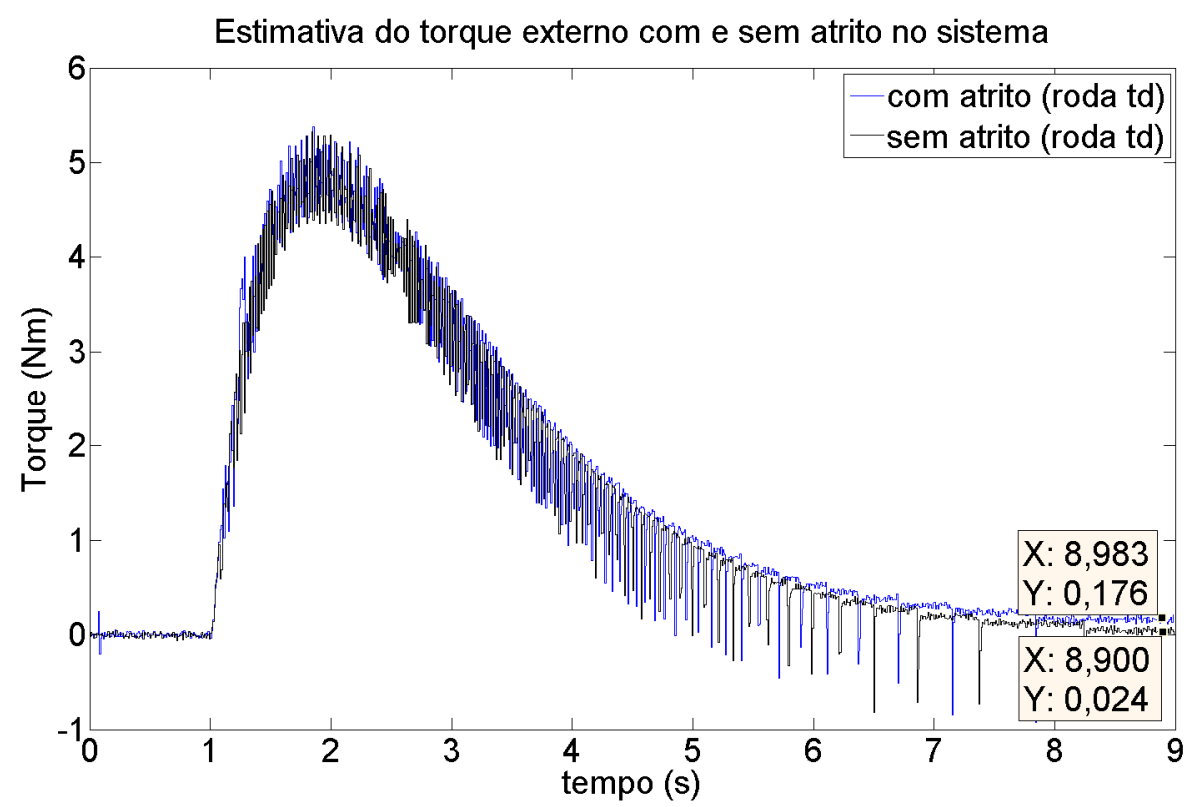

Figura 50: Comparação entre a estimativa de torque externo para o sistema com perdas por atrito viscoso e sem perdas. 
Para a simulação foram usadas as leituras dos sensores com ruído. O valor final da estimativa do torque externo para o caso com atrito foi sete vezes maior. Um valor de limiar para a decisão sobre o descolamento ou não da roda pode ser obtido após um ensaio de velocidade cruzeiro do veículo. Com esse valor, mesmo que a velocidade longitudinal do veículo não varie, o algoritmo continuará detectando contato com o terreno.

Para o caso em que manobras sejam realizadas e eventualmente o torque externo sobre a roda for nulo, e assumindo que esses instantes sejam breves, o sistema de controle deverá adotar um tempo mínimo de detecção positiva para efetivamente considerar que a roda descolou.

\subsection{2. \\ Detecção e controle da fase balística}

Simulações para teste do algoritmo de controle foram feitas em dois diferentes cenários com velocidade desejada de $10 \mathrm{~m} / \mathrm{s}$. No primeiro o veículo é acelerado até estabilizar a velocidade desejada e uma rampa de $3 \mathrm{~m}$ é colocada em frente como obstáculo. No segundo, depois de estabilizada a velocidade, um degrau invertido de $3 \mathrm{~m}$ é posto a frente. $\mathrm{O}$ desempenho dos algoritmos propostos é comparado ao desempenho de um controlador de velocidade simples que mesmo durante a fase balística tenta manter a velocidade constante.

Foram usados dois controladores PI da família PID para controlar a direção e a velocidade do veículo até o momento de contato com a rampa. Os controladores tiveram suas constantes ajustadas empiricamente por não serem o foco da pesquisa. Os valores ajustados foram: $\mathrm{Kp} \_$vel $=5,0 \mathrm{~N} / \mathrm{s} ; \mathrm{Ki} \_$vel $=1,0 \mathrm{~N}$; Kp_dir $=3,0$ Nm/rad e Ki_dir = 1,0 N/(rad.s).

O período de integração usado na simulação foi de $75 \mu \mathrm{s}$. A taxa do loop de controle de velocidade e de arfagem usada foi de $20 \mathrm{~Hz}$. Esse valor foi escolhido para simular a velocidade de processamento da eletrônica de controle embarcada no veículo usado como referência para a pesquisa. Nesse loop, estimativas e controles de parâmetros (como orientação, velocidade, aceleração, forças normais etc.) do chassi do veículo podem ser implementadas. A taxa usada para o loop de 
controle de corrente foi de $1 \mathrm{kHz}$. Nele são aquisitados e processados os sinais de corrente e velocidade de rotação dos motores. No sistema experimental, a eletrônica embarcada no veículo de referência possui um $\mu$ Controlador dedicado a cada par de rodas (dianteiras e traseiras) ao mesmo tempo. Os sinais aquisitados e processados (como a estimativa do torque externo) são usados pelo controle de mais alto nível para o controle de arfagem.

Para efeitos de simplicidade e com o objetivo de testar efetivamente o controle de arfagem, o valor simulado sem ruídos do ângulo de arfagem foi usado nas simulações.

As simulações foram executadas até que o tempo de $10 \mathrm{~s}$ se esgotasse ou até a capotagem do veículo. Como o impacto não foi durante o desenvolvimento do simulador, quase todas as simulações terminaram com a capotagem do veículo, mesmo ao retornar para o terreno com ângulo de arfagem nulo ou muito próximo de zero.

\subsubsection{1.}

Simulação com rampa

O perfil da rampa é uma curva gaussiana, descrita pela Equação (6.1), com média $\mu$ de $40 \mathrm{~m}$, desvio padrão $\sigma$ de $8 \mathrm{~m}$ e com amplitude ajustada de maneira a ter uma altura de $3 \mathrm{~m}$, resultando em uma inclinação em torno de $30 \%$. Ela foi ajustada no final da pista de maneira que o ponto mais alto fosse limite do terreno, como mostra a Figura 51.

$$
p(x, \mu, \sigma)=\frac{e^{-\frac{(x-\mu)^{2}}{2 \sigma^{2}}}}{\sqrt{2 \pi \sigma^{2}}}
$$




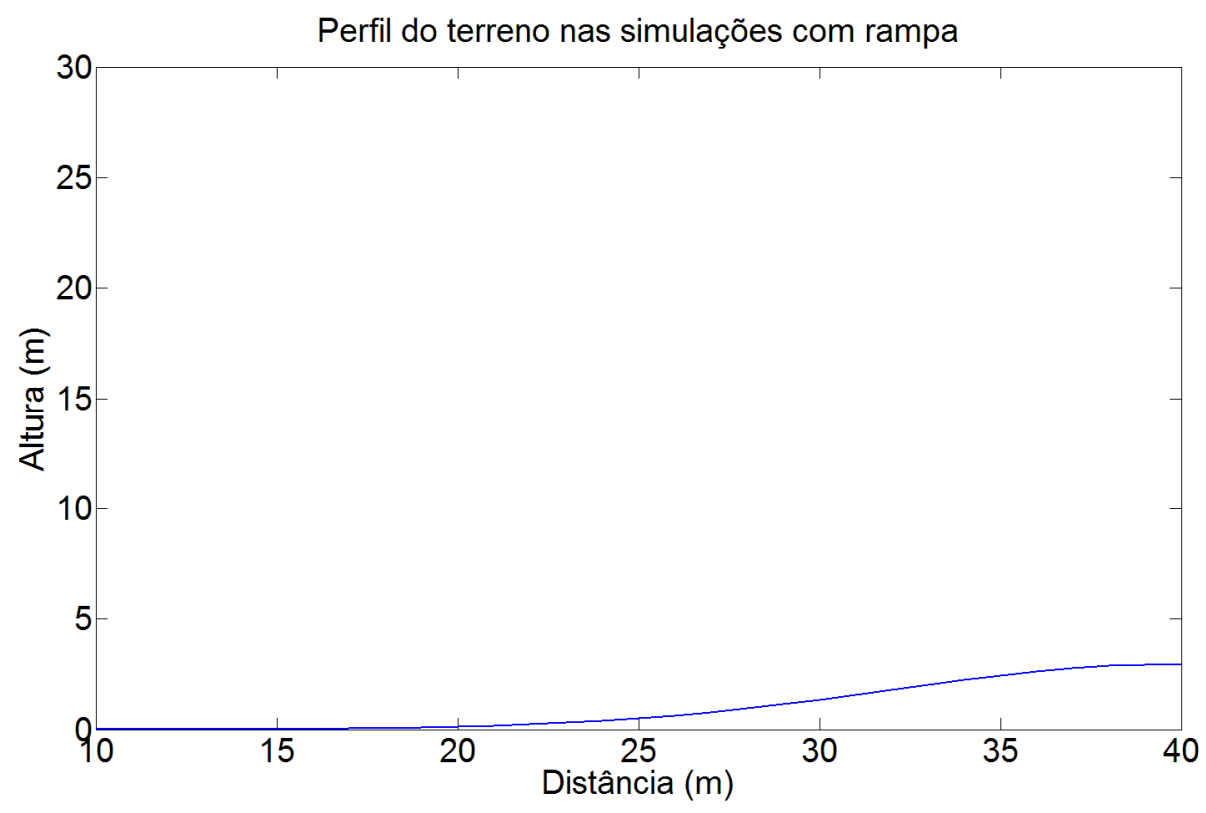

Figura 51: Perfil do terreno usado nas primeiras simulações.

A Figura 52 mostra o ângulo de arfagem e a velocidade de arfagem durante a simulação do algoritmo proposto com o terreno rampa.

$\mathrm{Na}$ primeira parte da simulação o veículo desenvolve a sua velocidade estabilizando-a pouco antes dos $5 \mathrm{~s}$, como pode ser visto pelo encontro em zero do ângulo com a velocidade de arfagem. O encontro com a rampa ocorre depois dos $5 \mathrm{~s}$ de simulação. A partir desse instante o veículo começa a subi-la, evidenciado pelo crescimento do ângulo de arfagem. A rigidez dos pneus fazem o veículo vibrar durante a subida deixando a leitura da velocidade angular ruidosa. No instante em que o veículo descola as rodas da rampa, o algoritmo ainda se encontra em estado de alerta aguardando uma confirmação da fase balística. Esse tempo de espera pode ser visto no breve instante próximo aos $7 \mathrm{~s}$ em que a velocidade angular é constante e o ângulo decresce linearmente. Isso ocorre, pois no estágio de alerta (terceiro estágio) do algoritmo de controle de arfagem proposto os torques do controle de velocidade e de direção são sobreescritos por torques nulos, até que a confirmação da fase balística seja feita. Após a confirmação da fase balística, o controle calcula os torques necessários para a convergência do ângulo e da velocidade de arfagem para zero. 


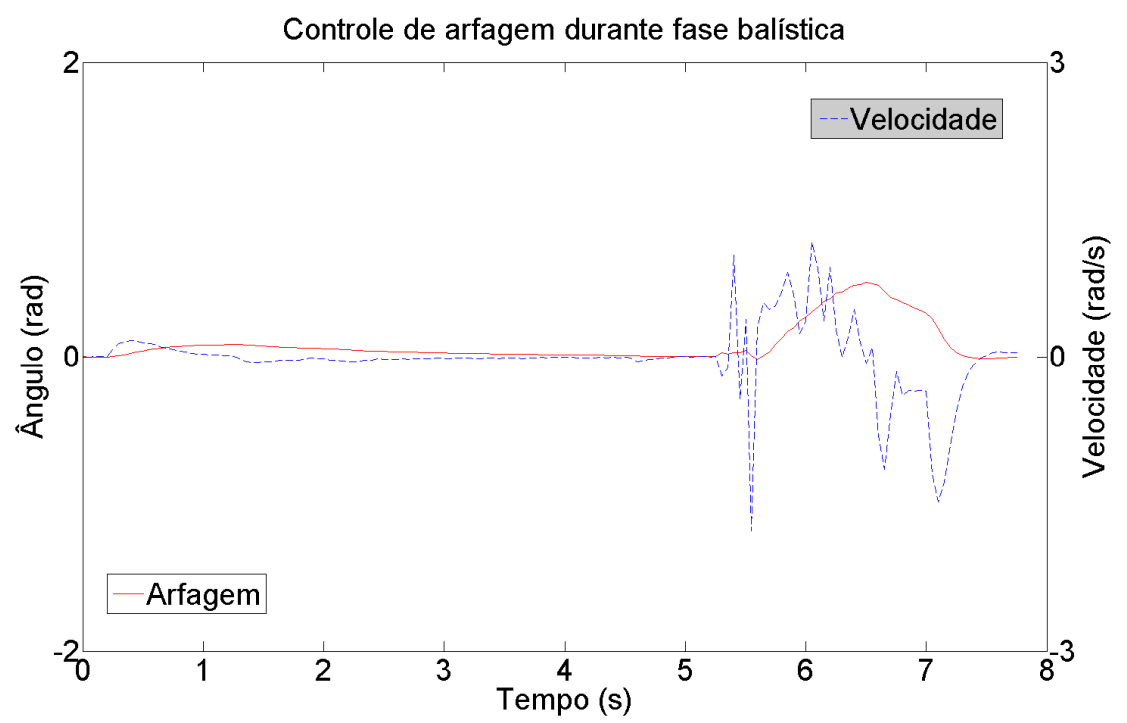

Figura 52: Progressão do ângulo e da velocidade de arfagem durante a simulação com os algoritmos propostos.

A Figura 53 mostra o somatório das forças normais calculadas no simulador juntamente com o indicador de estágios do algoritmo de detecção de fase balística.

Nela, pode-se ver a detecção de falsos-positivos de descolamento das rodas dianteiras pelo algoritmo depois que a velocidade desejada do veículo foi atingida. Essa informação pode ser interpretada como um avanço cinemático do eixo dianteiro, onde as rodas traseiras empurram as dianteiras devido à rigidez do chassi. Um pouco depois o contato com a rampa é percebido pela oscilação do somatório das forças normais. Essa oscilação segue até um pouco antes dos $7 \mathrm{~s}$, enquanto o veículo sobe a rampa. Logo após o algoritmo passa rapidamente ao estágio de alerta (estágio 2) como já foi comentado na Figura 52. Nos últimos instantes da simulação, o algoritmo de detecção da fase balística entra corretamente no estágio três e começa a executar o controle de arfagem. 


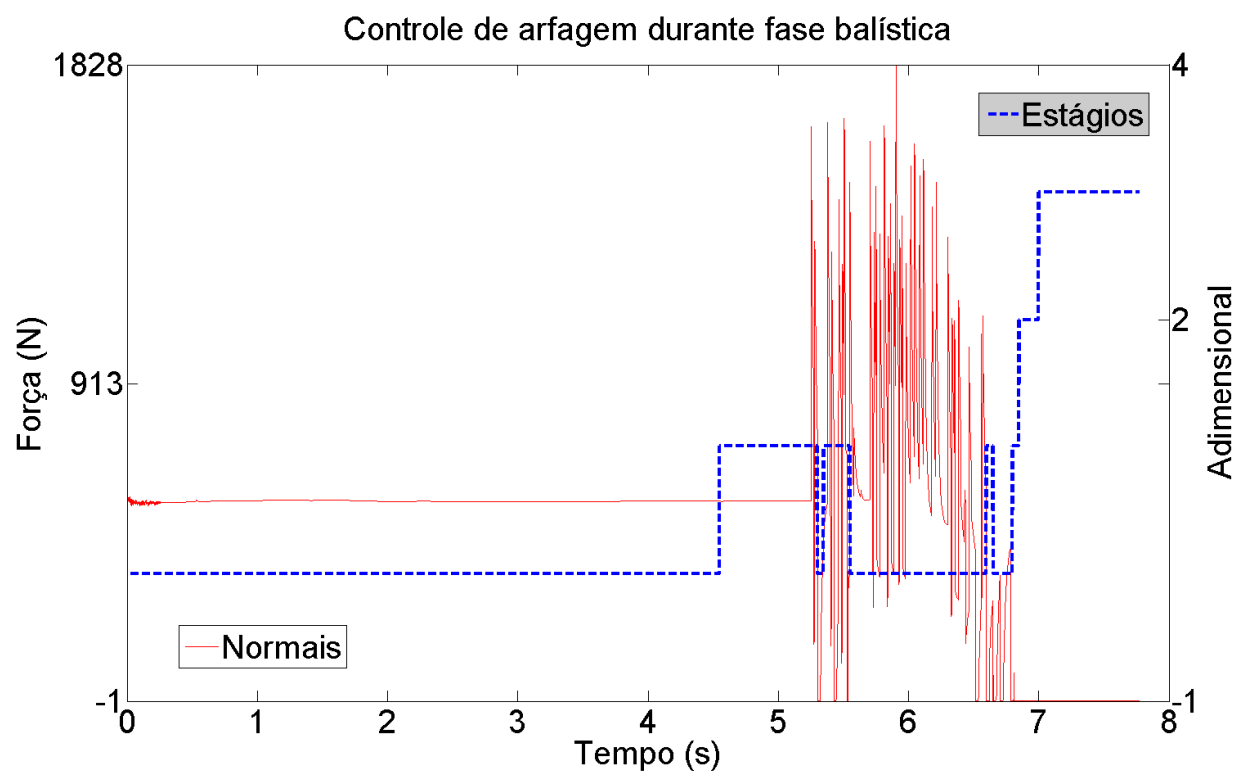

Figura 53: Somatório das forças normais e indicador de estágio do controle de arfagem durante a simulação com os algoritmos propostos.

É importante ressaltar que a alta frequência no somatório das forças normais, em torno dos seis segundos de simulação, é improvável em um sistema experimental. Sua ocorrência durante as simulações se deve ao não tratamento adequado da dinâmica do sistema quando há o contato do veículo em alta velocidade com a rampa. Para lidar com essa situação usando integração explícita, seria necessário um passo de integração muito pequeno para as equações dinâmicas, o que comprometeria a visualização do simulador em tempo real. No entanto, integração implícita não é possível para um terreno genérico.

Na Figura 54 percebe-se um longo período de aceleração do veículo até aproximadamente 4,5 s. Nesse instante falsos-positivos de descolamento das rodas dianteiras foram detectados e o comando de torque nulo foi enviado às rodas. Como o veículo estava em movimento, um comando de torque nulo representa manter a velocidade constante, evidenciado pelo período entre $4,5 \mathrm{~s}$ e $6 \mathrm{~s}$ em que a tensão fica constante. $\mathrm{O}$ encontro com a rampa é mostrado pela abrupta variação da tensão aplicada. Pela Figura 53 percebe-se que ao encontrar a rampa o algoritmo volta imediatamente para o estágio de controle de velocidade e direção. Essa variação na tensão de alimentação é então atribuída a uma correção na direção do veículo que pode ter sido desviado durante o contato com a rampa. Em 
seguida o algoritmo tenta manter a velocidade desejada durante a subida da rampa até que, próximo a $7 \mathrm{~s}$, por duas vezes, o algoritmo detecta descolamento das rodas dianteiras e a tensão se mantém constante. A partir dos $7 \mathrm{~s}$ o controle de arfagem assume o comando e a atitude do chassi do veículo é controlada.

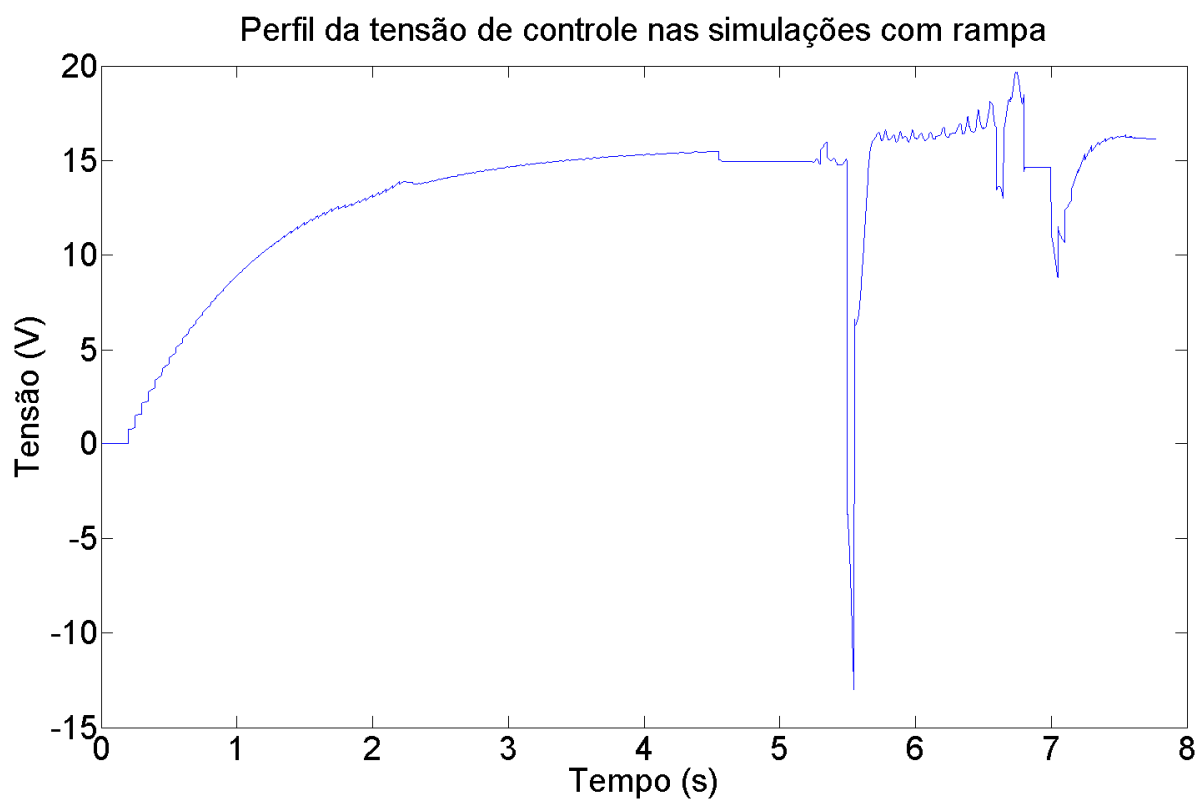

Figura 54: Perfil de tensão aplicada no motor traseiro direito durante a simulação com os algoritmos propostos.

Na simulação seguinte os mesmos controladores PI de velocidade e direção do veículo são mantidos ligados durante toda a simulação, sem a interferência do controle de arfagem. A Figura 55 mostra o ângulo e a velocidade de arfagem durante a simulação. A primeira parte da simulação é parecida com a simulação anterior, com a diferença dos instantes próximos a $5 \mathrm{~s}$. Como não há interferência do controle de arfagem, os controladores PIs podem continuar atuando nos motores para manter a velocidade desejada. Neste mesmo instante da simulação anterior, a detecção errônea de descolamento das rodas dianteiras fez com que os controladores de velocidade e direção fossem desligados. 


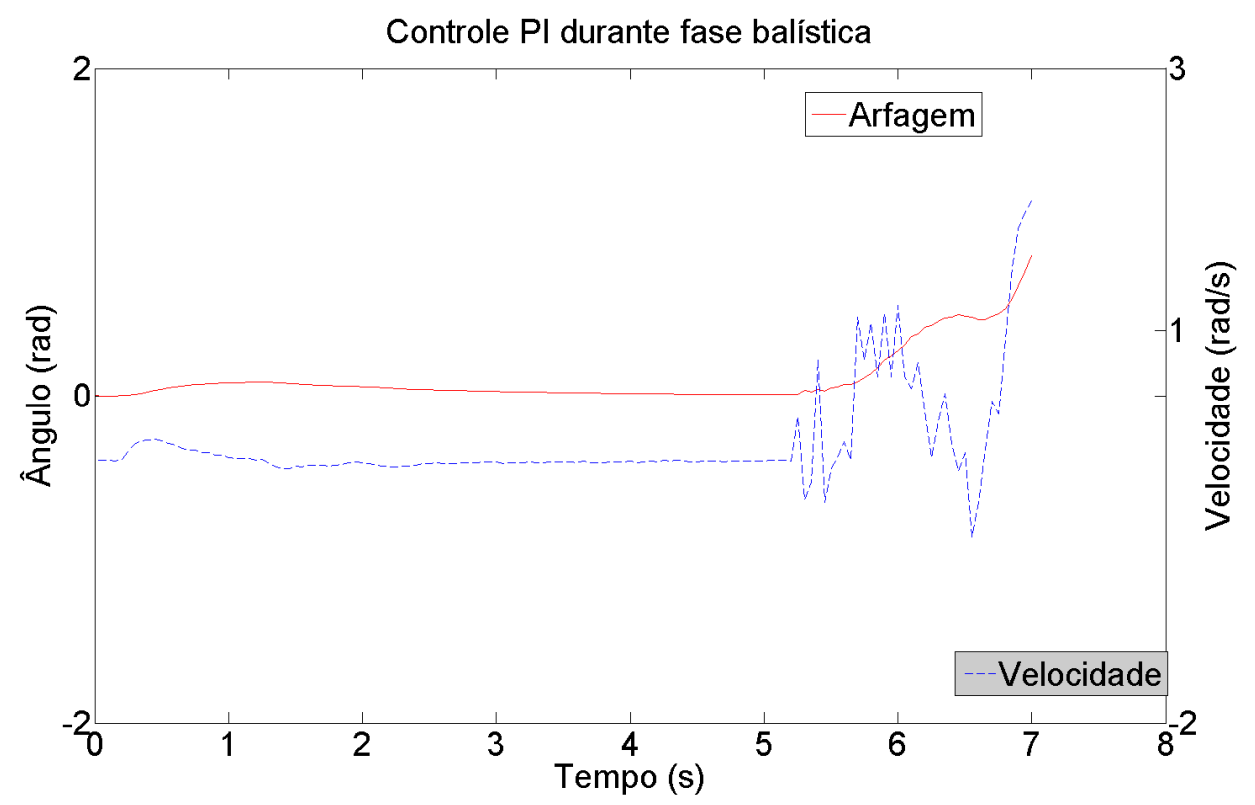

Figura 55: Progressão do ângulo e da velocidade de arfagem durante a simulação com os controladores PIs.

A partir dos $5 \mathrm{~s}$ a rampa é encontrada e o comportamento segue parecido com o já analisado na simulação anterior. A principal diferença ocorre no instante próximo a 6,5 s, quando o veículo perde contato com a rampa. Ao perder contato com o terreno, o veículo perde tração nas rodas e a velocidade que estava abaixo da desejada depois de subir a rampa, não consegue mais ser alcançada. A única ação que o controle de velocidade pode ter é acelerar mais as rodas. Nesse instante, a aceleração das rodas passa a influenciar a dinâmica de rotação do veículo exatamente como o previsto no controle de arfagem, com a diferença de ser um controle de malha aberta não planejado. Ao acelerar as rodas para baixo, o efeito de reação das rodas gira o chassi pra cima, aumentando drasticamente o ângulo de arfagem até o capotamento.

A Figura 56 mostra o somatório das forças normais e o indicador de detecção de descolamento das rodas durante a simulação. Duas diferenças podem ser notadas na comparação com a simulação anterior. Primeiro é o indicador em estágio de alerta pouco depois dos $5 \mathrm{~s}$, quando o veículo inicia a subida pela rampa. Enquanto que na primeira simulação, nesse momento, o algoritmo de detecção acusou descolamento apenas das rodas dianteiras, na segunda simulação todas as rodas foram consideradas brevemente descoladas. Atribui-se essa 
diferença à velocidade de chagada do veículo à rampa nas duas simulações. Como na primeira simulação o falso-positivo de descolamento das rodas dianteiras desligou momentaneamente o controle de velocidade, o contato do veículo com a rampa se deu a uma velocidade mais baixa e provavelmente não suficiente para descolar todas as rodas.

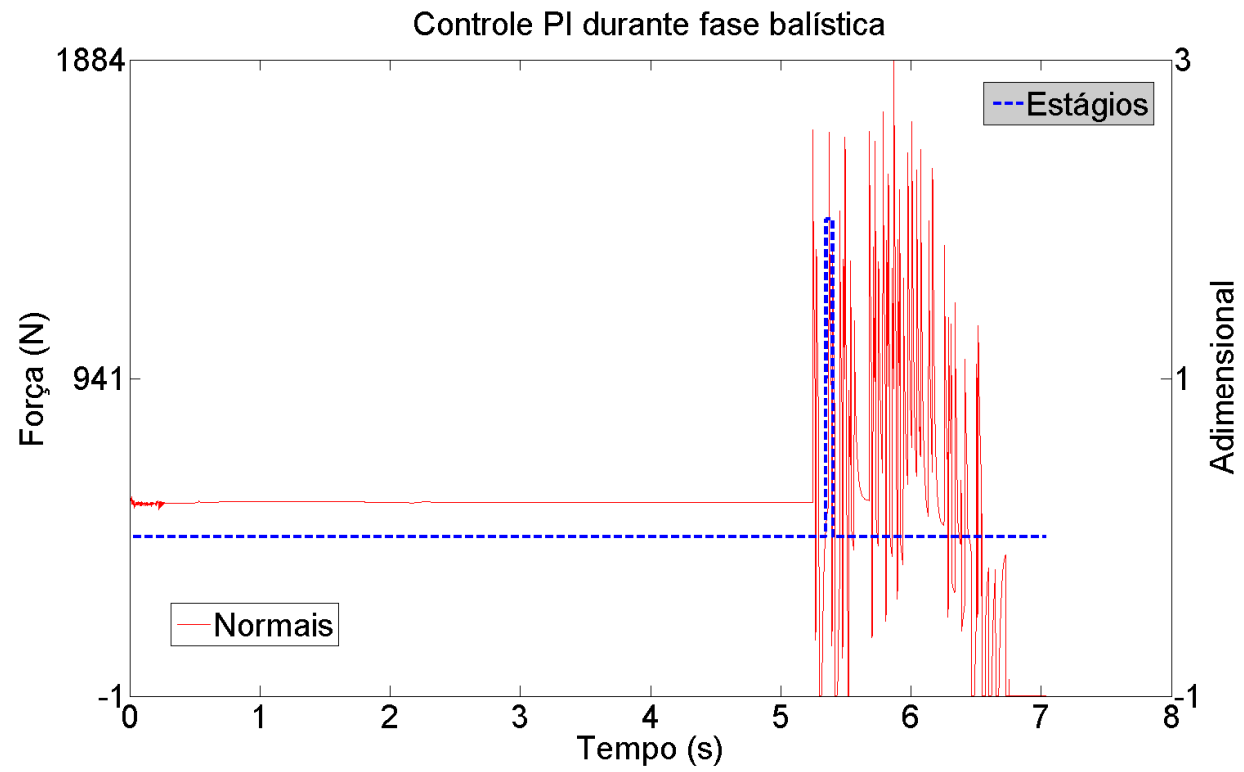

Figura 56: Somatório das forças normais e indicador de estágio do controle de arfagem durante a simulação com os controladores PIs.

A outra diferença é a não detecção da fase balística ou do estágio de alerta ao final da simulação. Atribui-se esse falso-negativo à saturação da tensão de comando do motor, que não é previsto pelo algoritmo.

Destaca-se, novamente, que se atribui a alta frequência do somatório das forças normais, em torno dos seis segundos de simulação, à falta de um algoritmo para tratamento de impactos como já fora comentado anteriormente.

A Figura 57 mostra a tensão de controle aplicada no motor traseiro direito durante a simulação. Nela percebe-se o aumento descontrolado da tensão a partir do contato com a rampa até a saturação. 


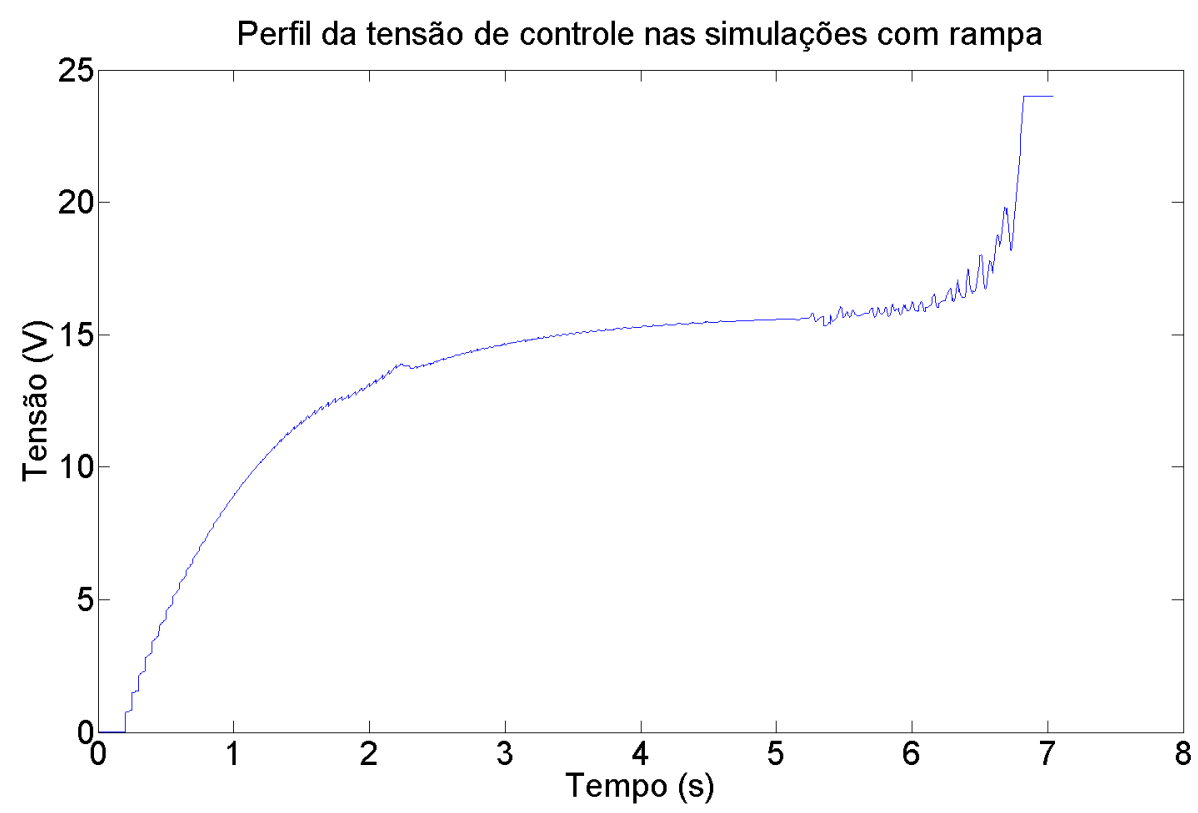

Figura 57: Perfil de tensão aplicada no motor traseiro direito durante a simulação com os controladores PIs.

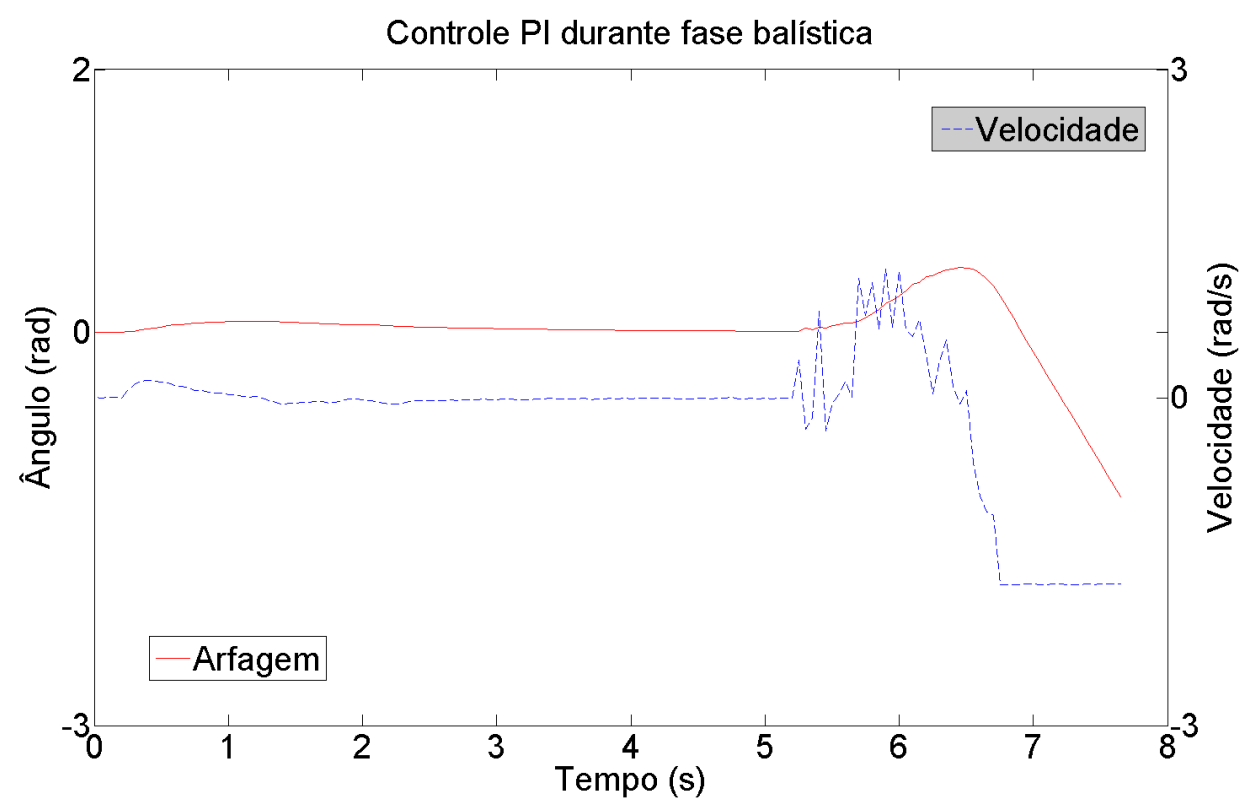

Figura 58: Progressão do ângulo e da velocidade de arfagem durante a simulação com os controladores PIs desligados na fase balística.

Uma terceira simulação foi feita desligando-se o controle de velocidade caso a fase balística fosse detectada. A detecção foi feita assumindo-se que as forças normais sobre as rodas são conhecidas. Caso o somatório de todas elas seja nulo, 
então o veículo encontra-se na fase balística. A Figura 58 mostra o ângulo e a velocidade angular do chassi durante a simulação. Pode-se perceber que mesmo desligando o controle de velocidade não é possível garantir uma volta segura ao terreno. Próximo aos $7 \mathrm{~s}$, quando o veículo descola da rampa, a velocidade angular do mesmo é diferente de zero e como nada foi feito para corrigir, o ângulo de arfagem diminui até o capotamento.

\subsubsection{2.}

\section{Simulação com precipício}

Nessa simulação o veículo foi acelerado novamente até a velocidade desejada e ao final do terreno um degrau de $3 \mathrm{~m}$ de profundidade foi colocado no final da pista. A Figura 59 mostra a evolução do ângulo e da velocidade de arfagem do chassi durante a simulação. Próximo a $8 \mathrm{~s}$ há uma variação abrupta na velocidade angular do chassi indicando que o degrau foi alcançado. Há convergência tanto do ângulo quanto da velocidade de arfagem.

Pela Figura 60 vê-se novamente a detecção de falsos-positivos de descolamento das rodas dianteiras pelo algoritmo.

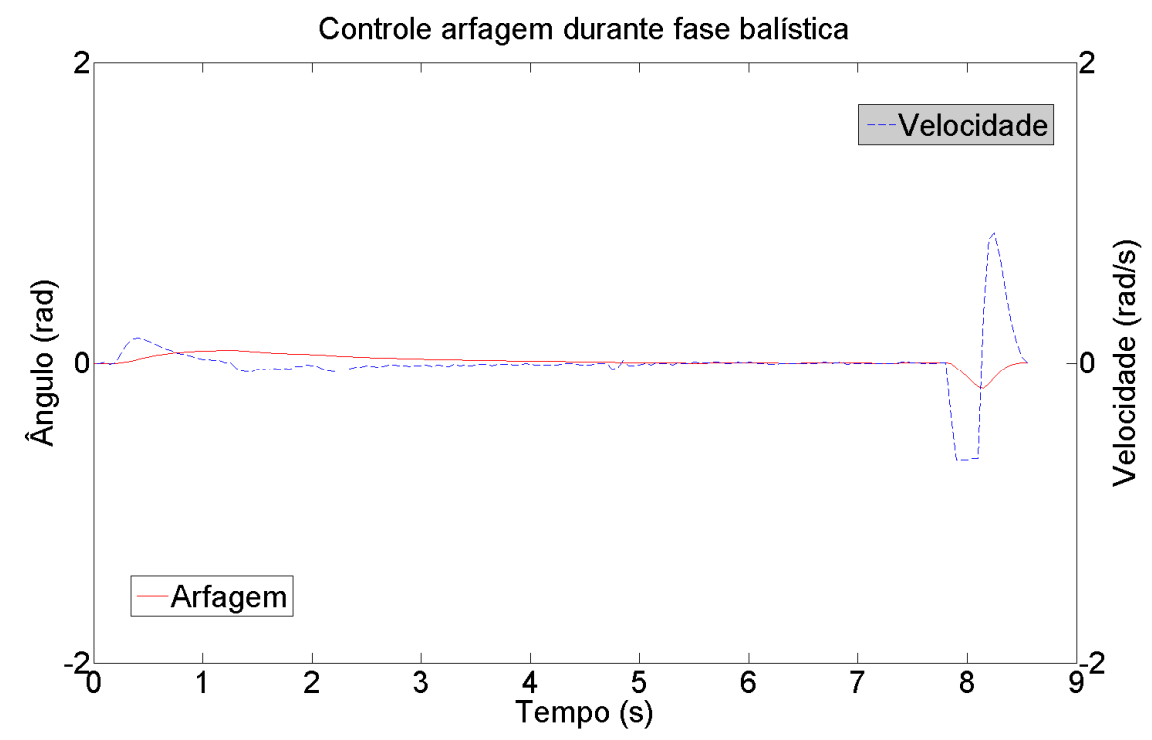

Figura 59: Progressão do ângulo e da velocidade de arfagem durante a simulação com os algoritmos propostos. 


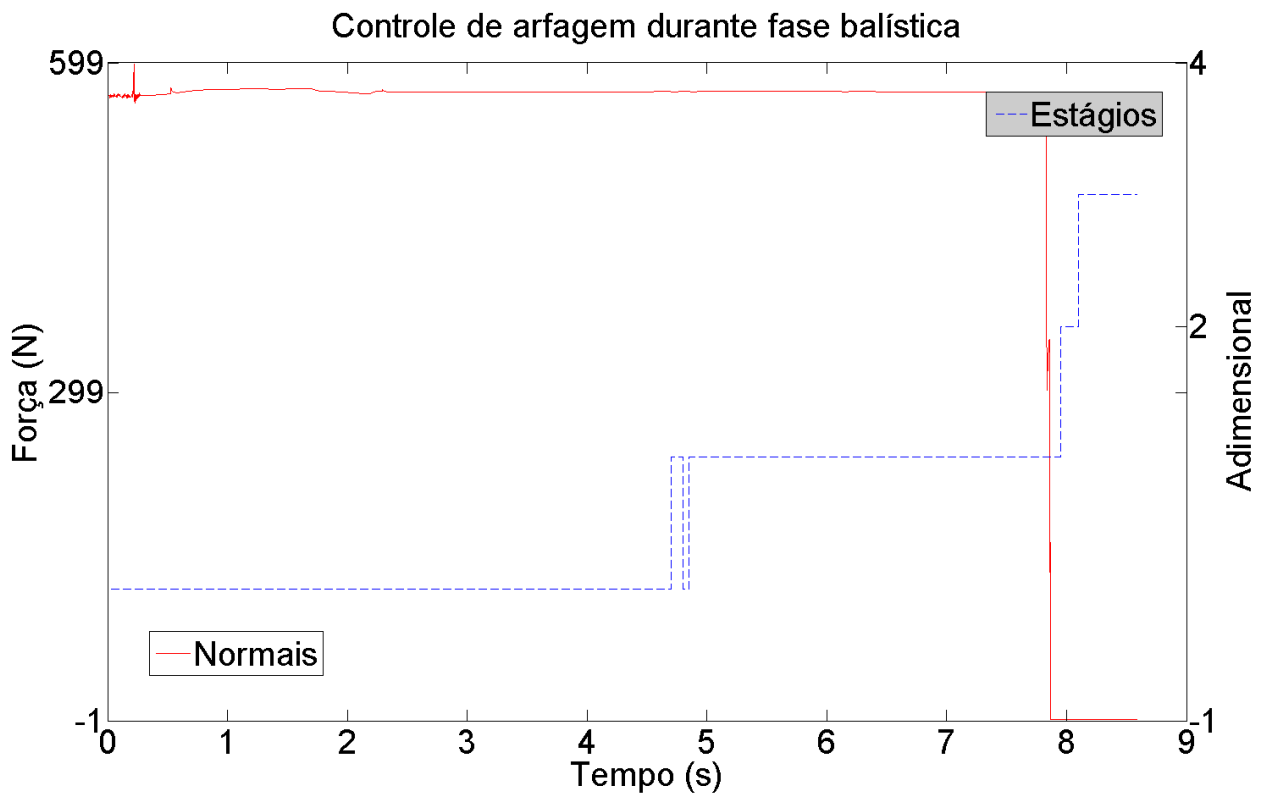

Figura 60: Somatório das forças normais e indicador de estágio do controle de arfagem durante a simulação com os algoritmos propostos.

Apesar dos falsos-positivos, o algoritmo consegue identificar a fase balística corretamente como pode ser visto na Figura 60 após os $8 \mathrm{~s}$ de simulação.

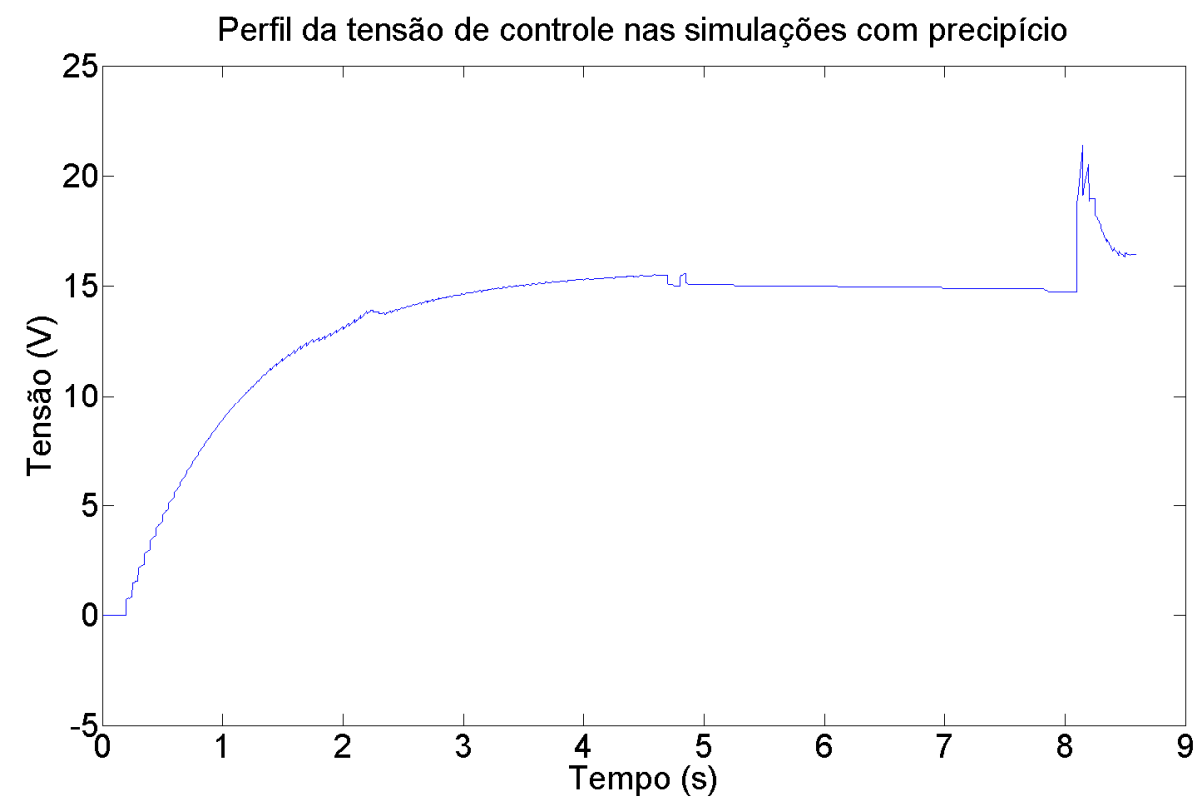

Figura 61: Perfil de tensão aplicada no motor traseiro direito durante a simulação com os algoritmos propostos. 
A Figura 61 mostra o perfil de tensão elétrica aplicado ao motor da roda traseira direita. Pode-se notar no intervalo de $5 \mathrm{~s}$ a $8 \mathrm{~s}$ o desligamento do controle de velocidade. Ao enviar torque nulo às rodas o sistema aos poucos vai perdendo velocidade devido às perdas inseridas na simulação. Isso pode ser visto pela suave diminuição da tensão aplicada que praticamente acompanha a velocidade de rotação da roda. No final da simulação pode ser visto o sinal de controle do ângulo de arfagem gerado pelo algoritmo desenvolvido.

Por fim foi simulado o desempenho do controle PI de velocidade ligado o percurso todo. Ao contrário da simulação com a rampa, ao cair do degrau o ângulo de arfagem do chassi diminuiu até ocorrer o capotamento. Como o efeito do desligamento do algoritmo de detecção de descolamento das rodas é desligar o controle de velocidade nas situações críticas, sua ausência não pôde ser percebida pois o controle de velocidade já havia atingido a velocidade desejada antes de cair do degrau. Com a convergência, o controlador de velocidade só necessita manter a tensão constante, que é aproximadamente o mesmo efeito de enviar torque nulo para os motores. Sem a aceleração das rodas não há torque de reação para rotacionar o chassi para cima, como ocorreu na simulação com a rampa.

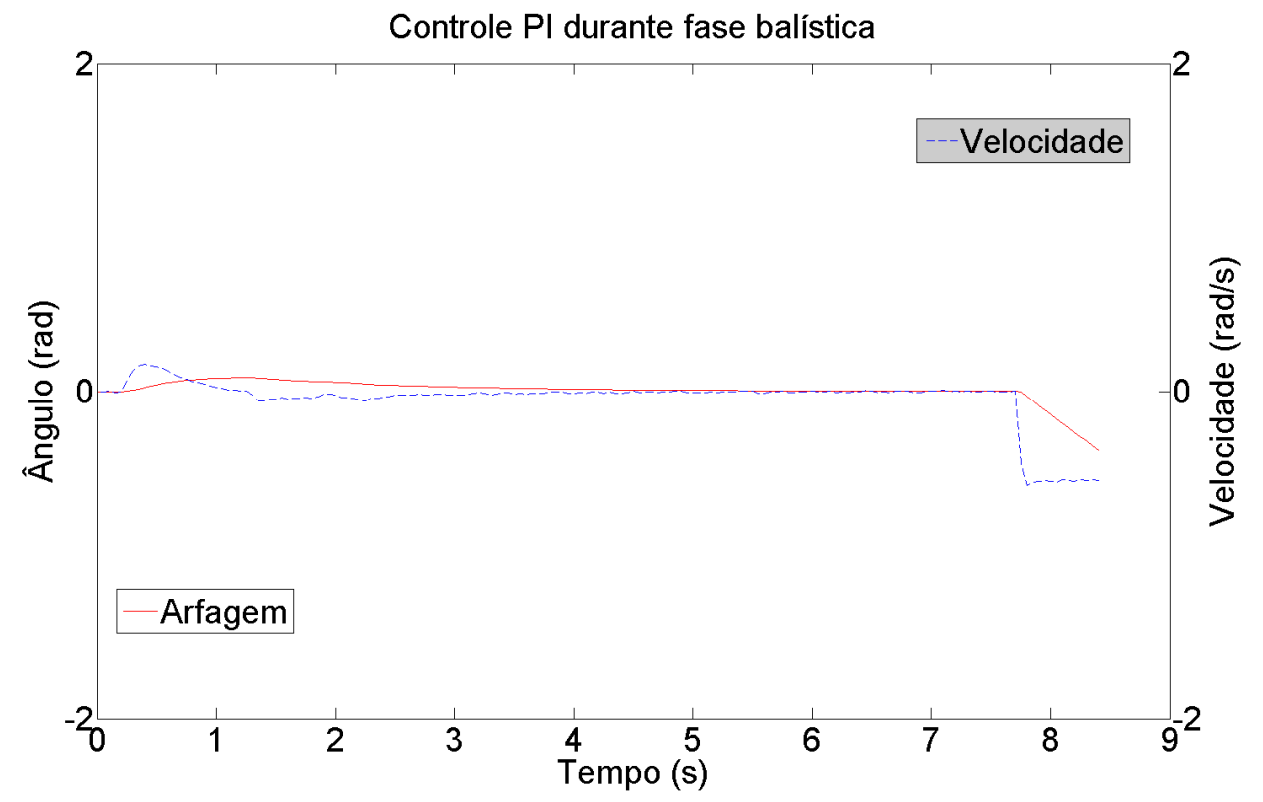

Figura 62: Progressão do ângulo e da velocidade de arfagem durante a simulação com os controladores PIs. 


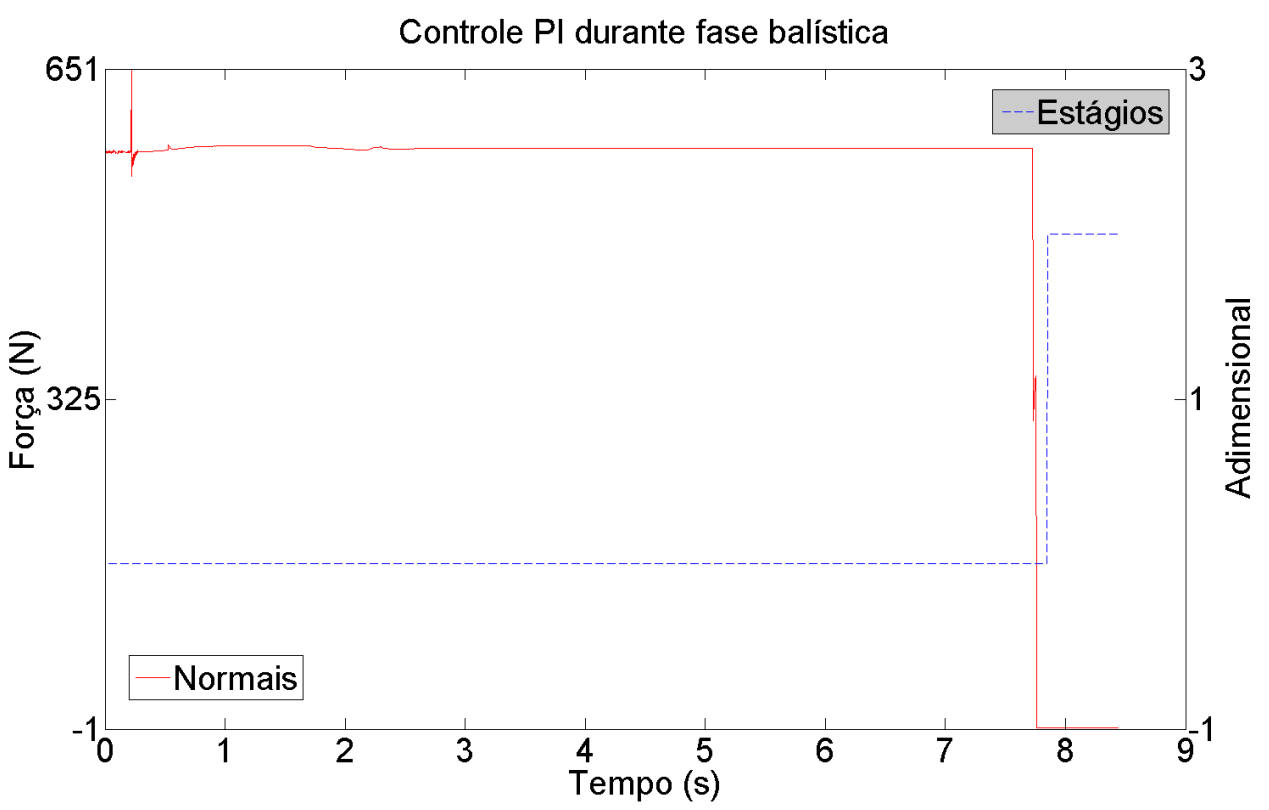

Figura 63: Somatório das forças normais e indicador de estágio do controle de arfagem durante a simulação com os controladores PIs.

A Figura 63 mostra a evolução do somatório das forças normais durante a simulação e a Figura 64 mostra que para o controlador de velocidade a queda do veículo não apresentou alteração alguma no sistema.

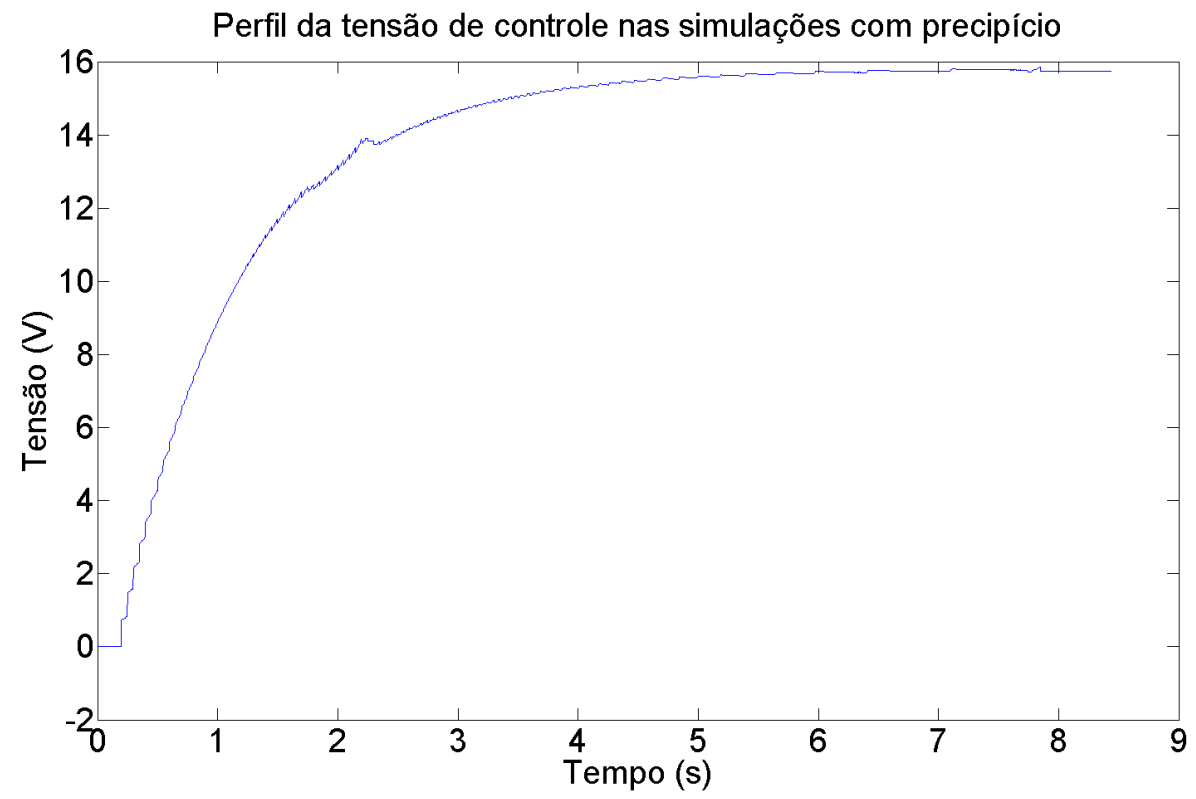

Figura 64: Perfil de tensão aplicada no motor traseiro direito durante a simulação com os controladores PIs. 
Como a ausência de um algoritmo de detecção da fase balística não representou alteração no comportamento do controlador PI, a simulação do controlador PI auxiliado pela informação de instabilidade calculada pelo somatório das forças normais não precisou se feita.

\section{5.}

\section{Experimentos}

Foram realizados dois experimentos para teste dos algoritmos desenvolvidos. No primeiro, um perfil de tensão senoidal é aplicado ao veículo que se encontra livre para trafegar no chão plano e horizontal e as estimativas de torque externo são analisadas. No segundo, uma queda de uma mesa plana e horizontal durante uma aceleração é utilizada para análise do algoritmo de detecção de fase balística e do controle de arfagem. O limiar usado na decisão sobre o descolamento foi de $+/-4 \mathrm{Nm}$.

\subsection{1. \\ Estimativa do torque externo}

Para testar o algoritmo de estimativa do torque externo aplicou-se um perfil de tensão senoidal de $10 \mathrm{Vpp}$, um offset de $2,5 \mathrm{~V}$ e uma frequência de $0,2 \mathrm{~Hz}$. O veículo foi ensaiado em um terreno plano e horizontal sem obstáculos. A Figura 65 mostra a corrente induzida nos motores das quatro rodas durante $\mathrm{o}$ experimento. A corrente no motor da roda dianteira direita mostra um dos problemas enfrentados durante os experimentos, em que há uma perturbação no valor médio fornecido pelo sensor, antes mesmo de se iniciar o ensaio. Esse problema era amenizado reposicionando-se o amperímetro antes do experimento. 


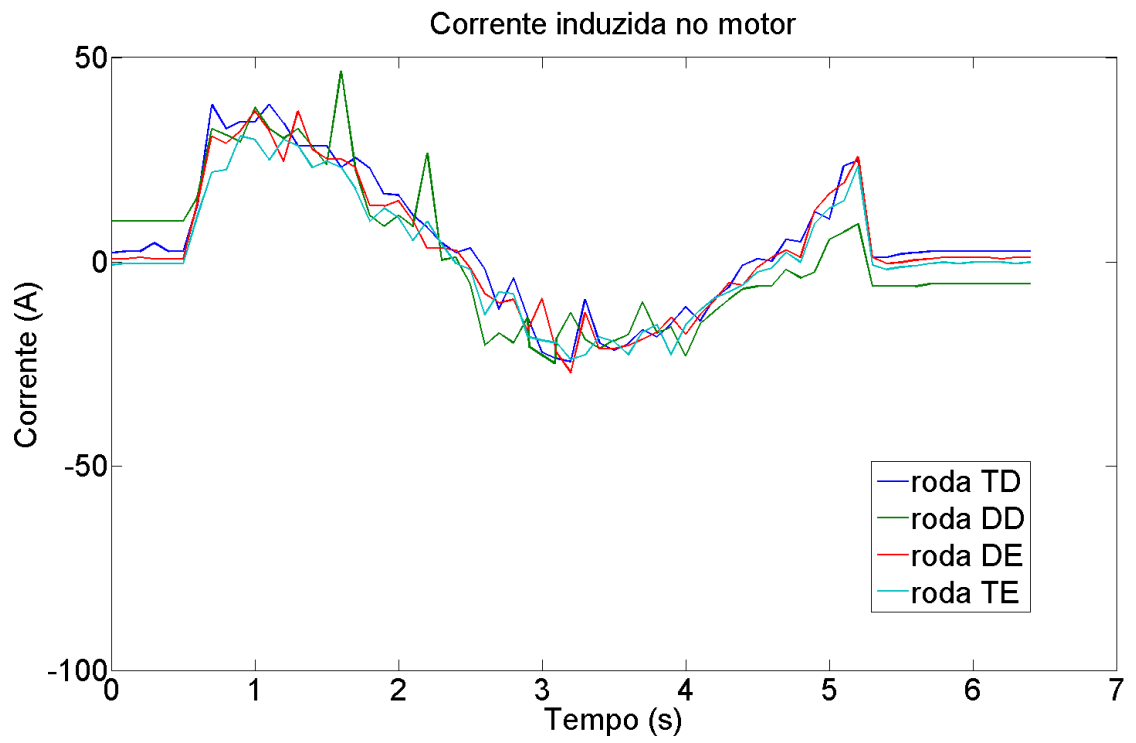

Figura 65: Correntes induzidas nos motores durante o experimento.

A Figura 66 mostra a evolução da velocidade de rotação das rodas durante o ensaio. É possível ver antes do primeiro segundo de ensaio que as rodas derrapam brevemente. Considerando-se que após o primeiro segundo de experiência observou-se derivas longitudinais desprezíveis, pode-se assumir que a velocidade longitudinal do veículo é proporcional à média das velocidades de rotação das rodas. Dessa forma pode-se assumir que entre $3 \mathrm{~s}$ e $4 \mathrm{~s}$ de experimento, o veículo passa a ter uma velocidade negativa até por volta dos $5 \mathrm{~s}$ de ensaio.

A estimativa de torque é mostrada na Figura 67, juntamente com o perfil de tensão elétrica aplicada sobre os motores. A parte plana e horizontal da estimativa do torque marca a origem do eixo da direita do gráfico.

Assim como na Figura 48, podem-se observar quatro mudanças de sinal na estimativa de torque nos momentos entre $2 \mathrm{~s}$ e $3 \mathrm{~s}$, entre $3 \mathrm{~s}$ e $4 \mathrm{~s}$, entre $4 \mathrm{~s}$ e $5 \mathrm{~s}$ e entre $5 \mathrm{~s}$ e $6 \mathrm{~s}$. Dessas, as mudanças entre $3 \mathrm{~s}$ e $4 \mathrm{~s}$ e entre $5 \mathrm{~s}$ e $6 \mathrm{~s}$ se deram exclusivamente devido à mudança no sinal de comando e as outras ocorreram em momentos em que a aceleração linear do veículo mudou de sentido, como foi mostrado anteriormente na seção 6.4.1. Durante o período entre o início do ensaio e a primeira mudança de sinal da estimativa do torque externo, o motor está impulsionando o veículo para frente, representado pelo valor positivo da estimativa. O mesmo acontece no período final do experimento, depois dos $5 \mathrm{~s}$. 


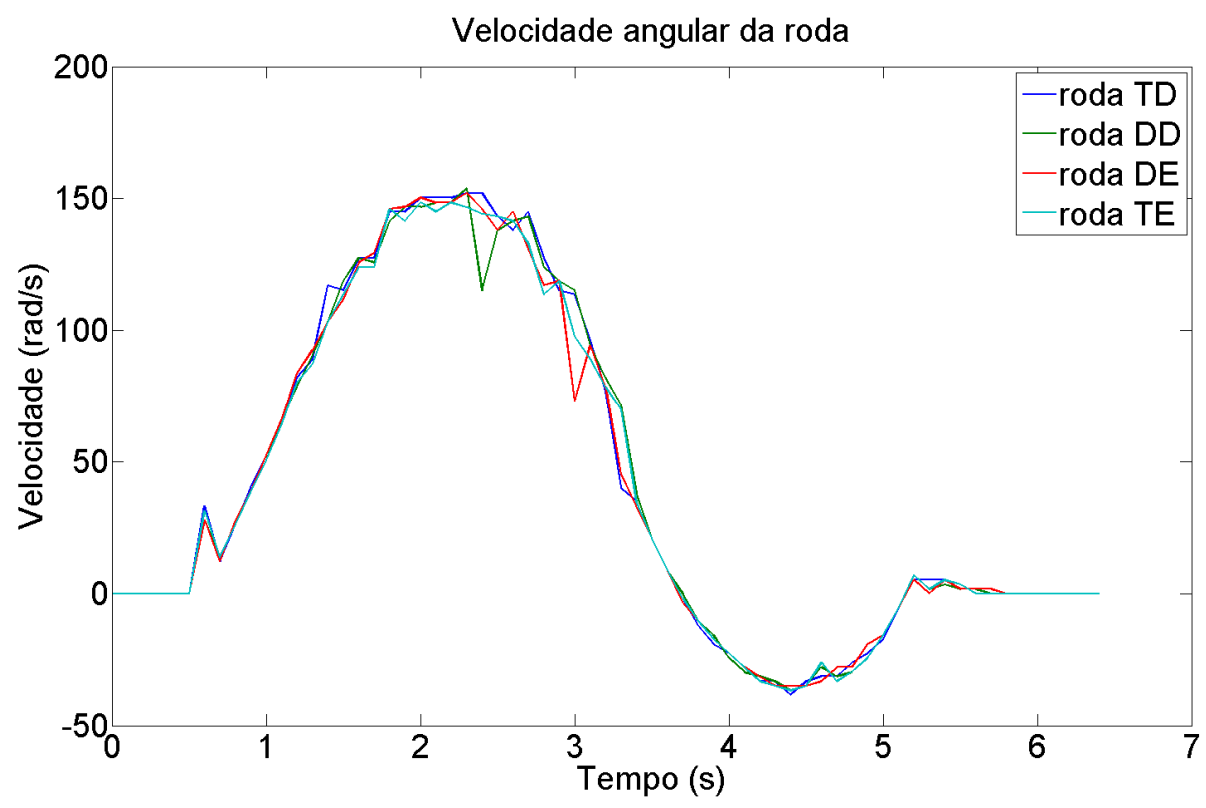

Figura 66: Velocidades angulares das rodas durante o experimento.

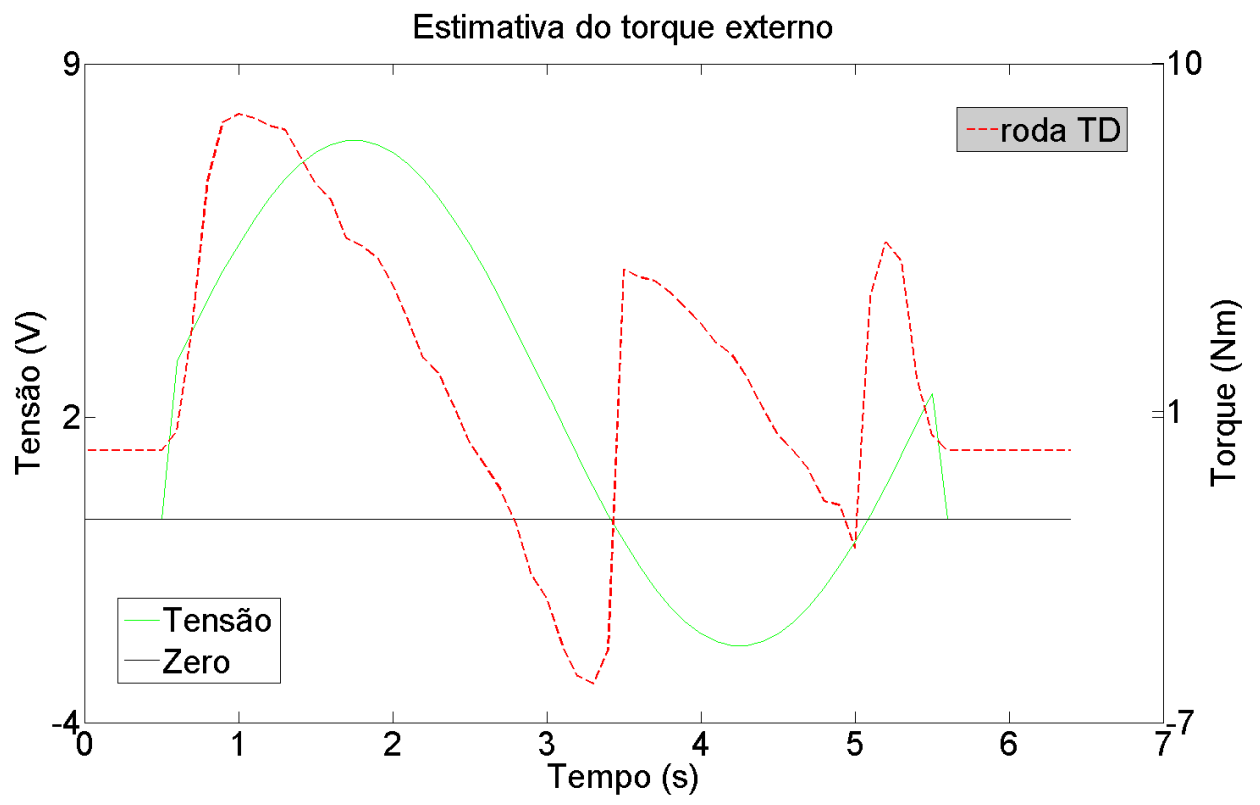

Figura 67: Estimativa do torque externo sobre a roda traseira direita e o perfil de tensão aplicada sobre a mesma.

A estimativa positiva do torque por volta do instante $4 \mathrm{~s}$ indica que o motor também está impulsionando o veículo, mas como o sinal de comando é negativo, essa impulsão se dá para trás, gerando velocidades negativas de rotação das rodas. Os breves momentos em que a estimativa do torque é negativa indica que o motor 
está freando o veículo, sendo que em torno dos $3 \mathrm{~s}$, este ainda se desloca para frente, enquanto que em torno dos $5 \mathrm{~s}$, a frenagem é sobre um deslocamento trás.

\subsection{2.}

Detecção e controle da fase balística

Uma mesa de $1 \mathrm{~m}$ de altura por 3,1 $\mathrm{m}$ de comprimento foi usada como plataforma para o salto do veículo. Foram realizados oito ensaios onde foram aplicados torques constantes (através de controle de corrente) na faixa de 6,7 Nm (25 A) a 13,4 Nm (50 A) nas rodas. Em 50\% dos ensaios, o algoritmo detectou o início da fase balística enquanto que nos outros quatro ensaios o algoritmo não detectou a fase balística. Em um deles onde houve falha do algoritmo, a detecção se deu tardiamente, imediatamente antes de tocar o solo. Nos dois primeiros ensaios o tempo usado para a fase de alerta antes da decisão pela fase balística foi de 0,1 s, como nas simulações. No entanto, verificou-se que esse tempo estava muito grande em relação ao tempo de queda livre (aproximadamente 0,3 s). Do terceiro ensaio em diante, esse tempo foi reduzido para 0,02 s com isso, em quatro dentre seis dos ensaios seguintes a fase balística foi detectada. Os gráficos e análises a seguir são de um dos ensaios onde o torque de arranque foi de 10,7 Nm (40 A).

A Figura 68 mostra as acelerações nos três eixos do veículo durante o ensaio. $\mathrm{O}$ acelerômetro foi instalado no veículo de forma que um aumento de velocidade do veículo para frente em um terreno plano e horizontal produz uma medida de aceleração negativa. A partir dela vê-se que o veículo sai do repouso por volta de $1 \mathrm{~s}$ e é acelerado até por volta dos 2,5 s. Nesse instante todas as acelerações se aproximam de zero indicando a queda livre até cerca de $300 \mathrm{~ms}$ depois quando os altos valores de aceleração mostram o impacto sentido pelo veículo ao chegar ao chão. 


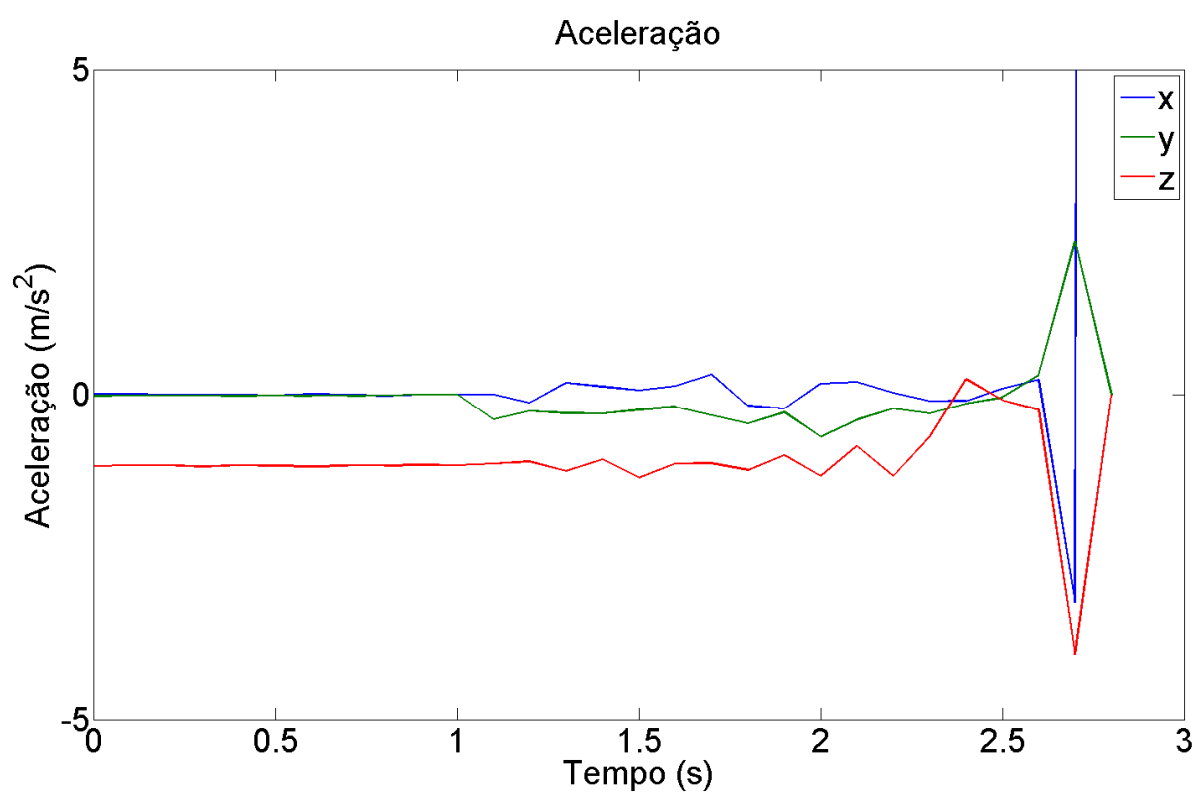

Figura 68: Acelerações nos três eixos durante o ensaio de fase balística.

A seguir, as velocidades de rotação das rodas são mostradas na Figura 69. Devido a problemas com uma eletrônica de potência nestes testes, a roda traseira esquerda não foi atuada durante os ensaios. Isso pode ser percebido pela imediata queda da sua velocidade próximo aos $2,5 \mathrm{~s}$. Até esse momento a velocidade da roda é aproximadamente a velocidade do veículo. Desse ponto em diante, o atrito no eixo do motor e a rotação negativa (frente do chassi abaixando) do chassi fazem com que a leitura de velocidade da roda diminua. Um pouco depois dos 2,5 s essa velocidade aumenta bruscamente indicando que o veículo encostou no chão.

A figura mostra ainda que assim que as rodas descolam da mesa (rodas traseiras por último) o controle de torque continua agindo causando uma aceleração nas rodas que quase as satura (velocidade máxima para $24,5 \mathrm{~V}$ é de $91,3 \mathrm{rad} / \mathrm{s})$. 


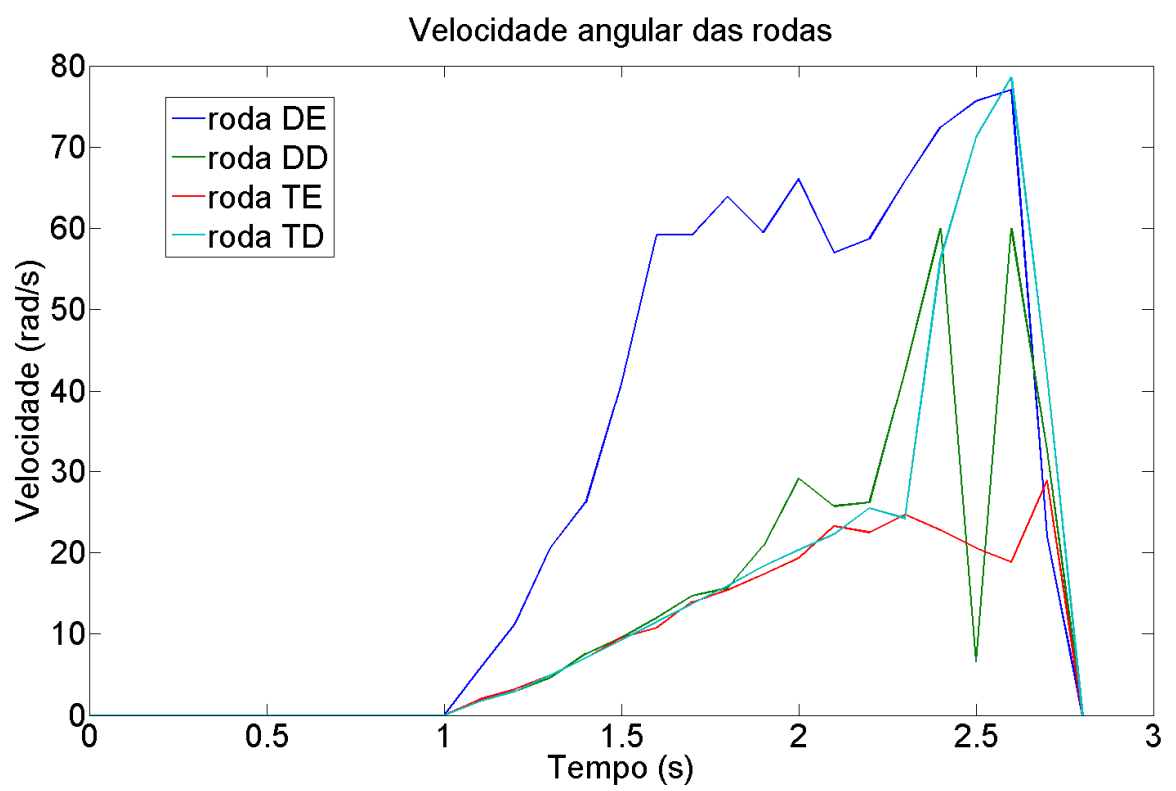

Figura 69: Velocidade angular das rodas durante o ensaio de fase balística.

Na Figura 70 são mostradas as estimativas de torque externo sobre as rodas. Um pouco antes dos 2,5 s, quando as rodas perdem contato com a mesa, as estimativas diminuem abruptamente para próximo a zero, como era de se esperar por estarem rodando no vazio. A roda traseira esquerda apresenta uma estimativa de torque externo negativa, pois está girando à mesma velocidade do veículo devido a força de tração do terreno. Como a roda não está sendo atuada, o torque externo sobre a mesma é baixo, pois é o suficiente para vencer o atrito no eixo do motor.

Os indicadores de descolamento das rodas e o da detecção da fase balística são mostrados na Figura 71. Assim que o veículo começa a se mover, uma falsa detecção de descolamento das rodas traseiras é acusada. Próximo aos 2,5 s de ensaio o indicador detecta o descolamento de todas as rodas (indicado pelo valor sete) e é imediatamente seguido pela evolução dos estágios de detecção de fase balística. Do estágio zero (funcionamento normal do sistema) o algoritmo, para o estágio de alerta (dois) e finalmente para o estágio de fase balística. Ambos indicadores retornam a zero mostrando que o veículo encostou o chão. 


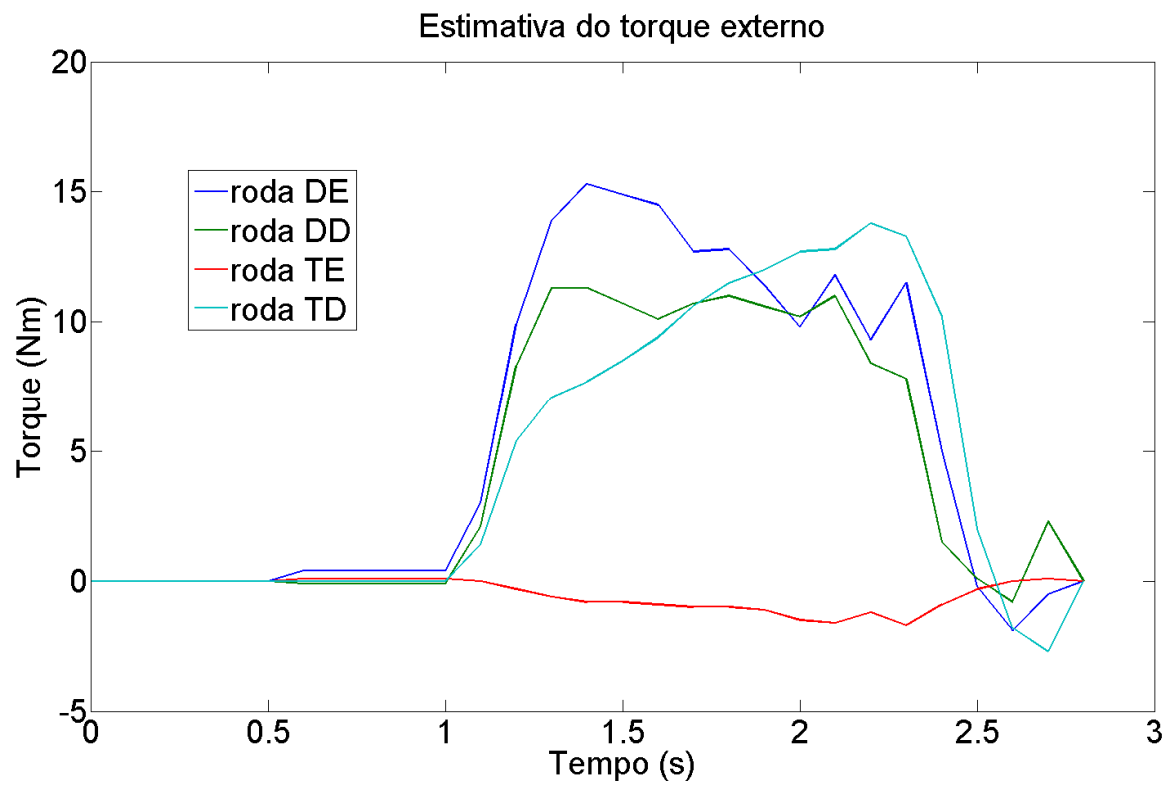

Figura 70: Estimativa dos torques externos sobre as rodas durante o ensaio de fase balística.

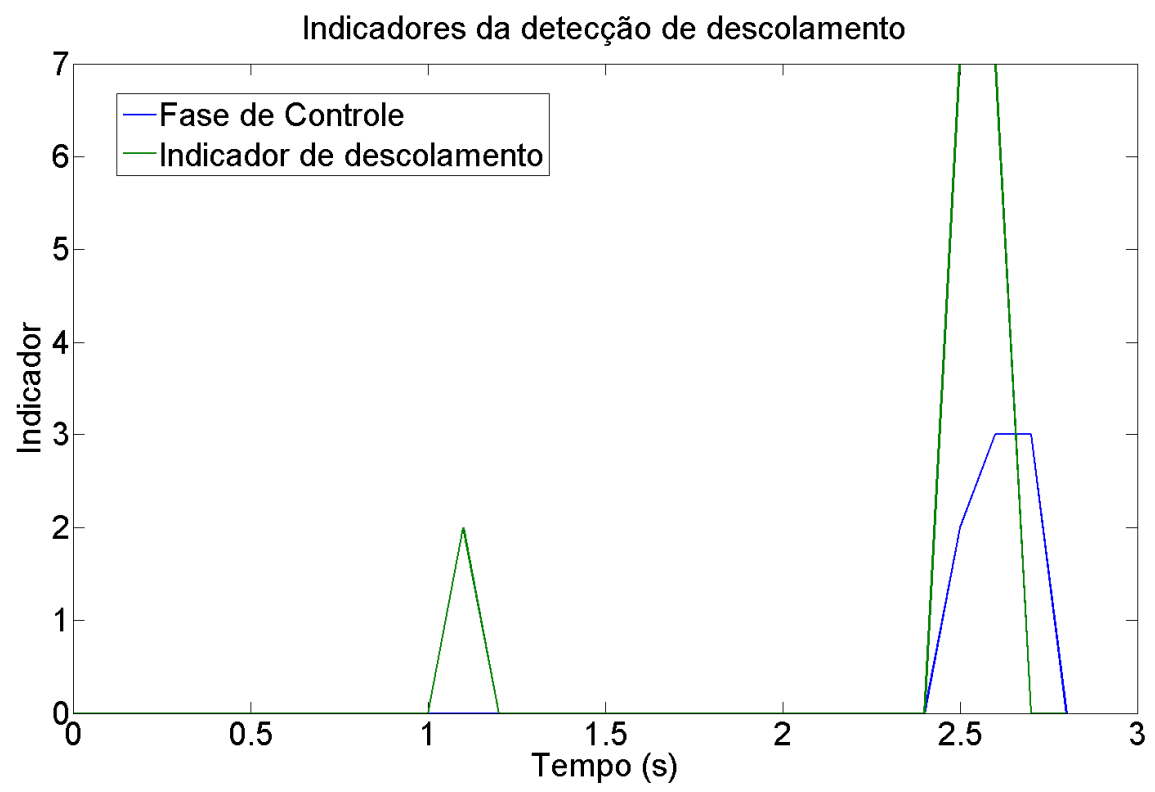

Figura 71: Indicadores de descolamento e da fase de controle durante ensaio de fase balística.

A Figura 72 mostra a evolução da estimativa do ângulo e da medição de velocidade de arfagem durante o ensaio. Pouco antes dos 2,5 s de ensaio pode ser visto que o veículo começa a apontar para baixo representado pelos valores negativos de ângulo e velocidade de arfagem. Em seguida a velocidade angular se aproxima de zero e passa a assumir valores positivos no segundo final de ensaio. 
O ensaio termina com esses valores muito próximos a zero indicando que o veículo atingiu o chão.

Esse comportamento estabilizante não pode ser atribuído ao controle de arfagem pois, como pode ser visto na Figura 73 (que mostra o perfil de comando de corrente durante o ensaio), este só começa a atuar depois dos 2,5 s de ensaio. Este comportamento se deve na verdade a resquícios do controle principal que ainda não fora desativado e continuara a tentar manter a corrente nos motores em $40 \mathrm{~A}$, acelerando as rodas até quase a sua máxima velocidade, como mostrado anteriormente na Figura 69. O comando de corrente mostra uma queda abrupta da corrente desejada para zero exatamente aos 2,5 s devido ao estágio de alerta do algoritmo onde os sinais de controle são zerados até que a fase balística seja detectada ou que o funcionamento normal do sistema seja reestabelecido.

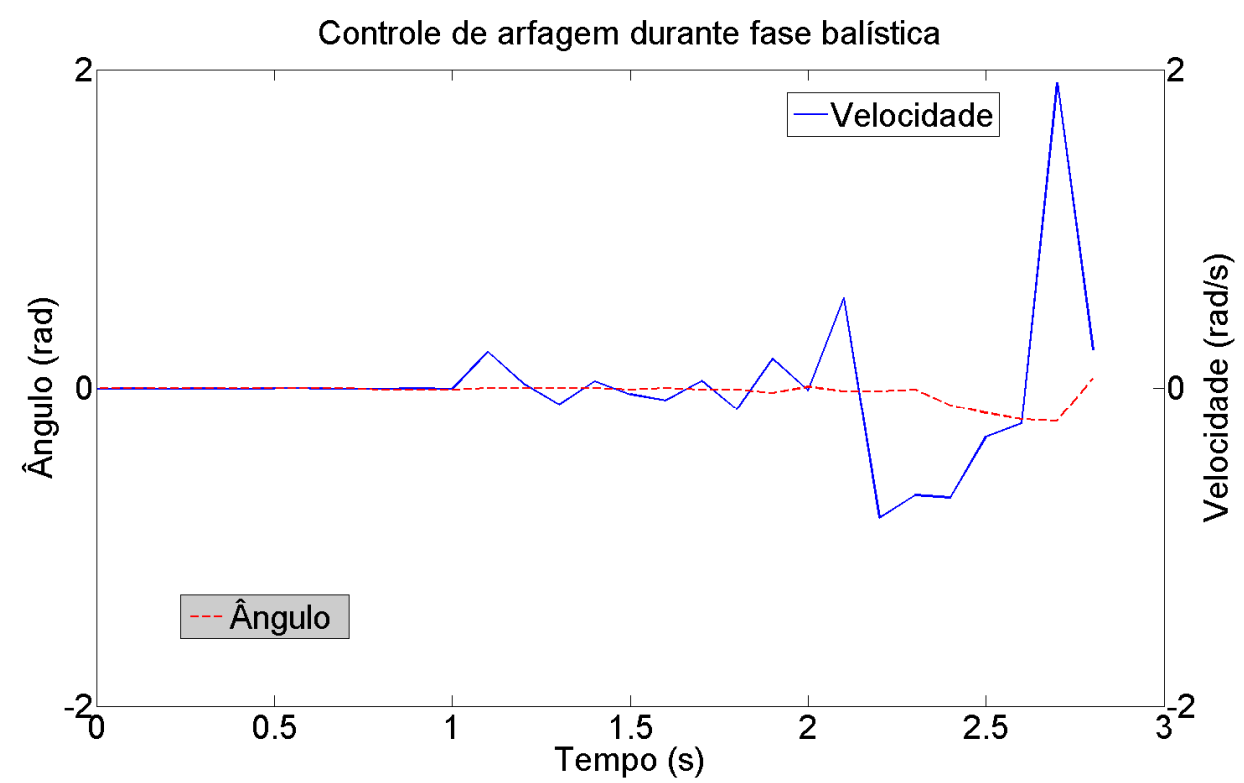

Figura 72: Ângulo de velocidade de arfagem durante ensaio de fase balística. 


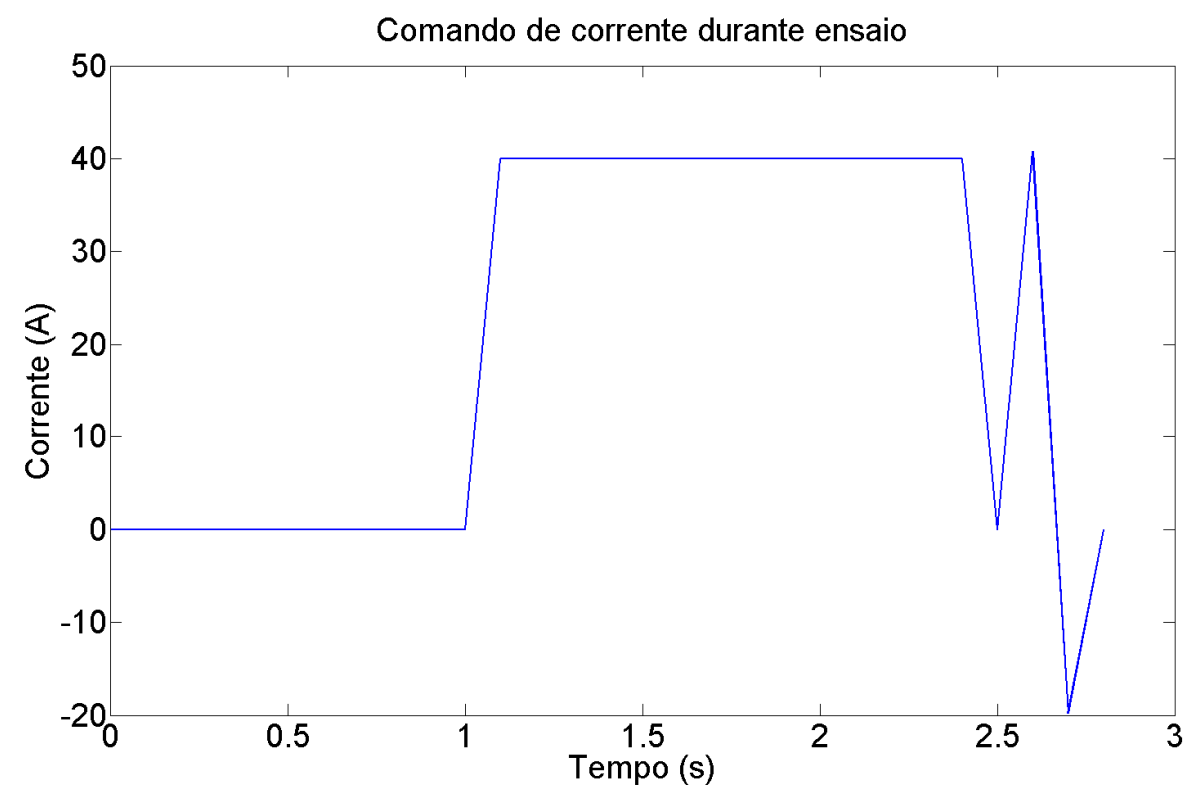

Figura 73: Perfil do comando de corrente desejada durante ensaio de fase balística.

Coincidentemente, o controle de arfagem calculou uma corrente desejada de aproximadamente $40 \mathrm{~A}$ para as rodas de maneira a corrigir a orientação do veículo. Em seguida, depois que a velocidade angular do chassi cresceu abruptamente, o controle tentou corrigir enviando um comando de corrente desejada de $-20 \mathrm{~A}$.

Por fim, a Figura 74 mostra as leituras de correntes drenadas pelos motores durante o ensaio. Ela mostra um patamar em aproximadamente $50 \mathrm{~A}$ (erroneamente controlada pelo sistema, pois deveria ser $40 \mathrm{~A}$ ) e em 2,5 s seu valor cai a próximo de zero de acordo com o comando do controle de arfagem. A forte oscilação para -100 A do motor da roda dianteira direita pode ser atribuída a um erro do sensor conforme comentado na seção 6.5.1. 


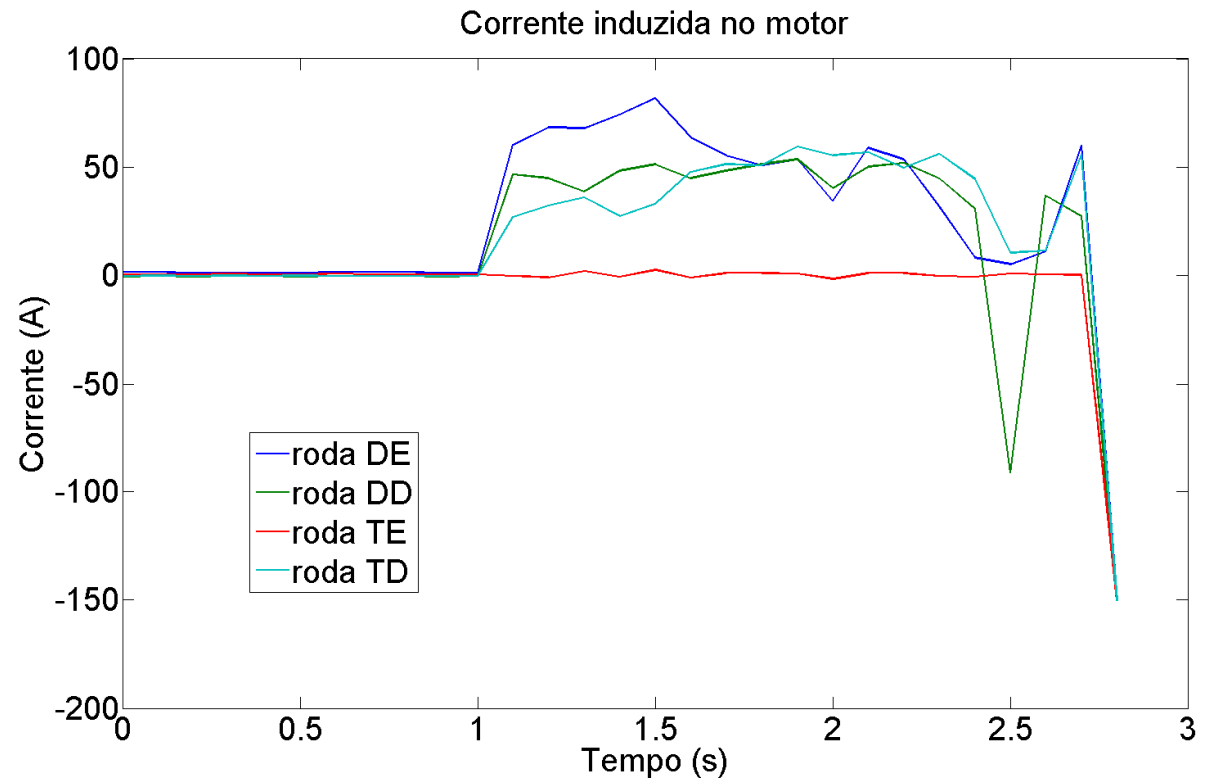

Figura 74: Correntes nos motores durante ensaio de fase balística. 


\section{7 \\ Conclusão e trabalhos futuros}

Controladores de estabilidade instalados em veículos automotivos minimizam as chances de ocorrência de acidentes devido à imperícia de motoristas ou a condições adversas do terreno. A maioria dos controles de estabilidade desenvolvidos lida com a prevenção ou correção de desestabilizações nos ângulos de guinada e de rolagem, por serem os eventos críticos de maior probabilidade de ocorrência. $\mathrm{Na}$ área da robótica exploratória ou em cenários com veículos robóticos desenvolvendo grandes velocidades em terrenos acidentados, a desestabilização dos ângulos de arfagem passa a ser uma ameaça real.

Essa pesquisa desenvolveu um simulador de veículos robóticos com motores elétricos capaz de simular terrenos acidentados em tempo real. O simulador permite a interação do usuário com a cena durante a simulação, ampliando as possibilidades de avaliação durante a fase de prototipagem virtual de sistemas mecânicos e algoritmos matemáticos. Foram implementados sensores com características reais de funcionamento como ruídos, resolução, offset etc. O simulador foi validado com testes cujas soluções analíticas eram conhecidas, obtendo erros de até 3,5\%. Uma comparação com dados experimentais de um motor mostraram um erro máximo de 6,5rad/s RMS para uma velocidade de $260 \mathrm{rad} / \mathrm{s}$.

Foi apresentada uma proposta de algoritmo para estimativa de torque externo aplicado sobre a roda. Mostrou-se que os níveis de ruídos são altos nas estimativas, atribuídos às grandes descontinuidades do sinal produzido pelo encoder óptico. Com as estimativas de torque externo, foi apresentado um algoritmo para detecção de descolamento entre rodas e terreno. A técnica pode ser utilizada sem custos adicionais, uma vez que os sensores necessários, amperímetros e encoders, já se encontram instalados em sistemas com controle de torque. $\mathrm{O}$ algoritmo foi testado no simulador desenvolvido durante a pesquisa, onde conseguiu detectar com sucesso todas as fases balísticas durante as simulações. Ele produziu alguns falsos-positivos durante as simulações em 
situações de velocidade de cruzeiro, onde as acelerações longitudinais são muito próximas a zero. Em testes experimentais, o algoritmo de detecção de fase balística acertou quatro dentre seis ensaios.

Um algoritmo para controle de arfagem durante a fase balística usando as próprias rodas do veículo foi apresentado e testado no simulador. O ângulo e velocidade angular do chassi convergiram para zero em todas as simulações em menos de $1 \mathrm{~s}$ e sem saturar os motores. Valores extremos para as condições iniciais de ângulo e velocidade angular para que o controle consiga convergir sem saturar os motores em até $0,3 \mathrm{~s}$ foram determinados. Nos experimentos, não foi possível avaliar eficientemente a ação do controle devido à prematura quase saturação dos motores antes do início da execução do algoritmo de controle. No entanto, o sistema de rodas de reação produziu efeitos significativos sobre a atitude do chassi, comprovando a viabilidade do algoritmo proposto.

$\mathrm{Na}$ área de simuladores, melhorias no código são necessárias de modo a permitir usar placas gráficas para os cálculos da dinâmica do sistema. O gargalo atual do simulador é o algoritmo de determinação do ponto de contato entre a roda e o terreno. Algoritmos que possam substituir o método iterativo implementado por um método analítico permitiriam menores tempos de integração, sem afetar as interações em tempo real do usuário.

Pesquisas futuras podem testar experimentalmente os algoritmos desenvolvidos em sistemas embarcados capazes de executar os algoritmos mais rapidamente, enquanto a telemetria e o regsitro de dados são feitos em paralelo. Filtros melhores são necessários para minimizar os ruídos nas medições para melhorar a eficácia na detecção do descolamento entre rodas e o solo.

$\mathrm{Na}$ área de controles na fase balística, inércias livres para girar podem ser estudadas na composição de veículos robóticos que trafeguem em alta velocidade sobre terrenos acidentados, com o objetivo de controlar também os ângulos de guinada e rolagem durante a fase balística. 


\section{8 \\ Referências bibliográficas}

1. IEA - International Energy Agency. www.iea.org. [Online] [Citado em: 23 de 05 de 2013.] http://www.iea.org/publications/globalevoutlook_2013.pdf.

2. Hori, Y., Toyoda, Y. e Tsuruoka, Y. Traction Control of Electric Vehicle Based on Estimation of Road Surface Condition-Basic Experimental Results Using the Test EV "UOT Electric March". Proceedings of Power Conversion Conference. 1997, pp. 1 - 8.

3. Beal, Craig E. Applications of Model Predictive Control to Vehicle Dynamics for Safety and Stability. Department of Mechanical Engineering, Stanford University. Stanford : s.n., 2011. Tese de Doutorado.

4. Carlson, Christopher R. and Gerdes, J. Christian. Optimal Rollover Prevention with Steer by Wire and Differential Braking. Proceedings of the ASME Dynamic Systems and Control Division. November 16-21, 2003, pp. 345-354.

5. Peters, Steven C., Frazzoli, Emilio e Iagnemma, Karl. Differential Flatness of a Front-Steered Vehicle with Tire Force Control. International Conference on Intelligent Robots and Systems. 2011, pp. 298-304.

6. Rajamani, Rajesh. Vehicle Dynamics and Control. New York: Springer, 2012.

7. Schofield, Brad. Vehicle Dynamics Control for Rollover Prevention. Department of Automatic Control, Lund University. Lund : s.n., 2006. Tese de Doutorado.

8. Iagnemma, Karl, et al. Experimental Study of High-Speed Rough-Terrain Mobile Robot Models for Reactive Behaviors. Experimental Robotics VIII. s.l. : Springer Berlin Heidelberg, 2003, pp. 654-663.

9. Tenenbaum, Roberto A. Dinâmica. Rio de Janeiro : UFRJ, 1997.

10. Asada, H. and Slotine, J. J. Robot Analysis and Control. New York : Wiley, 1985.

11. Nguyen, H. GPU Gems 3. Indiana : Addison-Wesley Professional, 2007. 
12. O'Brien, D., Fisher, S. e Lin, M. C. Automatic Simplification of Particles System Dynamics. Proceedings of the 14th Conference on Computer Animation. Novembro de 2001, pp. 210-219.

13. Smith, R. Open Dynamics Engine: User Guide v05. 2006.

14. Papadopoulos, E. G. e Rey, D. A. The Force-Angle Measure of Tipover Stability Margin for Mobile Manipulators. Vehicle System Dynamics: International Journal of Vehicle Mechanics and Mobility. 2000, pp. 29-48.

15. Peters, Steven C. and Iagnemma, Karl. Stability Measurment of High-Speed Vehicles. Vehicle System Dynamics. Junho 2009, Vol. 47, pp. 701-720.

16. - . An Analysis of Rollover Stability Measurement for High-Speed Mobile Robots. IEEE International Conference on Robotics and AQutomation. Maio de 2006, pp. 3711-3716.

17. Peters, Steven C. Optimal Planning and Control for Hazard Avoidance of Front-Wheel Steered Ground Vehicles. Department of Mechanical Engineering, Massachusetts Institute of Tecnology. Boston : s.n., 2012. Tese de Doutorado.

18. Silva, Alexandre F. Barral, et al. A Rough Terrain Traction Control Technique for All-Wheel-Drive Mobile Robots. Journal of the Brazilian Society of Mechanical Science \& Engineering. Outubro-Dezembro de 2010, pp. 489-501.

19. Santos, Auderi Vicente. Controle de Capotagem e Deslizamento de Sistemas Robóticos Móveis em Terrenos Acidentados. Departamento de Engenharia Mecânica, PUC-Rio. Rio de Janeiro : s.n., 2007. Dissertação de Mestrado.

20. Silva, Alexandre Francisco Barral. Modelagem de Sistemas Robóticos Móveis para Controle de Tração em Terrenos Acidentados. Departamento de Engenharia Mecânica, PUC-Rio. Rio de Janeiro : s.n., 2007. Dissertação de Mestrado.

21. Genta, Giancarlo. Motor Vehicle Dynamics: Modeling and Simulation. Singapore : World Scientific. Publishing Co. Pte. Ltd., 1997.

22. Jaza, Reza N. Vehicle Dynamics: Theory and Aplication. New York: Springer, 2009.

23. Iagnemma, Karl and Dubowsky, Steven. Traction Control of Wheeled Robotic Vehicles in Rough Terrain with Application to Planetary Rovers. The 
International Journal of Robotics Research. Outubro-Novembro 2004, pp. 1029-1040.

24. Lima, Ricardo Morrot. Simulação Tridimensional em Tempo Real de Veículos Robóticos em Terrenos Acidentados. Departamento de Engenharia Mecânica, PUC-Rio. 2010. Dissertação de Mestrado.

25. Zaccarian, Luca. Università degli Studi di Roma: Corso de Robotica con Laboratorio. [Online] [Citado em: 28 de maio de 2013.] control.disp.uniroma2.it/zack/LabRob/DCmotors.pdf.

26. Ramesh, K., et al. Design of Current Controller for Two Quadrant DC Motor Drive by Using Model Order Reduction Technique. International Journal of Computer Science and Information Security. 2010, pp. 17-24.

27. Krneta, Radojka, Antic, Sanja e Stojanovic, Danilo. Recursive Least Square Method inParameters Identification of DC Motors Models. Facta Universitatis Series: Electronics and Energetics. 2005, pp. 467-478.

28. Salah, Mohammed S. Z. Parameters Identification of a Permanent Magnet DC Motor. Departamento de Engenharia Eleétrica, The Islamic University of Gaza. 2009. Dissertação de Mestrado.

29. Ampflow. AmpFlow Motors. [Online] Ampflow. [Citado em: 27 de 07 de 2012.] http://www.ampflow.com/ampflow_motors.htm.

30. Kosow, Irving I. Máquinas Elétricas e Transformadores. São Paulo : Globo, 2005 .

31. Ogata, Katsuhiko. Engenharia de controle moderno. 5a. São Paulo : Pearson, 2011.

32. Ogata, K. Discrete-Time Control Systems. New Jersey: Prentice Hall, 2 ed, 1995.

33. Ryu, Jihan and Gerdes, J. Christian. Integrating Inertial Sensors with GPS for Vehicle Dynamics Control. Journal of Dynamics Systems, Measurement, and Control - Transactions of The ASME. Junho 2004, Vol. 126(2).

34. Three-axis Attitude Control with Two Reaction Wheels and Magnetic Torquer Bars. Roberts, Bryce, et al. Providence: s.n., 2004. AIAA Guidance, Navigation, and Control Conference and Exhibit.

35. Nudehi, Shahin S., et al. Satellite Attitude Control Using Three Reaction Wheels. American Control Conference. 11-13 de June de 2008, pp. 4850-4855. 
36. Ogata, Katsuhiko. Modern Control Engineering. New Jersey : Prentice Hall, 2002.

37. Pacejka, H. B. Tire and Vehicle Dynamics. s.l. : SAE, 2006.

38. Reimpell, J., Stoll, H. e Betzler, J. W. The Automotive Chassis: Engineering Principles. Woburn : Elsevier, 2001.

39. Santos, Ilmar Ferreira dos. Dinâmica de Sistemas Mecânicos: Modelagem, Simulação, Visualização, Verificação. São Paulo : Makron Books, 2001.

40. Meggiolaro, Marco Antônio. RioBotz Combot Tutorial. March 2009.

41. Al-Khazali, Hisham A. H. and Askari, Mohamad R. Geometrical and Graphical Representations Analysis of Lissajous Figures in Rotor Dynamic System. IOSR Journal of Engineering. Maio 2012, pp. 971-978.

42. Bastow, D., Howard, G. and Whitehead, J. G. Car Suspension and Handling. $4^{\circ}$. s.1. : SAE, 2004.

43. Song, Jeonghoon, Kim, Heungseob e Boo, Kwangsuck. A Study on an AntiLock Braking System Controller and Rear-Wheel Controller to Enhance Vehicle Lateral Stability. Institution of Mechanical Engineers - Journal of Automobile Engineering . 2007, pp. 777-787.

44. Wong, J. Y. Theory of Ground Vehicles. New Jersey : John Wiley \& Sons, Inc., 2008. 
Artigos produzidos durante a pesquisa:

Lima, R. M.; Blois, P. F. C. A.; Meggiolaro, M. A. "Real-Time ThreeDimensional Dynamic Simulation of Mobile Robots in Rough Terrain". In: 21st International Congress of Mechanical Engineering (COBEM), 2011, Natal.

O artigo "Real-Time Three-Dimensional Dynamic Simulation of Mobile Robot in Rough Terrain" também foi publicado no ABCM Symposium Series in Mechatronics, Vol. 5, Section VII - Robotics, $1^{\text {a }}$ edição, Rio de Janeiro, 2012, pp. 1074-1084.

Blois, P. F. C. A.; Meggiolaro, M. A. "Pitch Controlo of Robotic Vehicles During Ballistic". In: 22nd International Congress of Mechanical Engineering (COBEM), 2013, Ribeirão Preto. 


\section{Anexos}




\section{1}

\section{Sistemas de referências e as rotações entre eles}

Para modelar o sistema, foram escolhidos dois sistemas de referências. O referencial inercial (ou global) $F$ tem origem no ponto $\boldsymbol{O}$ e é representado pelos cursores $\boldsymbol{a}_{1}, \boldsymbol{b}_{1}$ e $\boldsymbol{c}_{\mathbf{1}}$ e o referencial local $S$ tem origem no ponto $\boldsymbol{A}$, é solidário ao veículo e é representado pelos cursores $\boldsymbol{n}, \boldsymbol{t}$ e $\boldsymbol{b}$. Para modelar a orientação do referencial $S$ (e consequentemente do veículo) foi escolhida a sequência de ângulos cardânicos $1 \rightarrow 2^{\prime} \rightarrow 3^{\prime \prime}$ como mostra o fluxograma abaixo:

$$
F \stackrel{\theta_{1}\left(\boldsymbol{a}_{1}\right)}{\longrightarrow} Q \stackrel{\theta_{2}\left(\boldsymbol{b}_{2}\right)}{\longrightarrow} R \stackrel{\theta_{3}\left(\boldsymbol{c}_{3}\right)}{\longrightarrow} S
$$

onde $\theta_{i}(\boldsymbol{a})$ representa uma rotação de $\theta_{i}$ radianos em torno do vetor $\boldsymbol{a}, \boldsymbol{b}_{\mathbf{2}}$ representa a nova orientação de $\boldsymbol{b}_{1}$ após a rotação $\theta_{1}\left(\boldsymbol{a}_{1}\right)$ e $\boldsymbol{c}_{3}$ representação a nova orientação de $\boldsymbol{c}_{\mathbf{1}}$ após as rotações $\theta_{1}\left(\boldsymbol{a}_{\mathbf{1}}\right)$ e $\theta_{2}\left(\boldsymbol{b}_{\mathbf{2}}\right)$.

As matrizes de transformação entre os sistemas referenciais são calculadas através de rotações elementares entorno de cada um dos vetores ortonormais, como mostram as equações (1.1), (1.2) e (1.3):

$$
\begin{aligned}
& { }_{F}^{F} \boldsymbol{\omega}_{Q}=\left[\begin{array}{c}
\dot{\theta}_{1} \\
0 \\
0
\end{array}\right] \rightarrow{ }^{F} \underline{T}^{Q}=\left[\begin{array}{ccc}
1 & 0 & 0 \\
0 & c_{1} & -s_{1} \\
0 & s_{1} & c_{1}
\end{array}\right] \\
& { }_{Q}^{Q} \boldsymbol{\omega}_{R}=\left[\begin{array}{c}
0 \\
\dot{\theta}_{2} \\
0
\end{array}\right] \rightarrow{ }^{Q} \underline{T}^{R}=\left[\begin{array}{ccc}
c_{2} & 0 & s_{2} \\
0 & 1 & 0 \\
-s_{2} & 0 & c_{2}
\end{array}\right] \\
& { }_{R}^{R} \boldsymbol{\omega}_{S}=\left[\begin{array}{c}
0 \\
0 \\
\dot{\theta}_{3}
\end{array}\right] \rightarrow{ }^{R} \underline{T}^{S}=\left[\begin{array}{ccc}
c_{3} & -s_{3} & 0 \\
s_{3} & c_{3} & 0 \\
0 & 0 & 1
\end{array}\right]
\end{aligned}
$$

onde $c_{i}$ e $s_{i}$ são, respectivamente, o cosseno e o seno de $\theta_{i}$.

Com as matrizes de transformação entre cada um dos referenciais, chega-se a matriz de transformação entre o referencial inercial $F$ e o local $S$ como sendo: 


$$
{ }^{F} \underline{T}^{S}={ }^{F} \underline{T}^{Q}{ }^{Q} \underline{T}^{R}{ }^{R} \underline{T}^{S}=\left[\begin{array}{ccc}
c_{2} c_{3} & -c_{2} s_{3} & s_{2} \\
c_{1} s_{3}+s_{1} s_{2} c_{3} & c_{1} c_{3}-s_{1} s_{2} s_{3} & -s_{1} c_{2} \\
s_{1} s_{3}-c_{1} s_{2} c_{3} & s_{1} c_{3}+c_{1} s_{2} s_{3} & c_{1} c_{2}
\end{array}\right]
$$

Caso a ordem de rotações escolhida fosse $3 \rightarrow 2^{\prime} \rightarrow 1^{\prime \prime}$, a matriz de transformação de coordenadas seria:

$$
{ }^{F} \underline{T}^{S}=\left[\begin{array}{ccc}
c_{1} c_{2} & c_{1} s_{2} s_{3}-s_{1} c_{3} & c_{1} s_{2} c_{3}+s_{1} s_{3} \\
s_{1} c_{2} & s_{1} s_{2} s_{3}+c_{1} c_{3} & s_{1} s_{2} c_{3}-c_{1} s_{3} \\
-s_{2} & c_{2} s_{3} & c_{2} c_{3}
\end{array}\right]
$$




\section{2 Velocidades e acelerações importantes do sistema}

A composição das rotações entre os sistemas referenciais resulta na velocidade angular do referencial local. Sua derivada temporal fornece a aceleração angular e pode ser feita diretamente se a velocidade angular incorporar as informações de todas as transformações entre o sistema referencial fixo e o referencial em questão, como pode ser visto nas equações (2.1) e (2.2):

$$
\begin{gathered}
{ }_{F}^{S} \boldsymbol{\omega}_{S}={ }_{{ }_{T}}{ }_{F}^{Q} \boldsymbol{\omega}_{Q}+{ }^{S} \underline{T}_{Q}^{R}{ }_{Q}^{R} \boldsymbol{\omega}_{R}+{ }_{R}^{R} \boldsymbol{\omega}_{S}=\left[\begin{array}{c}
\dot{\theta}_{2} s_{3}+\dot{\theta}_{1} c_{2} c_{3} \\
\dot{\theta}_{2} c_{3}-\dot{\theta}_{1} c_{2} s_{3} \\
\dot{\theta}_{3}+\dot{\theta}_{1} s_{2}
\end{array}\right] \\
{ }_{F}^{S} \dot{\boldsymbol{\omega}}_{S}=\left[\begin{array}{c}
\left(\ddot{\theta}_{1} c_{2} c_{3}-\dot{\theta}_{1}\left(\dot{\theta}_{2} s_{2} c_{3}+\dot{\theta}_{3} c_{2} s_{3}\right)\right)+\left(\ddot{\theta}_{2} s_{3}+\dot{\theta}_{2} \dot{\theta}_{3} c_{3}\right) \\
-\left(\ddot{\theta}_{1} c_{2} s_{3}+\dot{\theta}_{1}\left(\dot{\theta}_{3} c_{2} c_{3}-\dot{\theta}_{2} s_{2} s_{3}\right)\right)-\left(\ddot{\theta}_{2} c_{3}-\dot{\theta}_{2} \dot{\theta}_{3} s_{3}\right) \\
\ddot{\theta}_{3}+\left(\ddot{\theta}_{1} s_{2}+\dot{\theta}_{1} \dot{\theta}_{2} c_{2}\right)
\end{array}\right]
\end{gathered}
$$

Por serem rotações elementares cardânicas tem-se que ${ }_{F}^{Q} \boldsymbol{\omega}_{Q}={ }_{F}^{F} \boldsymbol{\omega}_{Q}$ e ${ }_{Q}^{R} \boldsymbol{\omega}_{R}={ }_{Q}^{Q} \boldsymbol{\omega}_{R}$. Por conveniência durante os cálculos da dinâmica rotacional, a velocidade e a aceleração angulares foram calculadas no referencial local $S$. Sua transformação para o referencial global pode ser obtida pré-multiplicando-se pela matriz de transformação ${ }^{F} \underline{T}^{S}$.

A velocidade e a aceleração lineares tanto do centro de massa do veículo quanto do centro geométrico das rodas podem ser calculadas utilizando-se as matrizes de transformação descritas anteriormente e a velocidade angular do sistema referencial local, bem como sua aceleração angular.

Se considerarmos que o centro de massa do veículo ${ }^{F} \boldsymbol{r}_{A}=\left[\begin{array}{lll}x & y & z\end{array}\right]^{T}$ coincide com a origem do referencial local, a sua primeira derivada temporal fornecerá a velocidade linear do centro de massa como ${ }^{F} \boldsymbol{v}_{A}=\left[\begin{array}{lll}\dot{x} & \dot{y} & \dot{z}\end{array}\right]^{T}$. Esta operação pode ser feita sem risco de perda de informação, pois o vetor é descrito no referencial inercial $F$. Da mesma maneira obtém-se a aceleração linear do centro de massa do veículo como ${ }^{F} \boldsymbol{a}_{A}=\left[\begin{array}{ccc}\ddot{x} & \ddot{y} & \ddot{z}\end{array}\right]^{T}$. 
A velocidade angular do veículo será ${ }_{F}^{S} \boldsymbol{\omega}_{S}$ e sua aceleração angular será ${ }_{F}^{S} \dot{\boldsymbol{\omega}}_{S}$, ambos calculados anteriormente.

Se considerarmos que a roda i encontra-se a uma distância ${ }^{S} \boldsymbol{r}_{i}$ do centro de massa do veículo, sua posição no referencial inercial $F$ será ${ }^{F} \boldsymbol{r}_{i}={ }^{F} \boldsymbol{r}_{A}+$ ${ }^{F}{ }^{S}{ }^{S} \boldsymbol{r}_{i}$. Assumindo-se que as rodas são equidistantes do centro de massa do veículo, a posição de cada uma das quatro rodas no referencial inercial será:

$$
\begin{aligned}
& { }^{s} \boldsymbol{r}_{0}=\left[\begin{array}{l}
-r_{x} \\
-r_{y} \\
-r_{z}
\end{array}\right] \therefore{ }^{F} \boldsymbol{r}_{0} \\
& =\left[\begin{array}{c}
x-r_{x} c_{2} c_{3}+r_{y} c_{2} s_{3}-r_{z} s_{2} \\
y-r_{x}\left(c_{1} s_{3}+s_{1} s_{2} c_{3}\right)-r_{y}\left(c_{1} c_{3}-s_{1} s_{2} s_{3}\right)+r_{z} s_{1} c_{2} \\
z-r_{x}\left(s_{1} s_{3}-c_{1} s_{2} c_{3}\right)-r_{y}\left(s_{1} c_{3}+c_{1} s_{2} s_{3}\right)-r_{z} c_{1} c_{2}
\end{array}\right] \\
& { }^{s} \boldsymbol{r}_{1}=\left[\begin{array}{c}
r_{x} \\
-r_{y} \\
-r_{z}
\end{array}\right] \therefore{ }^{F} \boldsymbol{r}_{1} \\
& =\left[\begin{array}{c}
x+r_{x} c_{2} c_{3}+r_{y} c_{2} s_{3}-r_{z} s_{2} \\
y+r_{x}\left(c_{1} s_{3}+s_{1} s_{2} c_{3}\right)-r_{y}\left(c_{1} c_{3}-s_{1} s_{2} s_{3}\right)+r_{z} s_{1} c_{2} \\
z+r_{x}\left(s_{1} s_{3}-c_{1} s_{2} c_{3}\right)-r_{y}\left(s_{1} c_{3}+c_{1} s_{2} s_{3}\right)-r_{z} c_{1} c_{2}
\end{array}\right] \\
& { }^{s} \boldsymbol{r}_{2}=\left[\begin{array}{c}
r_{x} \\
r_{y} \\
-r_{z}
\end{array}\right] \therefore{ }^{F} \boldsymbol{r}_{2} \\
& =\left[\begin{array}{c}
x+r_{x} c_{2} c_{3}-r_{y} c_{2} s_{3}-r_{z} s_{2} \\
y+r_{x}\left(c_{1} s_{3}+s_{1} s_{2} c_{3}\right)+r_{y}\left(c_{1} c_{3}-s_{1} s_{2} s_{3}\right)+r_{z} s_{1} c_{2} \\
z+r_{x}\left(s_{1} s_{3}-c_{1} s_{2} c_{3}\right)+r_{y}\left(s_{1} c_{3}+c_{1} s_{2} s_{3}\right)-r_{z} c_{1} c_{2}
\end{array}\right] \\
& { }^{s} \boldsymbol{r}_{3}=\left[\begin{array}{c}
-r_{x} \\
r_{y} \\
-r_{z}
\end{array}\right] \therefore{ }^{F} \boldsymbol{r}_{3} \\
& =\left[\begin{array}{c}
x-r_{x} c_{2} c_{3}-r_{y} c_{2} s_{3}-r_{z} s_{2} \\
y-r_{x}\left(c_{1} s_{3}+s_{1} s_{2} c_{3}\right)+r_{y}\left(c_{1} c_{3}-s_{1} s_{2} s_{3}\right)+r_{z} s_{1} c_{2} \\
z-r_{x}\left(s_{1} s_{3}-c_{1} s_{2} c_{3}\right)+r_{y}\left(s_{1} c_{3}+c_{1} s_{2} s_{3}\right)-r_{z} c_{1} c_{2}
\end{array}\right]
\end{aligned}
$$

A velocidade linear de cada roda i pode ser obtida derivando-se a posição da roda representada no referencial inercial ou utilizando a velocidade angular do veículo como mostrado na equação (2.7): 


$$
{ }^{F} \boldsymbol{v}_{i}={ }^{F} \boldsymbol{v}_{A}+{ }_{F}^{F} \boldsymbol{\omega}_{S} \times\left({ }^{F} \underline{T}^{S}{ }^{S} \boldsymbol{r}_{i}\right)
$$

A partir da equação acima, obtêm-se as velocidades mostradas na equação (2.8):

$$
{ }^{F} \boldsymbol{v}_{i}=\left[\begin{array}{c}
\dot{x}-R x_{i}\left(\dot{\theta}_{2} s_{2} c_{3}+\dot{\theta}_{3} c_{2} s_{3}\right)+R y_{i}\left(\dot{\theta}_{2} s_{S} s_{3}-\dot{\theta}_{3} c_{2} c_{3}\right)+R z_{i} \dot{\theta}_{2} c_{2} \\
\dot{y}+\left(\dot{\theta}_{2} s_{1}+\dot{\theta}_{3} c_{1} c_{2}\right)\left(R x_{i} c_{2} c_{3}-R y_{i} c_{2} s_{3}+R z_{i} s_{2}\right)-\cdots \\
\left(\dot{\theta}_{1}+\dot{\theta}_{3} s_{2}\right)\left(R x_{i}\left(s_{1} s_{3}-c_{1} s_{2} c_{3}\right)+R y_{i}\left(s_{1} c_{3}+c_{1} s_{2} s_{3}\right)+R z_{i} c_{1} c_{2}\right) \\
\dot{z}-\left(\dot{\theta}_{2} c_{1}-\dot{\theta}_{3} s_{1} c_{2}\right)\left(R x_{i} c_{2} c_{3}-R y_{i} c_{2} s_{3}+R z_{i} s_{2}\right)+\cdots \\
\left(\dot{\theta}_{1}+\dot{\theta}_{3} s_{2}\right)\left(R x_{i}\left(c_{1} s_{3}+s_{1} s_{2} c_{3}\right)+R y_{i}\left(c_{1} c_{3}-s_{1} s_{2} s_{3}\right)-R z_{i} s_{1} c_{2}\right)
\end{array}\right]
$$

onde $R x_{i}, R y_{i}$ e $R z_{i}$ são as componentes do vetor ${ }^{F} \boldsymbol{r}_{i}$.

A velocidade angular de cada roda será a soma da velocidade angular do veículo com o $\operatorname{spin}\left(\dot{\varphi}_{i}\right)$ de cada roda, como mostra a equação (2.9):

$$
{ }^{S} \omega_{i}={ }_{F}^{S} \omega_{S}+{ }^{S} \dot{\varphi}_{i}
$$

onde ${ }^{S} \dot{\boldsymbol{\varphi}}_{i}=\left[\begin{array}{lll}0 & \dot{\varphi}_{i} & 0\end{array}\right]^{T}$. Expandindo a equação acima para cada roda obtêm-se:

$$
{ }^{s} \boldsymbol{\omega}_{i}=\left[\begin{array}{c}
\dot{\theta}_{2} s_{3}+\dot{\theta}_{1} c_{2} c_{3} \\
\dot{\theta}_{2} c_{3}-\dot{\theta}_{1} c_{2} s_{3}+\dot{\varphi}_{i} \\
\dot{\theta}_{3}+\dot{\theta}_{1} s_{2}
\end{array}\right]
$$

Derivando no tempo a equação (2.9) obtêm-se a aceleração angular de cada roda como mostrado na equação (2.11).

$$
{ }^{S} \dot{\boldsymbol{\omega}}_{i}={ }_{F}^{S} \dot{\boldsymbol{\omega}}_{S}+{ }_{F}^{S} \boldsymbol{\omega}_{S} \times{ }^{S} \dot{\boldsymbol{\varphi}}_{i}+{ }^{S} \ddot{\boldsymbol{\varphi}}_{i}
$$


Um último ponto de interesse do sistema é a localização do acelerômetro. Devido a estrutura do veículo utilizado nos experimentos, é impossível instalar o sensor exatamente no centro de massa do mesmo. Essa distância do centro de massa implica em uma leitura da aceleração do mesmo somado aos efeitos da dinâmica de rotação do sistema como as acelerações normal (centrípeta) e tangencial.

Analogamente ao cálculo da posição de cada roda considera-se que o sensor encontra-se a uma distância ${ }^{S} \boldsymbol{r}_{B}=\left[\begin{array}{lll}R x_{b} & R y_{b} & R z_{b}\end{array}\right]^{T}$ do centro de massa do veículo. Com isso sua posição no referencial inercial $F$ será ${ }^{F} \boldsymbol{r}_{B}={ }^{F} \boldsymbol{r}_{A}+$ ${ }^{F}{ }^{S}{ }^{S} \boldsymbol{r}_{B}$, mostrada pela equação (2.12):

$$
{ }^{F} \boldsymbol{r}_{B}=\left[\begin{array}{c}
x+R x_{b} c_{2} c_{3}-R y_{b} c_{2} s_{3}+R z_{b} s_{2} \\
y+R x_{b}\left(c_{1} s_{3}+s_{1} s_{2} c_{3}\right)+R y_{b}\left(c_{1} c_{3}-s_{1} s_{2} s_{3}\right)+R z_{b} s_{1} c_{2} \\
z+R x_{b}\left(s_{1} s_{3}-c_{1} s_{2} c_{3}\right)+R y_{b}\left(s_{1} c_{3}+c_{1} s_{2} s_{3}\right)+R z_{b} c_{1} c_{2}
\end{array}\right]
$$

Pode-se obter a velocidade linear do sensor $\left({ }^{F} \boldsymbol{v}_{B}\right)$ através da equação (2.8), substituindo-se $R x_{i}, R y_{i}$ e $R z_{i}$ por $R x_{B}, R y_{B}$ e $R z_{B}$ respectivamente.

A aceleração linear do sensor pode ser obtida substituindo-se na equação (2.7) ${ }^{S} \boldsymbol{r}_{i}$ por ${ }^{S} \boldsymbol{r}_{B}$ e em seguida derivando-se com respeito ao tempo, como mostra a equação (2.13).

$$
{ }^{F} \boldsymbol{a}_{B}={ }^{F} \boldsymbol{a}_{A}+{ }_{F}^{F} \dot{\boldsymbol{\omega}}_{S} \times\left({ }^{F} \underline{T}^{S}{ }^{S} \boldsymbol{r}_{B}\right)+{ }_{F}^{F} \boldsymbol{\omega}_{S} \times\left({ }_{F}^{F} \boldsymbol{\omega}_{S} \times\left({ }^{F} \underline{T}^{S}{ }^{S} \boldsymbol{r}_{B}\right)\right)
$$

Todas as equações deste anexo foram obtidas com a ajuda de (39), (9) e (22). 